\title{
Foreign Exchange risk exposure
}

Citation for published version (APA):

Muller, A. (2005). Foreign Exchange risk exposure. [Doctoral Thesis, Maastricht University]. Maastricht University. https://doi.org/10.26481/dis.20050930am

Document status and date:

Published: 01/01/2005

DOI:

10.26481/dis.20050930am

Document Version:

Publisher's PDF, also known as Version of record

\section{Please check the document version of this publication:}

- A submitted manuscript is the version of the article upon submission and before peer-review. There can be important differences between the submitted version and the official published version of record.

People interested in the research are advised to contact the author for the final version of the publication, or visit the DOI to the publisher's website.

- The final author version and the galley proof are versions of the publication after peer review.

- The final published version features the final layout of the paper including the volume, issue and page numbers.

Link to publication

\footnotetext{
General rights rights.

- You may freely distribute the URL identifying the publication in the public portal. please follow below link for the End User Agreement:

www.umlib.nl/taverne-license

Take down policy

If you believe that this document breaches copyright please contact us at:

repository@maastrichtuniversity.nl

providing details and we will investigate your claim.
}

Copyright and moral rights for the publications made accessible in the public portal are retained by the authors and/or other copyright owners and it is a condition of accessing publications that users recognise and abide by the legal requirements associated with these

- Users may download and print one copy of any publication from the public portal for the purpose of private study or research.

- You may not further distribute the material or use it for any profit-making activity or commercial gain

If the publication is distributed under the terms of Article $25 \mathrm{fa}$ of the Dutch Copyright Act, indicated by the "Taverne" license above, 
Foreign Exchange Risk Exposure 
Foreign Exchange Risk Exposure / Aline Muller ISBN 2-87996-882-8 


\section{Foreign Exchange Risk Exposure}

\section{PROEFSCHRIFT}

ter verkrijging van de graad van doctor aan de Universiteit Maastricht, op gezag van de Rector Magnificus, Prof. mr. G.P.M.F. Mols, volgens het besluit van het College van Decanen, in het openbaar te verdedigen op vrijdag 30 september 2005 om 16.00 uur

door

Aline Muller 


\section{Promotor:}

Prof. dr. W.F.C. Verschoor

Beoordelingscommissie:

Prof. dr. C.G. Koedijk (Voorzitter)

Prof. dr. C.C.P. Wolff

Prof. dr. E. de Jong (Radboud Universiteit Nijmegen) 


\section{Acknowledgements}

Foreign Exchange Risk Exposure is the fruit of my professional and personal evolution during those four extraordinary years at the Finance Department of Maastricht University. At the beginning I felt an urge to learn and in the end I enjoy the excitement of having gone through so many different challenges, experiences and transitions - both of scientific and human nature.

During this extremely enriching adventure I had the chance to meet a lot of very special and unique people. Among these, the most important one is certainly Willem Verschoor, my daily supervisor. Without his unwavering enthusiasm and the confidence he put in me this thesis wouldn't have been completed in its present form. I thank him for sharing his financial intuition and his positive criticism. I regard our long discussions on research and life in general as inexhaustible sources of inspiration. For all these reasons, I would like to express him my most sincere gratitude.

I also particularly thank Christian Wolff who followed my first steps in the world of research and provided me with thoughtful support whenever it was needed. I am grateful to Albert Corhay too for his concern and for having instigated my discovery of two essential places in my life: Maastricht University and Africa. Many thanks as well to Kees Koedijk and Eelke de Jong for their valuable comments on the previous draft of this thesis.

I am especially indebted to Roger Otten for his support the first two years of this journey. Although he was very busy himself, he always had some time for me and our endless conversations. Frank, Bart, Bart and Thorsten: how many times didn't we share the excitement of a new research idea or the hopelessness of our motivation lacks? But fortunately we didn't only talk about research projects, desperate love or existential uncertainties, we also had very simple but extraordinary valuable moments of thoughtless happiness together. Balthazar in Koblenz, Havanna Club in Berlin, La Cave du Clair Obscur in Spa ... represent many irreplaceable memories I will never forget. Of course many more people like Francien, Rob ... who participated in these privileged moments and contributed to 
this thesis in one way or the other aren't mentioned here. They should however all be assured that though they aren't on this page, they will always remain in my heart.

Looking back to these four years, it would be unforgivable not to mention Babette. Even if thousands kilometers and "almost" as many hours separated us, we never stopped sharing our doubts and eccentricities. Thanks to her stubbornness and patience, I discovered many of my inner obscure parts. I am so grateful for that.

A toi Vincent, je te dis tout simplement merci. Merci du plus profond de mon coeur. Merci de me prendre tout entière, un rien excessive et remplie de contradictions. Durant ces quatre années tu as su apaiser mes peurs, bercer mes chagrins et partager mes folies. Notre vie est tumultueuse, pleine de contrastes et de couleurs, mais elle est belle ... car tu es l'éternel gardien de ma joie de vivre.

Je sais que toutes les mamans sont exceptionnelles. Mais mon âme d'enfant vous dira que ma maman est la plus exceptionnelle de toutes. Sans ses innombrables sacrifices et la force qu'elle n'a cessé de nous insuffler nous serions encore sur un petit bateau au milieu de la tempête... Sur ce petit bateau il y avait un homme, mon frère, que je ne cesse d'admirer et que je remercie pour tous ses petits gestes qui ont réchauffé mon coeur. Je remercie aussi ma grande petite soeur pour sa présence et toutes ses douces paroles qui ont toujours su traverser l'océan.

Mes dernières pensées vont a celui qui n'est plus mais qui malgré lui et malgré moi a determiné ma vie.

La vie ne vaut d'être vécue sans amour. [Serge Gainsbourg, 1928-1991] 


\section{Table of contents}

\section{CHAPTER 1}

Aims and Scope

\section{CHAPTER 2}

Foreign Exchange Risk Exposure: Survey and Suggestions

2.1 Introduction 15

2.2 Theoretical foundations of exchange risk exposure $\quad 16$

$\begin{array}{ll}2.3 \text { Selected issues on existing empirical evidence } & 21\end{array}$

2.3.1 Round 1: Early specifications $\quad 22$

2.3.2 Round 2: Refinements in research methods $\quad 26$

2.3.3 Round 3: Characteristics of exchange risk exposure $\quad 32$

$\begin{array}{lll}2.4 \text { Concluding suggestions } & 40\end{array}$

\section{CHAPTER 3}

Foreign Exchange Risk Exposure: Empirical Evidence on

Selected Markets

3.1 Introduction $\quad 45$

3.2 Measuring exchange rate exposure 49

3.3 Foreign exchange risk exposure: an European perspective 52

3.3.1 The firm-level data set and relevant economic factors 52

3.3.2 Empirical findings 55

3.4 Foreign exchange risk exposure: two emerging markets applications 66

3.4a The reaction of emerging stock markets to changes in the values of their local currencies: evidence from Asia 66

3.4a.1 The firm-level data set and relevant economic factors 66 
3.4b The reaction of mature stock markets to changes in the values of emerging markets' currencies: a trade-specific approach

3.4b.1 The firm-level data set and relevant economic factors: $\quad 72$

$\begin{array}{ll}3.4 \mathrm{~b} .2 \text { Empirical findings } & 73\end{array}$

3.5 Concluding remarks

\section{CHAPTER 4}

The Impact of Corporate Derivative Usage on Foreign Exchange Risk Exposure: Evidence from European Non-Financial Firms

$\begin{array}{lll}4.1 & \text { Introduction } & 85\end{array}$

$\begin{array}{lll}4.2 & \text { Research questions } & 88\end{array}$

4.2.1 Why do firms hedge? 88

4.2.2 Does corporate derivative usage influence foreign exchange risk exposure? : 92

$\begin{array}{lll}4.3 & \text { Data } & 93\end{array}$

4.4 Empirical evidence on the factors determining corporate $\begin{array}{ll}\text { derivative usage } & 97\end{array}$

4.5 Empirical evidence on the impact of corporate derivative usage $\begin{array}{ll}\text { on foreign exchange risk exposure } & 102\end{array}$

$\begin{array}{ll}\text { 4.6. Concluding remarks } & 113\end{array}$

\section{CHAPTER 5}

The Effect of Exchange Rate Variability on U.S. Shareholder Wealth

5.1 Introduction

5.2 Research design

5.3 Exchange rate crises and sample selection

5.3.1 Exchange rate crises

5.3.2 U.S. multinational firms

5.4 Exchange rate crises and stock retum volatility

5.5 Exchange rate variability and market risk (beta) of U.S. multinationals

5.6 Sensitivity analysis

5.6.1 Across industries

5.6.2 Across size 


\section{CHAPTER 6}

Asymmetric Foreign Exchange Risk Exposure: Evidence from U.S.

Multinationals

6.1 Introduction 145

6.2 Asymmetries in exchange risk exposure $\quad 146$

6.2.1 Asymmetries due to hedging activities 146

6.2.2 Asymmetries due to asymmetric pricing-t-market behavior and resulting pass-through effects

6.2.3 Asymmetries due to hysteresis behavior 148

6.2.4 Asymmetries due to investors' mispricing errors 149

6.2.5 Asymmetries due to the existence of 'trigger points' 150

6.3 Methodology 150

6.4 Sample selection 154

6.4.1 U.S. multinationals $\quad 154$

6.4.2 Economic factors $\quad 156$

6.5 Empirical findings 159

$\begin{array}{lll}6.5 .1 & \text { Linear exchange risk exposure } & 159\end{array}$

6.5.2 Sign-asymmetries in exchange risk exposure $\quad 164$

6.5.3 Magnitude-asymmetries in exchange risk exposure $\quad 164$

$\begin{array}{ll}6.6 \text { Concluding remarks } & 169\end{array}$

CHAPTER 7

Concluding Comments and Suggestions for Future Research

BIBLIOGRAPHY

NEDERLANDSE SAMENVATTING / Summary in Dutch 205 
$\vdots$
$\therefore \quad$
$\vdots$

-

$\because$

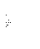



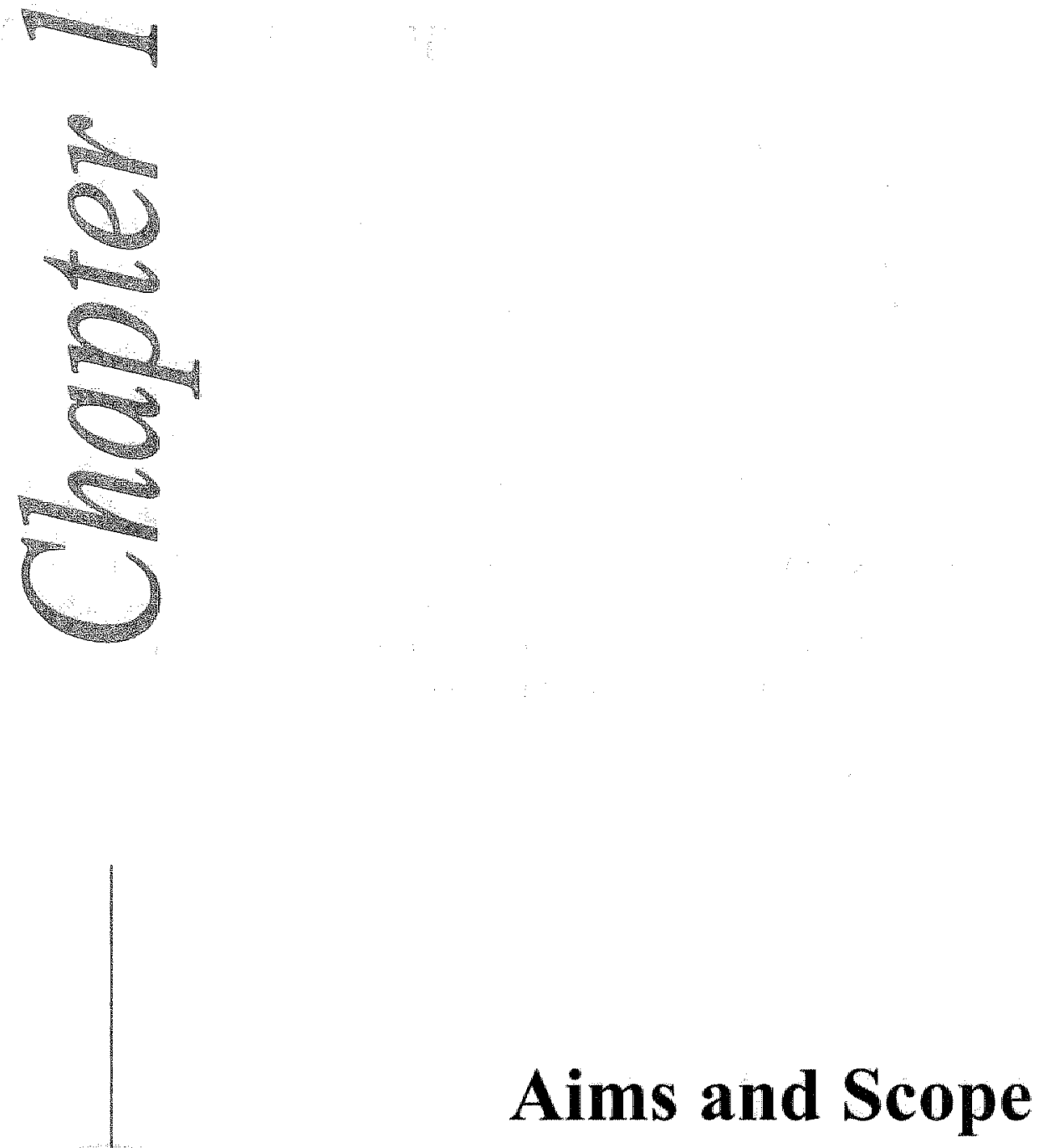

a

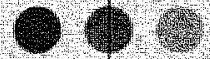




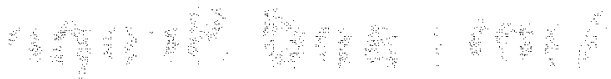

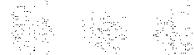




\section{Aims and scope}

One of the most striking financial developments of recent decades is the tremendous increase in exchange rate instability following the collapse of the Bretton Woods system in 1973. While exchange rates were fixed at levels determined by governments during the Bretton Woods era from 1946 to 1973 , currency movements are determined by people selling and buying currencies in the foreign exchange markets under the floating exchange rates system.

In the early 70 's concern over the variability of floating exchanges rates had been replaced by optimist expectations predicting greater flexibility of monetary policies, realignments of international payment imbalances, accommodations of fundamental economic divergences and, hence, purchasing power parity adjustments of exchange rate movements. A few years later, however, the instability of floating rates surprised and disappointed many advocates of the floating system who hadn't expected exchange rates to create so much uncertainty. The history of the relationship between EMU currencies and the U.S. dollarwhich is of major concern for our European economies - perfectly illustrates the increase in short-term volatility and the appearance of large cyclical exchange rates movements. From April 1973 to November 2004, the dollar / euro exchange rate variability (as measured by the standard deviation of weekly changes in percent) has been multiplied by more than 6.6 as compared to the exchange rate variability between January 1960 and December $1970{ }^{1,2}$ The run-up of the U.S. dollar from 1979 to 1985 contrasted with its sharp decline between 1985 and 1990 and, in recent years, the gradual appreciation of the dollar after 1992 has been followed by a huge depreciation of the U.S. currency against the euro by more than 55 percent since 2000. Such large exchange rate movements in opposite directions seem to clearly depart from any reasonable valuation theory. It has indeed been extensively documented (see, e.g., Frenkel, 1976; Branson et al, 1977; and Edison, 1985) that

\footnotetext{
${ }^{\prime}$ Calculations before 2002 are based on a synthetic value of the euro, measured as the U.S. dollar price of a basket of EMU currency values weighted according: to their importance in the final euro composition.

${ }^{2}$ The exchange rate variability (as measured by the standard deviation of weekly changes in percent) was 0.2035 between 1960 and 1970 as compared to 1.355 between April 1973 and Nowember 2004.
} 
fundamental variables such as international payment situations, money supplies, output levels, inflation rates and interest rates can hardly explain the large cyclical movements of exchange rates. Meese and Rogoff (1983a, 1983b) show furthermore that existing models of systematic exchange rate determination are unable to outperform the simple random walk forecasting rule when trying to predict floating currency rates between two countries with roughly similar inflation rates.

It is important to note, however, that while EU currencies have been freely floating against the U.S. dollar, EU countries, in contrast, have tried to narrow the extent to which they let their currencies fluctuate against each other. Since the breakdown of the Bretton Woods system European countries started indeed developing their own monetary arrangements moving from the rather informal snake - a European informal joint float against the dollar - to a more structured European Monetary System (EMS) in 1979 before the ultimate share of the same currency in 1999. With the aim of promoting intra-regional trade through the reduction of relative price uncertainty, continental Europe has thus adopted a development strategy that is fundamentally different from that chosen by the U.K. and the U.S.. Opinions diverge regarding this choice. Skeptics believe that trade may hardly rise because of the monetary union whereas Europhiles think that sharing a common currency will strengthen intra-EU trading relationships and create value. Whatever attitude privileged, the evolution of Europe's exchange rate arrangements and Europe's unwavering commitment to a fixed exchange rate zone shed unquestionably new light on the continuing debate between fixed and floating exchange rate regimes. On the eve of new negotiations to create currency unions in the Mercosur trading area and in Southeast Asia several questions acquire once more increasing significance: Do monetary unions really favor the creation of truly unified markets? Do they promote intra-regional and global trading activities? Do they help countries to become major actors in the world monetary system? More widely, how do exchange rate arrangements affect national and intemational business cycles? Do fixed excliange rate regimes favor international trade and foreign investment strategies? Do they affect output growth? And so on. These questions clearly emphasize the crucial implications of international currency arrangements for policymakers, business managers and investors. While periods of high and low exchange rate volatility affect trade and investment patterns, they constitute as well a major concern for regulators who want to promote economic activity and macroeconomic stability. With such important and interesting issues at hand, it is no surprise that the effects of exchange rate volatility on national and global economies have grown to one of the most active debates in both the popular, professional and academic press. 
Today, more than ever, the recent eurrency crises and the internationalization of trade strongly suggest the need to adopt new approaches to cope with the consequences of uncertainty created by exchange rate varability. In this perspective it is essential, first of all, to identify and understand the risks in order to be able, afterwards, to manage them to an acceptable level. The explicit measurement of the implications of foreign exchange uncertainty is in consequence a key element and essential preliminary step of any financial and political decisionmaking process dealing with foreign exchange rate risk It is for this reason that the primary objective of this thesis is to thoroughly investigate what measurable effects exchange rate movements have on firm value and economic wealth in general. Empirical results and clear answers in this field should not only help policymakers measure the consequences of their monetary choices, but also help business managers and investors recognize the benefits and costs of their international trade and investment strategies as well as the implications of the ongoing internationalization of trade around the globe.

According to De Grauwe (1996) lower exchange rate uncertainty associated with smaller exchange rate variability should increase the quality of information provided by the price mechanism of resource allocation. The fall in risk should reduce the risk premium incorporated in the expected return on investment projects and the real interest rate, thus boosting firm value and output growth. On a corporate level it seems evident that the values - in firms" reference currency - of many cash flows depend on foreign exchange rates. The unpredictability of currency movements is hence likely to have substantial consequences on shareholder wealth. But in reality, firms" cash-flows are not only affected through relative price changes in input and output products and services but also through the relative values of domestic and foreign assets and liabilities. Exchange rate variability influences moreover the competitive position of firms both in their domestic and foreign input and output markets. ${ }^{3}$ In response to these changing market conditions some firms may consider altering their input sources and the markets in which they sell their products and services, others may relocate their production to other countries, engage in active financial hedging activities or decide to leave their operations, assets and liabilities unhedged. Whatever alternatives chosen, the recent development of foreign exchange risk management departments

\footnotetext{
"Typically a firm's revenues and export activities will be favored (hurt) by a decline (appreciation) of the exchange rate of foreign currencies against the domestic currency. This is true, for instance, if the exporting company maintains its revenue in foreign currencies. If however the firm changes its prices in foreign currencies, the final affect depends on the demand elasticity of the company's prodiucts in foreign and domestic markets, the demand elasticity of the exporting company to imported inputs, and the weight of exponts in the company's sales relative to the weight of inports in their inputs (Amihud, 1994).
} 
and the substantial increase in forward exchange rate markets reveal that the significant growth of international trade and foreign direct investment has forced managers as well as investors to pay increasing attention to the impacts of currency movements on firm value and to acknowledge the fact that nowadays exchange rate uncertainty has grown to one of the most important sources of risk companies are facing 4

Surprisingly, academic research on foreign exchange risk exposure defined as the sensitivity of firm value to exchange rate movements - hasn't been able, until now, to give a clear answer regarding the impact of foreign exchange rate risk. The somewhat surprising, but fairly unanimous, early results suggested indeed that exchange rate fluctuations influence firm value very little, if at all. ${ }^{5}$ Since then, many authors have attempted to reassess the relationship between exchange rate shoeks and firm value enriching with their studies one of the most animated controversies in the financial literature of recent years. While Griffin and Stulz (2001) conclude that "the impact of exchange rate shocks is trivial in explaining the relative importance of U.S industries and small even in countries where international trade is much more important than in the United States", Gendreau (1994) finds it difficult and unconvincing that the weak empirical results imply that exchange rate changes have no effect on stock returns. After more than 14 years of intensive discussion on probable difficulties related to methodological issues (Bartov and Bodnar, 1994; Levi, 1994, Khoo, 1994), to the investigation field (He and $\mathrm{Ng}, 1998$ ) and to the impact of potential hedging activities (Bartov and Bodnar, 1994), empirical evidence still remains inconclusive and puzzling.

In this thesis we shed new light on the measurement and determinants of foreign exchange risk exposure of firms. Previous empirical research is extended by improvements of methodological designs and studies of new investigation fields. Although many papers have been written in this field, a careful reading of the literature suggests indeed that numerous directions haven't been fully explored yet. First, many papers documenting a weak impact of currency movements on asset values have been investigating the impact of exchange rate shocks on (industry) portfolio returns. We show, however, that there are a number of potential problems with this empirical work and that the analysis of individual firms "exchange rate exposure is statistically and economically more informative. Since our results are in

\footnotetext{
4he ratio of merchandise expotts 10 gross domestic products tor the world increased from 7.0 percent in 1950 to 19.7 pertent in 2001 which implies that international trade increased nearly three times as fast as world gross domestic products. At the same time, throughout the $1990 \mathrm{~s}$, foreign direct investment by multinational companies grew at the annual rate of about 10 percent. According to the United Nations" World Investment Report 1999, there are about 60,000 multinational corporations in the world with over 500,000 foreign affiliates.

see, for instance, Jorion (1990, 1991), Amihud (1994), Bodnar and Gentry (1993).
} 
contrast to some previously reported findings, we investigate furthermore why results differ and analyze in how far data quality and horizon length influence the magnitude and significance of our exposure estimates. We highight as well the possibility that many of the earlier studies present potential econometric problems due to the aggregation of data, the unawareness of heteroskedasticity effects and the neglect of temporal instability issues. Potentially more problematic even, is the ignorance of non-linearity when estimating the relationship between exchange rate shocks and firm value. There are numerous economic and financial arguments supporting the existence of asymmetries in the effect of currency movements on trade, revenues and, ultimately, firm value. We show in this thesis that the recognition of these asymmetries help clarify the mechanism through which exchange rate movements affect firm value and improve the identification of exposure effects. Another issue with the exchange rate exposture literature is that it barely addresses the important question of how the corporate use of derivative instruments affect the examined relationship between currency and firm values. Although many authors have been investigating companies' hedging activities, the impact these activities have on firms' exchange rate exposure hasn't received much attention until now. This thesis attempts to give clear answers on this topic as well. Finally, given that the recent decade has been punctuated by a series of severe financial and currency crises - the Latin American currency collapses in the $90^{\prime} \mathrm{s}$ and the East Asian crisis in 1997, for instance - a thotough analysis of exchange rate exposure issues would be incomplete if it didn't evaluate the consequences of these episodes of increased exchange rate uncertainty in terms of shareholder wealth.

The thesis addresses each of these issues and provides additional insight in several other methodological and economic puzzles. In general, we demonstrate, in contrast to Griffin and Stulz (2001), that exchange rate exposure effects can't be ignored and propose several models to capture the sensitivity of firm value to exchange rate movements. Results are obtained from U.S. as well as Asian and European stock markets and can thus be easily generalized to other financial markets. Our conclusions offer a large and informative perspective on the effects of exchange rate uncertainty on firm value. As such, they constitute direct appealling guidance for managers, investors, regulators and of course academics.

The outline of this thesis is as follows. In chapter 2 , we introduce a survey and discussion on the relationship between exchange rate movements and firm value. As the prior knowledge of the mechanisms through which exchange rate movements affect firm value is essential for the accurate measuring of foreign exchange exposure, we first focus on the theoretical foundations of exchange rate 
risk. The second part of the chapter is dedicated to an extensive overview on the development and performance of estimation models designed to empirically assess the sensitivity of firm value to exchange rate movements: The notion of exchange risk exposure is fintroduced and the seminal augmented market model proposed by Jorion (1990) - that constitutes the starting point of empirical research in this field is presented. After reviewing the empirical findings obtained with Jorion's seminal model, we thoroughly discuss the different model modifications that have been suggested in the literature to improve the estimation of firms' sensitivity to currency fuctuations. In essence, chapter 2 meets two purposes. First, it reveals the fierce contrast between the theoretical expectations that clearly predict an impact of currency movements on firm value and the puzzling results obtained in empirical sttidies when measuring these effects. Second, it highlights the areas of research in which our understanding of the mechanism of exchange risk exposure has still to be enhanced and discusses the empirical issues addressed in this thesis.

Chapter 3 is motivated by the growing body of empirical evidence against the hypothesis that exchange rates have measurable effects on firm value. It presents an empirical exploration of the relationship between stock returns and currency movements for a large and diversified set of firms. For the purpose of this chapter it is, however, useful to divide this broad set of empirical findings into two parts: exidence on mature stock markets and evidence on emerging markets. We examine first the sensitivity of European stock returns to the movements of the three most actively traded currencies towards the euro. Whereas previous studies mainly focus on U.S. firms, research on European firms is limited to only a few studies on individual countries. We fill this gap and concentrate our first empirical study on firms belonging to the European Monetary Union. The intense activity and openness of the European market, the large appreciation and depreciation cycles that occurred between 1988 and 2002, Europe's strong concern for exchange rate arrangements, and the interest paid by both the popular and financial press to the value of the euro are as many arguments supporting the relevance of this exploration field. In a second step, we verify the robustness of previous results in an emerging market context. Although the reaction of stock market prices to changes in the most actively trade currencies has been extensively investigated, the question whether the impact is quantitatively similar for emerging market economies remains a very challenging and interesting topic to study. We examine this issue from two different perspectives. On the one hand, we explore whether Asian firms experience economically significant exposure effects to the U.S. dollar and the Japanese yen. The reason for the use of the Asian database, in particular, lies in the diversity of the economic episodes undergone by Asian economies between 1993 and 2003, the openness of the market and the growing significance of Asian trading 
relationships. The Asian dataset allows us moreover to evaluate the reaction of emerging stock markets to the highly volatile movements of their own currencies. On the other hand, we are interested in quantifying the response of mature stock markets to the variability of foreign emerging market currencies. Even more visible consequences of exchange rate variability may indeed take place for companies belonging to mature economies that are developing active trading relationships with emerging market countries. We focus, thus, our last study of chapter 3 on the impact of Latin-American currency movements vis-à-vis the U.S. dollar on U.S. multinationals with real operations in Latin America. Triggered by the weakness of previously reported results for U.S. firms, this analysis has the advantage of focusing both on existing region-specific trading relationships and on the impact of highly volatile Latin-American currency movements. Collectively, these three distinctive investigation fields will enable us in the end to synthesize a comprehensive and diversified picture on the following four essential questions: (i) are firms significantly affected by currency movements?, (ii) does a firm-level analysis that avoids the averaging effect - due to grouping of companies with different exposures - lead to stronger results? (Choi and Prasad, 1995; Dahlquist and Robertsson, 2001; Dominguez and Tesar, 2001a, 2001 b), (iii) are exchange risk exposure patterns industry specific? (Griffin and Stulz, 2001), and (iv) are firms* exposure to exchange rate movements more evident across increasing time horizons? (Chow er al, 1997a, 1997b; Chow and Chen, 1998; Di lorio and Faff, 2001; Bodnar and Wong, 2003).

We know that exchange rate risk can be hedged, at a cost, for instance by recourse to foreign currency derivative instruments. Whether this type of risk management policies or other strategies based on operational hedges affect the sensitivity of firm value to foreign currency movements is the central question addressed in chapter 4 . Clearly many of the risks created by the instability of foreign exchange rates can be avoided. In this context, the practice of corporate risk management has dramatically changed over the past two decades. As a result, an increasing body of research studies is examining if and how firms should engage in risk management (Stulz, 1984; Smith and Stulz, 1985; Froot et al., 1993; Bodnar et al., 1998; Hentschel and Kothari, 2001). However, the effectiveness of resulting risk management activities hasn't received much attention in the literature until recently. In chapter 4 , we revisit both the determinants and effectiveness of firms" hedging policies that encompasses both financial and operational hedging initiatives. We present a detailed analysis of the determinants of foreign currency derivatives usage and explore the impact of these financial hedging strategies as well as the effect of their operational counterparts on firms" exposure to foreign exchange risk. 
Given that firms are presumed to hedge only a small proportion of the currency risks they are facing, Hodder's (1982) statement that "exchange rates (movements) constitute a source of risk for international firms which can affect actions taken by decision-makers within such firms" should remain of central concern. Convinced that the more exchange rates are volatile the more risk they induce for firms, we present in chapter 5 an empirical test for the impact of increased exchange rate uncertainty on U.S. shareholder wealth. Rather than analyzing the relationship between exchange rate movements and firm value in an augmented market model framework, as originally suggested by Jorion (1990), we investigate, hence, the foreign exchange risk exposure puzzle from a different angle. The approach first implemented by Bartov et al (1996), who tested for the impact of the breakdown of Bretton Woods on the riskiness of U.S. multinationals, requires that periods of minimal exchange rate uncertainty should be compared to periods where exchange rates are highly volatile. Identifying if these episodes of increased exchange rate uncertainty affect stock returns offers indeed complementary evidence for or against the existence of economically significant exchange rate exposure effects. In this framework, recent major financial crises provide us with very instructive currency regime shifts from so-called pegged currency systems to freely floating systems. These shifts from very stable currency regimes to highly volatile exchange rate systems - from periods in which firms are able to predict the impact of exchange rates on their cash-flows to periods in which the values of their domestic and foreign revenues and costs depend on highly volatile currency movements - constitute unique investigation fields to assess the effect of increased exchange rate uncertainty on firm value. The methodology doesn't only avoid the problems linked to the potential instability of firms' exchange risk exposure, but enables us to verify whether unexpected large exchange rate movements have real consequences in terms of firms' riskiness defined as the variability of their stock returns. The breakdown of the stock return volatility between systematic and unsystematic risk allows us moreover to evaluate the effects of exclange rate variability on firms' market beta. This will answer the crucial question whether - or not the impact of this increased uncertainty is priced on the market, has direct implications for firms' cost of equity, their investment choices and, hence, shareholder wealth.

Chapter 6 is devoted to the theoretical justification and empirical implementation of a new empirical model to estimate the relationship between currency movements and firm value. Motivated by presumed asymmetric influences of exchange rate movements on trade flows, prices, investor sentiment, firms' entry and exit decisions as well as by the asymmetric repercussions of financial and operational hedging strategies on firms" cash-flows, we postulate that the weak 
reported results in previous academic research may be partly explained by the ignorance of the nonlinear effects of currency movements on firm value. While the asymmetric reactions of trade flows and prices have been empirically investigated in prior literature (Baldwin and Krugman, 1989; Ohno, 1989; Knetter, 1994), only few authors have recently explored the potentialities of asymmetric exchange risk exposures (Di Iorio and Faff, 2000; Koutmos and Martin, 2003a; Koutmos and Knif, 2004; Bartram, 2004). In chapter 6, existing empirical frameworks are extended in order to incorporate these asymmetries - both with respect to size and magnitude - in a two regime model. The empirical application is performed using a sample of 1,000 U.S. multinational firms with operations in foreign countries and strengthened through the use of region-specific exchange risk factors that are individually selected according to existing trading relationship of individual sample firms. Thanks to the uniqueness of the dataset, the analysis constitutes a challenging and promising step towards a better understanding of the functional form of foreign exchange risk exposure effects.

Chapter 7 summarizes the main empirical findings of this thesis and formulates some general conclusions on the basis of the results presented. Suggestions for future research are presented. 


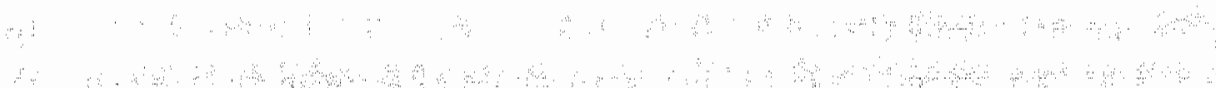

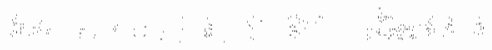

$\therefore \quad \therefore \quad \therefore$

a $\quad \therefore$ :

-

a $-\cdots$

औ

$\therefore \quad \because \quad \because$

a $\quad \cdots \quad:$

$\because \because \quad \cdots \quad$

$\therefore$ 

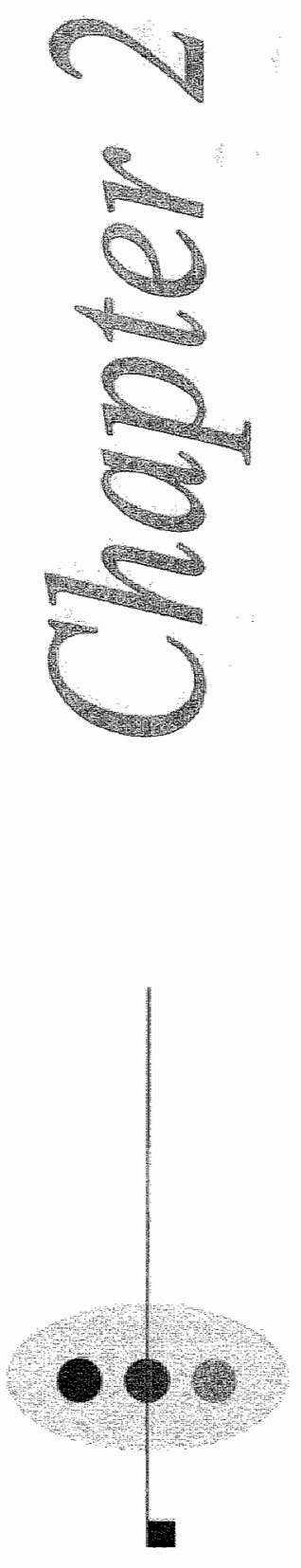

\section{Foreign Exchange Risk Exposure:} Survey and Suggestions 
औ

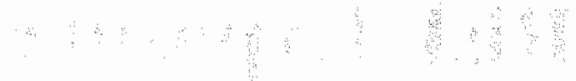

$\quad: \quad ; \quad ; \quad ;$

औ.

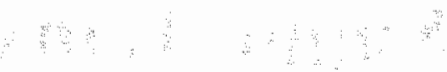




\section{Foreign Exchange Risk Exposure: Survey and Suggestions ${ }^{6}$}

\subsection{Introduction}

Since the breakdown of the Bretton Woods system, the volatility of exchange rates and its associated risks have become an increasingly important component of the world of business and international finance. Exchange risk exposure - defined as the sensitivity of asset values to currency movements - has spawned a considerable amount of literature and opened a large debate on the relationship between foreign exchange rate movements and shareholder wealth. As highlighted in chapter 1, this relationship has considerable consequences not only for investors and business managers but also for regulators and policymakers who have to coordinate monetary choices with economic prosperity.

From a theoretical perspective, it is a generally held view that exchange rate fluctuations are an important source of macroeconomic uncertainty. They should thus have a significant impact on firm value, regardless of whether the firm is domestically or internationally oriented (Shapiro, 1975; Hodder, 1982; Levi, 1994; Marston, 2001). Numerous papers analytically focus on the foundations of currency risk exposure and enhance our understanding of the mechanism through which exchange rate shocks influence firm value. Overall, their analyses emphasize the importance of a large and complex set of parameters - including among others a firm's cost and revenue structure, its competitive position and environment, the elasticity of its input and output markets as well as the pricing strategies adopted by the company itself and its competitors - in the determination of a firm"s sensitivity to exchange rate fluctuations.

\footnotetext{
"This chapter is based on A. Muller and W.F.C. Verschoor, "Foreign exchange risk exposture: Survey and suggestions", LIFE Working Paper, 2005 b.
} 
In contrast to theoretical expectations, empirical research on exchange risk exposure appears conflicting and is mixed at best. While studies have so far documented weak contemporaneous relationships between exchange rates and U.S. stock returns, international evidence focusing on more open economies yield more significant currency risk exposure estimates. The counter-intuitiveness of empirical findings has in turn influenced the developments of new estimation procedures. Starting from the seminal estimation models of Adler and Dumas (1984) and Jorion (1990), subsequent papers study the impact of different variable definitions, model specifications and estimation designs while others are exploring the interrelations between exchange rate exposures and economic competitive environments. Even though recent findings generally favor the conclusions that exchange rate fluctuations affect - to a certain extent - shareholder wealth, these endeavors meet nonetheless with limited success in documenting the levels of exposures that theoretical research suggests.

In this chapter, we survey the extensive literature on exchange risk exposure focusing on two broad issues: (i) the theoretical foundations of exchange rate exposure, and (ii) the empirical findings and recent development of estimation designs put forth over the last two decades. We will highlight the main conclusions that have emerged in these research areas and identify a number of unanswered questions. It is our purpose to present a comprehensive review of the literature, attempting to synthesize much of the recent work within common frameworks rather than summarizing the contributions of individual papers.

The chapter is organized as follows. Section 2.2 looks at the seminal and influential articles on the definition and mechanism of exchange risk exposure. This will serve as intellectual base for the rest of the paper. In section 2.3 , the focus of attention is turned to the challenges in empirically measuring firms' sensitivity to exchange rate uncertainty. Concluding remarks are presented in section 2.4.

\subsection{Theoretical foundations of exchange risk exposure}

Since the breakdown of the Bretton Wood system in 1973, exchange rate volatility has substantially increased throughout the world. Correspondingly, the volatility of both current and future cash flows of internationally active as well as domestic firms has been rising (see Bartov et al., 1996). As cash-flow volatility not only enhances the likelihood that a firm will need to access capital markets, but also increases the costs of doing so, it lowers the level of investment and, as a 
consequence, firm value (see, e.g., Shapiro and Titman, 1985, Lessard, 1990; Stulz, 1990; Froot et al, 1993; Minton and Schrand, 1999). ${ }^{7}$

There are many different approaches to analytically describing how currency fluctuations affect firm value. But before all else, it has to be stressed that exchange risk exposure - the sensitivity of firm value to currency movements - can only be defined with regard to an explicit time period; the exposure of a firm being directly contingent upon the investment horizon (Dumas, 1978). Lessard (1979) is first to document the extent to which the nature of eurrency risk exposure changes as the period for which one considers the exposure is farther in the future. Later, Stulz and Williamson (2000) decompose the overall impact of exchange rate movements on firm value distinguishing between transaction - respectively contractual - exposure, translation exposure and competitive exposure.

Transaction exposure is the exposure a firm is facing regarding all its specific commercial transactions that have already been booked. The terms of these transactions are established and settled at a given time period and their exposure can easily be measured by accounting systems. The implicit or explicit contractual agreements have to be taken into account as well when measuring the overall exchange rate exposure. While such commitments create contractual exposure ${ }^{8}$, a firm's domestic and foreign assets and liabilities, whose values are also affected by currency fluctuations, cause translation exposure. Measured over longer time horizons, the last component of a firm's exposure to exchange rate changes is called competitive - or economic - exposure. The basic idea is that as exchange rate variations affect the relative prices of goods sold in different countries, they affect a firm's competitive position and indirectly influence its economic envirenment and future development possibilities (Flood and Lessard, 1986; Levi, 1994; and Marston, 2001). While direct exposures (transaction, contractual and translation exposures) can be effectively managed by well-structured hedging strategies, indirect or competitive exposure provides significant variability in cash flows for most companies worldwide (Di lorio and Faff, 2000). Indeed, the complexity of the relationship between exchange rate fluctuations and competitiveness, makes it quite difficult to correctly estimate competitive exposure (Luehrman, 1990, 1991; Williamson, 2001) and, hence, to hedge it efficiently.

\footnotetext{
"That's the reason why a financially more constrained company tends to be more active in risk management activities (Geczy et al.; 1997; Mian, 1996; Nance et al, 1993; Tufano, 1996). Mello and Parsons (2000) ever argue that a financially unconstrained firm has no reason to hedge in order to reduce cash-flow volatility because the hedging strategy will have no impact on the value of the firm.

$\$$ The way contractual exposure can be measured mainly depends on its more or less explicit, respectively implicit character.
} 
Considering the different components of currency risk exposure, it appears that many parameters have to be taken into account when estimating a firm"s overall exchange risk exposure. To grasp the importance and the influence of all these parameters more accurately, some authors have tried to get a clearer view into the mechanism and have build theoretical models to relate the impact of exchange rate fluctuations on firm value in an analytical way.

Recognizing that the inappropriate definition of exchange risk exposure drawn from accounting information is virtually of no use for investors ${ }^{9}$, Shapiro (1975) made a first effort to formally model the relationship between firm value and exchange rates. His two-country model predicts that a depreciation in the value of the home currency leads to an increase in the value of the home country firm and a decrease in the value of its foreign competitors.

Elaborating on Shapiro's work, the models developed by Dumas (1978) and Hodder (1982) consider a company with both foreign and domestic activities. Describing the impact of currency fluctuations on a profit function that allows for purchasing, sales and payment collection at three different points in time, Dumas (1978) suggests that, whereas a firm's translation exposure is known, its total exposure always remains uncertain: it is a function of future exchange rate fluctuations, macroeconomic effects and the responsive behavior of the firm. Implicit in the formulation of Hodder's (1982) model is the idea that exchange rates affeet firm value through their influence on prices. ${ }^{10}$ Taking the net value of the firm as starting point, he shows that the firm's exchange rate exposure may be split in four different parts: the domestic price related exposure, the foreign real asset exposure, the inflation related exposure and the firm's fully exposed foreign bortowing exposure. Hodder's advance lies in the unambiguous expression of the

\footnotetext{
Goldberg ef al (1995), Venkatachalam (1995), Roulstone (1999) and Wong (2000) show that the documented relations between currency exposure and the quartitative disclosures about notional amount and fair values of foreign exchange derivatives, required by Statement of Financial Accounting Standinds (SFAS) No. 133 (FASB, 2000) and its predecessors SFAS No. 119 (FASB, 1994), SFAS No. 107 (FASB, 1991) and SFAS No. 105 (FASB, 1990) are only weakly consistent with those predicted in the conceptual analysis. Inconsistencies are mainly attributed to a lack of clarity and transparency in the implementation of these disclosure standards. The ambiguties - as well as the tepeated postponements in the implementation - of the disclosure regulations are easily explained by the firestorms of protest (both for more and for less disclosure) and political activity generated by the development of each of these regulations (Aggarval and Simkins, 2004).

10. Hodder (1982) shows that exchange risk exposure only accurs in the presence of market imperfections when prices don't adjust to exchange rate fluctuations in the short run-contradicting the law of one price. It has to be mentioned that the importance of the relationship between exchange rates and prices has already been analysed by Aliber and Stickney (1975), Ethier (1973), and Heckerman (1972), but generally these papers concentrate on the foreign activities and assets of a firm ignoring the domestie part of it.
} 
fact that even a purely domestic firm can be exposed to unanticipated exchange rate movements and that exposure is contingent upon the adjustment of prices.

Another set of models developed by Cornell and Shapiro (1983) and Flood and Lessard (1986) among others are driven by financial intuition. The idea is that, as the value of a firm is the present value of its current and future cash-flows, a firm's exchange rate exposure can be estimated by focusing on the effects exchange rate movements have on these cash flows. Limiting their analysis to operating cashflows, Flood and Lessard (1986) analyze the so-called operating exposure of the firm and distinguish between the competitive and the conversion effect of exchange rate fluctuations. The approach adopted by Booth and Rotenberg (1990) generalizes Flood and Lessard's model and allows for commodity arbitrage constraints. The model has interesting implications. It shows that the firm"s real price and cost structure, its discount rate, the observed deviation from the relative purchasing power parity and the transaction costs related to the economic barriers to arbitrage and the legislative ones imposed by government restrictions are key variables that influence the currency risk exposure of the company.

In Hekman's (1985) model corporate valuation theory, corporate macroeconomic linkages and an expectation theory of exchange rate movements are related. Hekman configures the model in such a way that all macroeconomic relationships are only dependent on the initializing rate of the stochastic process that exchange rate are expected to follow. Assuming perfect capital markets, a Cobb-Douglas production function with constant production parameters and constant returns, he examines the impact of these expected exchange rate fluctuations on three components of corporate value, which are the value of aftertax, non-financial, operating cash-flows, the value of outstanding debt and forward foreign exchange contracts. Hekman"s model is; - specifically, useful because it highlights the importance of hedging decisions and choices in terms of investment financing.

Tufano (1996) presents a model that isn't directly relevant to the exchange rate exposure literature, as it deals with the sensitivity of gold mining companies to changes in gold prices. Nevertheless, the contribution to the understanding and modeling of financial risk exposure is of high interest. Tufano analyses the gold price exposure in a fixed production model, a flexible production model and a third case where he considers fixed production with hedging. An interesting feature of his model is that, according to his flexible-production model, observed exposure decreases as the volatility of gold price increases. This conclusion is easily extended to currency risk exposure and finds empirical support in Friberg and Nydahl (1997), who find that the more volatile exchange rates are, the less impact they have on competition and exchange rate pass-through. 
Analogous to Shapiro's (1975) influential work, Levi (1994) explores the relationship between firm walue and exchange rates from a microeconomic point of view, relating foreign exchange risk exposure to economic and financial characteristics of the company. He therefore develops a multi-currency model, which takes both the tax rate and the firm's net monetary asset and liability position for each currency into account Distinguishing between a one-product exporting and a one-product importing firm, he shows that the sensitivity of the firm to exchange rate changes of currency $j$ depends directly on the elasticity of demand for the product in country $j$ and on the profit generated in country $j$. He also shows that the impact of exchange rate fluctuations varies inversely with the tax rate and the opportunity cost of capital. "In a similar context, Allayannis (1996) describes analytically the exposure of an exporter and that of an importer showing that they may not be symmetric as the former is related to the elasticity of demand in the foreign countries whereas the latter is depending on the ellasticity of demand in the home country.

In a subsequent paper, Allayannis and Ihrig (2001) focus on changing competitive structures. ${ }^{12}$ Using a Taylor series expansion of the value of a firm around a date state variable, they actually show that exchange rate changes affect a firm's retums through three channels: the competitive structure of the market where the firm sells its products, the export share and the industry structure, and finally, the import share and the competitive structure of the imported input market. The analysis of different competitive structures is the subject of a succeeding paper by Marston (2001). Building on results reported in von Ungern-Sternberg and von Weizsäcker (1990), Marston (2001) shows that, while transaction exposure is only determined by net revenues denominated in foreign currencies, economic exposure is contingent upon product demand elasticity, marginal cost behavior and the output reaction of competing firms.

Bodnar et al. (2002) associate the analytical modeling and the currency risk exposure decomposition from another perspective. Their duopoly model distinguishes between three different impacts of exchange rate changes on an exporter's firm value. The first is the impact of exchange rate movements on profits (the transaction. contractual and translation effect), the second is the impact of

\footnotetext{
"According to Levi (1994), Jorion's exchange rate exposure estimation model leads to insignificant exposure coefficients because the profit margin, the tax rate, the demand elasticity and the opportunity cost of capital of a firm are likely to change over the estimation period.

12 Von Ungern-Sternberg and won Weizsăcker (1990) were the first to explicitly investigate economic exposure under different assumptions of industrial structure. Integrating industrial organization and intermational tinance theories, they analyzed economic exposure under four different industrial structure assumptions which are Coumot competition, conjectural variation, price taking firms and a monopolistic competition model.
} 
exchange rate changes on the share of total expenditures accruing to the exporter and the third measures the influence on the domestic-currency profit margin of the exporter due to price changes (both impacts correspond to the economic exposure). Hence Bodnar et al. (2002) show that due to the impact of pricing on profitability pass-through effects and exchange rate exposures are linked. Their model has interesting implications. With constant market shares, product substitutability is shown to be negatively correlated with pass-through, and hence positively correlated with exposure. However, if product substitutability remains constant, a rise in market share diminishes pass-through and exposure. Further, the model suggests that pass-through, in case of a depreciation of the exporter"s currency is generally incomplete since the depreciation induces exporting firms to increase their markups.

In summary, all these contributions tend to indicate that the sensitivity of firm value to exchange rate movements depends on a large number of parameters as, for instance, the nature of a firm's activities, its import and export structure, its involvement in foreign operations, the currency denomination of its competition and the competitiveness of its input and output markets.

Still, it has to be acknowledged that there is neither real consensus concerning the most relevant parameters influencing currency risk exposure nor real hope for a unique model integrating all the complexity of the effects of exchange rate shocks on firm value.

\subsection{Selected issues on existing empirical evidence}

In contrast to previous reported theoretical arguments defining the origins of exchange rate exposure and the extensive use of foreign currency derivatives and other hedging instruments by corporations, empirical work on exchange rate exposure has found only limited support of a significant rellationship between firm value and exchange rate changes.

In this section, we review the empirical evidence regarding the impact of currency fluctuations on shareholder value in three "rounds" or waves of research that have all taken place within the two last decades. Each successive wave is marked by refinements on research methods that provide shifts in the empirical evidence.

Round 1 describes the fundamental exchange risk exposure estimation models and corresponding empirical evidence. In Round 2, we explore the beginning of a new wave of research that casts doubt on the specification of the variables to be included in the estimation model. Finally, Round 3 includes the 
results of the most recent group of studies that we survey. These studies suggest that the intrinsic characteristics of exchange risk exposure have to be taken into account when measuring the relationship between stock returns and exchange rate movements.

\subsubsection{Round 1: Early specifications}

In a seminal article, Adler and Dumas (1984) develop an easily applicable technique to measure exchange risk exposure. Defining currency risk exposure as:

the amounts of foreign currencies which represent the sensitivity of the future, real domestic-currency (market) value of any physical or financial asset to random variations in the future domestic purchasing powers of these foreign currencies, at some specific future date",

they estimate the exposure of an asset by regressing its domestic-currency market price on the contemporaneous foreign exchange rate. Since the use of level data in regression models raises a series of statistical complications, Adler et al (1986) suggest using stock returns and exchange rate changes in order to get stationary series and avoid statistical difficulties related to non-stationary series: $:^{13}$

$$
R_{i, t}=\alpha_{i}+\varphi_{i} \theta_{t}+\varepsilon_{i, t}
$$

where $R_{i, j}$ designates the total return of firm $i$ in period $t, \theta_{i}$ the exchange rate change in period $t, \varphi_{i}$ firm $i$ 's exposure to these currency movements, $\alpha_{i}$ the constant term and $\varepsilon_{i, t}$ denotes the white noise error term. Hence $\varphi_{i}$ describes the sensitivity of firm $i$ 's stock returns to unanticipated changes in exchange rates.

If the exchange rate index is defined as units of foreign currencies per unit of domestic currency, a positive exchange rate movement - hence an appreciation of the home currency - makes exporting goods more expensive in terms of foreign currencies and this may lead to a fall in foreign demand and foreign sales revenue. On the other hand, the importing firm may benefit from an appreciation of the domestic currency, as its imports become cheaper in terms of home currency. ${ }^{14}$

\footnotetext{
${ }^{13}$ The article by Adler ef al. (1986) gave rise to a series of empirically oriented studies that enploy its estimation model. See for instance Booth and Rotenberg (1990), Levi (1994), and Glaum et al. (2000).

${ }^{14}$ Note that the sign of the exchange rate exposure coefficient becomes less distinct for a company that imports as well as exports. See, for example Adler and Dumas (1984) and He and $\mathrm{Ng}$ (1998) for their suggestion that the sensitivity of the firm value to exchange rate fluctuations depends on the elasticity of the firm's demand for foreign goods relative to the elasticity of the foreign market's demand for the tirm's goods.
} 
Thus, the coefficient $\varphi_{i}$ should be positive for net-exporters and negative for netimporters. Likewise, domestic firms with net exposed foreign denominated liabilities will gain with a strengthening of the home currency, while firms with net exposed foreign denominated assets will lose.

As specified in the model developed by Adler et al. (1986), the exchange rate exposure of firm $i$ is simply measured by the part of firm $i$ 's stock return variance that is correlated to exchange rate movements. As such it is often referred to as the total exposure of firm $i$. Since other macroeconomic variables may nevertheless simultaneously covary with exchange rate movements and stock returns; failure to include them in the exposure model could result in exaggerated estimates of the proportion of variance in stock returns attributable to foreign currency movements. That's why Jorion (1990) prefers measuring the firm-specific exchange rate sensitivity, called residual exposure, in excess of the market's reaction to exchange rate movements. His augmented market model will serve as a roadmap for the remainder of the thesis:

$$
R_{i, t}=\bar{\alpha}_{i}+B_{i} R_{m, i}+\gamma_{i} \theta_{i}+\varepsilon_{i, t}
$$

where $R_{i, t}$ designates the total return of firm $i$ in period $t, R_{m i l}$ the overall stock market return in period $t, B_{i}$ firm $i$ 's return sensitivity to market risk, $\theta_{i}$ the movement in exchange rate in period $t, \gamma_{i}$ firm $i$ 's exposure to the exchange rate independent of the effect these currency movements have on the overall market; and $\varepsilon_{i, t}$ denotes the white noise error term. ${ }^{15}$ Implicit in this model is the fact that the modified exposure coefficient $\gamma_{i}$ measures the sensitivity of firm $i$ 's stock returns to exchange rate changes as the residual between the firm's total exposure and the market's exposure adjusted by the firm's market beta $B_{i}$. Therefore $\gamma_{i}$ is referred to as the residual exchange rate exposure of firm $i$.

Examining the monthly stock returns of 287 U.S. multinationals ${ }^{16}$ from 1971 to 1987, Jorion (1990) finds that the influence of nominal exchange rate movements on returns is statistically insignificant at the 5 percent confidence level,

\footnotetext{
is A zero exposure doesn't imply, thus, that the firm is not affected by currency movements. It rather means that the firm value reacts to exchange rate movements to the same degree as the market portfolio.

${ }^{16}$ Many authors prefer to focus their attention on multinational firms as the inclusion of firms with limited linkages to international conditions or firms that can react to elianges in international conditions at wery low cost introduces noise into the analysis and thereby reduces the abillity to identify significant exchange rate exposire (Bartov and Bodnar, 1994). This selection procedure finds support in many studies documenting a positive relation between exchange rate exposure and the ratio of foreign sales to total sales (see, e.g., Jorion, 1990; Chol and Prasad, 1995; He and Ng, 1998; Williamson; 2001; Dominguez and Tesar, 2001a; De Jong et al, 2004; Bartram, 2002; Nguyen and Faff, 2003).
} 
except for a few companies. ${ }^{17}$ These findings are confirmed in a subsequent paper (Jorion, 1991 ) where the returns of 20 value-weighted industry portfolios are shown to be insensitive to exchange rate changes. Sumilarly, Bodnar and Gentry (1993) report that only 9 of 39 two-digit industry portfolios exhibit significant exchange rate exposure at the 5 percent level from 1979 to 1988 . They notice however that export and import levels, reliance on internationally-priced inputs, product-type (traded or non-traded) and the degree of foreign assets help to determine exchange risk exposure at the industry level.

Given these weak results, Amihud (1994) tries to be more selective when defining his sample procedure. He focuses on the 32 largest U.S. exporting firms from 1982 to $1988 .{ }^{18.19}$ His findings show nevertheless that there is no sigmificant contemporaneous exposune, even for the portfolio composed of the 8 largest exporting companies where, on average, exports account for almost a quarter of their total sales. Choi and Prasad (1995) examine a data set of 409 multinational firms during a twelve-year period starting on January 1978 and ending December 1989. They document that there is only a small percentage of firms with significant exchange risk sensitivity (15 percent). Results using Standard Industrial Classification (SIC) portfolio returns are even less convincing. Over the entire estimation period, only two industries (Other Retailing and Mining) are significantly exposed to currency fluctuations. These findings are consistent with those of Miller and Reuer (1998) who analyze a sample of 404 U.S. manufacturing companies from 1988 to 1992 and show that only 13 to 17 percent are exposed to foreign exchange mowements. ${ }^{20}$ Chow et al. (1997) examine both bond and stock returns from 1977 to 1989 . Considering monthly returns; they demonstrate that there is a clear positive exchange rate exposure of bonds due to the interest rate effect but the sensitivity of stocks appears to be insignificant.

\footnotetext{
${ }^{17}$ Jorion (1990) finds however that 9 out of 14 foreign firms listed on the NYSE have significant exposures.

18 This procedure only concentrates on the exporting character of the firms and ignores the possible importing activities, which naturally hedge foreign exchange rate exposure arising from exporting activities (or, alternatively, for large importers, exporting activities may naturally hedge foreign exchange exposure arising from inporting activities). That"s why Allayannis (1996) decides to focus on firms that belong to industries with the largest "net" exports-to-sales ratio (respectively 'net' imports-to sales ratio).

19. Doukas et al (1999) suggest that pre-selecting at subset of assets according to prior assumptions of the main factors affecting exposure may introduce a bias in exposure tests.

20 See also Fraser and Pantzalis (2004) who document 5-12\% of significantly exposed U.S. firms over the 1995-1999 period.
} 
Whereas most papers focus on U.S. financial markets, several studies have also been exploring other markets. ${ }^{21}$. The argument here is that more open economies may provide a better investigation field for currency risk exposure because of the stronger relationship between these economies and foreign trading activities. Among this literature, the contribution of He and Ng (1998) reports that about 25 percent of their sample of 171 Japanese multinationals' stock returns experience significant exchange rate exposure. Chamberlain et al. (1997) compare U.S. bank holding companies to those of Japanese banks. They report that while stock returns of a significant fraction of U.S. firms move with exchange rates, only a few of the Japanese firms do so. Focusing on an emerging market economy, Kiymaz (2003) indicates that about 50 percent of his sample consisting of 109 Turkish firms is exposed to currency fluctuations between 1991 and 1998. On the other hand, Khoo (1994) finds that the sensitivity of stock returns of listed mining companies in Australia to exchange rate movements and the proportion of stock. returns explained by exchange rate movements are quite small. ${ }^{22}$ Focusing on industry portfolio returns, Griffin and Stulz (2001) recently show that the negligible impact of exchange rate shocks on U.S. portfolio returns also holds for industry portfolios of more open economies. ${ }^{23}$ According to their results, industry effects are much more relevant than competitive effects across countries. Their use of portfolio returns is nevertheless empirically called into question in an earlier paper by Allayannis (1995), who shows that aggregation reduces the statistical significance of the results as exposure at the 4-digit SIC level is often masked in the 2-digit level, rendering the underlying exposures undetected. Contributions by Khoo $(1994)^{24}$ and Choi and Prasad (1995) similarly point out that the significance level

\footnotetext{
${ }^{21}$ For instance, Khoo (1994), Chamberlain et al. (1997), Friberg and Nydahl (1997), He and Ng (1998), Nydahl (1999), Di lorio and Faff (2000), Glaum et al (2000), Entorf and Jamin (2000), Dominguez and Tesar (2001a, 2001b), Griffin and Stulz (2001), Doidge et al (2002), Parsley and Popper (2002), Bartram (2002), Kiymaz (2003), El-Masry (2004), Bartram (2004), Entorf and Jamin (2004), Priestley and $\varnothing$ degaard $\left(2004 a_{2} 2004 \mathrm{~b}\right)$, and Koutmos and Knif (2004) provide enpirical evidence on exchange risk exposure in intemational markets.

${ }^{22}$ For about half the number of companies the partial $R^{2}$ is zero.

${ }^{23}$ In contrast, Allayannis and Ihrig (2001) find that 4 out of 18 U.S. two-digit $51 \mathrm{C}$ industries are significantly affected by currency fluctuations between 1979 and 1995 .

${ }^{24}$ Khoo (1994) underlines that portfolio level analysis is more efficient compared to single equation estimation for individual firms because portfolio returns are less noisy than individual stock returns. But the procedure is only possible in his eyes if the grouped firms are expected to bave similar foreign exchange exposures, e.g. similar sized firms in the same industry sourcing from and selling to the same markets. As a matter of fact, iff the portfolio contans individual stoeks with exposures of opposite signs, the exchange rate exposure of the portfolio will be both affected in value and significance. So the implicit assumption in models aggregating firms at a portfolio or industry level is that no heterogeneity exists within portfolios, respectiwely industries. This assumption naturally contradicts a fundamental
} 
of currency risk exposure decreases when calculated on a portfolio level as compared to calculations on the firm level. These findings are corroborated in a subsequent paper by Allayannis (1996) who points out that, within the automotive industry, for instance, the currency risk exposures of the "big three? are strongly divergent between 1976 and 1990 . The analysis of U.S., German and Japanese automotive companies by Williamson (2001) similarly concludes that while at the fim level the significance and sign of exposure estimates is found to be contingent upon the elasticity of demand and type of competition, there are still significant cross-sectional differences in exposure coefficients across firms, industries and countries.

\subsubsection{Round 2: Refinements in research methods}

Jorion's residual firm-specific exposure to exchange rate changes has to: be carefully interpreted. Suppose indeed that all firms of country $j$ are negatively affected by a depreciation of the U.S dollar and that the market risk factor considered in Jorion's model is country $j$ 's overall market return. Under these assumptions, Jorion's estimation procedure is unable to dociment any significant residual exchange rate exposure for any firm in country $j$, despite the fact that in reality shareholder value is affected in country $j$ (Glaum et al, 2000). Furthermore, while the inclusion of a market risk factor mitigates the omitted variables problem (Priestley and Ødegaard, 2004a), the specification of the market risk factor has direct implications on the sign, magnitude and significance of the estimated exposure coefficients. Using consecutively equally-weighted, value-weighted and firm size-matched market portfolios, Bodnar and Wong (2003) are the first to demonstrate the importance of the definition of the stock market risk factor. Their results indicate that, because large firms are over-represented in these indices, value-weighted market indices induce a positive bias in exposure coefficients. ${ }^{25}$ Corroborating evidence is provided in Pantzalis et al. (2001), Dominguez and Tesar (2001a, 200lb) and Starks and Wei (2003).

Another difficulty with using Jorion's augmented market model is the definition of the exchange risk factor. ${ }^{26}$ Several kinds of questions arise in this context. For example, empirical research on economic exposure often employs a

premise of strategy research (Miller and Retee, 1998) and might introduce a bias into the results (Doukas et al., 1999).

${ }^{25}$ Due to this ower-representation, the market risk factor gives more weight to the more export-oriented casti flows exposure of these firms.

26. Dominguez and Tesar (2001a) and Fraser and Pantzalis (2004) empirically describe how the cholce of the index used to capture exposure influences the level of exposures observed. 
proxy, which is meant to translate all the exchange rate movements affecting the sample firms' value. This proxy may be a trade-weighted exchange rate index or a bilateral exchange rate. The single currency method is generally used when the authors assume that, due to the dominance of one country as trading partner, primarily one currency affects the value of the firms included in their sample (Booth and Rotenberg, 1990; Williamson, 2001; Glaum et al., 2000; Entorf and Jamin, 2004; Priestley and Ødegaard, 2004a). Other studies employ trade-weighted exchange rate indices, e.g., MERM, MG, X-131, G-10 or RX-101 (Jorion, 1990; Bodnar and Gentry, 1993; Amihud, 1994; Bartov and Bodnar, 1994; Choi and Prasad, 1995; Donnelly and Sheehy, 1996; Chow et al.; 1997a; He and $\mathrm{Ng}_{\text {; }} 1998$; Chow and Chen, 1998, Bodnar and Wong, 2003). ${ }^{27}$ It has to be emphasized that the use of such a trade-weighted index disregards the problem of low and negative correlations among exchange rates over time (Miller and Reuer, 1998). ${ }^{28}$ As such, weighted-index models of economic exposure may underestimate corporate exposures by omitting variables needed to capture the divergent movements in currency values $^{29}$. In order to translate these potential divergent movements in currency values and to solve the underestimation problem, Miller and Reuer (1998) include the most pertinent currencies by selecting the exchange risk factors using a principal components factor analysis. ${ }^{30,31}$ Considering a large sample of U.S. manufacturing firms, their main result is that the specitication of the exchange risk factor plays a significant role in the estimation of currency exposures as the methodology yields a substantially higher proportion of exposed U.S. firms than reported in previous research.

The use of trade-weighted baskets of currencies may moreover lack power if a firm is mostly exposed to only a few currencies within the basket (Williamson, 2001). Employing alternatively a trade-weighted exchange rate index and bilateral rates, Dominguez and Tesar $(200 \mathrm{lb})$ demonstrate that, since trade-weights do not correspond with individual firms' or industries' trade patterns, the use of tradeweighted exchange rate indices leads to an underestimation of the impact of

\footnotetext{
${ }^{27}$ Chamberlain et al. (1997) and Pantzalis et al. (2001) have tested the robustness of their results to different specifications of the trade-weighted exchange rate index. They consistently conclude that their exposures are not significantly affected by the choice of the exchange rate index.

${ }^{28}$ On the other hand, Miller and Reuer (1998) argue that the use of a bilateral exchange rate cannot address a firm's exposure to other currencies.

${ }^{29}$ Most of exchange rate indices tend indeed to average out the competitive effects resulting from billateral exchnange rate shocks.

${ }^{30}$ Principal components analysis can be viewed as a regression that tries to find a linear combination of the columns of the data matrix $X$ that best describes the data, subject to the normalization restrictions imposed to remove indeterminacy.

${ }^{31}$ See allso Doukas ef al. (1999).
} 
exchange rate shocks. ${ }^{32}$ Thus, the relevance of currencies should be a function of the firm-specific strategic position. In his study of the mining sector of Australia, Khoo (1994) examines for each subgroup of firms the relative importance of its trading partners and selects the exchange rates to take into account accordingly. Similarly, Thrig (2001) builds firm specific exchange rate indices that are composed of bilateral rates of all countries in which the firms in the sample have subsidiaries. Finding more significant exposures with the firm-specific index than earlier exposure studies, she concludes that the fallure of earlier studies to document a significant link between stock returns and currency fluctuations may be partly attributed to an imprecise specification of the exchange risk factor: In contrast, Fraser and Pantzalis (2004) show that when more currencies are included in an index - whether or not the firm operates in a particular currency"s home country more firms with significant exposures are detected. ${ }^{33}$ This constitutes indirect evidence in support of the notion that firns are exposed to currencies of countries where they are not operating, and further that all firms are subject to foreign exchange exposure, not just those operating in foreign countries. ${ }^{34}$

Several additional questions arise regarding the specification of the exchange risk factor. It seems indeed surprising that, while economic theory would intuitively suggest employing returns based on both real firm values and real exchange rates, most studies have used nominal returns. There are three main reasons which might explain this practice. First; it has to be stressed that if exchange rate movements are measured in real terms, all variables in the regression equation have to be measured in real terms for consistency. ${ }^{35}$ Second, as financial markets don't observe inflation rates instantaneously, it is highly probable that investors are primarily incorporating the impact of nominal exchange rates in stock prices (Bodnar and Gentry, 1993). Third, the low variability of inflation differentials relative to exchange rate movements on a monthly basis implies that nominal movements actually dominate real exchange rate movements. ${ }^{36,37}$ As a

\footnotetext{
${ }^{32}$ Dominguez and Tesar (200 lb) show that many firms are exposed to one or more bilateral currency rates whereas not exposed to the index. These results are in contradiction with Bartram (2002) who shows that the use of a currency index versus bilateral rates doesn't mitigate the significance of exposire estimates.

3.3 Similar to thrig (2001), Fraser and Pantzalis (2004) build firm-specific exchange rate indices. They compare their impact on stock returns with the influence of commonly used indices like the Broad index and the Major Currencies index provided by the Federal Reserve Board.

${ }^{34}$ Some of the competitors of these firms may be incorporated in these countries, or some of these firms' inputs to production may be denominated in those currencies.

35 In genera, nominal data are more easily available than real ones.

${ }^{36}$ Jorion (1990) notes that exchange rates were 10 times as volatile as inflation rates during the sample period 1971 to 1987.
} 
consequence, the use of real versus nominal exchange rates has a negligible effect on exposure estimates (e.g. Bodnar and Gentry, 1993; Amilhud, 1994, Choi and Prasad; 1995; Chamberlain et al, 1997; Griffin and Stulz, 2001).

Regarding the currency risk factor, another set of questions deals with the fact that for most currencies, exchange rate variation series are positively autocorrelated (Amihud and Mendelson, 1989). ${ }^{38}$ In order to take the effects of exclusively unanticipated exchange rate variations into account - as anticipated exchange rate changes are supposed to be already incorporated in stock prices by the time they take place - Amihud (1994) suggests the following two-step approach: the first step consists in regressing exchange rate variations on their lagged value; the second one estimates Jorion's model (Eq. 2.2) replacing $\theta_{i}$ by the residuals of the first estimation $d \theta_{1}$. Since Amihud's procedure only marginally increases the significance of the results, Gao (2000) recommends, in the first step, the regression of the exchange rate variable on macroeconomic variables:

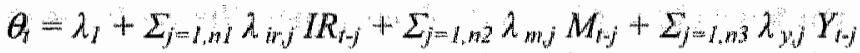

$$
\begin{aligned}
& +\sum_{j=1, n d} \lambda_{b_{j} j} T B_{t-j}+\Sigma_{l=1, n s} \lambda_{\pi j} \pi_{t-j}+d \theta_{t}
\end{aligned}
$$

where $I R_{t}$ stands for the interest rate, $M_{t}$ the money supply, $Y_{t}$ the level of industrial production, $T B_{i}$ net exports and $\pi_{i}$ the rate of inflation at time period $t$. The residual term $d \theta_{t}$ represents, thus, the unanticipated change in exchange rate at time period $t$. Investigating the impact of these unanticipated exchange rate changes $d \theta_{1}$ on a sample of 80 multinational firms (Eq. 2.4), Gao shows that unexpected currency movements have significantly stronger effects on firm value than the original exchange rate variation series.

Parallel to these contributions is a literature that focuses on the multicollinearity problem between market risk and exchange risk factors. To avoid any bias due to high correlations between independent variables, Choi and Prasad (1995) choose to orthogonalize the exchange risk factor. Following the standard approach of Elton and Gruber (1991), they run a side regression of exchange rates on the market risk factor and estimate the exchange rate exposure using Jorion's regression model (Eq. 2.2), replacing $\theta_{t}$ with the part of exchange rate variations

\footnotetext{
${ }^{37}$ Using montlyy data from 1973 to 1988 , Mark (1990) shows, for instance, that contemporaneous movements in real and nominal exchange rates are almost perfectly correlated for seven currencies examined.

${ }^{38}$ In contrast, Meese and Rogoff (1983a) show that individual exchange rates follow a nearly random walk process. Allayannis (1996) finds that the RX-10I and the MG indices are autocorrelated but the atutocorrelations are small.
} 
that can't be explained by the overall market behavior. ${ }^{39}$ On the other hand, the multicollinearity problem may as well be avoided by orthogonalizing market returns on exchange rate fuctuations (He et al, 1996 ; Kiymaz, 2003). ${ }^{40}$ In this case, $d R_{m}$ expresses the part of market returns that can't be explained by exchange rate changes and the new coefficient $\gamma_{i}$ measures both the direet and indirect ${ }^{4}$ - hence total - exchange rate exposure of firm $l^{42}$

A different way to handle the multicollinearity problem faced in Jorion's model ( $\mathrm{Eq} .22$ ) is to concentrate on the relationship between exchange rate variations and market retums. As same forces (e.g. interest rate fluctuations) may drive market returns and exchange rate fluctuations, it might be interesting to detect these forces (Chen et $a l, 1986$ ) and add them as additional explanatory variables into the model (Miller and Rever; 1998). But Gao (2000) goes further and doesn't simply enlarge the model by additional factors. Gao actually replaces the market risk factor by six macroeconomic variables. According to Gao, these macroeconomic variables $M_{k t}$ are essential determinants of firm value and have to be taken into aceount in order not to overestimate the exchange rate exposure when measuring the impact of exchange rate movements on firm value:

$$
R_{i, t}=\alpha_{i}+\Sigma_{k=1,4} \pi_{k, i} M_{k, t}+\gamma d \theta_{t}+\varepsilon_{i, i}
$$

where the macroeconomic variables $M_{k}$ represent consecutively the news to the unemployment rate, to a producer price index, to the money supply, to an energy price index, to an aggregate wage index and to an industry-specific wage index $d \theta_{t}$ stands for the unanticipated exchange rate change resulting from an orthogonalization procedure regressing exchange rate changes on its main determinants ( $\mathrm{cf}$ Eq. 2.3). By taking into account the essential forces influencing stock returns and exchange rate changes, the equation system aims to lower the endogeneity problem. The empirical investigation shows that the exchange rate exposure coefficient is mostly statistically significant, whereas it is statistically

\footnotetext{
39) It has to be stressed that, due to the orthogonalization procedure, the estimated variance of the coefficient $\gamma_{i}$ is biased; which means that the regular t-test is inappropriate for drawing inferences about the significance of exchange rate exposure (Giliberto, 1.985).

4he market risk factor may also be orthogonlized on macroeconomic risk variables to ensure that only residual market risk is included in the estimations model (see; for instance, Entorf and Jamim, 2004)

${ }^{41}$ 'The indirect exposure results from the interaction of the market's exchange rate sensitivity with the firm's sensitivity to the exchange rate related movements of the market.

42 The model becomes thus: $R_{i, t}=a_{i}+B_{i} d R_{B, i, i}+\gamma_{i} \theta_{i}+\varepsilon_{i, d}$, where $R_{i, t}$ designates the total retum of firm $i$ in period $t$, d $R_{\text {in, }, t}$ the part of market retuins that can't be explained by exchange rate changes in period $t$, $B_{i}$ firm $i$ 's return sensitivity to market risk, $\theta_{i}$ the movement in exchange rate in period $t, y_{i}$ firm $i^{\prime} \mathrm{s}$ total exposure to the exchange rate, and $c_{i, j}$ denotes the white noise error term.
} 
insignificant when the six macroeconomic variables are replaced by the market risk factor. But, on the other hand, it has to be noticed that none of the considered macroeconomic variables indicate a significant impact on stock returns.

Chow and Chen (1998) include business condition variables that have been found to explain expected stock returns to ensure that their results are not confounded by macroeconomic events:

$$
R_{i, t}=\alpha_{i}+\delta_{i i} \operatorname{Div}_{i, t}+\delta_{2 i} \operatorname{Tr} m P_{i, t}+\gamma_{i} \theta_{t}+\varepsilon_{i, t}
$$

where $\operatorname{Div} Y_{i, t}$ and $\operatorname{Trm} P_{i, t}$ denote the prevailing dividend yield and term premium at period $t$. $\theta_{t}$ stands for the rate of change in a real exchange rate index. Although their findings show significant exchange rate exposures for some Japanese firms, it has to be noticed that in line with Gao's (2000) findings results are shown to be qualitatively the same without including the business condition variables.

A different approach consists in orthogonalizing both market returns and exchange rate fluctuations on the same macroeconomic variables. Both orthogonalized factors will then describe the unanticipated components of market and currency risk. Contemporaneously, Doukas et al. (1999) suggest that other risk factors like size and financial distress should be accounted for in Jorion's model (Eq. 2.2) ${ }^{43}$ That's why they add two additional risk factors ${ }^{44}$ in their intertemporal multifactor asset-pricing model. The model is furthermore enlarged by the macroeconomic variables - initially used as regressors to calculate the unanticipated movements of the four main risk factors:

$$
R_{i, t}=\alpha_{i}+\Sigma_{j=l_{i},} \delta_{l, j} I V_{j, t}+\Sigma_{k=1,4} \chi_{i, k} d R F_{R, t}+\varepsilon_{i, t}
$$

where $I V_{j, r}$ 's are the predetermined macroeconomic variables ${ }^{45}$ and $d R F_{k, r}$ represent the set of four unanticipated risk factors obtained from the regression of the four risk factors - the foreign exchange rate changes, the market rates of return and the Fama and French (1996) type value minus growth and small minus large capitalization return spreads - on the predetermined macroeconomic variables and on the respective lagged values of these factors. As both macroeconomic variables

\footnotetext{
43 For: a complete argumentation see Fama and French (1996) and Arshanapalli et al. (1998).

44 The other two risk factors comprise the difference between the return on a portfolio of value stocks and the return on a portfolio of growth stocks, the difference between the return on a pontolio of small capitalization stocks and the returin on a portfolio of large capitalization stocks.

45. The choice of fundamental factors that explain equity risk premia relies on the work of Chen et al. (1986). These factors are: (a) IP, the industrial production growth, (b) U1, the unexpected inflation, (c) UTS, the term strueture, (d) MS, the money supply, (e) UNS, the U.S.-Japan interest rate spread and (f) TB, the trade balance series.
} 
and lagged values are varying over time, the risk premia are allowed to change through time in response to these fluctuations. Overall, the empirical implementation of the model reveals that the currency risk exposure is statistically significantly priced on the Japanese stock market. The results are consistent with those of Dumas and Solnik (1995) and De Santis and Gerard (1998) who find foreign exchange-risk premia to be a significant element of securities rates of return in international financial markets using a similar conditional asset pricing framework. They moreover complement and extend the studies of Fama and French (1996) and of Arshanapalli et al. (1998) in the sense that they confirm the validity of a multifactor asset pricing model.

\subsubsection{Round 3: Characteristics of exchange risk exposure}

The possibility investors make systematic errors when characterizing the relation between exchange rate movements and firm value is another potential source of the failing to relate significant exchange rate exposures. ${ }^{46}$ Bartov and Bodnar (1994) report that these systematic errors may arise because of the complex set of issues associated with estimating the relationship. The identification of the possible asymmetries in the impact of exchange rate changes, the differentiation between temporary versus permanent currency shocks and the determination of the impact of exchange rate shocks on a firm's competitive and economic environment are difficult tasks for investors. ${ }^{47}$ The difficulty is even enhanced by an information bias, as investors are not always fully aware of the firm's hedging activities nor of the strategy the firm plans to adopt if the competitive environment changes due to currency movements. That's why it is presumable that investors learn to evaluate the relationship between exchange rate changes and firms' future cash flows in a more efficient way over time and are able to assess the full impact of currency movements on firm value only as the past performance of the firm is made available (Bartov and Bodnar, 1994). This may lead to a lagged rellation between exchange rate changes and firm value. In consequence, Bartov and Bodnar (1994) suggest regressing stock returns on a constant and on both current and lagged changes in

\footnotetext{
4h. It has to be emphasized that this issue becomes increasingly rellevant when reducing the observation interval as investors may not be able to contemporaneously assess the impact of exchange rate fluctuations in the short-run.

47 The reasons why complex cireumstances lead to systematic mispricing are not well understood. But the phenomenon is not limited to the exchange rate premium. Lakonishok and Vermaelen (1990) document stock mispricing around announcements of repurchase tender offers; and, Bernard and Thomas (1990) as well as Bartov (1992) consider situations in which complex issues involved in modeling and estimating the time-series of earnings lead to systematic errors in predicting future firm performance and pricing stock.
} 
exchange rates. ${ }^{48}$ Their results are quite convincing as they indicate that lagged exchange rate returns have more explanation power for the returns of U.S firms than contemporaneous exchange rate returns. ${ }^{49}$ Results indicate furthermore that the impact of exchange rate movements on firm value is delayed until information regarding past performance, assets and liabilities of the firm is disseminated. However, it has to be stressed that the lagged relationship between foreign exchange movements and firm value is more pronounced in the 1973-1983 subperiod than in the 1984-1990 sub-period, whereas the mispricing is present for the entire sample period from 1976 to 1990 in Allayannis (1996). Analyzing Japanese, respectively Swedish, multinationals, He and $\mathrm{Ng}$ (1998) and Nydahl (1999) provide contradicting results. He and Ng's (1998) findings suggest, for instance, that less than 4 percent of the examined Japanese stock returns experience a significant lagged response to exchange rate movements. It turns out moreover that the inclusion of lagged exchange rate changes has no significant impact on the explanatory power of the model..$^{51}$

One of the most critical questions arising in the exposure literature concerns the potential temporal instability of firms' currency risk exposure. An implicit assumption in Jorion's (1990) estimation model is indeed that exposure is constant through time. But is it realistic to assume that individual firm's exchange rate exposure remains constant over time whereas the overall economic environment, the firm's competitive position, its operational structure, its hedging policy are changing over time (Bartov and Bodnar, 1994)? The potential temporal instability of the conventionally defined exchange rate exposure causes Levi (1994) to recognize that the volatility of exposure forces exposure coeflicients toward statistical insignificance unless the variability of exposure coefficients is explicitly modeled by special variable-coefficients econometric techniques. There are

\footnotetext{
48 Bartov and Bodnar (1994) suggest as well a second procedure: regressing the abnormal stock performance returns over measurement a period called "period $T$ " on unexpected changes in the foreign currency value over the same period and, or over a preceding period called "period L". They verify as well whether investors use the information associated with earnings announcenents to deterinitie the impact of past exchange rate changes on firm performance.

49 Bartov and Bodnar (1994) measure the economic magnitude of this market imperfection by calculating the return of the following trading strategy: selling short the fraction of firms when the previous fiscal quarter witnessed an appreciation of the dollar and buying long the portion of firms when the previous quarter observed a depreciation of the dollar. The returns are found to be economically relevant and increasing when the sample of firms is restricted to firms exposed to large dollar fluctuations in the previous quarter.

50 Glaum et al. (2000), Williamson (2001) and El-Masry (2004) also find evidence to support the hypothesis advanced by Bartov and Bodnar (1994).

31 It has to be stressed that so far these lag structures have mainly been explored using monthly data. One might reasonably expect that empirical evidence in support of the inclusion of lagged variables improves when working with higher observation frequencies.
} 


\section{Chapter 2}

different ways of assessing the time variability of exposure coefficients. In the manner of Engel and Hamilton (1990), some authors simply divide the time series they are studying into several sub-periods and test for constant exchange rate exposure in different sub-periods (Jorion, 1990, Amihud, 1994, Choi and Prasad, 1995; He and Ng, 1998, Glaum et al, 2000; Williamson, 2001; Doukas et al, 2003). Williamson's empirical analysis of the automotive industry is quite interesting in this context, as for each separate sub-period the exchange rate exposure is related to the prevailing competitive enviromment of the sector. In general, all these empirical studies lend support to the assumption of a time varying exposure.

Another approach has been to use moving-window or rolling regression techniques to provide some insight whether currency exposures fluctuate randomly from period to period or whether clear patterns or trends may be detected (Glaum et al, 2000, Entorf and Jamin, 2000, 2004). Empirical evidence so far indicates that exposure coefficients display pronounced swings over time and that they even experience sign changes. It appears however quite difficult to detect clear, comprehensive patterns. ${ }^{52}$

The reported time varying behavior of exchange rate exposure raises several questions regarding the origins of these fluctuations (Levi, 1994). Presuming that time-variation in exposure estimates should be related to changes in real operations - imports versus exports -, Allayannis (1995) cites evidence that the exchange exposure of 4-digit SIC U.S. manufacturing industries is systematically correlated with the share of exports and imports in these industries Focusing on individual firm level data, Gao (2000) proposes and tests a model that explicitly incorporates both the positive (negative) impact of a depreciation (appreciation) of the domestic currency due to the impact on foreign sales and the negative (positive) one related to the firm's share of production located in foreign countries. To be able to distinguish between these two effects of exchange rate movements on stock returns, Gao designs exchange rate exposure as a linear function of the share of foreign sales in the firm's total sales, $s_{i, t}$ and the share of foreign output in the firm's total output, $x_{i, i}$ :

$$
\gamma_{i, t}=\varphi_{i i} s_{i, t}+\varphi_{2 i} x_{i, t}+\varphi_{3, i}
$$

where the estimated coefficients $\varphi_{l i}$ and $\varphi_{2 i}$ measure the opposite effects of exchange rate movements due to foreign sales, respectively foreign production and

\footnotetext{
${ }^{52}$ Entorf and Jamin (2004) provide limited evidence of a cointegration relation between the U.S dollar exposure of DAFOX companies and Germany's trade balances.
} 
$\varphi_{3 i}$ is an estimation of the residual effect. As both $s_{i, t}$ and $x_{i,}$ change over time, the exchange rate exposure $\gamma_{i, t}$ is allowed to be time varying. This specification enables Gao to identify two channels through which the firm value is affected by exchange rate movements. His results indicate that the coefficients have the expected sign ( $\varphi_{i i}$ reveals to be positive and $\varphi_{2 i}$ negative) and are statistically significant. Overall, the empirical implementation of the model offers useful insights into firm's decisions on sales and production, and on how exchange rate risk can be practically reduced through these decisions.

Inevitably, the time-varying feature of exchange rate exposure leads to the investigation of the right observation frequency to use when estimating the relationship between stock returns and currency fluctuations. If exchange rate exposure is varying e.g. from year to year, it reveals indeed irrelevant to estimate the exposure coefficient over a period of five or ten years: the estimated coefficient will only translate the average exchange exposure over the whole estimation period while the variability of the exposure over the estimation period will force the coefficient toward statistical insignificance. ${ }^{53}$ Some authors investigate hence the possibility that the most frequently used observation frequency, the monthly frequency, is not the adequate specification to capture the exchange rate exposure of firms. Although theory assuming market efficiency suggests that the exchange rate exposure should be independent of the observation frequency used, empirical results indicate that due to market inefficiencies and to the complexity of the relationship between exchange rate movements and firm value, the estimated exposure coefficient differs according to both observation frequency and return horizon.

In this context, empirical results by Chamberlain et al. (1997) promote the use of daily data to estimate the sensitivity of U.S. and Japanese banking institutions to currency fluctuations. ${ }^{54}$ Corroborating these findings, Di Lorio and Faff (2000) and Glaum et al. (2000) show that evidence of exchange rate exposure is significantly weaker when using monthly data than when employing daily data. ${ }^{5.5}$ By contrast, Chow et al. (1997) specify longer than 1-month return horizons and find more statistically significant relationships between stock returns and foreign exchange movements. Subsequent studies (e.g. Chow and Chen, 1998; Griffin and Stulz, 2001; Dominguez and Tesar, 2001a; Di Iorio and Faff, 2001) similarly

\footnotetext{
53 Unless the variability of coefficients is explicitly modeled by special variable-coefficients econometric techniques (cf. discussion above).

54 It has to be emphasized that when employing daily data series, several issues like nonsynchronization and heteroscedasticity have to be empirically addressed in order to achieve reliable results.

${ }^{55}$ In contrast, Luehrman's findings (1991) are robust to the use of either daily or weekly frequencies.
} 
demonstrate that the sensitivity of stock returns to exchange rate movements is stronger when returns are measured over longer intervals. This is justified by the fact that long-horizon regressions capture the long swings that currencies experience and reveal the more fundamental long-term relationship between exchange rates and firm value.

Levi (1994), Booth (1996), and Bartov et al (1996) argue that the low significance of empirically reported exposure coefficient estimates may be to a certain degree explained by the fact that firms have effectively hedged their exposures. ${ }^{56}$ In the limit, if a firm had the possibility and decided to hedge totally its exchange rate risk, exposure would always be zero. It appears thus that, to the extent that hedging activities are efficiently implemented, they have a direct impact on the nature and characteristics of a firm's exposure. Exposure will hence become unstable, if the hedging policy of a firm varies over time (Levi, 1994). Likewise, the implementation of particular hedging strategies and the non-linear pay-off structure of some hedging instruments will induce a non-linear pattern in the relationship between exchange rates and firm value. ${ }^{57}$

Notwithstanding the recognition of the influence of internal and external hedging activities on firms' currency risk exposures ${ }^{58}$, only a few authors try to incorporate the impact of hedging strategies on exposure coefficients. ${ }^{59,60}$ Focusing on internal hedging strategies, Pantzalis et al. (2001) find that firms with a greater breadth of foreign operations have lower foreign exchange rate exposure. Corroborating conclusions are drawn by Carter et al. (2001), Williamson (2001) and De Jong et al. (2004). In a subsequent paper by Fraser and Pantzalis (2004) the empirical impact of a firm's foreign operational network is explicitly tested using a two-step approach. Results remain however inconclusive, as the determinants of:

5t Excellent studies of firms' derivative usage include Geczy et al. (1997), Bodnar et al. (1998), Howton and Perfect (1998), Bodnar and Gebhardt (1999), De Ceuster et al (2000), Joseptr (2000), Allayannis and Ofek (2001) and Bartram et al. (2004).

57 This non-linearity might constrain exposure coefficients toward statistical insignificance unless explicitly taken into account in the estimation nodel.

${ }^{38} \mathrm{See}, \mathrm{g} . \mathrm{g}$. Allayanis ef al (2001) for a discussion on internal wersus external hedging strategies.

${ }^{89}$ Marshall (2000), Glaum (2000) and Bartram et al. (2004) highlight the fact that the majority of nonfinancial firms conduct foreign exchange risk management activities to hedge transaction risk. In most cases, translation exposure and particularly economic exposure aren't actively managed. Marshall documents moreover that $96 \%$ of his UK sample firms manage trasaction exposure using external hedging techniques while $82 \%$ of them make intensive use of intemal methods. See as well Allayannis and Weston $(1999,2001)$.

60 It has to be stressed that, according to Bodnar et al (1998), Glaum (2000) and Bartram et al. (2004), many firms do not hedge their exposure positions to the full extent, but pursue instead selective hedging strategies based on home-made forecasts. Theoretically this only makes sense if the company has superior knowledge of the market compared to other investors. Evidence of selective hedging is furthermore provided in Di lorio and Faff (2000), De Jong et al. (2004) and Glaum (2002). 
foreign exchange rate exposure are found to differ a lot according to the foreign exchange rate index used to obtain the exposure coefficients. Another set of studies (He and Ng, 1998; Chow and Chen, 1998; Glaum et al, 2000; Choi and Kim, 2003) are based on optimal hedging theories that postulate that non-hedging firms should be more exposed to currency movements than hedging companies. Since data on hedging activities are difficult to obtain, they use variables that proxy firms' incentives to hedge to examine the influence of 'presumed' hedging activities on exposure estimates. ${ }^{61}$ The main points of their findings are that high leveraged firms and firms with weaker short-term liquidity positions have more incentives to hedge and hence are less exposed to foreign currency fluctuations. Recent work (Allayannis and Ofek, 2001; De Jong et al, 2004; Nguyen and Faff, 2003) tries to empirically link estimated exposure coefficients with data on foreign derivative usage. While Allayannis and Ofek (2001) provide evidence for U.S. non-financial firms, Nguyen and Faff (2003) report results for Australian companies. Both studies show that consistent with optimal hedging theories and the fact that firms use foreign derivative instruments for hedging rather than for speculation, foreign exchange risk exposures have a tendency to decrease with the extent of foreign derivatives used. Results are however statistically weak. On the other hand, De Jong et al. (2004) find no evidence to suggest that external hedging activities decrease currency risk exposure on the Dutch market. The impact of foreign derivative usage on exposure is also the subject of a study by Crabb (2002) who incorporates the level of foreign assets, the level of foreign income and the intensity of foreign derivatives use in Jorion's augmented market model (Eq. 2.2):

$$
R_{i, t}=\alpha_{i}+B_{i} R_{m i, t}+\left(\gamma_{0 i}+\gamma_{h i} C_{I, t}+\gamma_{2 i} C_{2 i, t}+\gamma_{3 i} C_{3 i, i}\right) \theta_{t}+\varepsilon_{i, t}
$$

where $C_{h i, t}$ stands for the level of foreign profits, $C_{2 i,}$ the level of foreign assets and $C_{3 b_{0},}$ the level of foreign currency derivatives use. Crabb's findings yield to the conclusion that external hedging activities decrease the currency risk exposure of firms.

Booth (1996) discusses the role of transaction costs and the asymmetry produced in the firm's profit function due to these hedging activities. The asymmetric payoffs resulting from hedging and the possibility of government interventions lead him to the hypothesis that exchange rate exposure may display a non-linear and asymmetric behavior and that this may be the reason why previous studies have failed to uncover significant evidence of exchange rate sensitivity.

\footnotetext{
${ }^{6}$ By doing this, they assume that a firm strictly determines its hedging policy according to its incentives to hedge and that no other factors than those reported in their study explain the degree of hedging of the firm.
} 
While the asymmetric impact of exchange rate shocks on trade flows and prices has spawned a large theoretical and empirical literature (Balldwin and Krugman, 1989; Ohno, 1989; Knetter, 1994; Kanas, 1997; Pollar and Coughlin, 2003), the nonlinear response of stock returns to exchange rate movements hasn't received much attention until now. Realizing nevertheless that positive exchange rate shocks may have a different impact on firm value than negative ones, some authors (Choi and Prasad, 1995; Baba and Fukao; 2000; Krishnamoorthy, 2001; Koutmos and Martin, $2003 a_{3}$ Priestley and Ødegaard, 2004b) have empirically investigated whether stock returis react asymmetrically to positive versus negative currency movements. While results of Choi and Prasad (1995) and Krishnamoorthy (2001) refute the hypothesis of asymmetric stock price reactions, other empirical findings (Koutmos and Martin, 2003 $\mathrm{a}^{62}$; Priestley and Ødegaard, 2004b $\mathrm{b}^{63}$ ) seem to consistently indicate that many firms" exposure is asymmetric during appreciations and depreciations. ${ }^{64}$

As firm value might simultaneously react asymmetrically to large versus small exchange rate shocks ${ }^{65}$, Di Iorio and Faff (2000) use the same methodology as Fabozzi and Francis (1977) ${ }^{66}$ applying a "substantial up and down" month analysis. Specifically, the non-linear and asymmetric hypothesis is accommodated in the empirical analysis in the form of a dummy variable regression whereby the time series sample is partitioned according to the sign and the importance of exchange rate movements. Indeed, as stated in Dewenter et al. (2004) it is difficult to envision stock prices responding to small changes in exchange rates that could be random draws from a stable distribution, i.e. noise. It is moreover plausible that firms adopt different policies to hedge positive versus negative as well as large versus small exchange rate movements. The empirical findings of Di lorio and Faff (2000) show, however, that there is relatively little evidence of statistical significant contemporaneous sensitivity when taking into account the possible asymmetric and non-linear oharacteristics of exposure: Nevertheless there is some evidence of asymmetry. Further, taking into account the lagged response, they find some

\footnotetext{
${ }_{62}$ Koutmos and Martin (2003a) relate their findings of nonlinear exposures to pricing-to-market, bysteresis and asymnetric hedging behavior.

${ }^{6}$ Priestley and $\emptyset$ degaard (2004b) show that the nonlinear shape of exchange rate exposure is consistent with industries" importexport orientations.

5.4 Priestley and Ddegaard (2004b) argue that if exchange rate changes are small, the linear estimation model should be preferred. However, when currency values experience large fluctuations, the exposure should be estimated separately for appreciations and depreciations.

65 Studies by Baldwin and Krugman (1989) and Pollard and Coughlin (2003) provide some justifications for this view in terms of pass-through and trade flow effects.

${ }^{6.6}$ Fabozzi and Francis (1977) adjusted the beta coefficient to changing market conditions, such as bull and bear market changes.
} 
evidence of significant exchange rate exposure of the predicted sign in several industries.

In their analysis of Japanese industries' reactions responding to an unexpected appreciation of the dollar, Griffin and Stulz (2001) explore the potentialities of asymmetric specifications in a different way. Intuitively; they expect that an unanticipated appreciation of the dollar affects adversely the U.S. industry and positively the Japanese industry. This prediction implies that periods of volatile exchange rates are periods where shooks affect the two industries in opposite directions. They therefore watch for a negative relation between crosscountry co-movements and exchange rate volatility. To separate the effects of movements in exchange rate levels from the implications of changes in exchange rate volatility they specify their model as follows:

$$
\begin{aligned}
R_{J a_{i, i}, t}= & \alpha_{i}+\gamma_{1 i} \theta_{t}+\gamma_{2 i} \mid \theta_{i} /+\gamma_{3 i} R_{U S, i, t}+\gamma_{i i}\left[\theta_{t} * R_{U S, i, t}\right] \\
& +\gamma_{S i}\left[/ \theta_{t}{ }^{*} R_{U S i, t}\right]+\varepsilon_{i, t}
\end{aligned}
$$

where $R_{J a, j, l}$ represent the returns of Japanese industries at time $t, R_{U S, i, t}$ those of the corresponding U.S. industries and $\theta_{t}$ the U.S. dollar-yen exchange rates. $\alpha_{i}$ is the constant term and $\varepsilon_{i, \text { the }}$ thite noise error term. It has to be noticed that $\gamma_{i}$ allows for an effect of the absolute value of exchange rate changes on Japanese industry returns whereas $\gamma_{i}$ measures the level effect. As a consequence if the volatility of the exchange rate does not matter, one expects $\gamma_{2 i}$ to be equal to zero. ${ }^{67}$ Exchange rates are also allowed to affect the co-movement between the Japanese and U.S. industries, distinguishing between a level effect $\gamma_{4 i}$ and an absolute value effect $\gamma_{5 i}$. If exchange rate shocks have competitive effects, these effects should be more important when exchange rate volatility is high and therefore industry comovements should be smaller during these periods. $\gamma_{s_{i}}$ is meant to measure this effect. Despite the fact that this model is based on a lot of realistic theoretical foundations, empirical evidence shows that, though the additional variables $\left(\mid \theta_{i} /\right.$, $\left[\theta_{t}^{*} R_{U S, i, d}\right.$ and $\left[/ \theta_{t}{ }^{*} R_{U S, i, d}\right]$ sometimes have significant coefficients, they do not significantly increase the explanatory power of the model.

In his analysis of the automotive industry in the U.S., Japan and Germany, Williamson (2001) investigates the potentialities of non-linear exchange rate exposure in a different functional relationship. Assuming that depreciations have the same impact in magnitude on firm value as appreciations, he suggests adding a quadratic foreign exchange rate variable in the classical linear approach. But, the

\footnotetext{
${ }^{67}$ See also Koutmos and Martin (2003b) for a discussion of the impact of first and second moment exchange rate exposures on the daily returns of 9 U.S. sectors from 1992 to 1998.
} 
assumption of a similar response to either appreciations or depreciations is quite unrealistic. Therefore, Bartram (2004) suggests convex regression specifications, which allow stock returns to contemporaneously react differently to positive versus negative exchange rate changes. In his study of 490 publicly traded non-financial corporations in Germany, he shows that, particularly, sinus hyperbolicus or cubic functions tend to improve the statistical significance of exchange rate exposure. ${ }^{68}$ While the approach definitively supports the investigation of nonlinear patterns in exchange rate exposure, remaining problems, however, are the lack of theoretical arguments justifying the choice of these specific functional forms and the still weak empirical support for a significant link between stock returns and currency fluctuations:

\subsection{Concluding suggestions}

The last two decades have seen the emergence of a substantial literature in exchange risk exposure, the area of finance that examines the impact of currency shocks on firm value. This chapter offers an extensive overview on the considerable amount of theoretical and empirical studies performed in this field of research. It highlights the main conclusions that have emerged in these research areas and identifies a number of unanswered questions.

Although it has to be acknowledged that there is neither a real consensus conceming the most relevant parameters influencing currency risk exposure nor real hope for a unique model integrating all the complexity of the effects of exchange rate shocks on firm value, the analytical literature surveyed in this paper has considerably enhanced our understanding of the black box through which exchange rate shocks affect firm value. A major achievement of this literature is to emphasize the importance of firms' cost and revenue structure, their competitive environment, their own competitive position as well as the elasticity of their input and output markets in the determination of firms' sensitivity to exchange rate fluctuations. Recent models are also shown to demonstrate the impact of pricing strategies and pass-through effects on the mechanism linking stock returns and exchange rate changes.

While the literature on the theoretical justifications of exchange risk exposure is still evolving, financial economists have spent much of the last two decades amassing empirical evidence on foreign currency risk exposure. We review the evidence regarding the impact of currency fluctuations on shareholder value in

\footnotetext{
66s It should, however, be mentioned that the robustness tests performed by Bartram (2004) provide only limited support in favour of non-linear exposures.
} 
three "rounds" or waves of research. Each successive wave is marked by refinements on research methods that provide shifts in the empirical evidence. Round 1 describes the fundamental exchange risk exposure estimation model and corresponding empirical evidence. In Round 2 , we describe the beginning of a new wave of research that casts doubt on the specification of the variables to include in the estimation model. Finally, Round 3 includes the results of the most recent group of studies that we survey. These studies suggest that the intrinsic cliaracteristics of exchange risk exposure have to be taken into account when measuring the relationship between stock returns and exchange rate movements. It is fair to conclude that although the findings of empirical studies are mixed, the bulk of the evidence suggests that exchange rate fluctuations affect - to a certain extent shareholder wealth. In this sense, the literature has demonstrated that exchange risk exposure does matter in both a practical and academic sense.

Finally, although considerable advances have been made in our understanding of currency risk exposure, many puzzles remain. As highlighted in this survey, empirical findings still warrant a more complete understanding of the nature and determinants of foreign exchange risk exposure of firms. We will therefore extend in this thesis previous empirical research both through the improvement of methodological designs and the investigation of new research fields. Possible explanations for the weak empirical results relate indeed to the use of certain research designs. For example, many papers documenting a weak rellationship between currency movements and asset values have been exploring the impact currency shocks on (industry) portfolio returns. We will hence thoroughly analyze the potential problems of this empirical work. The question whether data quality and horizon length influence the magnitude and significance of the exposure estimates will be similarly explored. We also build on previous work by investigating whether other potential econometric problems - aggregation of data, the unawareness of heteroskedasticity effects, the neglect of temporal instability may bias empirical results. In chapter 4, we will focus our attention on a central issue of the exchange rate exposure literature: how does the corporate use of derivative instruments affect the examined relationship between currency and firm values? - or, equivalently, which companies should and which companies should not hedge their foreign currency exposure in order to maximize firm value? Although many authors have been investigating companies hedging activities, we have seen in this chapter that the impact of these activities on firms" exchange rate exposure hasn"t received much attention until now. Given that recent decades have been punctuated by numerous financial currency crises a thorough analysis of exchange rate exposure issues would be incomplete if it didn't address the particular effect of increased exchange rate volatility during currency crises on 
shareholder wealth. We will show in chapter 5 that the Latin American crises in the $90 \% \mathrm{~s}$ and the East Asian crisis in 1997 are types of events that are particularly interesting to analyze in this context. Ultimately, chapter 6 will focus on a particularly problematic issue in the estimation of exchange risk exposures: the ignorance of non-linearity when estimating the relationship between exchange rate shocks and firm value. We will show that there are numerous economic and financial arguments supporting the existence of asymmetries in the effect of currency movements on trade, revenues and, hence, firm value and demonstrate that the recognition of these asymmetries significantly improves the identification of exposure effects: 

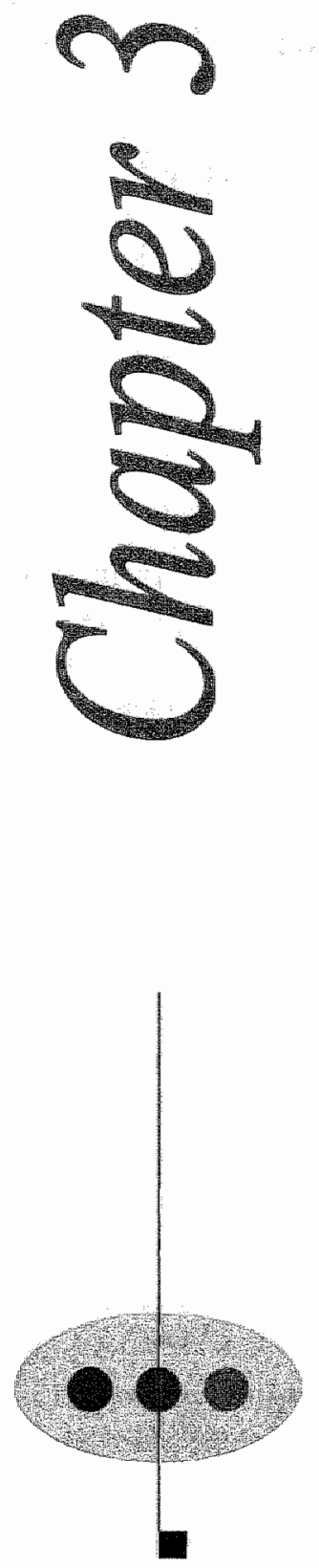

\section{Foreign Exchange Risk Exposure:} Empirical Evidence on Selected Markets 



\section{Foreign Exchange Risk Exposure: Empirical Evidence on Selected Markets $^{69}$}

\section{1 Introduction}

In the previous chapter we have seen that the potential vulnerability of multinational firms to foreign exchange rate risk has spawned a considerable amount of empirical research (see, e.g., Jorion, 1990; Amihud, 1994; Bartov and Bodnar, 1994; Chow et al, 1997a, 1997b; He and Ng, 1998; Doukas et al, 1999; Nydahl, 1999; G Gaum et al, 2000; Dominguez and Tesar, 2001a, 2001 b; Griffin and Stulz, 2001; Doukas et al, 2003). However, as stressed in chapter 2, the empirical evidence has produced mixed results and most studies have relied on U.S. data. Jorion (1990), for instance, finds that the impact of exchange rate changes on stock: returns is statistically significant for only 15 of the 287 U.S. multinationals between 1971 and 1987 and that this impact is increasing with firms foreign operations. These results are consistent with Amihud (1994) who reports no significant contemporaneous exposure for the largest 32 U.S. exporting firms from 1979 to 1988. Comparably, Bartov and Bodnar (1994) observe insignificant relationships between US. exchange rate changes and stock returns in a sample of 208 firms with foreign operations between 1978 and 1990 . Interestingly, the international exposure evidence differs substantially from the U.S. experience. Bodnar and Gentry (1993), for instance, note that among 39 industry portfolios from the U.S., Japan and Canada 11 exhibit significant exchange risk exposure between 1979 and 1988. Similarly, He and $\mathrm{Ng}$ (1998) find that for the period 1979 to 1993,25 percent of the 171 Japanese multinationals have significant positive exposure. Using conditional testing procedures, Doukas et al. (1999) even find a significant relation between

\footnotetext{
${ }^{69}$ This chapter is based on A. Muller and WF.C. Verschoor, "The Latin American exchange risk exposure of U.S. multinationals", LIFE Working Paper, 2003a; "The Asian foreign exclaange risk exposure", LIFE Working Paper, 2003b; and "European foreign exchange risk exposure", European Financial Monagement, forthooming, 2004a.
} 
contemporaneous stock returns and unanticipated yen fluctuations for their entire sample - 1,079 firms traded on the Tokyo Stock Exchange over the 1975-1995 period. $^{70}$ These findings are corroborated in a subsequent paper where exchange rate risk is found to be likewise priced at the industry level (Doukas et al., 2003). In contrast to this study, Griffin and Stulz (2001) suggest that, in an unconditional framework, exchange rate shocks have almost a negligible impact on the value of industries around the world.

There are several potential reasons why most preceding studies fail to detect the valuation effects of exchange rate fluctuations. First, the weak previously reported results may be attributable to the research field chosen to explore currency risk exposure. Prior research is typically focused on the U.S., which is one of the least open economies in the world. One may expect that exchange risk exposure is more prevalent in other regions with more open economies. Moreover, when empirically documenting the link between exchange rates and U.S. stock markets, earlier studies haven't concentrated on existing international trading relationships. As U.S. multinationals with real operations in foreign countries are expected to be more affected by corresponding foreign currency fluctuations than other U.S. firms, the analysis of the sensitivity of these multinationals to trade-specific exchange rate movements should lead to stronger exposure estimates (Khoo, 1994; Dominguez and Tesar, 2001 a, $2001 \mathrm{~b}$; Ihrig, 2001). Finally, the difficulty in finding a significant relationship between firm value and exchange rate changes may be due either to probable restrictions imposed on the data sample and the use of too aggregated economic measures (Choi and Prasad, 1995; Dahlquist and Robertsson, 2001; Dominguez and Tesar, $2001 \mathrm{a}, 2001 \mathrm{~b}$ ), or to the ignorance of the intervalling effect - short-term returns may contain errors made by investors in forecasting the longterm effects of current exchange rate changes (Bodnar and Wong, 2003; Chow et $a l, 1997 \mathrm{a}, 1997 \mathrm{~b}$; Di Iorio and Faff, 2000).

This chapter is intended to address the key issues mentioned above and to fill the gap left by previous research in performing a comprehensive analysis of the exposure effect on two fairly distinctive types of investigation fields: we first study the valuations effects of movements in actively traded currencies and, afterwards, we examine the consequences of fluctuations in the highly volatile exchange rate values of emerging countries' currencies. The comparative research between the economical implications of these two kinds of currency fluctuations enables us to enrich the existing literature and to perform additional tests on the robustness of

\footnotetext{
70. The results of Doukas ef al. (1999) are consistent with those of Dumas and Solnik (1995) and De Santis and Gerard (1998) who find foreign exchange-risk premia to be a significant element of securities rates of return in international finamcial markets using a comparable conditional asset pricing framework.
} 
earlier findings. By providing a far-reaching and diversified picture on foreign exchange risk, this study delivers hence potentially more powerful results than marginally more sophisticated tests on markets already thoroughlly studied.

Among all actively traded currencies our choice to focus on continental Europe's currencies is motivated by several reasons. First, no study has yet conducted an extensive analysis of the nature of foreign eurrency risk exposure of European multinational firms. Second, the European Monetary Union (EMU) is particularly well suited for investigating exchange risk exposure issues as it is a very open and active economy. The voluminous attention paid by both the financial and popular press to the fluctuations of the euro shows, moreover, that it is commonly believed, among practitioners as well as academics, that changes in the exchange rate values of the EMU's major trading partners do influence financial decision-making and the profitability of European multinational firms. Lastly, since the trading relationships of the EMU with the U.S., Japan and the U.K. exhibit different patterns and have undergone many different economic episodes during the last 15 years, it provides us with a very enlightening research area.

Two main reasons justify our concern for the exchange risk exposure generated by emerging countries" currencies. First, investigating the impact of the variability of the exchange rate values of emerging countries" currencies on stock markets represents an outstandingly instructive approacla to verify the existence of foreign exposure effects. The history of these currencies is, indeed, punctuated by high inflation episodes as well as rapid and strong depreciation and appreciation waves. As the maeroeconomic uncertainty brought about by the stronger volatility of these currency values is more pronounced (compared to that caused by the volatility of the most actively traded currencies), we expect to find a stronger impact on stock markets. ${ }^{71}$ Secondly, it is important to note that although exchange rate exposure issues have been extensively explored in the literature, emerging currencies haven't received much recognition in this field until recently. The foreign exchange exposure literature pays, indeed, voluminous attention to the exposure effects of the most actively traded currencies, but, to a much lesser extent, to the consequences of the large valuation swings experienced by emerging countries' currencies. In order to fill this gap, we examine the impact of changes in the value of emerging countries' currencies from both the 'insider' and 'outsider'

\footnotetext{
"During a currency crisis, in particular, the rise in volatility of exchange rates - and the subsequent increase in macroeconomic uncertainty - may have significant consequences on trade flows. It may, thus, affect both local companies and foreign firms with active trading relationships with the crisis countries. To analyze this particular issue, we will concentrate on this context of increased exchange rate uncertainty in chapter 5 .
} 
perspective: we investigate what effects these novements have both on local emerging stock markets and on foreign mature stock markets.

To perform the analysis from an "insider" point of wew, the very open and active Asian economy is particularly appealing. The rapid growth in market capitalization and the growing significance of the Asian share of world trade over the past few decades has indeed positioned Asia among the leading global economic powers. Additionally, our sample period, January 1993 - January $2003_{\text {; }}$ is covering three significantly different economic phases: sustained economic growth, the international financial crisis, and the current economic recovery. It offers, hence, a broad and divensified picture of the impact of extemal trade relationships on shareholder wealth. A series of currency crises have furthermore punctuated our sample period which provides us with particularly interesting depreciation swings. Finally, to the best of our knowledge, no study has yet conducted a comprehensive analysis of the nature of the foreign exchange risk exposure of Asian multinational companies.

The second empirical study concentrates on the foreign eurrency exposure of US. multinationals with real foreign activities in Latin-American emerging markets: On one hand, the highly inflationary and turbulent currency environment in Latin America is particularly well-suited to explore the impact of exchange rate uncertainty. On the other, the lack of convincing U.S. evidence warrants further investigation that is based on individual firms that actively engage in specific international trading relationships (Ihrig, 2001). Given the steadily increasing volume of trade flows between Latin-America and the U.S. over the past few decades, the rapid growth in market capicalization and trading value of LatinAmerican stock markets, its increasing significance in the intemational financial arena, and the large set of economic events experienced by the Latin-American economy, the analysis of the sensitivity of U.S. multinationals to Latin-American currency movements will, thus, provide peculiarly informative evidence to complenent the existing, extensive evidence on the foreign exchange rate exposure of U.S. finms.

Unlike previous studies, we conduct on all three investigation fields a firmlevel analysis that avoids the averaging effect due to grouping of firms that is based on a coarser information set. For this reason, we will not suffer from the aggregation problems as in previous studies. ${ }^{72}$ By using a disaggregated data set of multinational firms, we examine - recurrently - the following four questions concerning the effects of unexpected exchange rate movements: (i) Is the value of a

\footnotetext{
${ }^{72}$ Allayamnis (1995) and He and $\mathrm{Ng}$ (1998) point out that significant exposure effects are oftem masked at a coarser classification of industries. The two-digit industry grouping may, hence, result in averaging out the exposure effect, rendering the underlying exposure undetected.
} 
multinational firm affected by exchange rate changes?; (ii) Are the exchange risk exposure patterns industry-specific?; (iii) Is a firm's exposure to exchange rate movements more evident across increasing time horizons? ${ }^{73}$; and (iv) What are the similarities and differences among the foreign currency exposures of European, Asian and U.S. stock returns?

This chapter provides an enlightening and far-reaching complement to previous empirical work on foreign exchange risk exposure that has primarily focused on the value of U.S. companies vis-â-vis changes in the most actively traded currencies. Considering three new data sets of firms, we show that the link between exchange rate fluctuations and stock returns is empirically significant for 13 to 25 percent of our sample firms. Since exposure of individual firms belonging to the same industry sector; are found to be strongly divergent in sign and magnitude, our results lend support to Allayannis' (1995) argumentation that empirical evidence of currency exposure tends to disappear under data aggregation. In addition to exploring individual firms' foreign exchange risk exposure across different industries; we compare our findings using different return horizons. Results form a consistent body of evidence in favor of the hypothesis that currency risk exposure becomes increasingly evident when lengthening investors' return horizons.

The chapter is presented in four sections. The next section describes the methodology and discusses briefly the relationship between exchange rate fluctuations and individual firms' stock returns. Empirical results based on the European data sample are presented in section 3.3. Section 3.4 describes the valuation effects of movements in emerging countries' currencies. The section is divided in two sub-sections. The first sub-section analyzes the exchange rate exposure of Asian firms. The second one concentrates on U.S. multinational companies with real operations in Latin America. Ultimately, section 3.5 brings all our results together, compares them and concludes the chapter.

\section{2 Measuring Exchange Rate Exposure}

Following the extensive literature on foreign exchange rate exposure - see, Adler and Dumas (1984) and Jorion (1990), for instance - we define, in this chapter, the

\footnotetext{
73. The analysis of the latter is motivated by Chow ef al "s (1997a, 1997b) and Di lorio and Faff's (2000) findings that foreign exchange exposure of individual firms increases with lengthening shareholder return horizons; short-horizon returns may contain errors made by investors in forecasting the long-term effects of current exchange rate changes.
} 
firm-specific exchange rate sensitivity, called firm-specific exposure, as the effect of exchange rate changes on the value of a firm in excess of the global market's reaction to foreign exchange rate movements. Thus, the exchange exposure of a firm can be measured by the following augmented market model:

$$
R_{i, t}=\alpha_{i}+B_{i} R_{m, t}+\gamma_{i} X_{i}+\varepsilon_{i, t}
$$

where $R_{f, r}$ designates the total return of firm $i$ in period $t, R_{m, i}$ the global stock market return in period $t, B_{i}$ firm $i$ 's return sensitivity to market fluctuations, $X_{t}$ the change in the exchange rate ${ }^{74}, y_{i}$ firm $i$ 's exposure to exchange rate movements independent of the effect these variations have on the overall market, and $\varepsilon_{i, t}$ denotes the white noise error term. ${ }^{75} \gamma_{i}$ is, hence, the so-called foreign exchange risk exposure measure. It describes the sensitivity of firm $i$ 's stock returns to unanticipated changes in exchange rates. From an exporter point of view, if the home currency appreciates, exporting goods get more expensive in terms of the foreign currencies and this may lead to a fall in foreign demand and foreign sales revenue. On the other hand, the importing firm will benefit from an appreciation of the domestic currency, as its imports become cheaper in terms of domestic currency. ${ }^{76}$ Similarly, firms with net exposed foreign denominated liabilities will

\footnotetext{
${ }^{74}$ The currency movements are measured as the natural logarithms of the change in the exchange rate. The use of this variable definition relies on the implicit assumption that exchange rates follow a random walk. The hypothesis that a random walk forecast of the exchange rate generally outperforms alternative models drawn from economic theory, including purchasing power parity (PPP), uncovered interest rate parity (UTP), and simple versions of the monetary and portfolio balance models of exchange rates ${ }_{j}$ - especially at short horizons - has been first established by Meese and Rogoff (1983a, 1983b). While a large number of studies have subsequently claimed to find success for various fundamentals-based models - sometimes at longer horizons and over specific time periods - the success of these findings has not proved to be robust. On the other hand, many paper continue to lend support to Meese and Rogoff's (1983) view (see, e.g., Unutia, 1992; Smoluk et al, 1998; Newbold et al, 1998; Choi, 1999; Karemera et al. , 1999; Lee et al., 2001; Faust et al., 2003; Belaire-Franch and Opong, 2005)

${ }^{75}$ Including the stock market retum in Eq. (3.1) dramatically reduces the residual variances of the regressition. In addlition, the market return implicity controls for the value-relevant macroeconomic factors that are correlated with the exchange rates. As suggested by Bodnar and Wong (2003) this measurement of a firm's exposure estimate improves (somewhat) the precision of the exposure elasticity estimates, but more importantly, improves the interpretation of a firm having zero firmspecific exposure. The empirical result of having zero exposure no longer implies that the firm's value is independent of exchange rates; rather, a zero firm-specific exposure implies that firm value is affected to the same degree as the market portfolio.

76 Note that the impact of the exchange rate movements becomes less distinct for a company that imports as well as exports. See, for example Adler and Dumas (1984) and He and $\mathrm{Ng}$ (1998) for their suggestion that the sensitivity of the firm value to exchange rate fluctuations depends on the elasticity of the firm's demand for foreign goods relative to the elasticity of the foreign market's demand for the firm's goods.
} 
gain with a strengthening home currency, while firms with net exposed foreign denominated assets lose.

One of the most important features of financial weekly time series is the presumable presence of heteroskedasticity. The hypothesis of constant variance, we implicitly make in the above-mentioned model (Eq. 3.1), is undeed often rejected for common financial weekly time series - like exchange rate and stock returns series. ${ }^{77}$ As the presence of heteroskedasticity invalidates the test statistics, we decide to start with testing whether the residuals $\varepsilon_{i, k}$ exhibit time-varying heteroskedasticity. We use the test Engle derived from the Lagrange multiplier principle to check the validity of the null hypothesis that $\varepsilon_{i, t}$ presents no heteroskedasticity. If we do not reject the null hypothesis, we perform an ordinary least squares regression (Eq. 3.1). Otherwise we add a $\operatorname{GARCH}(1,1)$ specification to the basic regression model. The choice of a GARCH $(1,1)$ specification is supported by many empirical studies which show that the $\operatorname{GARCH}(1,1)$ specification is valuable for modeling the variance generating process of financiall time series. Thus, the regression model we use under the latter condition can be described as:

$$
\begin{aligned}
& R_{i, t}=\alpha_{i}+B_{i} R_{m, t}+\gamma_{i} X_{t}+\varepsilon_{i, t} \quad \varepsilon_{i, t}=\mu_{i, t} *\left(h_{i, j}\right)^{l / 2} \\
& h_{i, t}=\delta_{i}+\tau \varepsilon_{i, t-1}^{2}+v h_{i, t-1}
\end{aligned}
$$

where $h_{i, t}$ denotes the conditional variance of the residuals and $\mu_{i, l}$ the white noise error term. In order to investigate the nature of exchange rate exposure across increasing return horizons we moreover define the above-mentioned returns on horizons from $t$ to $t+T$, where $T$ equals 1,4 and 12 weeks:

$$
R_{i, r, t+T}=\alpha_{i, T}+B_{i, T} R_{m, t, t+T}+\gamma_{i, T} X_{i, r+T}+\varepsilon_{i, r, t+T}
$$

In order to fully exploit the information contained in the data, overlapping return observations are used in this analysis for return horizons greater than one week. The overlapping of observations creates, however, a moving average error term $\mu_{i, t}$ which will be autocorrelated of order t-1. Moreover, the estimation of Eq. (3.2) for one week return horizons may in some cases reveal that the assumption of conditional normality for the standardized innovations $\mu_{i,}$ is not strictly verified. As shown in Weiss $(1984,1986)$, maximization of the Gaussian log likelihood function still provides consistent estimates of the parameters $\left(\alpha_{i}, B_{i}, \gamma_{i}, \delta_{i}, \tau_{i}, v_{i}\right)$ even if the distribution of $\mu_{i, t}$ is non-Gaussian. However, the estimated variance-covariance

${ }^{77}$ See, for example, Bollerslev ef al. (1992) and Nieuwland ef al. (1994). 
matrix is ineonsistent and invalidates the hypothesis tests. We, therefore, use an approximate variance-covariance matrix that is robust to misspecifications in the probability density of $\mu_{i}$ :

$$
V=A_{0}{ }^{-1} B_{0} A_{0}{ }^{-1}
$$

where the $A_{0}$ matrix is consistently estimated by the sample counterpart of the inverse of the information matrix evaluated at the true parameter vector $\left(\alpha_{i,}, B_{i n} \gamma_{i j} \delta_{i s}\right.$ $\left.\tau_{k} v_{i}\right)$ and $B_{0}$ is similarly measured by the sample counterpart of the expected value of the outer product of the gradients evaluated at the true parameter vector $\left(\alpha_{i}, \beta_{i}, \gamma_{i}\right.$ $\left.\delta_{i}, \tau_{i}, v_{i}\right)$. This variance-covariance matrix has been proposed by White $(1982)$, who described this approach as quasi-maxmum likelihood estimation. ${ }^{78}$ The overlapping data problem and the fact that the residuals $\varepsilon_{i r}$ do not strictly follow a Gaussian white noise process are also taken into account in the ordinary least squares regressions (Eq. 3.1). In this case, we use the Newey-West variance estimator to calculate autocorrelation- and heteroskedasticity-consistent standard errors.

\section{3 Foreign exchange risk exposure: a European perspective}

\section{3. 1 The firm-level data set and relevant economic factors}

The selection procedure for our sample of European firms consists of three steps. Oul first selection step investigates firms that have their registered offices in the European Monetary Union and are quoted on a European stock market. A total of 2,153 firms are identified. ${ }^{79}$ We only include firms that have at least two consecutive years of weekly stock return data in the Datastream International database and check for the number of employees. Considering that the percentage of firms with export and import activities is higher among larger companies, we only include firms with more than 1,000 employees. In total 1,336 firms are excluded. The 817 firms of our final sample are sorted into 20 industry groups according to their first four industrial classification numbers, knowing that Datastream International applies the same criteria for defining industries across

\footnotetext{
${ }^{78}$ See, for example, Bollerslev and Wooldridge (1992) for a formal discussion on the test statisties based on this robust variance-covariance matrix.

${ }^{79}$ The 2,153 firms have their registered offices in France (469), Germany (372), Italy (246), The Netherlands (234), Denmark (161), Spain (137), Portugal (129), Belgium (124), Austria (99), Finland (95), lireland (46) and Luxembourg (41).
} 
countries. For all the firms of our sample we obtained the main financial ratios from Datastream International and for approximately 80 percent of the 817 firms we could observe the entire balance sheet reports. The market value and mimber of employees figures in table 3.1 indicate the presence of some relatively large firms in our sample. Furthermore, it is interesting to note that the distribution of many statistics are highly skewed; for instance, the mean earnings per share ratio (EPS) of 4.95 is mainly attributed to the highest quartile of firms, as the first three quartiles of the 817 firms have an EPS of only $0.49 ; 1.22$, and 2.81 , respectively. Overall, it appears that European firms were generally profitable during the sample period.

\section{Table 3.1: European sample description}

This table reports descriptive statistics for European companies included in the sample. The sample used in this study consists of European firms that (1) have their registered offices in the European Monetary Union, (2) are quoted on a European stock market, (3) have at least two consecutive years of weekly stock return data in the Datastream International database and (4) have at least 1000 employees. The sample covers the period of January 1988 to December 2002 .

\begin{tabular}{rrrrrr}
\hline Variable & $\mathrm{N}$ & Mean & $\begin{array}{r}\text { Lower } \\
\text { Quartile }\end{array}$ & Median & $\begin{array}{r}\text { Upper } \\
\text { Quartile }\end{array}$ \\
\hline Market value * & 817 & $3,896,713$ & 288,406 & 828,169 & $2,691,720$ \\
Market to book value & 817 & 2.89 & 1.19 & 2.02 & 3,63 \\
Book value per share & $771^{\dagger}$ & 16.12 & 1.57 & 5.52 & 13.98 \\
Return on equity & $771^{\dagger}$ & $23.69 \%$ & $7.60 \%$ & $14.23 \%$ & $22.06 \%$ \\
Dividend Yield & 817 & $3.21 \%$ & $2.03 \%$ & $2.89 \%$ & $3.89 \%$ \\
Total debt value * & $771^{\dagger}$ & $1,844,395$ & 75,385 & 267,707 & $1,215,298$ \\
Borrowing ratio & $771^{\dagger}$ & 1.66 & 0.32 & 0.86 & 1.84 \\
Quick assets ratio & $771^{\dagger}$ & 1.19 & 0.79 & 1.02 & 1.33 \\
Operating profit * & $676^{\dagger}$ & 293,589 & 27,844 & 73,852 & 226,913 \\
Operating profit margin & $578^{\dagger}$ & $8.92 \%$ & $4.19 \%$ & $7.23 \%$ & $11.19 \%$ \\
Earnings per share & 817 & 4.95 & 0.49 & 1.22 & 2.81 \\
Sales per employee & $676^{\dagger}$ & 323.24 & 119.12 & 164.15 & 243.58 \\
Number of employees & $756^{\dagger}$ & 19,290 & 1,842 & 4,971 & 15,383 \\
\hline
\end{tabular}

Nore: *arket walues, total debt vallues and operating profits are in thousands of euros. ${ }^{\dagger}$ For some firms book value per share, return on equity, total debt value, borrowing ratio, quick assets ratio, operating profits operating profits margin, sales per employee and/or number of employees measures are not made available by the Datastream International database. N reports the number of observations.

The data employed are continuously compounded weekly total returns obtained from Datastream International. The sample period starts on January $1^{\text {st }}$, 1988 and ends on December 27, 2002. In order to test whether the results are robust 
over sub-samples and unveil any structural change in the European corporations" exposure to exchange rate fluctuations - and whether specific sub-samples drive the full sample results - the sample is divided into three equal sub-periods: January 1988 to December 1992, January 1993 to December 1997 and January 1998 to December 2002. Following the usual conventions, these periods were selected so as to cover five years each.

We use two economic factors in this study: the market risk factor and the exchange rate risk factor. The proxy for the market portfolio used is the valueweighted European Monetary Union's market index as provided by Datastream International. The exchange rate risk factor is alternately measured as the euro's bilateral continuously compounded change in the exchange rate with the U.S. dollar, the Japanese yen, and the U.K. pound (measured as the euro exchange price of these foreign currencies). ${ }^{80}$ Our choice of the euro / U.S. dollar, euro / Japanese yen and euro / U.K. pound exchange rates is supported by the fact that the U.S., Japan and the U.K. are the three most important trading partners of the European Monetary Union. ${ }^{81}$

For the period analyzed (January $1^{\text {st }}, 1988$ through December 27,2002 ) all mean weeklly log price changes are positive, indicating that the euro depreciated against the U.S. dollar, the Japanese yen, and the U.K. pound ${ }^{82}$ It is interesting to note that the standard deviations of the euro relative to the U.S. dollar and the Japanese yen are significantly larger than the standard deviations of the euro relative to the U.K. pound. Furthermore, the distribution of weekly exchange rate returns is highly skewed to the right for the Japanese yen and to the left for the U.K. pound, which may be a result of asymmetric movements in the exchange rates parity adjustments. The kurtosis measure for these two series is higher than the value associated with the normal distribution, indicating that their distributions have fat tails. Overall, the statistics suggest that the observed weekly exchange rate series are likely not drawn from normal distributions.

\footnotetext{
40 Note that any test that restricts the meastrement of exposure to one exchange rate - whether it be a trade-weighted rate or a billateral rate - is likely to biased downward. See, for instance, Dominguez and Tesar (2001 20016 ) for a discussion on the selection of exchange rates in testing exposure effects.

8lease refer to the external trade figures disclosed by Eurostat during the period $1988-2002$ Overall, trade flows with all the EMU's major partners grew from 1988 to 2002 . Trade with the U.S went up strongly, with exports growing faster than imports, and trade surplus rising to more than 36 billion euros. A similar pattern can be observed in the trade relationships between the EMU and the UKK., where the trade surplus of the EMU reached its peak in 1999. On the other hand, since 1996 the EMU has a strongly rising trade deficit with Japan:

${ }^{82}$ Summary statistics on weekly log price changes of the euro / U.S. dollar, euro / Japanese yen and the euro / U.K. pound over the entire sample period are available upon request.
} 


\section{3. 2 Empirical findings}

Table 3.2 provides the cross-sectional distribution of the 817 European firms estimated exposure coefficients, $\gamma_{i}$, as defined in Eq. (3.1), alternatively (Eq. 3.2) and (Eq. 3.3), for the full sample period and three sub-sample periods. It reports the mean, median, variance, minimum and maximum values of $\gamma_{i}$ together with the number of significant positive and negative coefficients obtained.

Collectively, the evidence presented suggests that for the full sample period European firms exhibit significant exchange rate exposure; about 13 percent of the firms experienced economically significant exposure effects to the Japanese yen (about 10 percent yield significant negative exposure coefficients and about 3 percent yield positive coefficients), 14 percent to the U.S. dollar (about 7.5 percent yield significant negative exposure coefficients and about 6.5 percent yield positive coefficients) and 22 percent to the U.K. pound (about 19 percent yield significant negative exposure coefficients and about 3 percent yield positive coefficients). The extent of exchange rate exposure is remarkably high, differs substantially from the U.S. experience and is clearly above the ratios one would expect to see in sample of firms that engage in international trade. ${ }^{83}$ The negative $\gamma_{i}$ coefficients suggest that an appreciation of the U.S dollar, Japanese yen and U.K. pound against the euro has a negative impact on European stock returns. Operationally, this is consistent with a notion that these firms are net-importers from these countries, and/ or have foreign operations for export to the world market. On the other hand, the positive $\gamma_{i}$ coefficients obtained suggest that European firms experience a beneficial valuation effect when the U.S. dollar, Japanese yen and U.K. pound appreciates. This is the case if these firms are net-exporters to these countries, and $/$ or if they set up foreign operations for the purpose of local sales. The predominance of negative $\gamma_{i}$ coefficients indicates that the value of European firm share values benefits (is hurt) when the euro appreciates (depreciates). This may reflect the fact that the European Monetary Union relies heavily on imported material for both production for domestic consumption and exports to the world market.

Our findings suggest, however, time-variation in exposure at the individual firm level; during the first and third sub-sample periods - that may primarily be characterized as financial turmoil periods - the European multinationals' exposure to exchange rate changes is predominantly negative, while these firms experience adverse valuation effects of euro appreciations during the second sub-sample period.

\footnotetext{
${ }^{83}$ Indeed, one might argue that these firms would be the least likely to be exposed since they are the most likely to have access to both financial and operational hedging strategies.
} 


\section{Table 3.2: Cross-sectional distribution of exchange rate exposures of Curopean firms over the entire sample period and across sub-periods}

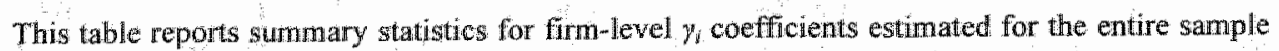
consisting of 817 European firms ower, consecutively, the entire period $01 / 01 / 1988-27 / 12 / 2002$ and the sub-sample periods.

$$
R_{i, t}=\alpha_{i}+g_{i} R_{m, t}+\eta_{i} X_{i}+\varepsilon_{i, t}
$$

where $R$, the total return of firm $i$ in week $t, R_{\text {noy }}$ designates the overall stock market return in week $t$ and $X$, is the change in the euro/U.S. dollar, euro/Japanese yen, respectively, euro/U.K. pound exchange rate in week $t, E_{\text {, }}$ denotes the white noise enor term.

\begin{tabular}{|c|c|c|c|c|c|c|c|c|}
\hline \multirow{2}{*}{ Sample Period } & \multicolumn{8}{|c|}{ Cross-Sectionall Summary Statistics } \\
\hline & N & Mean & Median & Variance & Minimum & Maximum & $N^{*}(-) N$ & $(+)$ \\
\hline & \multicolumn{8}{|c|}{ Panel A. U.S dollar exchange rate exposure } \\
\hline $01 / 01 / 1988-27 / 12 / 2002$ & 817 & $\begin{array}{l}-0.0020 \\
-0.264\end{array}$ & $\begin{array}{r}0.0021 \\
0.217\end{array}$ & 0.0481 & -0.9719 & 1.2785 & 61 & 53 \\
\hline $01 / 01 / 1988-25 / 12 / 1992$ & 508 & $\begin{array}{r}-0,0236 * \\
-2.607\end{array}$ & $\begin{array}{r}-0,03268 \\
-2.876\end{array}$ & 0.0672 & -11.7190 & 1.8143 & 42 & 30 \\
\hline $01 / 01 / 1,993-26 / 12 / 1997$ & 6441 & $\begin{array}{r}0,1181 * * 4 \\
-1.966\end{array}$ & $\begin{array}{c}0,0731^{* *} \\
-2.094\end{array}$ & 0.1355 & -1.9911 & 1.9523 & 21 & 49 \\
\hline $02 / 01 / 1998-27 / 12 / 2002$ & 790 & $\begin{array}{r}-0,0583^{*} \\
-5.746\end{array}$ & $\begin{array}{r}-0,0623^{*} \\
4899\end{array}$ & 0.0841 & -1.5755 & 2.10782 & 80 & 59 \\
\hline \multicolumn{9}{|c|}{ Panel B. Japanese ven exchange rate exposure } \\
\hline $01 / 01 / 1988-27 / 12 / 2002$ & 817 & $\begin{array}{r}-0,0231: * * \\
0.264\end{array}$ & $\begin{array}{r}-0,0188^{* *} \\
-0.217\end{array}$ & 0.0336 & -1.1992 & 1.2538 & 82 & 24 \\
\hline $01 / 01 / 1988-25 / 12 / 1992$ & 508 & $\begin{array}{r}-0,0836 \times 4 \\
-8.094\end{array}$ & $\begin{array}{r}-0,0752^{*} \\
\quad-5.806\end{array}$ & 0.0872 & -2.2879 & 2.5139 & 64 & 20 \\
\hline $01 / 01 / 1993-26 / 12 / 1997$ & 641 & $\begin{array}{r}0,0362^{* * *} \\
-1.966\end{array}$ & $\begin{array}{c}0,0302 * * 2 * \\
-2.094\end{array}$ & 0.0632 & -1.4154 & 1.0858 & 35 & 57 \\
\hline $02 / 01 / 1998-27 / 12 / 2002$ & 790 & $\begin{array}{r}-0,0269^{* * *} \\
-3.692\end{array}$ & $\begin{array}{r}-0,0229^{* *} \\
-2.514\end{array}$ & 0.0434 & -0.9107 & 1.212 & 78 & 40 \\
\hline \multicolumn{9}{|c|}{ Panel $C$ UK $K$ pownd exchange rate exposure } \\
\hline $01 / 01 / 1988-27 / 12 / 2002$ & 817 & $\begin{array}{r}-0.1336^{34} \\
-12.154\end{array}$ & $\begin{array}{r}-0.1179 \\
-8.562\end{array}$ & 0.0976 & -1.7234 & 11.8486 & 156 & 24 \\
\hline $01 / 01 / 1988-25 / 12 / 1992$ & 508 & $\begin{array}{r}-0,2228 * * \\
-3.649\end{array}$ & $\begin{array}{r}-0,2377 * * \\
-2.618\end{array}$ & 0.2084 & -1.6917 & 1.7595 & 99 & 10 \\
\hline $01 / 01 / 1993-26 / 12 / 1997$ & 641 & $\begin{array}{r}0,0398 * * \\
2.753\end{array}$ & $\begin{array}{c}0.0303 \\
1.675\end{array}$ & 0.1705 & -1.9182 & 1.7664 & 47 & 48 \\
\hline $02 / 01 / 1998-27 / 12 / 2002$ & 790 & $\begin{array}{r}-0,1844 * 3 \\
-13,744\end{array}$ & $\begin{array}{r}\times 0,1699 * * \\
-10.104\end{array}$ & 0.1471 & -1.6129 & 1.8711 & 142 & 17 \\
\hline
\end{tabular}

Note: The table reports the mean, median, variance, minimum and maximum values of $y_{i}$ together with the number of significant positive and negative coefficients obtained. 1-statistics are in italics. N reports the number of firms inchuded in each sub-sample. $N^{*}(-)$ reports the number of firms with negative $\gamma_{i}$ significant at the 5 percent level, and $N^{*}(+)$ reports the number of firms

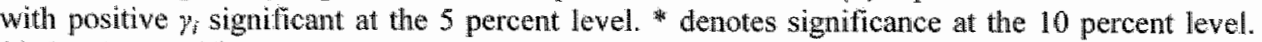
* denotes significance at the 5 percent level. 


\section{Table 3.3: Cross-sectional distribution of U.S. dollar, Japanese yen and U.K. pound exchange rate exposures of European firms by country}

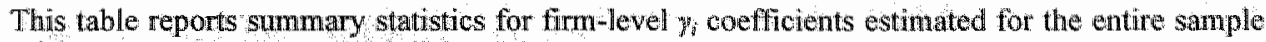
consisting of 817 European firns by country:

$$
R_{i, t}=a_{i}+B_{i} R_{m, t}+\gamma_{i} X_{i}+\varepsilon_{i}
$$

where $R_{i, t}$ the total return of firm $i$ in week $t_{0} R_{m, r}$ designates the overall stock market return in week $t$ and $X_{t}$ is the change in the euroJU.S. dollar, euro/Japanese yen, respectively, euro/U.K. pound exchange rate in week $t . \varepsilon_{k,}$ denotes the white noise error term.

\begin{tabular}{|c|c|c|c|c|c|c|c|c|}
\hline \multirow[b]{2}{*}{ Sample Period } & \multirow[b]{2}{*}{$\mathbb{N}$} & \multicolumn{5}{|c|}{ Cross-Sectional Summary Statistics } & \multirow{2}{*}{\multicolumn{2}{|c|}{$\mathbb{N}^{*}(-) \mathbb{N}^{*}(+)$}} \\
\hline & & Mean & Median & Variance & Mininum & Maximum & & \\
\hline \multicolumn{9}{|c|}{ Panel A: US dollar exchange rate exposure } \\
\hline Austria & 37 & $\begin{array}{r}0.0236^{*} \\
1.780\end{array}$ & $\begin{array}{c}0.0244 \\
1.466\end{array}$ & 0.0065 & -0.1487 & 0.2159 & 0 & $\overline{1}$ \\
\hline Belgium & 31 & $\begin{array}{c}0.0449 \\
0.908\end{array}$ & $\begin{array}{r}0.0112 \\
0.180\end{array}$ & 0.0757 & -0.4685 & 1.2785 & 1 & 4 \\
\hline Demmark & 37 & $\begin{array}{r}0.0064 \\
0.206\end{array}$ & $\begin{array}{r}0.0155 \\
0.401\end{array}$ & 0.0353 & -0.7268 & 0.3531 & 2 & 4 \\
\hline Finland & 39 & $\begin{array}{c}-0.0303 \\
-1.111\end{array}$ & $\begin{array}{c}-0.0162 \\
-0.474\end{array}$ & 0.0290 & -0.4282 & 0.2640 & 2 & 1 \\
\hline France & 174 & $\begin{array}{c}0.0256 \\
1.317\end{array}$ & $\begin{array}{r}0.0135 \\
0.552\end{array}$ & 0.0660 & -0.6954 & 1.1157 & 10 & 12 \\
\hline Germany & 161 & $\begin{array}{r}-0.0334 \\
-1.787\end{array}$ & $\begin{array}{c}-0.0076 \\
-0.325\end{array}$ & 0.0573 & -0.9719 & 1.1712 & 20 & 7 \\
\hline Ireland & 13 & $\begin{array}{r}0.0979 * \\
2.051\end{array}$ & $\begin{array}{r}0.0835 \\
1.396\end{array}$ & 0.0228 & -0.1446 & 0.3916 & 1 & 1 \\
\hline Italy & 93 & $\begin{array}{r}0.0505^{* * *} \\
2.441\end{array}$ & $\begin{array}{c}0.0460^{*} \\
1.773\end{array}$ & 0.0399 & -0.3728 & 1.2722 & 0 & 8 \\
\hline Luxembourg & 11 & $\begin{array}{r}-0.0361 \\
-0.616\end{array}$ & $\begin{array}{c}-0.0178 \\
-0.243\end{array}$ & 0.0343 & -0.3934 & 0.1983 & 1 & 0 \\
\hline Netherlands & 85 & $\begin{array}{c}-0.0135 \\
-0.633\end{array}$ & $\begin{array}{r}-0.0224 \\
-0.839\end{array}$ & 0.0386 & -0.6453 & 0.7073 & 9 & 10 \\
\hline Portugal & 46 & $\begin{array}{r}-0.0834 * \\
-3.766\end{array}$ & $\begin{array}{r}-0.0362 \\
-1.304\end{array}$ & 0.0226 & $-0.681 \|$ & 0.1892 & 7 & 0 \\
\hline Spain & 90 & $\begin{array}{r}-0.0252 \\
-1.129\end{array}$ & $\begin{array}{r}-0.0149 \\
-0.532\end{array}$ & 0.0450 & -0.9647 & 0.6741 & 8 & 5 \\
\hline \multicolumn{9}{|c|}{ Panel B: Japanese yen exchange rate exposure } \\
\hline Austria & 37 & $\begin{array}{c}0.0294 \\
1.463\end{array}$ & $\begin{array}{c}0.0262 \\
1.038\end{array}$ & 0.0150 & -0.2280 & 0.4427 & 2 & $\overline{4}$ \\
\hline Belgium & 31 & $\begin{array}{r}0.0022 \\
0.067\end{array}$ & $\begin{array}{r}-0.0227 \\
-0.550\end{array}$ & 0.0336 & -0.2463 & 0.8359 & 0 & 1 \\
\hline Denmark & 37 & $\begin{array}{c}-0.0545^{* *} \\
-3.114\end{array}$ & $\begin{array}{r}-0.0505^{*} * \\
-2.281\end{array}$ & 0.0115 & -0.3396 & 0.3132 & 4 & 0 \\
\hline Finland & 39 & $\begin{array}{r}-0.0838^{* * *} \\
-2.844\end{array}$ & $\begin{array}{c}-0.0706^{*} \\
-1.911\end{array}$ & 0.0339 & -0.7095 & 0.2489 & 5 & 2 \\
\hline France & 174 & $\begin{array}{r}-0.0005 \\
-0.034\end{array}$ & $\begin{array}{r}-0.0091 \\
-0.467\end{array}$ & 0.0422 & -0.9957 & 1.2538 & 19 & 7 \\
\hline Germany & 161 & $\begin{array}{c}-0.0405^{*} * \\
-2.315\end{array}$ & $\begin{array}{r}-0.0479^{* *} \\
-2.186\end{array}$ & 0.0502 & -0.8944 & 1.0434 & 24 & 1 \\
\hline Ireland & 13 & $\begin{array}{c}-0.0144 \\
.0 .371\end{array}$ & $\begin{array}{r}-0.0404 \\
-0.834\end{array}$ & 0.0150 & -0.1491 & 0.2896 & 0 & 0 \\
\hline
\end{tabular}


Table 3.3. contunued

\begin{tabular}{|c|c|c|c|c|c|c|c|c|}
\hline \multirow[b]{2}{*}{ Sample Period } & \multirow[b]{2}{*}{$N$} & \multicolumn{5}{|c|}{ Cross-Sectional Summary Statistics } & \multirow{2}{*}{\multicolumn{2}{|c|}{$N^{*}(-) N^{*}(t)$}} \\
\hline & & Mean & Median & Variance & Mininum & Maximum & & \\
\hline \multicolumn{9}{|c|}{ Panel B: Japanese yen exchange rate exposure (continued) } \\
\hline Italy & 93 & $\begin{array}{l}-0.0075 \\
-0.400\end{array}$ & $\begin{array}{r}-0.0055 \\
-0.288\end{array}$ & 0.0217 & -0.3647 & 0.6240 & 6 & 5 \\
\hline Luxembourg & 11 & $\begin{array}{r}-0.0326 \\
-0.827\end{array}$ & $\begin{array}{r}-0.0206 \\
-0.419\end{array}$ & 0.0155 & -0.2279 & 0.1194 & 0 & 0 \\
\hline Netherlands & 85 & $\begin{array}{c}-0,0464 * \\
-2744\end{array}$ & $\begin{array}{c}-0.0197 \\
-0.931\end{array}$ & 0.0243 & -0.5779 & 0.2650 & 12 & 1 \\
\hline Portugal & 46 & $\begin{array}{r}0.0272^{* *} \\
2118\end{array}$ & $\begin{array}{r}0.0223 \\
1385\end{array}$ & 0.0076 & -0.1684 & 0.1914 & $\mathbb{1}$ & 1 \\
\hline Spatin & 90 & $\begin{array}{r}-0.0466^{*} * \\
-2303 \\
\end{array}$ & $\begin{array}{l}0.0284 \\
-1.120\end{array}$ & 0.0369 & -1.1992 & 0.3528 & 9 & 2 \\
\hline \multicolumn{9}{|c|}{ Panel $C$ U.K pound exchange rate exposure } \\
\hline Austria & 37 & $\begin{array}{r}-0.1220^{* *} \\
-3.159\end{array}$ & $\begin{array}{r}-0.1194^{*} \\
-2.468\end{array}$ & 0.0552 & -0.5902 & 0.4187 & 7 & $\overline{0}$ \\
\hline Belgium & 31 & $\begin{array}{r}-0.1389^{*} \\
-1.770\end{array}$ & $\begin{array}{r}-0.2278 * * \\
-2.316\end{array}$ & 0.1912 & -1.0871 & 1.8487 & 10 & 1 \\
\hline Denmark & 37 & $\begin{array}{c}-0.0110 \\
-0.277\end{array}$ & $\begin{array}{r}-0.0054 \\
-0.108\end{array}$ & 0.0580 & -0.9574 & 0.6578 & 3 & 1 \\
\hline Finland & 39 & $\begin{array}{c}-0.0680 \\
-1.585\end{array}$ & $\begin{array}{r}-0.0521 \\
-0.970\end{array}$ & 0.0717 & -0.9937 & 0.4218 & 5 & $\mathbb{1}$ \\
\hline France & 174 & $\begin{array}{r}-0.1374 * * \\
-5.072\end{array}$ & $\begin{array}{r}-0.1072 * * \\
-3.158\end{array}$ & 0.1277 & -1.4455 & 1.0275 & 35 & 8 \\
\hline Germany & 161 & $\begin{array}{r}-0.1797 * * \\
-7.216\end{array}$ & $\begin{array}{c}-0.1569^{* * *} \\
-5.029\end{array}$ & 0.0999 & -1.5093 & 0.8450 & 39 & 3 \\
\hline Irelland & 13 & $\begin{array}{c}-0.1576^{*} \\
-1.75 I\end{array}$ & $\begin{array}{r}-0.1577 \\
-1.398\end{array}$ & 0.0810 & -0.3410 & 0.6450 & 1 & 0 \\
\hline Italy & 93 & $\begin{array}{r}-0.1159^{*} \\
4.300\end{array}$ & $\begin{array}{r}-0.1268^{* *} \\
-3.755\end{array}$ & 0.0676 & -0.7626 & 1.0074 & 11 & 2 \\
\hline Luxembourg & 11 & $\begin{array}{r}-0.0972 \\
-1.337\end{array}$ & $\begin{array}{r}-0.0055 \\
-0.060\end{array}$ & 0.0528 & -0.5500 & 0.2377 & 1 & $\mathbb{1}$ \\
\hline Netherlands & 85 & $\begin{array}{r}-0.2000 * \\
-5.881\end{array}$ & $\begin{array}{r}-0.1745^{*} \\
-4.096\end{array}$ & 0.0983 & -1.2693 & 0.4747 & 20 & 4 \\
\hline Portugal & 46 & $\begin{array}{r}-0.0731 * * \\
-2.310\end{array}$ & $\begin{array}{r}-0.0713^{*} \\
-1.797\end{array}$ & 0.0462 & -0.5104 & 0.5268 & 7 & 1 \\
\hline Spain & 90 & $\begin{array}{r}-0.1464^{* *} \\
-4.298\end{array}$ & $\begin{array}{r}-0.1196 * * \\
-2.802\end{array}$ & 0.1044 & -1.7235 & 0.6921 & 17 & 2 \\
\hline
\end{tabular}

Note. The table reports the mean, median, variance, minimum and maximum values of $y_{i}$ together with the number of significant positive and negative coefficients obtained. t-statistics are in italics. $N$ reports the number of firms included in each sub-sample. $N^{*}(-)$ reports the number of firms with negative $\gamma_{i}$ significant at the 5 percent level, and $\mathrm{N}^{*}(+)$ reports the number of firms with positive $\gamma_{2}$ significant at the 5 percent level. denotes significance at the 10 percent level. ** denotes signiticance at the 5 percent level. 
In order to further investigate the nature of the foreign exchange exposure of European firms, we disaggregate the European multinationals by individual countries. This approach allows us to determine the extent to which individual firms with significant exposures are concentrated in particular European countries. Table 3.3 provides the cross-sectional distribution of the multinational firm's estimated exposure coefficients for each of the twelve European countries.

Overall, the extent to which European firms are exposed to fluctuations in foreign exchange rates differs substantially across countries; multinationals with significant foreign exchange exposure are concentrated mainly in four countries, namely France, Germany, the Netherlands and Spain. Interestingly, (almost) none of the multinational firms in Ireland and Luxembourg experiences a significant exchange rate exposure effect. The number of firms significantly exposed to U.S. dollar exchange risk contemporaneously varies from 3 percent in Austria to 22 percent in the Netherlands. Correspondingly, the number of firms significantly exposed to Japanese yen (U.K. Pound) exchange risk varies from 0 (8) percent in Luxembourg (Ireland) to 16 (28) percent in Gerimany (the Netherlands).

Since our data cover individual firms, we are able to analyze the exposure of individual firms within different European industries, as opposed to average industry exposures. This approach allows us to determine the extent to which individual firms with significant exposures are concentrated in particular European industries and also to ascertain the type of industry that is more exposed to foreign exchange rate influences. Previous empirical research on how exposure varies across industries suffers from the aggregation problems ${ }^{84}$ : for instance, Bodnar and Gentry (1993) find that only a few industries in Canada, Japan, and only 9 of 39 U.S. industries exhibit significant foreign exchange exposure during the period 1979 to 1988. On the contrary, Allayannis (1995) finds strong evidence of significant industry exposure of U.S. manufacturing industries at the four-digit (SIC) level. Allayannis' study points out that significant exposures are often masked at a coarser classification of industries and that the two-digit industry grouping may result in averaging out the exposure effect, hence rendering the underlying exposure undetected. In order to avoid this effect, we look at a finer classification of European industries to determine the extent to which certain types of industries are exposed to currency influences. In table 3.4 we report the distribution of exposure coefficients from table 3.2 by 20 selected industry groups. ${ }^{85}$

\footnotetext{
84 Aggregating across firms with positive and negative exchange risk expostures might result in finding an insignificant exposure coefficient for the industry group.

${ }^{85}$ Note that the results obtained from table 3.2 were generated using individual firms" information. They reveal high positive as well as negative exposures, suggesting that exposure is not necessarily economically significant in the aggregate.
} 
Table 3.4: Cross-sectional distribution of U.S. dollar, Japanese yen and U.K. pound exchange rate exposures of European firms by industry

This table reports stumary statistics for fim-level $y_{i}$ coeffieients estimated for the entire sample consisting of 817 . European firns across 20 different industry classes:

$$
R_{i, t}=\alpha_{1}+R_{n, 1}+\gamma_{i}+\alpha_{M}
$$

where $R_{i,}$ the total return of firm $i$ in week,$R_{\text {mid }}$ designates the overall stock market return in wek $t$ and $X_{t}$ is the change in the euro/U.S. dollar, euro/lapanese yen, respectively, euro/U.K. pownd exchange rate in week $t \sigma_{1}$, denotes the white noise error term.

\begin{tabular}{|c|c|c|c|c|c|c|c|c|c|c|c|}
\hline \multirow[b]{4}{*}{ No. } & \multirow{4}{*}{ lustry } & \multirow[b]{4}{*}{$\mathrm{N}$} & \multicolumn{9}{|c|}{ Summary Statistics } \\
\hline & & & \multicolumn{3}{|c|}{ U.S. dollar } & \multicolumn{3}{|c|}{ Japanese yen } & \multicolumn{3}{|c|}{ U.K. pound } \\
\hline & & & Mean & \multicolumn{2}{|c|}{$N^{*}(+) N^{*}(-)$} & Mean & \multicolumn{2}{|c|}{$N^{*}(+) N^{*}(-)$} & Mean & \multicolumn{2}{|c|}{$N^{*}(f) N^{*}(-)$} \\
\hline & & & \multicolumn{9}{|c|}{ Entire Sample period: $01 / 101 / 1988-27 / 12 / 2002$} \\
\hline 1 & Construction & 67 & $\begin{array}{r}0.0181 \\
0.1124\end{array}$ & 1 & 4 & $\begin{array}{l}0.0192 \\
0.1010\end{array}$ & 0 & 3 & $\begin{array}{r}-0.1446 \\
0.2073\end{array}$ & 1 & 15 \\
\hline 2 & $\begin{array}{l}\text { Food, beverages \& } \\
\text { tobacco }\end{array}$ & 44 & $\begin{array}{l}0.0271 \\
0.2618\end{array}$ & 6 & 1 & $\begin{array}{r}-0.0083 \\
0.1953\end{array}$ & 2 & 5 & $\begin{array}{r}-0.0124 \\
0.3444\end{array}$ & 1 & 2 \\
\hline 3 & Textile \& apparel & 32 & $\begin{array}{l}0.0148 \\
0.1621\end{array}$ & 3 & 1 & $\begin{array}{l}-0.0157 \\
0.1637\end{array}$ & 3 & 5 & $\begin{array}{r}-0.0737 \\
0.2339\end{array}$ & 1 & 2 \\
\hline 4 & $\begin{array}{l}\text { Paper, publishing \& } \\
\text { printing }\end{array}$ & 29 & $\begin{array}{l}0.0192 \\
01172\end{array}$ & 1 & 2 & $\begin{array}{l}0.0292 \\
0.1270\end{array}$ & 0 & 2 & $\begin{array}{l}-0.0896 \\
0.2350\end{array}$ & 1 & 2 \\
\hline 5 & $\begin{array}{l}\text { Chemicals \& allied } \\
\text { products }\end{array}$ & 50 & $\begin{array}{l}0.0212 \\
01853\end{array}$ & 7 & 4 & $\begin{array}{c}-0.0602 \\
0.1338\end{array}$ & 0 & 6 & $\begin{array}{r}-0.1211 \\
0.2618\end{array}$ & 2 & 14 \\
\hline 6 & Oil $\&$ gas & 18 & $\begin{array}{l}0.0838 \\
0.1404\end{array}$ & 4 & 0 & $\begin{array}{l}0.0583 \\
0.1320\end{array}$ & 2 & 1 & $\begin{array}{l}0.0325 \\
0.2019\end{array}$ & 2 & 2 \\
\hline 7 & Rubber products & 4 & $\begin{array}{l}0.0492 \\
0.1199\end{array}$ & 1 & 0 & $\begin{array}{c}-0.1278 \\
0,2052\end{array}$ & 0 & 1 & $\begin{array}{c}-0.0789 \\
0.3690\end{array}$ & 1 & 1 \\
\hline 8 & $\begin{array}{l}\text { Steel and non- } \\
\text { ferrous metals }\end{array}$ & 17 & $\begin{array}{r}-0.0007 \\
01707\end{array}$ & 1 & 2 & $\begin{array}{l}0.0010 \\
0.1163\end{array}$ & 1 & 1 & $\begin{array}{r}-0.2167 \\
0.1954\end{array}$ & 0 & 4 \\
\hline 9 & $\begin{array}{l}\text { Automobille \& } \\
\text { related products }\end{array}$ & 27 & $\begin{array}{l}0.0511 \\
0.1191\end{array}$ & 1 & 0 & $\begin{array}{c}-0.0458 \\
0.1340\end{array}$ & 0 & 5 & $\begin{array}{c}-0.1296 \\
0.2492\end{array}$ & 1 & 7 \\
\hline 10 & Engineering & 48 & $\begin{array}{l}-0.0459 \\
0.1868\end{array}$ & 0 & 3 & $\begin{array}{r}-0.0401 \\
0.1769\end{array}$ & 3 & 5 & $\begin{array}{c}-0.1566 \\
0.2472\end{array}$ & 0 & 8 \\
\hline 1. & Electrical & 37 & $\begin{array}{l}0.0191 \\
0.2367\end{array}$ & 1 & 3 & $\begin{array}{l}-0.0062 \\
0.3069\end{array}$ & 1 & 2 & $\begin{array}{r}-0.1412 \\
0.4358\end{array}$ & 1 & 7 \\
\hline 12 & $\begin{array}{l}\text { Computer \& related } \\
\text { products }\end{array}$ & 36 & $\begin{array}{r}-0,0292 \\
0.3919\end{array}$ & 1 & 3 & $\begin{array}{l}0.0695 \\
0.3931\end{array}$ & 1 & 4 & $\begin{array}{r}-0.5671 \\
1.1967\end{array}$ & 0 & 12 \\
\hline 13 & Transport: & 40 & $\begin{array}{l}0.0449 \\
0.2624\end{array}$ & 3 & 1 & $\begin{array}{r}-0.0346 \\
0.1730\end{array}$ & 3 & 5 & $\begin{array}{r}0.1093 \\
0.3743\end{array}$ & 2 & 5 \\
\hline 14 & Media \& & 43 & $\begin{array}{l}0.0223 \\
0.3872\end{array}$ & 4 & 2 & $\begin{array}{c}-0.0224 \\
0.2623\end{array}$ & 0 & 5 & $\begin{array}{c}-0.1537 \\
0.5772\end{array}$ & 3 & 8 \\
\hline 15 & Utilities & 34 & $\begin{array}{c}-0.0308 \\
0.1495\end{array}$ & 2 & 2 & $\begin{array}{r}-0.0145 \\
0.1047\end{array}$ & 0 & 5 & $\begin{array}{c}-0.1130 \\
0.2301\end{array}$ & 1 & 4 \\
\hline 16 & Wholesale \& retail & 50 & $\begin{array}{r}-0.0446 \\
0.2349\end{array}$ & 4 & $\mathbb{1 1}$ & $\begin{array}{r}-0.0605 \\
0.2252\end{array}$ & 2 & 7 & $\begin{array}{r}-0.1347 \\
0.2350\end{array}$ & 0 & 10 \\
\hline
\end{tabular}




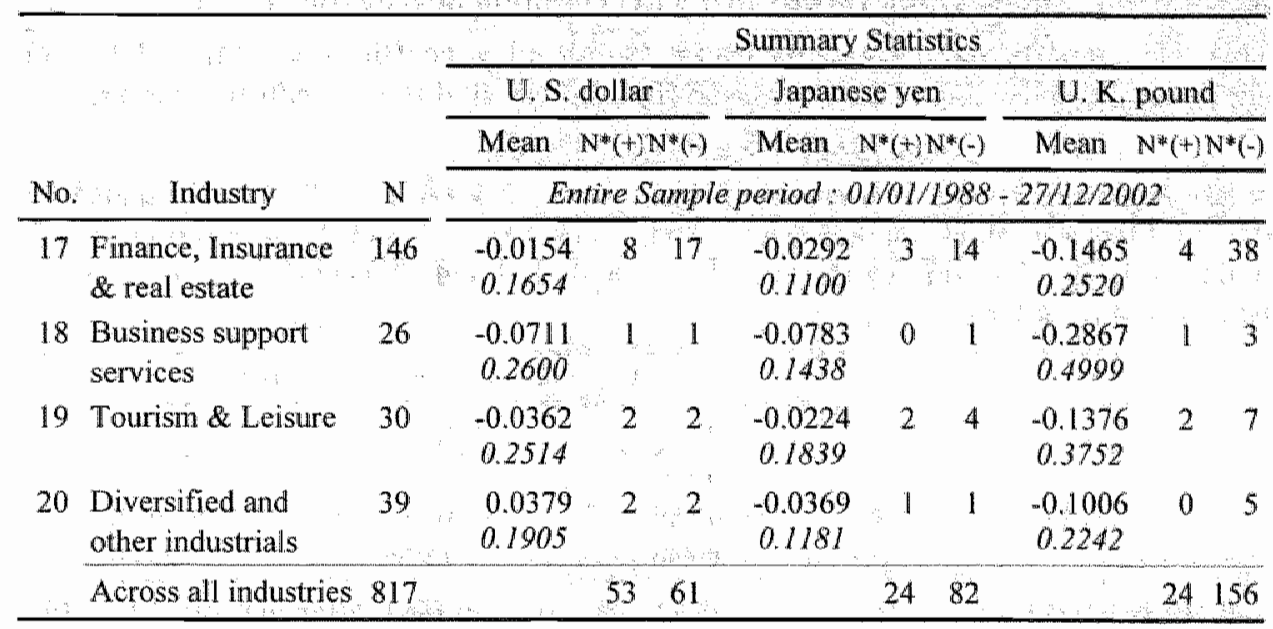

Mate: The table reports the mean values of $\gamma_{i}$ together with the number of significant positive and negative coefficients obtained. Standard deviations are in italics. N reports the number of firms included in each industry sub-sample. $N^{*}(-)$ reports the number of firms with negatiwe $y_{i}$ significant at the 5 percent level, and $\mathrm{N}^{*}(+)$ reports the number of firms with positive $y_{j}$ significant at the 5 percent level.

Overall, evidence suggests that the magnitude of industry exposure is relatively large. Consistent with the results of table 3.2, all but one European industry experience a predominantly negative exposure effect; the oil and gas industry experiences a beneficial valuation effect when the euro depreciates against the U.S. dollar and Japanese yen and suffers when the euro appreciates. Furthermore, firms with insignificant exposure effects are concentrated mainly in four industries, namely paper, publishing and printing, utilities, business support services and diversified and other industrials. Clearly, firms active in these industry sectors are relatively less exposed to currency movements than the others. In a world of market imperfections, extensive use of derivatives should diminish a firm's exposure. ${ }^{86}$ It might, therefore, be the case that corporations in these industries use foreign currency derivatives and other financial instruments to shield themselves from foreign exchange rate movements.

Table 3.5 reports the distribution of U.S. dollar exposure coefficients for $\mathbb{1}$ week, 4 week and 12 week return measurement intervals. Consistent with Chow et al.'s (1997a, 1997b) argument that the total impact of currency movements on a firm's future cash-flows can only be correctly evaluated by investors in the long run, our findings suggest that there is a general increase in the number of significant

\footnotetext{
\$t Please refer to chapter 4, Allayannis and Orek (2001) and Geczy et al (1997) for a detailed discussion on the use of foreign currency derivatives and its impact on foreign exchange rate risk.
} 
Table 3.5: U.S. dollar exchange rate exposure coefficients $\psi_{\text {f }}$ of European firms by industry: Intervalling results using overlapping observations

This table reports summary statistics for firm-level $\%$ coefficients estimated for the entire sample consisting of 817 European firms across 20 different industry classes:

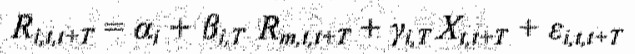

where $R_{l, n+r}$ reports the total retum of firm $i$ from week $t$ to $t+T, R_{m, t, t}$ designates the overall European stock market return from week to $t+T$ and $X_{i, r}$ is the euro/U.S. dollar exchange rate from week $t$ to $t+T$ ( $T$ equals 1,4 and 12 weeks). $\varepsilon_{i_{i} t+T}$ denotes the white noise error term.

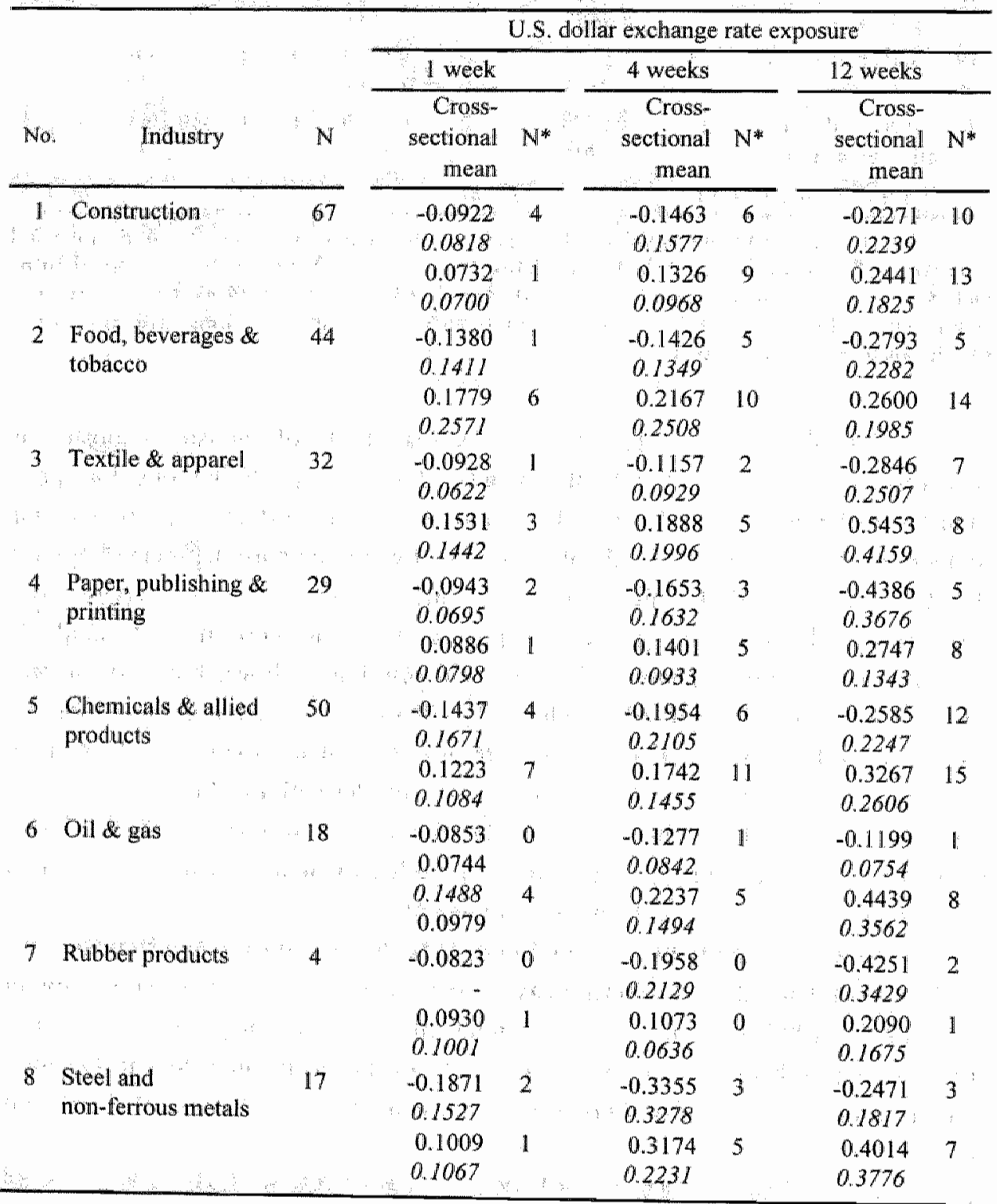




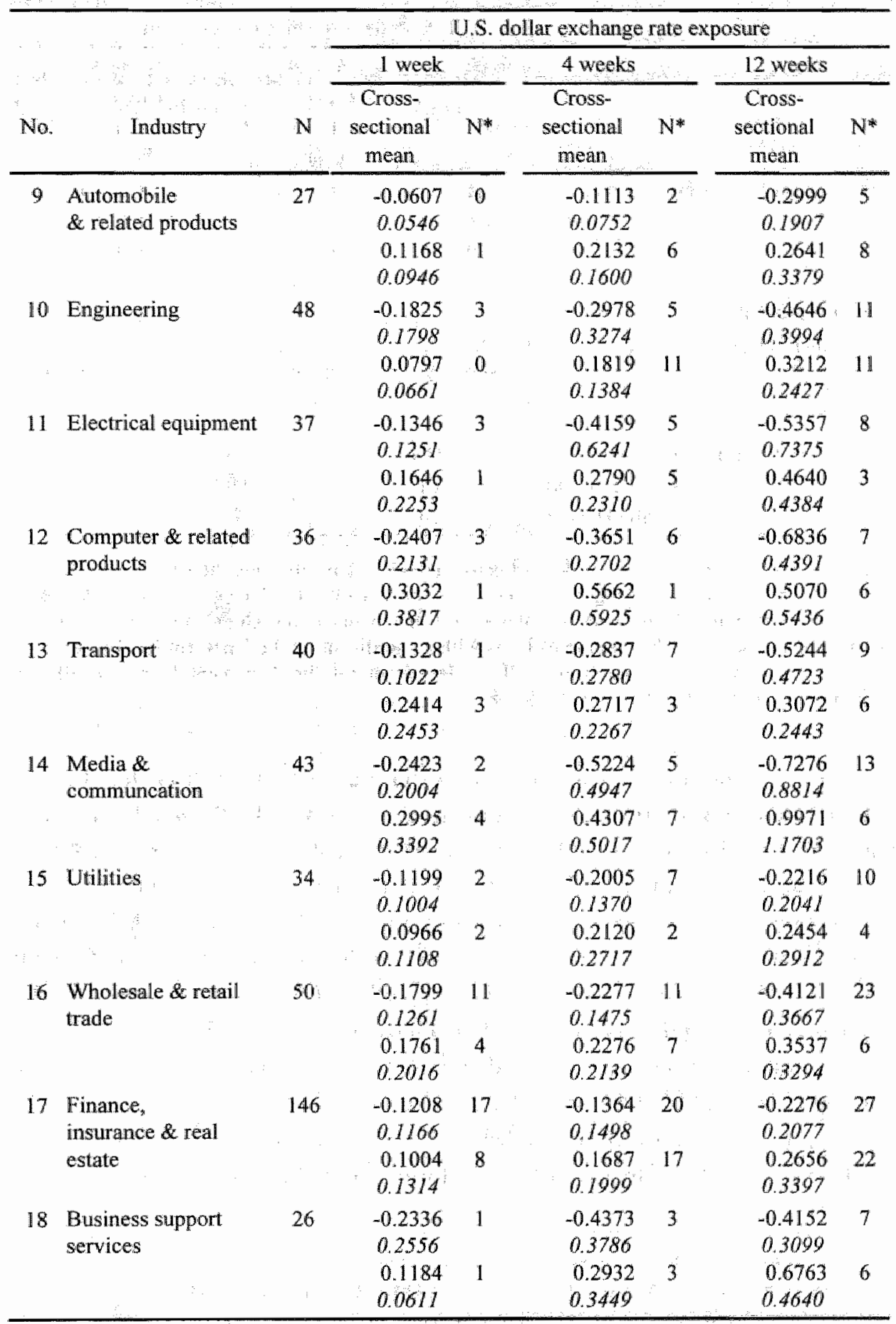


Table 3.5: continued

\begin{tabular}{|c|c|c|c|c|c|c|c|c|}
\hline \multirow[b]{3}{*}{ No: } & \multirow[b]{3}{*}{ Industry } & & \multicolumn{6}{|c|}{ U.S. dollar exchange rate exposure } \\
\hline & & \multirow[b]{2}{*}{ N: } & \multicolumn{2}{|l|}{1 week } & \multicolumn{2}{|l|}{4 weeks } & \multicolumn{2}{|l|}{12 weeks } \\
\hline & & & $\begin{array}{l}\text { Cross } \\
\text { sectional } \\
\text { mean }\end{array}$ & $W^{*}$ & $\begin{array}{l}\text { Cross } \\
\text { sectional } \\
\text { mean }\end{array}$ & $\mathbb{N}^{*}$ & $\begin{array}{c}\text { Cross- } \\
\text { sectional } \\
\text { mean }\end{array}$ & $\mathrm{N}^{*}$ \\
\hline \multirow[t]{4}{*}{19} & Tourism \& Leisure & 30 & -0.1964 & 2 & $-0.3 \sqrt{59}$ & 2 & -0.4699 & 4 \\
\hline & & & 0.2481 & & 0.2861 & & 0.3822 & \\
\hline & & & 0.1239 & 2 & 0.1930 & 5 & 0.3112 & 7 \\
\hline & 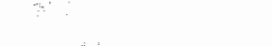 & 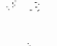 & 0.1207 & & 0.1210 & & 0.3048 & \\
\hline \multirow[t]{4}{*}{20} & Diversilied and & 39 & -0.1561 & 2 & -0.1493 & 0 & -0.3621 & 3 \\
\hline & other industrials & & 0.1730 & & 0.1542 & & 0.3481 & \\
\hline & & & 0.1349 & 2 & 0.1675 & 10 & 0.3218 & 11 \\
\hline & : : & & 0.1074 & & 0.1358 & & 02310 & \\
\hline \multicolumn{4}{|c|}{ Total nber of significant exposures } & 114 & & 226 & & 342 \\
\hline \multicolumn{4}{|c|}{ Total nber of neg. significant exposures } & 61 & & 99 & & 172 \\
\hline \multicolumn{4}{|c|}{ Total nber of pos. significant exposures } & 53 & & 127 & & 170 \\
\hline
\end{tabular}

Note: The table reports the mean values of consecutvely the positive and negative $\gamma_{i}$ coefficients together with the number of significant positive and negative coefficients obtained. Standard deviations are in italics. $N$ indicates the number of firms included in each industry sub-sample. $N^{*}$ reports - consecutively - the number of firms with a significant (at the 5 percent level) positive $y_{i}$ coefficient and the number of firms with a significant (at the 5 percent level) riegative $\gamma_{1}$ coefficient. "significant at the 5 percent level.

- positive and negative - exchange rate exposure coefficients from the 1 week horizon to the longer term 12 week horizon. Correspondingly, the number of firms which yield significant U.S. dollar exposure coefficients increases from 114 for the 1 week horizon return to 226 for the 4 week horizon return, and to 342 representing almost 42 percent of the entire sample - for the 12 week horizon. ${ }^{87}$ Moreover, we find that the magnitude of firms' exchange rate exposure coefficients increases as the horizon lengthens. Thus, it appears that European exchange rate risk becomes more perceptible as the return horizon lengthens. Interestingly, these figures are comparable with those documented on long-term foreign exchange exposures of both Japanese and U.S. firms provided by Chow and Chen (1998) and Bodnar and Wong (2003), but considerably higher than those reported by Di Iorio and Faff (2001) on Australian stock returns. Di Iorio and Faff (2001), however, focus

\footnotetext{
87 The impact of intervaling for the euro / Japanese yen and euro / U.K. pound exchange rates is similar to the impact observed for the eurof U.S. dollar excliange rate and lead to the same conclusions. The corresponding tables can be obtained from the authors on request.
} 
exclusively on the long-tern exposure of industry portfolios, thereby ignoring the aggregation problems. ${ }^{88}$

\section{Table 3.6: Correlation between exchange rate risk exposures of European firms estimated using different horizons}

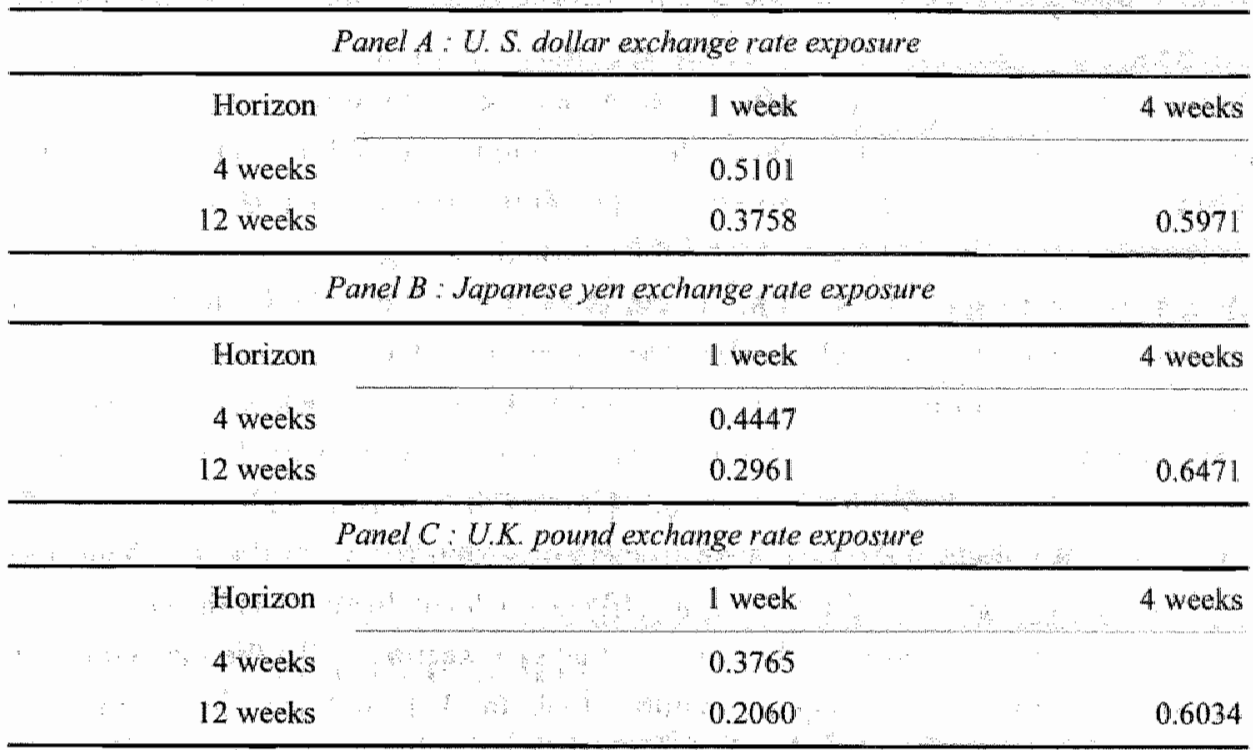

Note: Reported are the correlation coefficients between $\gamma_{i, T}$ and $\gamma_{i, T}$, exposure coefficients estimated using horizon intervals ( $T$ and $T^{\prime \prime}$ ) ranging from $T=1,4$ till 12 weeks. The $\gamma_{i,}$ coefficients are estimated using the following regression model: $R_{i, r, t+T}=a_{i}+B_{i, T} R_{m, \tau, r+T}+\gamma_{i, t}$

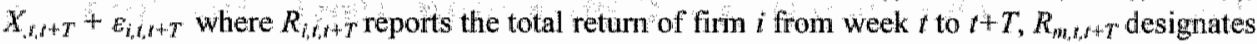
the overall European stock market return from week $f$ to $t+T$ and $X_{i, t} T$ is the euro/U.S. dollar exchange rate from week $t$ to $t+T$ ( $T$ equals $I_{t} 4$ and 12 weeks). $\varepsilon_{i, t}+T$ denotes the white noise error term.

Table 3.6 reports the correlation coefficients between the exchange rate exposure coefficients of different return horizons. The results indicate a strong positive correlation between the estimated exchange exposures across return horizons. Interestingly, the correlation between the 1 week exchange rate exposure and other horizons declines slowly as the horizon length increases. These results are consistent with those of Chow et al. (1997a, 1997b) and Di lorio and Faff (2001) who also find strong, positive correlations between the estimated foreign exchange

\footnotetext{
We performed an additional test on the sample to examine the robustness of our results. We anallyzed whether our results depend on the estimation method - maximum likelihood estimation with GARCH $(1,1)$ extension or ordinary least squares - that we use to estirnate firm exposures across time horizons. The results are very similar for both methods indicating in both cases that the significance of firm exposure increases as the time horizon لengthens.
} 
exposures across horizons. They likewise observe that correllation diminishes as the difference between two return horizons increases.

\section{4 Foreign exchange risk exposure: two emerging market applications}

The exchange rate values of many emerging countries" currencies experience very contrasting episodes during their evolution through time. While some periods are characterized by hard exchange rate arrangements - pseudo or real pegs to one or more currencies -, others are identifiable through strongly pronounced valuation movements leading even sometimes to currency crises. The volatile fluctuations are mostly generated by the highly inflationary pressures that characterize developing economies. Since firms' market values are expected to be influenced by unexpected exchange rate fluctuations, it is thus especially appealing to explore the foreign exchange risk exposure of companies that are in contact with these specific currencies. We investigate this issue from two perspectives: on the one hand, we explore (in section 3.4a) the valuation effects on local firms established in these emerging economies; on the other, we evaluate (in section $3.4 \mathrm{~b}$ ) the consequences for foreign firms that belong to mature stock markets but use these emerging countries" currencies in their daily trading activities

\section{4 a}

\section{The reaction of emerging stock markets to changes in the values of their local currencies: evidence from Asia}

\section{4a. 1 The firm-level data set and relevant economic factors}

The selection procedure for our sample of Asian firms consists of two steps. First, we identify the constituents of the total market indices of Hong Kong, Indonesia, South Korea, Malaysia, Philippines, Singapore and Thailand provided by Datastream International. Firms that aren't established in these countries are excluded. A total of 4,573 firms are identified. Our second selection step investigates whether these firms have at least two consecutive years of weekly stock return data in the Datastream International database. As we only include firms that satisfy this last condition, we exclude in total 939 firms. The 3,634 firms of our final sample are sorted into 20 industry groups according to their first four industrial 
classification numbers, knowing that Datastream International applies the same criteria for defining industries across countries. ${ }^{89}$

We use continuously compounded weekly total returns obtained from Datastream International. Our data set begins on January 13, 1993 and ends on January 8, 2003. The sample is divided into three sub-periods: January $\$ 993$ to December 1996, January 1997 to December 1999 and January 2000 to January 2003 to test whether empirical results are robust over sub-samples or experience any structural change and whether specific sub-samples drive the full sample results.

The economic factors employed in this study are the market risk factor and the exchange rate risk factor. We use the value-weighted Asian market index provided by Datastream International - as proxy for the market portfolio. The exchange rate risk factor is alternately measured as the continuously compounded change in the disaggregated billateral exchange rate with the U.S. dollar and the Japanese yen (the local currency per U.S. dollar and Japanese yen, respectively). ${ }^{90}$ These exchange rates have been sellected due to the fact that U.S. and Japan are the two most important trading partners of the Asian economies.

\section{4a. 2 Empirical findings}

Table 3.7 reports the number of Asian firms that have a significant positive and negative foreign exchange exposure coefficient $y_{i}$-as defined in Eq. (3.1), alternatively (Eq. 3.2) and (Eq. 3.3) - for the full sample period and three subsample periods. Overall, the evidence presented suggests that for the full sample period Asian firms exhibit significant exchange rate exposure; about 25 percent of the firms experienced economically significant exposure effects to the U.S. dollar (about 22 percent yield significant negative exposure coefficients and about 3 percent yield positive coefficients), and 22.5 percent to the Japanese yen (about 19 percent yield significant negative exposure coefficients and about 3.5 percent yield positive coefficients).

It appears that foreign exchange rate changes predominantly negatively affect Asian firm values, which means that an appreciation of the U.S dollar and Japanese yen against the Asian home currencies has a negative impact on Asian stock market returns. This finding is economically troubling, because it implies that

\footnotetext{
The 3,634 firms have their registered offices in Hong Kong (569), Indonesia (259), south Korea (216), Mallaysia (336), Philippines (531), Singapore (1101) and Thailand (622).

90 Note that any test that restricts the measurement of exposure to one exchange rate - whether it is a trade-weighted rate or a bilateral rate - is likely to be biased downward. See, for instance Dominguez and Tesar (2001 a, 200I b) for a discussion on the selection of exchange rates in testing exposure effects.
} 
most Asian companies experience gains (relative to the market) when their domestic currency appreciates. These results are nevertheless consistent with the literature (Dominguez and Tesar, 2001a: Parsey and Popper, 2002) and may reflect the fact that the Asian markets rely heavily on imported material for the production for both domestic consumption and exports to the world market.

\section{Table 3.7: Significance of exchange rate exposures of Asian firms over the entire sample period and across sub-periods}

This table reports the significance of the $y_{i}$ coefficients for the entire sample consisting of 3634 Asian firns:

$$
R_{i, r}=a_{i}+B_{i} R_{m, i}+\gamma_{i} X_{8}+\varepsilon_{i, i}
$$

where $R_{i, i}$ the total retum of firm $i$ in week $t_{3} R_{n, i}$ designates the domestic stock market return in week $t$ and $X_{t}$ is the change in the domestic currency / U. S. dollar, respectively domestic currency $/ J$ Japanese yen exchange rate in week $t . \varepsilon_{i,}$ denotes the white noise error term.

\begin{tabular}{|c|c|c|c|}
\hline \multicolumn{4}{|c|}{ Cross-Sectional Significance } \\
\hline Sample Period & $\mathrm{N}$ & $N *(+)$ & $N^{*}(-)$ \\
\hline \multicolumn{4}{|c|}{ Panel A. U.S dollar exchange rate exposure } \\
\hline $13 / 01 / 1993-08 / 01 / 2003$ & 3634 & 121 & 786 \\
\hline $13 / 01 / 1993-25 / 12 / 1996$ & 2314 & 188 & 85 \\
\hline $01 / 01 / 1997-29 / 12 / 1999$ & 3077 & 111 & 830 \\
\hline $05 / 01 / 2000-08 / 01 / 2003$ & 2798 & 127 & 217 \\
\hline \multicolumn{4}{|c|}{ Panel B: Japanese yen exchange rate exposure } \\
\hline $13 / 01 / 1993-08 / 01 / 2003$ & 3634 & 128 & 679 \\
\hline $13 / 01 / 1993-25 / 12 / 1996$ & 2314 & 133 & 159 \\
\hline $01 / 01 / 1997-29 / 12 / 1999$ & 3077 & $\mathbb{1 1 7}$ & 605 \\
\hline $05 / 01 / 2000-08 / 01 / 2003$ & 2798 & 109 & 366 \\
\hline
\end{tabular}

$N$ reports the number of firms inoluded in each sub-sample. $N *(-)$ reports the number of firms with negative $\gamma_{i}$ coefficients significant at the 5 percent level, and $N^{*}(+)$ reports the number of firms with positive $\gamma_{i}$ coefficients significant at the 5 percent level.

Furthermore, the evidence suggests time-variation in exposure at the individual firm level; the number of significant $y_{i}$ coefficients increases from 565 (U.S. dollar exposure: 273 and Japanese yen exposure: 292) in the first sub-sample period to 1663 (941 and 722) in the second sub-period, and subsequently decreases to 819 (344 and 475 ) in the third sub-period. It seems likely that the increase in exchange rate fluctuations during the period of structural turmoil from January 1997 to December 1999 faced by Asian multinationals generally has led to a higher 
percentage of firms with significant exchange risk exposure. ${ }^{91,92}$ In general, however, the overall extent of foreign currency exposure is not sample dependent; a depreciating (appreciating) Asian currency against foreign currencies has a net adverse (favorable) impact on stock returns of Asian multinationall firms.

In order to further investigate the nature of the foreign exchange exposure of Asian firms, we disaggregate the Asian multinationals by individual countries. Table 3.8 provides the cross-sectional distribution of the firm's estimated exposure coefficients for each of the seven Asian countries. The number of firms significantly exposed to U.S. dollar exchange risk contemporaneously varies from 20.5 percent in Singapore to 30 percent in Thailand, while the number of firms exposed to Japanese yen exchange risk varies from 20 percent in Hong Kong to 27 percent in Indonesia. Consistent with previous results, all Asian countries experience a predominantly negative exposure effect.

In order to avoid the aggregation problem due to the grouping of significant exposures of opposite signs within two-digit (SIC) industry sectors (Allayannis, 1995) we look at a finer classification of Asian industries. The firm level analysis allows us to explore the exposure of individual firms within different Asian industries, as opposed to average industry exposures. As a consequence we are able to examine whether individual firms with significant positive and negative exposures are grouped within same sectors and whether significant exposures are concentrated in particular Asian industries. The distribution of exposure coefficients from table 3.7 by 26 selected Asian industry groups are presented in the first two result columns of table $3.9 .^{93}$ Across all industries many exchange rate coefficients are significant. One feature consistent with the results of table 3.7 stands out: nearly all Asian industries experience a predominantly negative foreign currency exposure effect. Furthermore, firms with insignificant exposure effects are concentrated only in five industries, namely petroleum refining, pharmaceuticals, media services, retail and other industrials. Firms active in these industry sectors are relatively less exposed to foreign exchange rate movements than the others. This might either be due to fact that these markets are less influenced by the international environment or to fact that firms within these industries have stronger incentives to use foreign

\footnotetext{
91 The Asian financial crisis began in 1997 when the involved countries received assistance from the IMF, which ranged from July 1997 for Thailand to December 1997 for South Korea.

92 Bartov et al. (1996) show that there is an increase in the variability of equity returns following a period of increased exchange rate variability; the increase in exchange rate fluctuations suggests an increase in the riskiness of multinationals' cash flows.

${ }^{93}$ Results in table 3.7 are obtained using individual firms" information. They report positive as well as negative exposures, suggesting that exposure is not necessarily economically significant in the aggregate.
} 
Table 3.8: Cross-sectional distribution of exchange rate exposures of Asian firms by country

This table reports summary statistics for $\gamma_{1}$ coefficients for the entire sample (3634 Asian firms):

$$
R_{i}=a_{i}+B_{i} R_{m, t}+\eta_{i}+E_{i, h}
$$

where $R_{i, i}$ the total return of firm $t$ in week $t, R_{n, i}$ designates the domestic stock market return in week $t$ and $X_{i}$ is the change in the domestic currency / U.S. dollar, respectively domestic currency J Japanese yen exchange rate in week $t, \varepsilon_{i,}$ denotes the white noise error term.

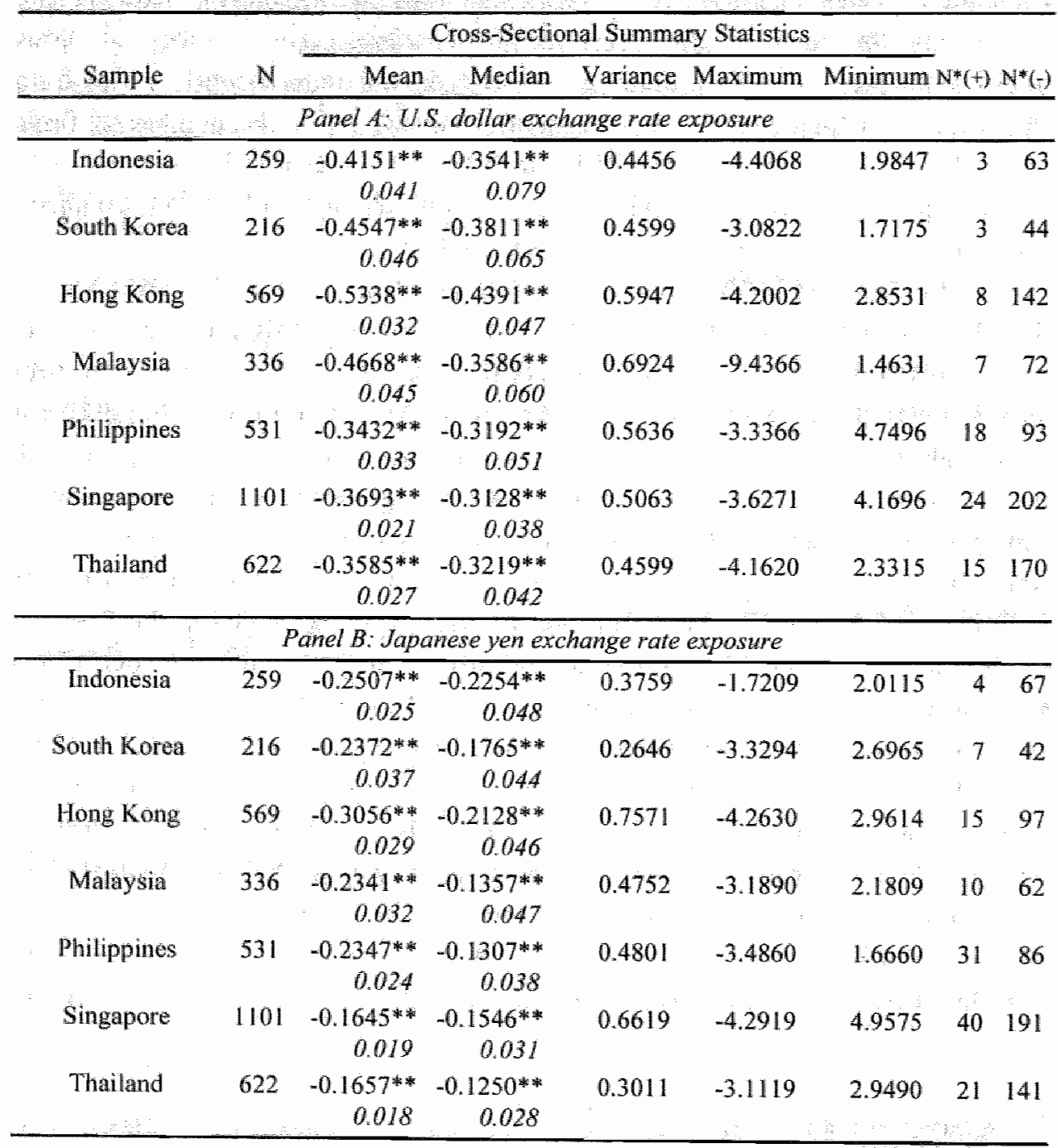

Note: standard deviations are in italics. $N$ reports the number of firms included in each subsample, $N^{*}(-)$ reports the number of firms with negative $\gamma_{1}$ coefficients significant at the 5 percent level, and $\mathrm{N}^{*}(+)$ reports the number of firms with positive $y_{i}$ coefficients significant at the 5 percent level. ** denotes significance at the 5 percent level. 
Table 3.9: Significance of U.S. dollar exchange rate exposure coefficients $\gamma_{i}$ of Asian firms by industry: Intervalling results using overlapping observations

This table reports the number of significant $\gamma$, by twenty industry groups:

$$
R_{i, t, T+T}=a_{i, T}+B_{i, T} R_{m, i t+T}+\eta_{i, T} X_{t ;+T}+\varepsilon_{i, t}+T
$$

where $R_{i, t_{i} t T}$ reports the total return of firm $i$ from week $t$ to $t+T, R_{m t_{i} t+T}$ designates the domestic stock market return from week $t$ to $t+T$ and $X_{t, i}+T$ is the domestic currency / U.S. dollar exclange rate from week $t$ to $t+T$, where $T$ equals 1,4 and 12 weeks. $\varepsilon_{i, l+T}$ is the white noise error term.

\begin{tabular}{|c|c|c|c|c|c|c|c|c|}
\hline \multirow[b]{3}{*}{ No. } & \multirow[b]{3}{*}{ Industry } & \multirow[b]{3}{*}{$\mathbb{N}$} & \multicolumn{6}{|c|}{ U S dollar exchange rate exposure } \\
\hline & & & \multicolumn{2}{|c|}{1 week } & \multicolumn{2}{|c|}{4 weeks } & \multicolumn{2}{|c|}{12 weeks } \\
\hline & & & $\begin{array}{l}N^{*} \\
(+)\end{array}$ & $\begin{array}{l}N^{* *} \\
(-)\end{array}$ & $\begin{array}{l}\mathrm{N}^{*} \\
(+)\end{array}$ & $\begin{array}{l}N^{*} \\
(-)\end{array}$ & $\begin{array}{l}N^{*} \\
(+)\end{array}$ & $\begin{array}{l}N^{81} \\
(-)\end{array}$ \\
\hline$\llbracket$ & Mining, farming \& forestry & 186 & 8 & 41 & 7 & 67 & 33 & 83 \\
\hline 2 & Construction \& construction & 333 & 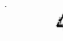 & 93 & 22 & 167 & 30 & 205 \\
\hline 3 & Food \& beverages & 208 & ? & 34 & 3 & 89 & 25 & 100 \\
\hline 4 & Textiles & 205 & 2 & 46 & 16 & 93 & 21 & 107 \\
\hline 5 & Paper, printing \& related & 109 & 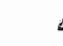 & 24 & 4 & 48 & 6 & 62 \\
\hline 6 & Petroleum refining \& related & 58 & ( & $\Perp 4$ & 4 & 29 & 4 & 37 \\
\hline 7 & Chemicals \& related industries & 184 & & 51 & 4 & 93 & 16 & 101 \\
\hline 8 & Pharmacenticals & 85 & s & 18 & 3 & 37 & 9 & 43 \\
\hline 9 & Steel \& primary metals & 112 & 2 & 23 & 7 & 53 & 12 & 66 \\
\hline 10 & Automobiles & 112 & 3 & 32 & 7 & 52 & 11 & 64 \\
\hline 11 & Machinery \& engineering & 224 & ( & 36 & 14 & 81 & 33 & 94 \\
\hline 12 & Electrical equipment & 201 & 3 & 42 & 11 & 86 & 37 & 87 \\
\hline 13 & Computers & 116 & 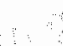 & 13 & 1 & 29 & 15 & 29 \\
\hline 14 & Miscellaneous manufacturing ind. & 96 & t & 23 & 3 & 39 & 8 & 52 \\
\hline 15 & Transport & 123 & ( & 22 & 12 & 49 & 22 & 53 \\
\hline 16 & Telecommunications & 134 & 5 & 27 & 14 & 48 & 21 & 50 \\
\hline 17 & Media services & 37 & ( & 8 & 3 & 8 & 6 & 11 \\
\hline 18 & Leisure \& Tourism & 106 & 3 & 17 & 0 & 36 & 18 & 46 \\
\hline 19 & Utilities & 39 & 3 & 5 & 15 & 8 & 16 & 8 \\
\hline 20 & Utility services & 37 & & 6 & 3 & 14 & 3 & 17 \\
\hline 21 & Retail & 103 & r & 22 & 8 & 48 & 15 & 48 \\
\hline 22 & Banks & 328 & 3 & 71 & 7 & 148 & 22 & 156 \\
\hline 23 & Insurance & 74 & 2 & 3 & 0 & 26 & 5 & 38 \\
\hline 24 & Real Estate & 240 & 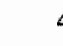 & 81 & 7 & 118 & 15 & 134 \\
\hline 25 & Other & 61 & 3 & 9 & 7 & 23 & 12 & 25 \\
\hline \multirow[t]{4}{*}{26} & Diversified and other industrials & 123 & tis & 25 & 1 & 70 & 12 & 75 \\
\hline & Total number of signif exposures & 3634 & \multicolumn{2}{|c|}{864} & \multicolumn{2}{|c|}{1742} & \multicolumn{2}{|c|}{2218} \\
\hline & \multicolumn{2}{|c|}{ Total number of pos. signif. exposures ${ }^{3}$} & \multicolumn{2}{|c|}{78} & \multicolumn{2}{|c|}{183} & \multicolumn{2}{|c|}{427} \\
\hline & \multicolumn{2}{|l|}{ Total number of neg. signif. exposures. } & \multicolumn{2}{|c|}{786} & \multicolumn{2}{|c|}{1559} & \multicolumn{2}{|c|}{1791} \\
\hline
\end{tabular}

$\mathrm{N}$ indicates the number of firms included in each industry sub-sample. $N *$ reports the number of firms with significant (at the 5 percent level) positive - respectively negative - $\gamma_{i}$ coefficients.

significant at the 5 percent level. 
currency derivatues and other financial instruments to shield themselves from U.S. dollar and Japanese yen exchange rate mowements.

The distribution of U.S. dollar exchange risk exposure coefficients for 4 week and 12 week return measurements intervals are presented in the four last columns of table 39 . Confirming Chow et als (1997b) arguments, we find that there is a monotonic increase in the number of significant - positive and negative exchange rate exposure coefficients from the one week horizon to the longer term 12 week horizon. As a matter of fact, the number of firms that are significantly affected by U.S. dollar fluctuations increases from 864 for the 1 week horizon return to 1,742 for the 4 week horizon return, and to 2,218 for the 12 week horizon, - representing 61 percent of the entire sample. ${ }^{94}$ Moreover, we find that the firm"s exchange rate exposure coefficient becomes larger as the horizon lengthens. Thus, it appears that Asian foreign exchange risk becomes more evident as the return horizon lengthens. ${ }^{95}$

\section{4b The reaction of mature stock markets to changes in the values of emerging markets' currencies: a trade-specific approach on U.S. multinationals}

\section{3. $4 \mathrm{~b} .1$ The firm-level data set and relevant economic factors}

The selection procedure for our sample of U.S. multinational firms active in Latin America consists of three steps. We first select multinational firms based on infomation about their foreign activities in Latin America as reported in the 1969 , 1979, 1987 and 1999 versions of the Directory of American Firms Operating in Foredgn Counries. A total of 2,146 firms are identified as U.S. firms with real operations either in Mexico, Brazil, Chile or Argentina between 1969 and 1999. These firms are then checked for their weekly stock market return availability in the University of Chicago Center for Research in Security Prices (CRSP) database. A total of $\|, 116$ firms are identified. As we include only firms that have more than two years of consecutive weekly returns between January 1970 and December 2001, we exclude 41 firms. Ultimately our sample consists of 1,075 U.S.

\footnotetext{
94 The impact of intervalling for the domestic currency / Japanese yen exchange rates is similar to the impact observed for the domestic currency / U.S. dollar exchange rates and lead to the same conclusions. The cortesponding tables can be obtained from the authors on request.

${ }^{5}$ "These figures are comparable with those reported on long-term foreign exchange exposures of both European firms (cf. section 3.3) and Japanese firms (see Chow and Chen, 1998).
} 
multinationals that actively engage in Latin-American trade. All these firms are sorted into 20 industry groups according to their first four Standard Industrial Classification (SIC) numbers.

We use continuously compounded weekly total returns. The sample period starts on January, $2^{\text {nd }}, 1970$ and ends on December 31,2001 . Consistently with previous analyses (cf. section 3.3 and 3.4) we follow the usual conventions and divide the sample into three equally long sub-samples - January 1970 to December 1979, January 1980 to December 1989 and January 1990 to December 200 - to verify whether results are consistent over sub-samples, undergo any structural or whether findings in a specific sub-sample drive the full sample results.

The value-weighted stock market return as provided by the University of Chicago CRSP database is employed to proxy the market risk factor. The exchange rate risk factor is measured as the continuously compounded rate of change in a trade-weighted exchange rate index (measured as the foreign currency exchange price per unit of U.S. dollar). Following Jorion (1990) and Dominguez and Tesar (2001a, 2001b), an exchange rate index is indeed a parsimonious representation of the effect of multiple exchange rate changes. ${ }^{96}$ However the use of currency indices may lack power if firms are mostly exposed to only a few currencies within the basket (Williamson, 2001). As suggested by lhrig (2001) we therefore use a tradeweighted exchange rate index that is composed of bilateral currency rates of LatinAmerican countries in which our sample firms have real operations. The index is computed as a weighted average of four bilateral exchange rates of interest, defined as the Mexican Peso, Brazilian Real, Chilean Peso and Argentinean Peso price of one U.S. dollar as delivered by Global Financial Data. ${ }^{97}$ The weights, updated monthly, are based on each country's proportion of the four countries' total import and export flows with the U.S. as reported by the Foreign Trade Division of the U.S. Census Bureau.

\section{4b. 2 Empirical findings}

The empirical findings of this study are reported in tables 3.10-12. The crosssectional distribution of the 1,075 U.S. multinationals' estimated exposure

\footnotetext{
${ }^{34}$ In contrast, any test that restricts the measurement of exposure to one exchange rate - whether it is a trade-wienghted rate or a bilateral rate - is likely to be biased downwards.

${ }^{97}$ For the Latin-American exchange rate series included in the trade-weighted index we note that the all mean weekly log price changes are positwe, revealing that the U.S. dollar appreciated against the LatinAmerican currencies over the selected sample period (Jantuary 2, 1970 through December 28, 2001). The series are fat tailed and skewed to the right - indicating asymmetric movements in the exchange rates parity adjustments - . On the whole, the summary statistics suggest that the weekly rates of return for Latin-American exchange rates are not normally distributed.
} 


\section{Chapter 3}

coefficient estimates, $y$, wilizing models (Eq. 3.1), alternatively (3.2) and (3.3), for the full sample period and three sub-sample periods are shown in table 3.10 . Mean, median, variance, minimum and maximum values of $y_{i}$ together with the number of significant positive and negative coefficients obtained are reported.

\section{Table 3.10: Cross-sectional distribution of Latin-American exchange exposures of U.S. multinationals over the entire sample period and across sub-periods}

The table reports summary statistics for $y_{i}$ for the entire sample consisting of 1,075 U.S. multinational firms operating in Latin America:

$$
R_{i, t}=a_{i}+B_{i} R_{m i l}+Y_{i} X_{t}+\varepsilon_{i, t}
$$

whete $R_{i, g}$ the total return of firm $t$ in week $t, R_{n, y}$ designates the owerall stock market return in week $t$ and $X_{i}$ is the change in the trade-weighted Latin-American exchange rate index, and $\varepsilon_{b, \pi}$ denotes the white noise error term.

\begin{tabular}{|c|c|c|c|c|c|c|c|c|}
\hline \multirow{2}{*}{ Sample Period } & \multicolumn{8}{|c|}{ Cross-Sectional Summary Statistics } \\
\hline & $N$ & Mean & Median & Variance & $\mathrm{Mm}$ & Max: & $N^{2}(-)$ & $N(+)$ \\
\hline $02 / 01 / 1970-28 / 12 / 2001$ & 1075 & $\begin{array}{r}-0,0804 \\
-9.257\end{array}$ & $\begin{array}{r}-0,0702^{*} \\
-6.446\end{array}$ & 0.0865 & -3.0161 & 2.2307 & 131 & 39 \\
\hline $02 / 01 / 1970-28 / 12 / 1979$ & 909 & $\begin{array}{l}-0,1302^{*} \\
-16.791\end{array}$ & $\begin{array}{l}-0,1277 \\
-13.144\end{array}$ & 0.0546 & -11.8899 & 0.4574 & 109 & 22 \\
\hline $04 / 01 / 1980-29 / 12 / 1989$ & 920 & $\begin{array}{r}-0,0957^{*} \\
-9.872\end{array}$ & $\begin{array}{r}-0,0933^{*} \\
-7.678\end{array}$ & 0.0865 & -2.9053 & 0.9549 & 117 & 27 \\
\hline $05 / 01 / 1990-28 / 12 / 2001$ & 796 & $\begin{array}{r}-0,0788^{\circ} \\
-8.481\end{array}$ & $\begin{array}{r}-0,0883 \\
-7.578\end{array}$ & 0.0688 & -1.2801 & 1.0921 & 60 & 25 \\
\hline
\end{tabular}

Note: $t$-statistics are in italics. $N$ reports the number of firms included in each sub-sample. $N^{*}(-)$ reports the number of firms with negative $\gamma_{i}$ significant at the 5 percent level, and $N^{*}(+)$ reports the number of firms with positive $\gamma_{i}$ significant at the 5 percent level: * denotes significance at the 10 percent level.

Results show that 184 of the 1,075 U.S. multinationals in the sample have significant foreign exchange wariable coefficients for the full sample period; about 5 percent of the 1,075 lirms yield significant positive exposure coefficients and about 12 percent yield negative coefficients. This high proportion of significantly exposed U.S. companies is in sharp contrast to previous U.S. experience. Another interesting result concerns the sign of the exposures. The vast majority of firms with significant exposure have negative exposure coefficients indicating adverse impact of U.S. dollar appreciations on U.S. firm values. This finding is consistent with the fact that U.S. multinationals are predominantly net-exporters regarding the specific trading relationships with Mexico, Brazil, Chile and Argentina. As a consequence, U.S. multinationals" stock prices generally increase (decline) when the U.S. dollar depreciates (appreciates). 
In addition, the evidence suggests time-variation in exposure at the firm level; the number of significant $\gamma_{i}$ coefficients increases from 83 in the first subsample period to 151 in the second sub-period, and subsequently decreases to 114 in the third sub-period. The considerable increase in the number of firms with significant foreign exchange exposures during the period $1980-1989$ may be explained by the increase in exchange rate fuctuations during this period. ${ }^{98}$ Yet, the sign of exposure is not sample dependent; the majority of hirms with significant exchange risk sensitivity ( 60 percent -64 percent) gain from a depreciation in the value of the U.S. dollar.

Our individual firm level dataset allows us moreover to examine the exposure of individual firms across different industry sub-samples, as opposed to average industry exposure. As a consequence, we are able to determine the U.S. industry sectors in which individual firms with significant exposure are particularly concentrated and to identify the industries that are more sensitive to Latin-American influences. To prevent aggregation effects, the classification is based on fourdigit SIC codes - a precise classification of U.S. industries. The distribution of exchange exposures across 20 selected U.S. industry sub-samples are presented in table 3.11.

In general, the extent to which U.S. industries are affected by LatinAmerican currency fluctuations is relatively large; 15 U.S. industries report statistically significant - positive and negative - exposure coefficients at the fourdigit level. Consistent with the results of table 3.10, all but four industries experience a predominantly negative exposure effect; a depreciation of the dollar against the Latin-American currencies has a positive impact on stock returns of U.S. multinational "firms in these industries. However, four industries experience an adverse valuation effect when the dollar depreciates and benefit when the dollar appreciates. More importantly firms with insignificant exposure effects are concentrated only in five industries, namely rubber and plastics products, stone and glass, primary metals, transport and communication, and utilities. Among these industries, firms appear to be less sensitive to Latin-American influences than among other industries. This finding doesn't necessarily imply that firms in these industry sectors have weaker trading relationships with Latin-American countries; as already emphasized in section 3.3 and section 3.5 , it may as well be attributable to the competitive structure of the market in which they are active or to the use of financial derivative instruments.

\footnotetext{
${ }^{9}$ See Bartov et al. (1996) for a discussion about the effects of increased exchange rate variability on firm value.
} 


\section{Table 3.11: Cross-sectional distribution of Latin-American exchange rate exposures of U.S. multinationals by industry}

The table reports summary statistics for $\gamma_{\text {lis }}$ by twenty industry groups, from the following regression model:

$$
R_{i, i}=a_{i}+b_{i} R_{m, i}+y_{i} X_{i}+\varepsilon_{i, t}
$$

where $R_{i, r}$ the total retum of firm $l$ in week $t, R_{m, t}$ designates the overall stock market return in week $t$ and $X_{f}$ is the change in the trade-weighted Latin-American exchange rate index in week $t$, and $\varepsilon_{i,}$ denotes the white noise error term. The sample consists of 1,075 U.S. multinational firms operating in Latin America.

\begin{tabular}{|c|c|c|c|c|c|c|c|}
\hline \multirow[b]{3}{*}{ No. } & \multirow{3}{*}{ Industry } & \multirow[b]{3}{*}{$\mathbb{N}$} & \multicolumn{3}{|c|}{ Summary Statistics } & \multirow[b]{2}{*}{$N^{*}(-)$} & \multirow{2}{*}{$N^{*}(+)$} \\
\hline & & & Mean & Median & Variance & & \\
\hline & & & \multicolumn{5}{|c|}{ Sample period: 02/01/1970-28/12//2001 } \\
\hline 1 & Mining, construction \& agriculture & 48 & $-0,0241$ & -0.0551 & 0.0199 & 3 & 2 \\
\hline 2 & Food, beverages \& tobacco & 51 & 0.0756 & 0.0366 & 0.0850 & 4 & 2 \\
\hline 3 & Textile \& apparel & 25 & $-0,0953$ & -0.0833 & 0.1520 & 3 & 1 \\
\hline 4 & Paper, publishing \& printing & 43 & -0.1167 & -0.0901 & 0.0142 & 6 & 0 \\
\hline 5 & Chemicals \& allied products & 117 & -0.0672 & -0.0628 & 0.0114 & 14 & 7 \\
\hline 6 & Petroleum refining \& related industries & 19 & 0.0199 & 0.0328 & 0.0065 & 1 & 2 \\
\hline 7 & Rubber \& plastics products & 19 & -0.0673 & -0.0557 & 0.0043 & 4 & 0 \\
\hline 8 & Stone, clay \& glass & 19 & -0.0754 & -0.0638 & 0.0011 & 1 & 0 \\
\hline 9 & Primary metals & 31 & -0.1221 & -0.0921 & 0.0343 & 3 & 1 \\
\hline 10 & Fabricated metals & 43 & -0.0511 & -0.0665 & 0.0128 & 8 & 1 \\
\hline 11 & Machinery & 123 & -0.1047 & -0.0792 & 0.0412 & 18 & 2 \\
\hline 12 & Electrical equipment & 97 & -0.1438 & -0.1052 & 0.3139 & 19 & 1 \\
\hline 13 & Transport equipment & 81 & -0.0620 & -0.0543 & 0.0352 & 8 & 1 \\
\hline 14 & Miscellaneous manufacturing industries & 77 & -0.0043 & -0.0688 & 0.0167 & 9 & 2 \\
\hline 15 & Transport \& communcation & 32 & -0.0550 & -0.0740 & 0.0075 & 1 & 0 \\
\hline 16 & Utilities & 11 & 0.0723 & 0.0501 & 0.0029 & 0 & 3 \\
\hline 17 & Wholesale \& retail trade & 33 & -0.0401 & -0.0475 & 0.0355 & 3 & 2 \\
\hline 18 & Finance, insurance \& real estate & 75 & -0.0769 & -0.0439 & 0.0444 & 9 & 3 \\
\hline 1.9 & Personal and business services & 95 & -0.0986 & -0.0781 & 0.0981 & 12 & 5 \\
\hline 20 & Diversified and other industrials & 36 & -0.1145 & -0.0858 & 0.1946 & 5 & 4 \\
\hline & Across all industries & 1075 & & & & 131 & 39 \\
\hline
\end{tabular}

Note: $N$ reports the number of firms included in each industry sub-sample. $N *(-)$ reports the number of firms with negative $\gamma_{i}$ significant at the 5 percent level, and $N^{*}(+)$ reports the number of firms with positive $\%$ significant at the 5 percent level. 


\section{Table 3.12: Latin-American exchange rate exposure coefficients $y_{1}$ of U.S. maltinationals by industry: Intervalling results using overlapping observations}

The table reports cross-sectional mean values and standard deviations for $\%$, by twenty industry groups, estimated by the following regression model:

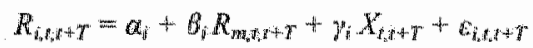

where $R_{i, t_{r}+T}$ reports the total return of firm $i$ from week $t$ to $t+T, R_{m, w i t}$ designates the overall stock market retum from week $t$ to $t+T$ and $X_{t, T}$ is the change in the trade-weighted LatinAmerican exchange rate index from week it to $t+T$, where $T$ equals 1,4 and 12 weeks, and $c_{i, t}+t$ denotes the white noise error term. The sample consists of 1,075 U.S. multinational firms operating in Latin America.

\begin{tabular}{|c|c|c|c|c|c|c|c|c|}
\hline \multirow[b]{2}{*}{ No. } & \multirow[b]{2}{*}{ Industry } & \multirow[b]{2}{*}{$\mathrm{N}$} & \multicolumn{2}{|l|}{ I week } & \multicolumn{2}{|l|}{4 weeks } & \multicolumn{2}{|l|}{12 weeks } \\
\hline & & & $\begin{array}{l}\text { Cross- } \\
\text { sectional } \\
\text { mean }\end{array}$ & $N^{*}$ & $\begin{array}{l}\text { Cross- } \\
\text { sectional } \\
\text { mean }\end{array}$ & $N^{*}$ & $\begin{array}{l}\text { Cross- } \\
\text { sectional } \\
\text { mean }\end{array}$ & $N^{*}$ \\
\hline 1 & $\begin{array}{l}\text { Mining, construction \& } \\
\text { agriculture }\end{array}$ & 48 & $\begin{array}{l}0.0393 \\
0.0318\end{array}$ & 2 & $\begin{array}{l}0.0370 \\
0.0355\end{array}$ & 4 & $\begin{array}{l}0.0741 \\
0.0586\end{array}$ & 6 \\
\hline & & & $\begin{array}{r}-0.0562 \\
0.0505\end{array}$ & 6 & $\begin{array}{r}-0.0816 \\
0.0629\end{array}$ & 19 & $\begin{array}{r}-0.1185 \\
0.1040\end{array}$ & 29 \\
\hline 2 & $\begin{array}{l}\text { Food, beverages \& } \\
\text { tobacco }\end{array}$ & 51 & $\begin{array}{l}0.0395 \\
0.0539\end{array}$ & 5 & $\begin{array}{l}0.0458 \\
0.0526\end{array}$ & 12 & $\begin{array}{c}0.0860 \\
0.0715\end{array}$ & 30 \\
\hline & & & $\begin{array}{r}-0.0901 \\
0.2736\end{array}$ & 3 & $\begin{array}{r}-0.0451 \\
0.0518\end{array}$ & 4 & $\begin{array}{r}-0.0601 \\
0.0723\end{array}$ & 8 \\
\hline 3 & Textile \& apparel & 25 & $\begin{array}{l}0.0334 \\
0.0228\end{array}$ & 1 & $\begin{array}{r}0.0261 \\
0.0876\end{array}$ & 2 & $\begin{array}{l}0.0710 \\
0.0265\end{array}$ & 7 \\
\hline & & & $\begin{array}{r}-0.0452 \\
0.0512\end{array}$ & 2 & $\begin{array}{r}-0.0897 \\
0.0638\end{array}$ & 6 & $\begin{array}{r}-0.1435 \\
0.1183\end{array}$ & 11 \\
\hline 4 & Paper products & 43 & $\begin{array}{l}0.0282 \\
0.0206\end{array}$ & 1 & $\begin{array}{c}0.0358 \\
0.0243\end{array}$ & 8 & $\begin{array}{r}0.0796 \\
0.0764\end{array}$ & 22 \\
\hline & & & $\begin{array}{r}-0.0457 \\
0.0498\end{array}$ & 5 & $\begin{array}{r}-0.0446 \\
0.048 .5\end{array}$ & 6 & $\begin{array}{r}-0.0806 \\
0.0950\end{array}$ & 12 \\
\hline 5 & $\begin{array}{l}\text { Chemicals \& alled } \\
\text { products }\end{array}$ & 117 & $\begin{array}{l}0.0403 \\
0.0612\end{array}$ & 10 & $\begin{array}{l}0.0360 \\
0.0369\end{array}$ & 24 & $\begin{array}{l}0.0829 \\
0.1121\end{array}$ & 43 \\
\hline & & & $\begin{array}{r}-0.0474 \\
0.0589\end{array}$ & 8 & $\begin{array}{r}-0.0618 \\
0.0951\end{array}$ & 14 & $\begin{array}{r}0.0642 \\
0.0886\end{array}$ & 29 \\
\hline 6 & $\begin{array}{l}\text { Petroleum refining \& } \\
\text { related industries }\end{array}$ & 19 & $\begin{array}{l}0.0365 \\
0.0222\end{array}$ & 1 & $\begin{array}{r}0.0265 \\
0.0339\end{array}$ & 4 & $\begin{array}{r}0.0466 \\
0.0416\end{array}$ & 4 \\
\hline & & & $\begin{array}{r}-0.0505 \\
0.0757\end{array}$ & 2 & $\begin{array}{r}-0.0503 \\
0.0320\end{array}$ & 3 & $\begin{array}{r}-0.0435 \\
0.0348\end{array}$ & 8 \\
\hline 7 & $\begin{array}{l}\text { Rubber \& plastics } \\
\text { products }\end{array}$ & 19 & $\begin{array}{l}0.0386 \\
0.0502\end{array}$ & 0 & $\begin{array}{l}0.0469 \\
0.0663\end{array}$ & 0 & $\begin{array}{l}0.0639 \\
0.0430\end{array}$ & 5 \\
\hline & & & $\begin{array}{r}-0.0292 \\
0.0230\end{array}$ & $\mathbb{1}$ & $\begin{array}{r}-0.0420 \\
0.0379\end{array}$ & 5 & $\begin{array}{r}-0.12011 \\
0.0922\end{array}$ & 9 \\
\hline 8 & Stone, clay \& glass & 19 & $\begin{array}{l}0.0196 \\
0.0087\end{array}$ & 0 & $\begin{array}{l}0.0402 \\
0.0221\end{array}$ & 3 & $\begin{array}{l}0.0721 \\
0.0560\end{array}$ & 6 \\
\hline & & & $\begin{array}{r}-0.0316 \\
0.0240\end{array}$ & 0 & $\begin{array}{r}-0.0691 \\
0.0728\end{array}$ & 4 & $\begin{array}{c}-0.0873 \\
0.0411\end{array}$ & 9 \\
\hline
\end{tabular}


Table 3.12: continued

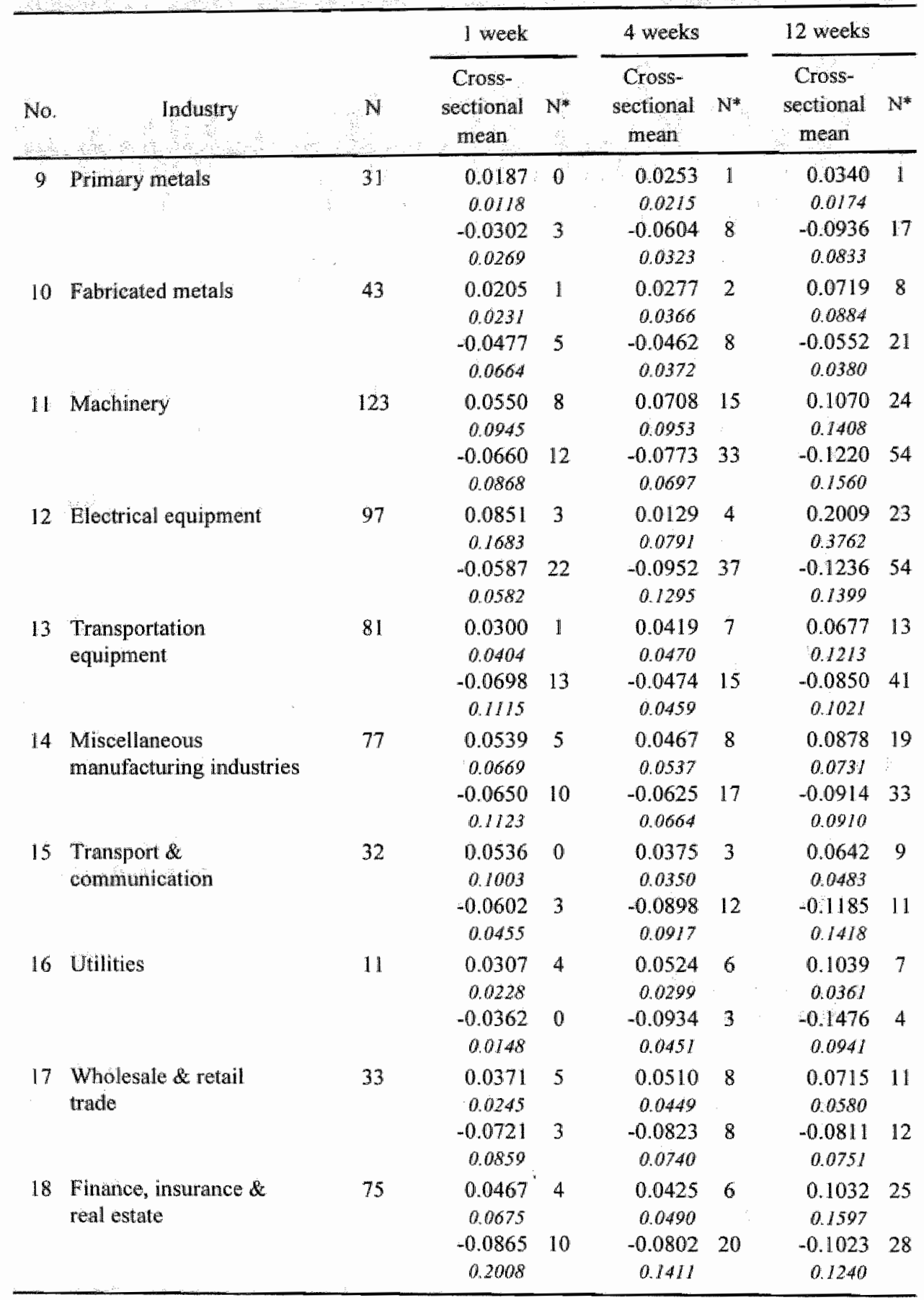




\begin{tabular}{|c|c|c|c|c|c|c|c|c|}
\hline \multirow[b]{2}{*}{ No. } & \multirow[b]{2}{*}{ Industry } & \multirow[b]{2}{*}{$\mathrm{N}$} & \multicolumn{2}{|l|}{1 week } & \multicolumn{2}{|l|}{4 weeks } & \multicolumn{2}{|l|}{12 weeks } \\
\hline & & & $\begin{array}{l}\text { Cross- } \\
\text { sectional } \\
\text { mean }\end{array}$ & $\mathbf{N}^{*}$ & $\begin{array}{c}\text { Cross } \\
\text { sectional } \\
\text { menn }\end{array}$ & $N^{*}$ & $\begin{array}{l}\text { Cross- } \\
\text { sectional } \\
\text { mean }\end{array}$ & $N$ \\
\hline \multirow[t]{4}{*}{19} & Services & 95 & 0.1074 & 3 & 0.1078 & 11 & 0.1180 & 32 \\
\hline & & & 0.1942 & & 0.1568 & & 0.1688 & \\
\hline & & & -0.1157 & 11 & -0.0942 & 28 & -0.1830 & 31 \\
\hline & & & 0.2531 & & 0.1233 & & $0.25 \% 6$ & \\
\hline \multirow[t]{4}{*}{20} & Other & 36 & 0.0970 & 5 & 0.0708 & 6 & 0.2074 & 10 \\
\hline & & & 0.0949 & & 0.0399 & & 0.3119 & \\
\hline & & & -0.0404 & 6 & -0.0838 & 12 & -0.0967 & 17 \\
\hline & & & $0.0343^{\prime \prime}$ & & 0.0675 & & 0.0939 & \\
\hline \multicolumn{3}{|c|}{ Total nber of significant exposures } & & 184 & & 396 & & 743 \\
\hline \multicolumn{3}{|c|}{ Total nber of neg. significant exposures } & & 125 & & 262 & & 438 \\
\hline \multicolumn{3}{|c|}{ Total nber of pos. significant exposures } & & 59 & & 134 & & 305 \\
\hline
\end{tabular}

Note: Standard deviations are in italics. $\mathrm{N}$ indicates the number of firms included in each industry sub-sample. $N^{*}$ reports the number of firms with respectively positive, and negative, $\gamma_{i}$ coefficients that are significant at the 5 percent level. ${ }^{8}$ significant at the 5 percent level.

Table 3.12 presents the distribution of exposure coefficients for 1 week, 4 week, and 12 week return measurements intervals. Overall, it appears that there is a general increase in the number of significant - positive and negative - exchange rate exposure coefficients from the one week horizon to the longer term 12 week horizon. The number of firms who yield significant exposure coefficients increases from 184 for the 1 week horizon return to 396 for the 4 week horizon return, and to 743 for the 12 week horizon; while firms' exchange rate exposure coefficients become larger, in magnitude, as the horizon lengthens. Thus, findings suggest that Latin-American exchange exposure becomes more perceptible when measured utilizing longer return horizons. Consistent with our previous results (see section 3.3 and 3.4) the impact of lengthening the return horizon is stronger than reported in previous empirical research on long-term foreign exchange exposure effects on U.S. stock and bond returns - see Chow et al. (1997a, 1997b) - and Australian stock returns - see Di Iorio and Faff (2000). There may be two interpretations for these findings. First, as already mentioned, the studies by Chow et al. (1997a, 1997b) and Di lorio and Faff (2001) examine the long-term exposure of industry portfolios and suffer consequently from the aggregation problem. Another plausible interpretation for the higher incidence of long-run exposure may be the greater volatility attached to the Latin-American exchange rates, as it is 
likely to take longer for random fluctuations to net out and for investors to distinguish between temporary versus permanent currency shocks.

\section{5 Concluding remarks}

This chapter examines across three different stock markets whether there exists any relationship between individual firms' stock returns and fluctuations in the currency values of major trading partners, whether the explored exchange risk exposure patterns are industry-specific, and whether firms' exchange exposures are more evident actoss increasing time horizons.

The study is subdivided in two parts. The first evaluates the impact of actively traded currency fluctuations, whereas the second concentrates on the valuation effects of the more pronounced exchange rate movements in emerging countries' currencies. This second approach is investigated both from the viewpoint of local firms that are established in these developing economies and from the perspective of companies belonging to mature stock markets but using these currencies in their foreign trading relationships. Figure 3.1. summarizes our results.

Figure 3.1: Growth in percentage of significantly exposed companies for increasing estimation horizons

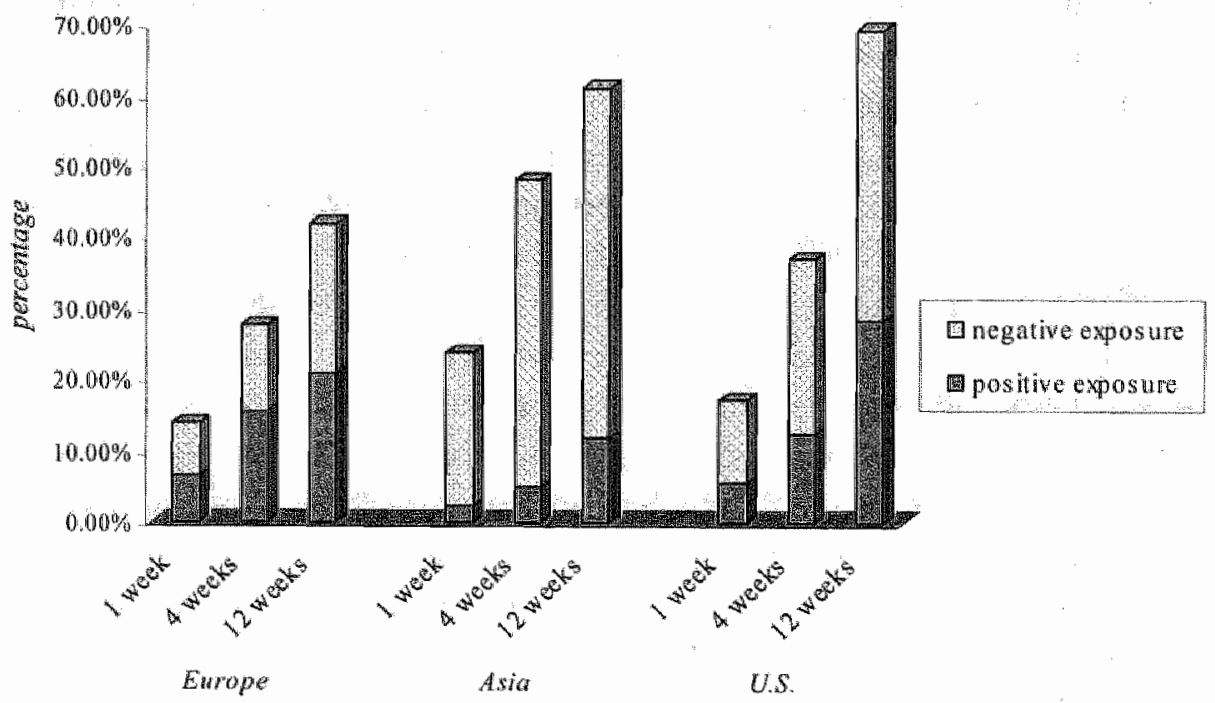

Notes: This figure presents the percentage of significantly - positively and negatively - exposed companies for increasing estimation horizons. The results concern consecutively the U.S. dollar exposure of the 817 European firms, the U.S. dollar exposure of the 3,634 Asian firms and the Latin-American exposure of the 1,075 U.S. multinationals with real operations in Latin America. 
Among the sample of 817 European firms, we find that for the period from January 1988 to December 2002, about 13 percent of these experienced economically significant exposure effects to the Japanese yen, 14 percent to the U.S. dollar and 22 percent to the U.K. pound. Among the 3,634 selected Asian firms, we find that approximately 25 percent of these companies are significantly exposed to the U.S. dollar and 22.5 percent to the Japanese yen for the period January 1993 to January 2003. Finally, roughly 17 percent of 1,075 U.S. multinationals with real operations in Latin America document a significant relationship between their stock returns and fluctuations in a trade-weighted LatinAmerican exchange rate index. Our evidence of significant exposure effects differs substantially from previously reported empirical findings and is basically robust across sub-sample periods. Overall it appears that a depreciating (appreciating) home currency against foreign currencies has a net negative (positive) impact on European and Asian stock returns; while U.S. multinationals gain (loose) from a depreciation (appreciation) of the U.S. dollar in terms of Latin-American currencies. Figure 3.1 reveals furthermore that the valuation effects of emerging countries' currencies tend to be stronger than those of the more actively traded currencies. One may argue that these results are attributable to the higher volatility of these currency fluctuations. As the question of the impact of increased exchange rate volatility deserves further attention, we will specifically concentrate on this particular issue in chapter 5 .

We also studied in this chapter the exposure of individual firms across industry sub-samples, as opposed to average industry exposure. Importantly, individual firms within these industry groups show high positive as well as negative exposure, suggesting that exposure is not necessarily economically significant in the aggregate. Firms with insignificant exposure effects are predominantly concentrated in a small number of industries. We further investigate the nature of exchange exposure across increasing return measurement intervals. ${ }^{99}$ As represented in figure 3.1 , our findings suggest that the extent to which firms are exposed to foreign

\footnotetext{
${ }^{99}$ One of the well-known particularities of financial markeis is that wariables - stuch as exchange rates and stock prices -, which are not predicable at short horizons, appear to contain a significant predictable component at longer horizon. Fama and Frnech (1988), Poterba and Sumners (1988) and Mark (1995) attribute this feature to the fact that short-run movements are largely affected by investors" under and overreactions. In the long run these noisy under and overreactions tend to average out and the relation to economic fundamentals gets more discernible. Berben and van Dijk (1998) and Berkowitz and Giorgianni (2001) argue, in contrast, that inferences from long horizon regressions depend largely on the null hypothesis that a cointegrating relationship exists between the variables involved. They therefore derive the asymptotic distribution of least-squares coeffichent estimates under the null that this cointegration does not hold. Investigating this line of reasoning, Campbell's (2001) findings tend to suggest however that long horizon regressions still have power advantages remaining after the use of new asymptotical critical values.
} 
currency fluctuations varies with return horizons. Short-term exposure seems to be relatively well hedged, where considerable evidence of long-term exposure is found. We find, indeed, that more than 42 percent ( 61 percent, 69 percent) of European (Asian, U.S. multinational) firms are significantly affected by foreign currency fluctuations in the long-term. It would seem either that financial managers ignore their shareholders" exposure to the currencies of major trading partners in their long-term risk-management decision-making process or that it represents an economic exposure that is unrelated to known transactions, and hence very difficult to manage. The stronger perceptibility of long-term foreign exchange risk exposure may, however, as well be caused by investors' mispricing errors. Since it is a particularly complex task to distinguish between temporary versus permanent exchange rate shocks, it is possible that investors make systematic errors when characterizing the impact of short-term exchange rate movements on firm value rendering, hence, the relationship statistically and economically difficult to identify in the short-run. 

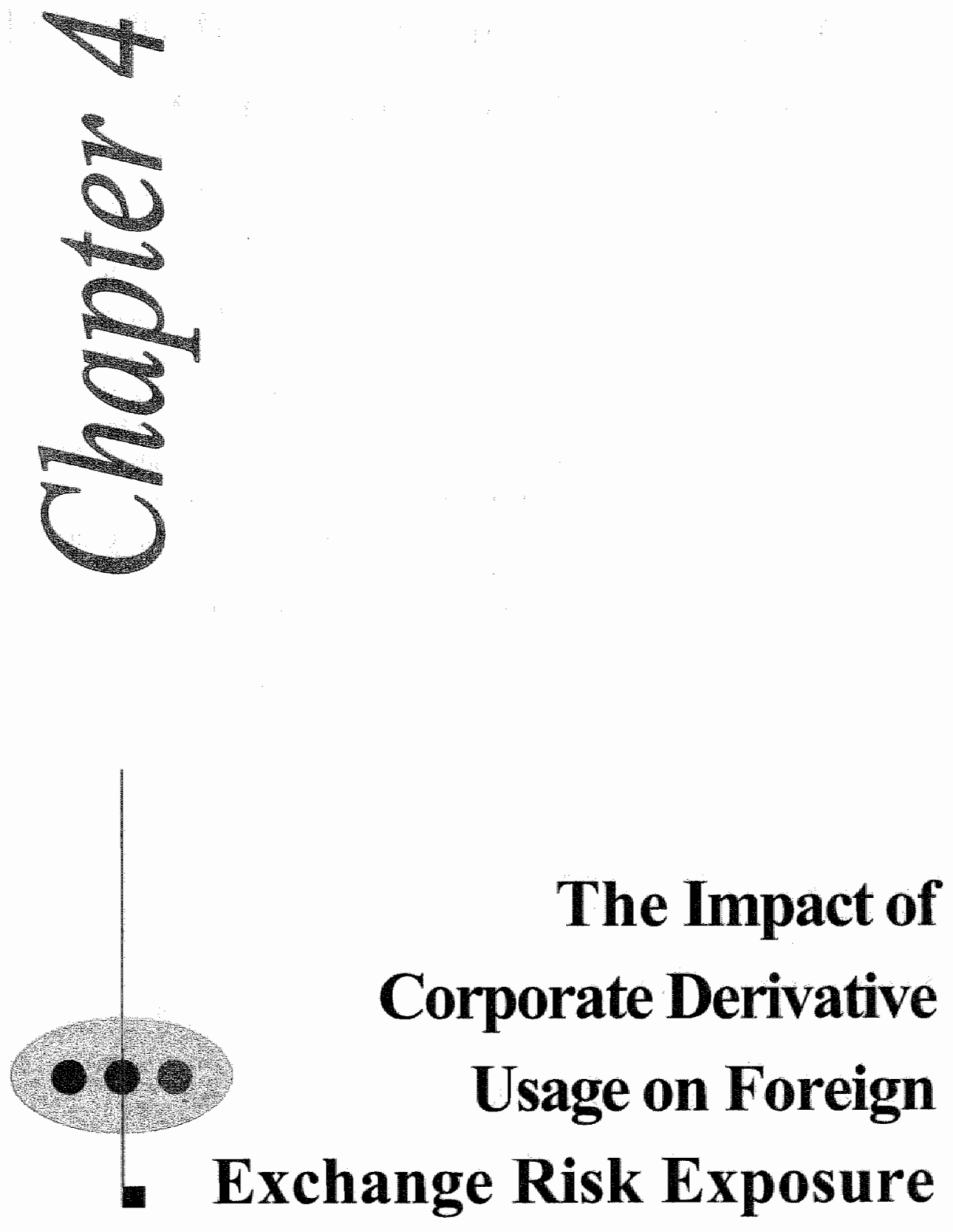


$$
\begin{aligned}
& 3 \quad-48+4 \\
& \text { a } 3 \text { a } \\
& \therefore \quad 349+4
\end{aligned}
$$

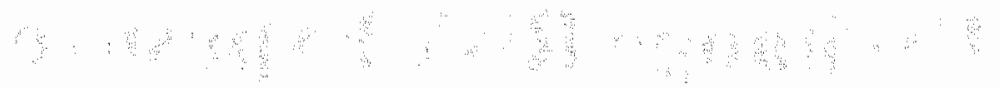




\section{The Impact of Corporate Derivative Usage on Foreign Exchange Risk Exposure ${ }^{100}$}

\subsection{Introduction}

Today all firms are facing various sources of exchange rate risk in exercising their daily activities. ${ }^{101}$ In this context, financial derivative contracts - such as forwards, swaps and options - provide managers with a whole series of instruments to manage these risks. However, the question whether companies should or should not implement hedging strategies to reduce their foreign currency exposure is still going on. While the Modigliani and Miller (1958) paradigm postulates that the financial risk management activities of a company are irrelevant to shareholder wealth since shareholders have access to the same risk management tools as corporate managers, more recent theories suggest that hedging activities could be value-increasing. Stulz (1984), Smith and Stulz (1985), DeMarzo and Duffie (1995), Froot et al. (1993), Nance et al. (1993), Mian (1996), Tufano (1996), and Geczy er al. (1997) among others have conducted research on potential hypothetical rationales for corporate risk management. They provide useful information on numerous valid reasons why companies should consider hedging to maximize shareholder wealth. As firms didn't reveal their position in derivatives until the $1990 \mathrm{~s}$, the empirical validation of these theories has, however, been confronted with the long-lasting unavailability of reliable data on hedging activities. Since then, widespread corporate use of derivatives has been documented in Dolde (1993), Bodnar et al. (1998), Berkman and Bradbury (1996), Berkman ef al. (1997), Henstchel and Kothari (2001), and Bodnar et al. (2003). A recent stream of research has also sought to identify which hedging theories best describe a firm's choice to use financial hedging instruments (e.g., Nance et al., 1993; Howton and Perfect, 1998; Joseph, 2000). More recent studies (e.g., Geczy et al., 1997; Marshall, 2000; Judge, 2004) have even differentiated between different types of risks (e.g., interest rate, currency and

\footnotetext{
${ }^{100}$ This chapter is based on A. Muller and W.F.C. Verschoor, "The impact of corporate deriwative usage on foreign exchange risk exposure", LIFE Working Paper, 2005a.

"For a detailed discussion, please refer to section 2.2 of this thesis.
} 
commodity risks) suggesting that factors determining derivative usage may differ for each type.

Since reasons to hedge may exist to either decrease or increase risk exposure, the expected effect of financial hedging instruments is primarily an empirical issue. However if we assume that the objectives of corporate derivative usage are to reduce firms foreign exchange risk, the question emerges whether these activities may constitute one possible explanation for the fact that empirical research has found limited evidence of a significant link between exchange rates movements and firm value (see, e.g., Jorion, 1990; Amihud, 1994; Bodnar and Gientry, 1993). This argument has first been supported by Bartow and Bodnar (1994) who affirm that firms are aware of their currency exposures and efficiently manage it. ${ }^{102}$ Analyzing the impact of currency fluctuations on U.S., Japanese and Canadian industries, Bodnar and Gentry (1993) likewise suggest that the reported effect of exchange rates on industry returns is insignificant because companies are using various hedging instruments to hedge their exposure. The difficulty of quantifying the importance of hedging activities doesn't enable them however to test for the impact of these presumed hedging activities. Similarly acknowledging the impact of hedging activities on exchange rate exposure, several other studies (He and $\mathrm{Ng}$, 1998; Chow and Chen, 1998) examine the relationship between variables that proxy firms "incentives to hedge and estimated exchange rate exposures. Their results suggest that firms with high leverage and low liquidity - thus, having more incentives to hedge - are nevertheless more sensitive to currency fluctuations.

Up till now, the direct interdependence between actual firms" risk management strategies and their risk exposures has not received much attention in the literature. Notable exceptions are provided in Simkins and Laux (1997) and Allayannis and Ofek (2001). While the former find no statistically significant impact of foreign currency derivative usage on exposure, the latter suggest that a firm's use of derivatives tends to reduce its exchange risk exposure. In a different context, Pantzalis et al. (2001) show that a firm's capacity to construct operational hedges moderates its sensitivity to currency fluctuations. Overall, the evidence is, however, scarce and relatively little is known about the impact of corporate hedging activities on firms' foreign exchange risk exposure - leaving many questions unanswered: How widespread is the use of foreign currency derivatives? What are the main determinants of FCD usage? Do firms use derivatives to hedge - or to speculate? What are the real effects of their hedging strategies?

\footnotetext{
${ }^{102}$ See Loderer and Pichler (2000) for a discussion on firms" awareness of their foreign exchange risk exposure.
} 
Regarding all these questions, this study has four primary advantages over previous studies. First, it has to be emphasized that until now, continental European non-financial firms barely disclosed any information on derivative usage: Consequently, there is only very limited knowledge about their hedging patterns and motivations. Hardly any empirical studies have been able to investigate the determinants of derivative usage in continental Europe. With the exception of Bodnar and Gebhardt (1998) and De Ceuster et al. (2000) who have respectively explored German and Belgian companies, this study is, hence, the first extensiwe analysis on the foreign exchange risk management practices of a large sample of German, Dutch, Belgian and U.K. firms. ${ }^{103}$ Thanks to this new extensive data set consisting of 471 European multinationals, we are able to provide not only descriptive but also analytical evidence regarding many questions raised in the literature. Second, while most studies exploring firms' hedging incentives employ a dependent binary yariable indicating whether a firm uses FCDs or not, we extend this methodology by investigating both the factors that determine a firm's decision to use FCDs and those affecting the level of external hedging activities. Third, as no study thus far has addressed the question of whether there is a direct relationship between the FCD usage of European non-financial firms and their currency risk exposure, we fill the existing gap and examine whether FCD users are less exposed to market and exchange rate movements than FCD non-users. We specifically verify, moreover, whether the level and significance of measured foreign currency risk exposures reflect the outcomes of financial risk management activities. Following Allayannis and Ofek (2001), we estimate therefore a multivariate regression linking a firm's exchange rate exposure to both its foreign sales ratio and its financial hedging activities. To extend Allayanis and Ofek's work, we include furthermore variables that are proxies for firms' operational hedging activities as well as for firms' incentives to hedge. Fourth, our analysis examines the impact of FCDs both on weekly and on monthly exchange rate exposures. The variation of the time period used in estimating the currency exposures gives us not only the possibility to perform robustness checks - by examining if our results vary with the exposure horizon - but it enables us primarily to evaluate the effectiveness of hedging techniques across different time horizons. Chapter 3 has indeed demonstrated that exchange rate exposure becomes increasingly evident when lengthening return measurement intervals. We are able, in this chapter, to validate or refute - one potential explanation for this horizon-dependent impact of currency fluctuations on firm value. A stronger impact of FCD usage on monthly than on

\footnotetext{
103 It has to be noted that information on European risk management activities is as well discussed in Bartram et al (2004) who provide large-scale international evidence on derivative usage for a sample of 7,263 non-financial firms from 48 countries including the United States.
} 
weekly foreign risk exposures would de facto suggest that longer-term exposures characterize, to a larger degree, economic exposures that are unrelated to known transactions and hence difficult to hedge.

The chapter is organized as follows. After reviewing our research questions in the next section, we describe the sample procedure and data characteristics in section $4: 3$. Section 4.4 provides empirical findings on the determinants of hedging while the impact of corporate derivative usage on foreign exchange risk exposure is presented in section 4.5 . Section 4.6 concludes.

\subsection{Research questions}

\subsubsection{Why do firms hedge?}

Under the classical Modigliani and Miller (1958) paradigm, no financial derivative contract can influence firm value. Assuming perfect capital markets, the classical Modigliani and Miller paradigm implies thus that firms have no reasons to engage in hedging activities since shareholders of the company who wish to mitigate their risk exposures always have the possibility to perform the necessary hedging transactions on their own. In reality however, capital markets are imperfect and (i) financial distress, (ii) taxes, (iii) information asymmetries and (iv) agency problems are costly to firms. Smith and Stulz (1985), Bessembinder (1991), Nance et al. (1993) and Froot et al. (1993), among others, show why these capital market imperfections may lead to an increase in firm value through the implementation of hedging activities.

It has to be stressed, however, that, while capital market imperfections are necessary to justify hedging activities, the existence of sufficiently large risk exposures and the costs related to the implementation of these hedging programs have as well to be taken into account when ultimately evaluating the impact of financial derivative instruments usage on firm value.

But before analyzing the impact of corporate derivative usage, we will first construct the theoretical framework of this study and present hereafter a short and concise overview on the most popular hedging theories. ${ }^{104}$ As already mentioned, most of them arrive at optimal hedging policies by introducing some frictions to the classical Modigliani and Miller model:

This overview provides as well useful insight in the choice of the variables to be used in section 4.4 . 


\section{i. expected cost of financial distress}

In real world, financial obligations that cannot be fully or timely settled due to illiquidity cause financial distress and lead to transaction costs (Shapiro and Titman, 1985). By reducing the variance of firm value and, with that, the probability that the firm will encounter financial distress, hedging can reduce these expected costs of financial distress (Smith and Stulz, 1985). As a consequence, firms with high leverage and low liquidity are expected to have strong incentives to hedge their risky positions. However, as direct costs of financial distress have been shown to be less than proportional to firm size ${ }^{105}$, Nance et al. (1993) maintain that smaller firms should hedge more than larger ones. On the other hand, one may as well support the point of view that large firms have more sophisticated risk management strategies and benefit from scale economies, being thus likely to hedge more (Martin and Mauer, 2004).

\section{ii. taxes}

Smith and Stulz (1985) argue that the structure of the tax code may determine a firm's decision to hedge. They demonstrate that for corporations facing tax-function convexity $^{106}$, hedging lowers expected tax liabilities by reducing the volatility of taxable income. Graham and Smith (1999) suggest that, in particular, carrybacks and carryforwards are strong incentives to engage in hedging activities while other tax-code provisions have minor impacts. ${ }^{107}$

\section{iii. information asymmetries}

Corporate risk management activities may also result from managerial incentives based on asymmetric information, i.e. managers as opposed to shareholders are better informed about the sources and extent of risk faced by the firm. While De Marzo and Duffie (1995) argue that firms are sometimes hedging based on private information that cannot be costlessly conveyed to shareholders, Breeden and Viswanathan (1998) claim that managers have incentives to hedge away uncertainty about future performance to influence the market"s judgement about their management ability. Whatever justification preferred, shareholders in both situations may benefit from corporate hedging through the reduction of firms' profit variability and shareholders' noise perception in the information set regarding unobservable risks. Hence, the more the management of the firm possesses

\footnotetext{
${ }^{505}$ See Wamer (1977) and Ang ef al. (1982) for an analysis of the relationship between firm size and financial distress costs.

${ }^{106}$ Graham and Smith (1999) show that the firms that are most likely to have convex tax functions are small firms which have expected income near zero and alternate between profits and losses.

${ }^{107}$ Graham and Rogers (2002) find no empirical evidence that companies hedge in response to tax convexity.
} 
proprietary information, the more corporate hedging may be beneficial to shareholder wealth (De Marzo and Duffie, 1995).

\section{iv. agency problems}

Conflicts of interest between bondholders and shareholders give rise to underinvestment problems as residual claimholders may have the incentive not to realize all investment opportunities with positive net present values if the gains accrie primarily to fixed claimholders. Hedging mitigates this underinvestment problem because it redistributes cash from states in which cash flow exceeds fixed obligations to states with insufficient cash flow. The value of the debt becomes thus less: sensitive to incremental investment decisions (Bessembinder, 1991). On the other hand, Froot et al. (1993) argue that by shifting internal funds into states where they would otherwise be scarce, hedging permits the company to engage in valuable investment projects with cheaper funds. In both cases, we predict that a firm's hedging activities should be positively related to proxies of potential underinvestment costs, i.e. leverage and growth opportunities. Nance et al. (1993) stiggest, however, that firms have still the possibility to reduce the conflict between shareholders and bondholders by means other than hedging with financial instruments. They may, e.g., issue convertible bonds or preferred stocks.

Agency costs may as well emerge because managers act on behalf of their goals. As already mentioned above, managers may not be able to diversify away risks as they have an extremely undiversified wealth position resulting from their employment in the firm, the related current and futures incomes, and associated factors such as reputation and awards (Smith and Stulz, 1985; Bartram, 2002). Smith and Stulz (1985) demonstrate that the expected utility of wealth of risk-avers managers with large ownerships in the firm are significantly affected when expected profits are volatile. ${ }^{108}$ As a result, managers with large firm ownerships have stiong incentives to persuade the firm to engage in hedging activities. ${ }^{109}$

To conclude, it has to be emphasized that, in general, the presence of hedging substitutes is expected to reduce the need for hedging. Low dividend

\footnotetext{
108 Assuming no hedging costs, corporate hedging activities should hence increase managers' utility without reducing firm value. Froot et al. (1993) criticize, however, the argumentation of Smith and Stulz (1985) as it relies as well on the assumption that managers' personal hedging activities are very costly and leads to the conclusion that, without the introduction of transaction costs of hedging at the firm level, firms should hedge as much as possible, lie. to minimize the stock price variance.

109 Consistent with the argumentation of Smith and Stulz (1985), Tufano (1996) and Schrand and Unal (1998) find evidence that hedging increases with managerial shareholdings and decreases with managerial option ownership. Other studies (see, e.g.x Geczy et al., 1997 and Haushalter, 2000) find, however, no evidence that managerial risk aversion or shareholdings affect corporate hedging.
} 
yields ${ }^{110}$ and high liquidity ratios may, as an illustration, enable the firm to retain sufficient liquidity to make corporate hedging useless," analyzing the use of foreign currency derivatives, the relative importance of foreign sales relative to total sales and the geographical dispersion of foreign operations have as well to be taken into consideration.

From an empirical point of view, earlier studies have examined the consistency between optimal hedging theories and derivative usage in general (see, e.g., Nance et al., 1993; Dolde, 1993; Mian, 1996; Pennings and Garcia, 2004). More recent studies tend to acknowledge, however, that factors determining derivative usage may differ for each type of hedging (see, e.g., Tufano, 1996; Haushalter, 2000; Gezcy et al, 1997; Allayannis and Ofek, 2001; Judge, 2004; Bartram et al., 2004). ${ }^{112}$ Tufano's (1996) empirical findings on the use of commodity derivatives in the gold mining industry lend support to theories of managerial risk aversion, while the hypothesis that expected financial costs provide an incentive to hedge is confirmed in Haushalter (2000) and in Visvanathan (1998). Geczy et al. (1997) investigate the relation between the likelihood that a firm uses FCDs, proxies for incentives to hedge as well as proxies for foreign exchange exposure among U.S. non-financial firms. ${ }^{113}$. Their findings suggest that the use of FCDs depends on a firm's degree of foreign sales, foreign trade and size. Consistent with the notion that hedging is used to mitigate the underinvestment problem, the amount of R\&D expenditures is as well found to be an important determinant of hedging. However no clear relation between foreign debt and derivative usage could be established. Judge (2004) explores the determinants of the decision to hedge among U.K. non-finaneial firms. Consistent with previously reported results, his findings ascribe strong explanatory power to firm size and the foreign currency transactions dummy, thus providing support for the economies of scale and exchange exposure hypotheses. Judge finds, moreover, proxy variables for the financial distress argument to be similarly significant in explaining FCD use. Conversely, Bartram et al. (2004) who investigate the use of currency, interest and commodity derivatives by non-financial firms from 48 countries come to the conclusion that none of the afore-mentioned hedging theories are clearly supported

\footnotetext{
110 As dividend yields proxy dividend restrictions as well as growth opportunities, the sign of the relationship between diwidend yields and derivative ussige is theoretically difficult to predict.

${ }^{111}$ Low dividend yields (Nance et al, 1993) and higli quick ratios (Tufano, 1996; Minton and Schrand, 1999) have been shown to be empirically negatively related to derivalive usage.

112 For a general overview on corporate derivative practices, we recommend the papers by Bodnar et al. (1998), Bodnar and Gebhardt (1999), De Ceuster et al. (2000), Marshall (2000), Guay and Kothari (2003), Bodnar et al (2003). Bartram et al (2004).

113 Geczy ef al (1997) empirically investigate what factors influence the decision to hedge using a logit regression.
} 
by the data. Recent studies exploring the determinants of hedging intensity based on continuous measures of corporate derivative usage lead to similar results. Howton and Perfect (1998), for instance, find that derivative use is unrelated to most of the proxies for the theoretical hedging determinants. ${ }^{1: 4}$

\subsubsection{Does corporate derivative usage influence foreign exchange risk exposure?}

If market imperfections - like those outlined in the previous section - exist, theory expects that the more derivatives a firm uses to hedge its exposures, the less risk exposure it will face. As a consequence the relationship between a firm's riskiness after the use of hedging and its foreign currency derivative usage should be negative. This anticipation is nevertheless based on the assumption that FCDs are exclusively used for hedging while existing theories suggest that firms might also use derivatives to take on additional risks. ${ }^{15}$ Consequently, the question whether FCD usage decreases - or increases - a firm's risk exposures remains unsolved.

Thus far, limited empirical evidence has been brought to answer this question for non-financial firms. In large part, the lack of evidence is attributable to poor data availability. Among recent papers, Guay (1999) uses an event-study approach and finds a statistically significant decrease in firm risk exposure, measured by interest rate and exchange rate exposures, following the initiation of derivative usage. ${ }^{116}$ In contrast, Hentschel and Kothari (2001) find that firms who hedge their exposures with derivative positions display few, if any, measurable differences in risk compared to firms that do not use financial derivatives. The analysis of 7,263 non-financial firms from 48 countries by Bartram et al. (2004) reveals some support for a positive value effect of general derivative use but only for firms without exposure. The impact of FCD use, however, is found to be insignificant. Marshall (2000) empirically shows, furthermore, that contrary to the general view found in the literature derivative use doesn't always decrease the variability of the firm's value and that the degree of usage of certain techniques is even associated with an increase in the variability of certain financial measures.

Focusing on the use of foreign currency derivatives in a sample of 720 large U.S. multinationals, Allayannis and Weston (2001) find a positive relation between firm value and the use of FCDs. The hedging premium is statistically and

\footnotetext{
1.44 The lack of link between derivative use and theoretical hedging determinants is most apparent for currency contracts (Howton and Perfect, 1998).

115. An owner of a leveraged firm can, for instance, have incentives to increase the firm's riskiness in order to transfer wealth from bondholders to stockholders (Jensen and Meckling, 1976; Myers, 1977)

116 It has to be underlined that this study is limited to new FCD users only.
} 
economically significant for firms with exposure to exchange rates and is on average 4.87 percent of firm value. Using a similar methodology, Pramborg (2004) shows that for Swedish companies transaction exposure hedging seems to add value whille there is no positive value effect from translation exposure hedging. Empirical evidence on the relation between a firm's currency hedging activities and its exchange risk exposure is provided in Allayannis and Ofek (2001) and Nguyen and Faff (2003). Whereas the former tend to suggest that firms use currency derivatives mainly for hedging - as their use tends to reduce the foreign exchange risk exposure firms face -, the latter find that the impact of FCD usage on exchange rate exposure is generally weak and lacks consistency. Moreover Nguyen and Faff fail to document any relationship between the use of FCDs and long horizon exposure. This last finding may lend support to the hypothesis formulated in section 4.1 according to which horizon exposure captures economic exposure which is difficult to hedge with financial derivatives.

\subsection{Data}

This study analyses, as of year-end 2003 , the determinants of corporate FCD usage and its role in reducing foreign exchange risk exposure for European non-financial firms established in 4 distinctive sample countries: the U.K, Germany, the Netherlands and Belgium. The selection procedure for the sample used in this study encompasses 5 steps. First the constituents of the FTSE 350 , the AEX, the DAX and the BEL 20 are identified. ${ }^{117}$ Next, foreign firms, i.e. firms that do not have their headquarters in the U.K, Germany, the Netherlands or Belgium are excluded from the sample. Since financial firms' business nature causes them to use foreign currency derivatives also for purposes other than hedging, they are as well excluded. As we are interested in the attitude of corporations to foreign exchange risk, firms that are most likely to be exposed to these risks are considered. We therefore investigate whether firms included in the sample have international linkages. As exposures are most obvious for firms that sell abroad through foreign subsidiaries or export operations, reported foreign sales as provided in the notes to the financial statements, are taken as proxies for foreign operations. ${ }^{118}$ Moreover,

\footnotetext{
${ }^{113}$ All firms that are included in these indices are listed and stock price movements are provided by Datastream International.

"18 Firms may also be sensitive to exchange rate movements when utilizing imported inpurs with prices that are influenced by currency fluctuations. They are however only required to disclose information on foreign revenues and don't report useful information on foreign expenses. Consequertly, we concentrate in this paper on the ratio of foreign sales to total sales and assume in to be a reasonable proxy of a firm's international trading involvement.
} 
whenever a firm discloses any other type of information on foreign operations or currency risk in the operational and financial review of its annual report, we include it in the sample. All the final sample-firms meet at least one of the above-mentioned criteria. In a final step, only: firms that have at least 2 consecutive years of weekly stock return data in the Datastream International database between January 2002 and October 2004 are included. The selection procedure provides thus an ultimate sample of 471 European non-financial firms. Weekly and monthly stock price series of individual companies are obtained from Datastream International.

In addition to stock return data, two economic factors are employed when estimating the foreign exchange risk exposure of the sample companies. The proxies used for the market factor are either national Datastream calculated total market return indices or the European Darastream calculated total market return index as provided by Datastream International. The exchange rates are respectively the effective euro exchange rate index ${ }^{119}$ of the ECB, the effective U.K. pound exchange rate index of the Bank of England and the WMR bilateral euro, respectively U.K. pound exchange rates towards the U.S. dollar. ${ }^{120}$ The sample period covers the period January 2002 to October $2004 .{ }^{121}$

A thorough analysis of the 2003 annual reports enables us to collect data on foreign operations and hedging practices of the 471 European non-financial firms. Information on notional as well as fair values of currency hedging positions is sourced from the notes to the annual accounts. As we do not restrict the definition of currency hedging to FCD usage, qualitative and / or quantitative data on any other type of currency risk management activity is as well investigated in financial reports, operational reports, footnotes and notes to the annual accounts. Finally, information on variables that are used in section 4.5 to proxy hedging incentives is likewise obtained from the annual reports.

Panel A of table 4.1 presents an overview on the balance sheet characteristics as well as the annual reports disclosures of foreign operations of Belgian, Dutch and German non-financial firms included in our sample. Out of these 335 firms, 223 (66.6 percent) report the use of $\mathrm{FCDs}{ }^{122}$ If we compare

\footnotetext{
119. The effective U.K. pound (euro) exchange rate index is calculated by geometrically weighting together bilateral exchange rates against sterling for 21 (23) cuirencies where each currency is given a competitiveness weight reflecting that currency's re lative importance in U.K. (EU) trade.

120 All exchange rate series are measured in terms of foreign currency price per unit of donestic currency.

121 A 34-montli return period surrounding the disclosure year 2003 is assumed to provide a good basis to analyze the contempotaneous impact of FCD use on sample firms' foreign currency exposure.

122 Anong all derivatiwe instruments, forwards appear to be the most intensively used by our sample firms: This observation is consistent with previous empirical findings (Bodinar et al, 1998, Bartram et al., 2004).
} 
companies that use FCDs with companies that don'ts we note that FCD users tend to be larger in terms of size ${ }^{123}$, total assets and employees. This finding is in line with the existence of fixed costs related to FCD hedging that act as a barrier to hedging for small firms. Consistent with the financial distress motives to hedge, we observe moreover that debt ratios of FCD hedgers exhibit higher values. However, in contrast to the underinvestment hypothesis (Froot et al., 1993; Allayamis and Weston, 2001; Graham and Rogers, 2000), the observations for the book to market variable tend to suggest that firms that have more investment opportunities use less derivative instruments. Regarding their foreign involvement, approximately 80 percent of the firms in our sample provide precise information on the volume of foreign sales. ${ }^{124}$ Among these firms foreign sales account on average for approximately 34 percent of total sales for FCD users while these sales represent on average only 14 percent of total sales for FCD non-users. The exposure to foreign currency movements through foreign sales and trade seems thus to be an important factor explaining the use of FCDs. Usable information on the volume of foreign debt is only disclosed by 94 companies in the Belgian, Dutch and German firm sample. The ratios of volume of foreign debt to size appear to be larger for firms that use financial derivative instruments.

Equivalent information on U.K. companies is displayed in Panel B of table 4.1. Overall observations are in agreement with those reported above. However, in contrast to panel A, only 3 out of 136 U.K. firms do not declate the use of foreign currency derivatives. ${ }^{125}$ U.K. companies seem moreover to rely on a higher degree of overseas buisiness and to have stronger international linkages than Belgian, Dutch and German companies. ${ }^{126}$ Among FCD hedgers foreign sales amount on average to roughly 60 percent of total sales whereas this percentage approximates 30 percent on average for FCD non-users. ${ }^{127}$ The ratio of foreign debt to size is similarly higher for FCD hedgers compared to companies that don't use FCDs.

\footnotetext{
${ }^{123}$ Size is measured as the sum of the market value of equity and book value of total debt.

124 Wher precise infornation on the volume of foreign sales isn't provided in firms' annual reports, we consider these variables as missing and don't assume them to be zero.

125 These findings are consistent with Marshall's (2000) observations on hedging practices of U.K. firms. He noted indeed that a high proportion of U.K. firms that responded to his quesionnaire ranked foreign exchange risk management as significantly important or most important.

126 Almost all U.K. firms included in our sample disclose precise information on their volume of foreign salles and foreign debt.

${ }^{122}$ Compared to the values reponted for Belgian, Dutch and German firms, the higher values exhibited by the ratio of foreign sales to total sales for U.K. firms may be due to the fact that for U.K. firms foreign sales correspond to sales outside of the U.K. whereas for Belgian, Dutch and German firms, foreign sales correspond to sales outside of the Euro-zone.
} 
Table 4.1: Sample description

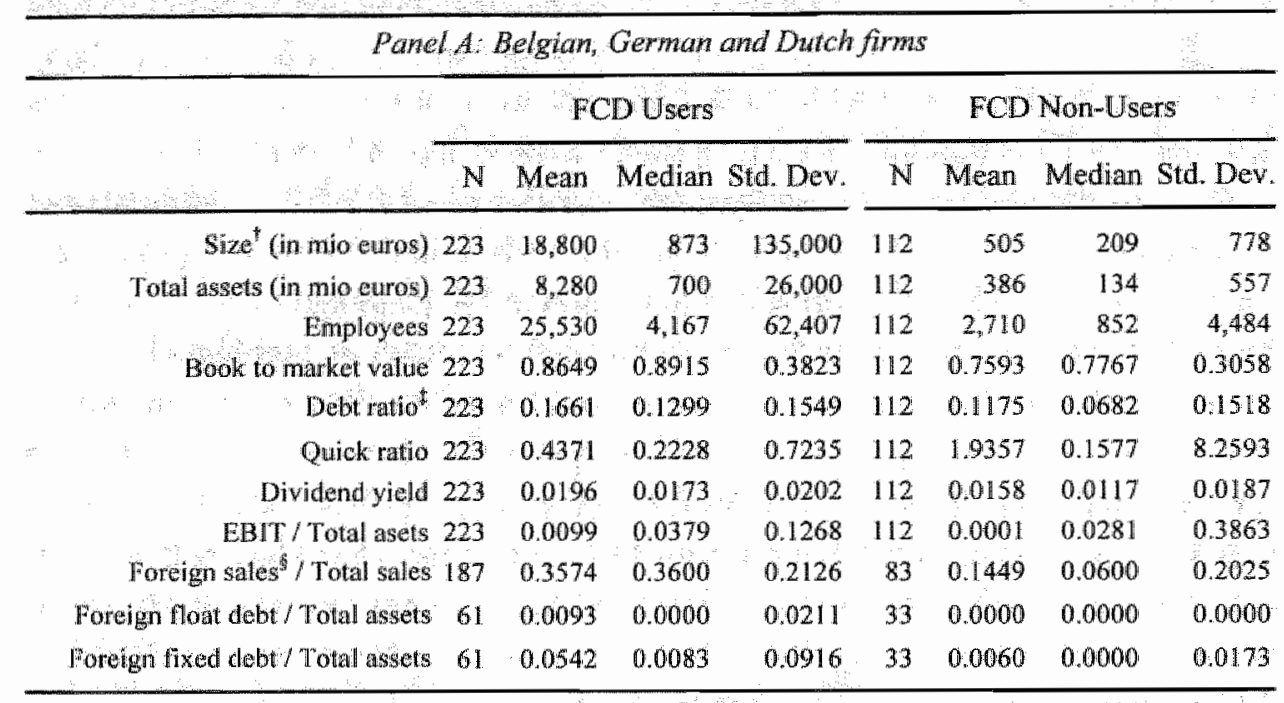

Panel B: UK firms

\begin{tabular}{|c|c|c|c|c|c|c|c|c|}
\hline & \multicolumn{4}{|c|}{$\mathbb{F C D}$ Users } & \multicolumn{4}{|c|}{ FCD Non-Users } \\
\hline & $\mathbf{N}$ & Mean & Mediam & Std. Dev. & $\mathrm{N}$ & Mean & Median & Std. Dev. \\
\hline Size (in mio UK pounds) & 133 & 8,450 & 1,710 & 47,700 & 3 & 367 & 428 & 161 \\
\hline Total assets (in mio UK pounds) & 133 & 16,700 & 1,680 & 103,000 & 3 & 294 & 335 & 149 \\
\hline Employees & 131 & 19,700 & 11,123 & 22,575 & 3 & 1,103 & 988 & 735 \\
\hline Book to market value & 133 & 0.9710 & 0.9419 & 0.4284 & 3 & 0.7870 & 0.6969 & 0.1660 \\
\hline Debt ratio* & 1.33 & 0.2123 & 0.1892 & 0.1670 & 3 & 0.0595 & 0.0291 & 0.0630 \\
\hline Quick ratio & 133 & 0.0633 & 0.0092 & 0.2662 & 3 & 0.0099 & 0.0099 & 0.0010 \\
\hline Dividend yield & 133 & 0.0297 & 0.0321 & 0.0185 & 3 & 0.0000 & 0.0000 & 0.0000 \\
\hline EIT / Tofal asets & 133 & 0.0358 & 0.0403 & 0.0687 & 3 & 0.0634 & 0.0974 & 0.0821 \\
\hline Foreign sales ${ }^{\text {IV }} /$ Total sales & 133 & 0.6065 & 0.6902 & 0.2709 & 3 & 0.2991 & 0.2991 & 0.3614 \\
\hline Foreign float debt / Total assets & 13 & 0.0883 & 0.0723 & 0.0844 & 3 & 0.0440 & 0.0000 & 0.0762 \\
\hline Foraign lixed debt / Total assets & 131 & 0.0878 & 0.0357 & 0.1083 & 3 & 0.0000 & 0.0000 & 0.0000 \\
\hline
\end{tabular}

The total sample of 335 Belgian, German and Dutch firms as well as the sample of 136 U.K. firms is subdivided between FCD users and FCD non-users. Reported data are obtained of the 2003 annuall reports. ${ }^{\dagger}$ Size is measured as the sum of market value of equity and book value of debt. * Leverage is defined as the ratio of long term debt to total assets. Foreign sales for Belgian, Dutch and German companies are sales to non-euro zone countries (Sales to non-euro zone countries are sometimes approximated by sales to non-European countries). ${ }^{\$ \delta}$ Foreign sales for U.K. companies are sales to non-U.K. countries. 


\subsection{Empirical evidence on the factors determining corporate foreign derivative usage}

Consistent with Allayannis and Ofek (2001), we examine the decision and the level of FCD usage in a two-step procedure originally suggested by Cragg (1971). We explain thus separately the firm's choice to hedge using FCDs - or not - and the firm's decision of how much to hedge with these instruments. ${ }^{128}$

To model the decision to hedge - or not - we use a binary measure of FCD usage. Companies that use FCDs are assigned a value of 1 while all other firms are assigned a value of zero. Variables that have been found to make cash flow volatility costly for companies (see, e.g., Geczy et al., 1997; Schrand and Unal, 1998) are chosen to explain the decision or not to use FCDs. Specifically, to test theories of hedging related to financial distress costs motives, we use leverage ${ }^{129}$. measured as the ratio of total debt to total assets -, the ratio of EBIT to total interest expenses and the ratio of EBIT to total assets. Agency costs related incentives to hedge are tested using the ratio of book to market value. Firms with lower book to market ratios are expected to have greater investment opportunities. These firms are potentially facing higher underinvestment costs and are expected, hence, to hedge more. To verify whether liquidity may serve as a hedging substitute, we add the quick ratio to our model. Nance et al.'s (1993) argument that firms retain dividends to reduce their need to hedge is also considered. The tax incentive to hedge is verified by the inclusion of a tax dummy variable that is equal to 1 if the firm has tax-loss carryforwards and 0 otherwise. We test the managerial risk aversion hypothesis by the inclusion of a variable that measures the option holdings of CEOs. ${ }^{130,131}$ The information asymmetry hypothesis is verified by adding the log of the number of analysts that follow the company. The log of the sum of the market value of equity and book value of debt is used to proxy firm size. The tatios of foreign sales to total sales as well as of total foreign debt to firm size are employed to measure the firm's international linkages.

\footnotetext{
12: We presume here that firms use FCDs primarily for hedging purposes - as elaimed in their annual reports. This assumption enables us to test the optimal hedging theories described in section 4.2. However the question, whether firms are effectively using FCDs for hedging - versus speculation motives will be empirically tested in section 4.5 .

${ }^{729}$ According to Stulz (1996), Ross (1997) and Leland (1998), leverage and hedging practices may also be positively correlated due to the positive effect of hedging on firms' debt capacity. This increased debt capacity may result in an effective increase in leverage, thus increasing interest deductions, decreasing tax liabilities and finally increasing firm value.

${ }^{130} \mathrm{CEO}^{\prime} \mathrm{s}$ option holdings are calculated as the ratio of the number of options held by CEOs multiplied by the year-end price of the share to the sum of the market walue of equity and book value of debt.

${ }_{131}$ The share holdings of CEOs have also been considered. Results are weaker but consistent.
} 
The first two columns of table 4.2 present the results of the binomial probit model estimated using all firms in the sample. In line with previous studies, we observe that foreign involvement, measured as the percentage of foreign sales and size are significantly positively related to the decision to use FCDs. These results are in contradiction with the bankruptcy costs and informational asymmetries motives to hedge that predict that small firns have a greater incentive to hedge. They lend nevertheless support to the existence of economies of scale in hedging. These economies of scale facilitate the justification of hedging programs when the firm is larger and the volume of foreign activity is sufficiently large to justify the costs (Martin and Mauer, 2004). Additionally, the significance of the positive tax dummy $^{132}$ coefficient in model 1 seems to confirm the convexity-based tax incentive to hedge. The statistically significant positive coefficient of the dividend yield factor indicates moreover that retained dividends may be regarded as a substitute for hedging. The four last columns of table 4.2 describe the estimation output when additional explanatory variables are progressively added to the model. ${ }^{133}$ Generally speaking, most results of column 1 and 2 are confirmed. Furthermore, the volume of foreign debt is found to be a strong incentive to hedge for European firms. ${ }^{134}$ These results are in strong opposition with the expectations described in Geczy et al. (1997) and empirical evidence presented on U.S. multinationals by Elliott et al. (2003). They support however evidence provided by Fok et al. (1997) that natural hedges - like the use of foreign debt for net-exporting firms - complement and don't substitute for the use of FCDs in reducing currency risk. In model 6 , the residuals of the regression of the ratio of foreign debt to size against the ratio of foreign sales to total sales and size replace the raw ratios of foreign debt to size in orden to avoid the multicolinearity problems arising between these variables. The contemporaneous inclusion of all three variables enables us to identify among these variables the stronger incentives to hedge. Results suggest that the decision to use FCDs depends more on the percentage of foreign sales and the size of the firm than on the importance of foreign debt. In contrast to previous models, model 6 confirms moreover the financial distress hypothesis. Highly leveraged firms are shown to be significantly more inclined to hedge. In contrast, no evidence is found in support of liquidity acting as a hedging substitute. Similarly, the ratio of EBIT to total assets, the number of analysts and the options held by CEOs are found to have no influence on firms' decision to use FCD instruments.

\footnotetext{
1:32 The tax durmy wariable is equal to $\mathbb{1}$ if the firm has tax loss carryforwards; 0 otherwise.

13. Due to the strong correlation between some explanatory variables the inclusion of additional explanatory variables may require the exclusion of previously incorporated explanatory variables.

i.34 A priori, foreign debt may be regarded as an operational hedging strategy for net exporting firms. In contrast foreign debt emphasizes the foreign currency risks importing firms are facing.
} 


\section{Table 4.2: Factors explaining the decision to use FCDs}

\begin{tabular}{|c|c|c|c|c|c|c|}
\hline \multirow{2}{*}{ Independemt variables } & \multicolumn{6}{|c|}{ Dependent variable: Use FCD $=1$ otherwise $=0$} \\
\hline & Model 1 & Model 2 & Modiel 3 & Model 4 & Model 5 & Model 6 \\
\hline \multirow{2}{*}{ Intercept } & $-9.4991^{\text {* }}$ & $-8.2269 * * *$ & $-9.6051^{* * * *}$ & $.8 .3984 * *$ & $-10.5028^{*}$ & $-9.4717 * * *$ \\
\hline & -5.0271 & -4.2322 & -4.0418 & -3.3609 & -17487 & -2.9850 \\
\hline \multirow{2}{*}{$\begin{array}{r}\text { Foreign Siales }{ }^{a} / \text { Total } \\
\text { Sales }\end{array}$} & $3.1412^{* * * *}$ & $3.2397^{* * * * * * * 1 *}$ & $3.6836 * * *$ & & & $5.0068^{* * * * * *}$ \\
\hline & 5.9489 & 48820 & 4.7586 & & & 3.4104 \\
\hline \multirow[t]{2}{*}{$\operatorname{Ln}($ Size $)$} & $0.4131 * *$ & $0.3591^{*} *$ & $0.4017 *$ & $0.4096^{*}$ *水* & $0.5108^{*}$ & $0.3470 *$ \\
\hline & 4.4191 & 3.6626 & 3.5005 & 3.2461 & 1.6773 & 2.1564 \\
\hline \multirow{2}{*}{ Long term debt / Size } & 0.9497 & 0.7980 & 0.9826 & & & $3.8166^{*}$ \\
\hline & 1.1166 & 0.3568 & 0.9143 & & & 1.8783 \\
\hline \multirow{2}{*}{ Quick ratio } & 0.2710 & & 0.4887 & -0.0183 & 0.5763 & 0.4981 \\
\hline & 1.1679 & & 1.4197 & -0.4268 & 0.9540 & 0.7043 \\
\hline EBIT / Interest & & 0.0013 & & & & \\
\hline Expenses & & 0.3757 & & & & \\
\hline \multirow{2}{*}{ Market to Book Value } & 0.5747 & 0.4975 & 0.7709 & -0.0214 & 0.7416 & 0.6033 \\
\hline & 1.4587 & 1.1774 & 1.5971 & -0.0401 & 0.9064 & 0.8194 \\
\hline \multirow{2}{*}{ Dividend Yield } & $10.8939^{*}$ & 8.2903 & 8.5212 & 15.8340 & 30.0315 & $23,9608^{*}$ \\
\hline & 1.7036 & 1.1739 & 1.1019 & 1.5357 & 1.4490 & 1.7274 \\
\hline \multirow{2}{*}{ Tax convexity } & 0.5129 * * & 0.3975 & 0.3675 & $0.6198^{*}$ & 0.2166 & $0.8533^{*}$ \\
\hline & 2.1805 & 1.3368 & 1.1602 & 1.7278 & 0.4071 & 1.8461 \\
\hline EBIT/Total Assets & & $\begin{array}{l}-0.4481 \\
-0.8101\end{array}$ & $\begin{array}{r}-0.6355 \\
-0.7386\end{array}$ & & & \\
\hline \multirow{2}{*}{ Ln (\# of analysts) } & & & & & 0.3052 & \\
\hline & & & & & 1.0541 & \\
\hline Managerial options & & & $\begin{array}{r}12.3101 \\
0.6971\end{array}$ & & & \\
\hline \multirow[t]{2}{*}{ Foreign debt / Size ${ }^{b}$} & \multirow{2}{*}{\multicolumn{4}{|c|}{$\begin{array}{r}13.3336 * * \\
3.1456\end{array}$}} & $15.6878 * *$ & $6.3932^{\mathrm{e}}$ \\
\hline & & & & & 2.3205 & 1.2697 \\
\hline Observations & 406 & 406 & 204 & 228 & 142 & 228 \\
\hline Likelihood & -31.5416 & -57.7185 & -47.6440 & -47.0471 & -118.3864 & -30.8849 \\
\hline Mc-Fadden $\mathrm{R}^{2}$ & $45.42 \%$ & $45.53 \%$ & $49.05 \%$ & $47.40 \%$ & $52.48 \%$ & $57.89 \%$ \\
\hline
\end{tabular}

This table presents logit regression estimates of the relation between the likelihood that a firm hedges foreign currency exposure with FCDs and proxies for incentives to hedge respectively proxies for complement or substitute hedging activities, ***,*** denote significance at the 10,5 and 1 percent levels, respectively. $t$-statistics are in italics.

"Foreign sales for Belgian, Dutch and German companies are sales to non-euro zone countries (Sales to non-euro zone countries are sometimes approximated by sales to non-European countries). Foreign sales for U.K. companies are salles to non-U.K. countries.

"Size is measured as the sum of market value of equity and book value of debt.

"Tax convexity is measured by a dummy variable that is assigned the value 0 if the furm has tax loss canry forwards and 0 otherwise.

'Managerial options are calculated as the ratio of CEO's option holdings multiplied by the yearend price of the firm share to the sum of the market value of equity and book value of debt:

"In model 6 the ratio foreign debt to size is replaced by the residuals of the regression of the ratio of foreign debt to size againust the ratio of foreign sales to total sales and size. 
Table 4.3: Factors explaining the level of FCD use

\begin{tabular}{|c|c|c|c|c|c|c|}
\hline \multirow[b]{2}{*}{ Independent varibles } & \multicolumn{6}{|c|}{ Dependent variable: $\mathrm{FCD}^{\mathrm{e}} /$ Total Assets } \\
\hline & Model I & Model 2 & Model 3 & Model 4 & Model 5 & Model 6 \\
\hline \multirow[b]{2}{*}{$\begin{array}{r}\text { Foreign Sales / Total } \\
\text { Sales }\end{array}$} & $\begin{array}{l}-0.1778^{*} \\
-1.6751\end{array}$ & $\begin{array}{l}-0.1604 \\
-1.2809\end{array}$ & $\begin{array}{l}-0.1908 \\
-1.4096\end{array}$ & $\begin{array}{l}-0.1442 \\
-1.0052\end{array}$ & $\begin{array}{r}-0.1539 \\
-0.7731\end{array}$ & $\begin{array}{l}-0.2066 \\
-1.2398\end{array}$ \\
\hline & $\begin{array}{r}0.0644^{* * *} \\
2.0980\end{array}$ & $\begin{array}{r}0.0696 * \\
2,0154\end{array}$ & $\begin{array}{l}0.0557 \\
1.5291\end{array}$ & & & $\begin{array}{l}0.0476 \\
1.1720\end{array}$ \\
\hline \multirow[b]{2}{*}{ Long term debt/Size } & $\begin{array}{c}0.0124 \\
2.3347\end{array}$ & $\begin{array}{c}0.0123^{*} \\
1.9377\end{array}$ & $\begin{array}{r}0.0125 * \\
1.8779\end{array}$ & $\begin{array}{l}0.0115 \\
1.7289\end{array}$ & $\begin{array}{l}0.0101 \\
1.0050\end{array}$ & $\begin{array}{l}0.0131 \\
1.5298\end{array}$ \\
\hline & $\begin{array}{l}0.0799 \\
1.2958\end{array}$ & $\begin{array}{l}0.0475 \\
0.7113\end{array}$ & $\begin{array}{l}0.0757 \\
1.0443\end{array}$ & & & $\begin{array}{l}0.1038 \\
1.3704\end{array}$ \\
\hline \multirow[b]{3}{*}{ Market to Book Value } & $\begin{array}{l}-0.0100 \\
-0.5642\end{array}$ & & $\begin{array}{l}-0.0169 \\
-0.8289\end{array}$ & $\begin{array}{l}-0.0002 \\
-1.1047\end{array}$ & $\begin{array}{r}-0.0875 * * \\
-2.1295\end{array}$ & $\begin{array}{l}-0.0705^{*} \\
-1.6772\end{array}$ \\
\hline & & $\begin{array}{l}-0.0003 \\
-1.3369\end{array}$ & & & & \\
\hline & $\begin{array}{r}0.0519^{* * *} \\
2.0616\end{array}$ & $\begin{array}{c}0.0649^{*} \\
2.4163\end{array}$ & $\begin{array}{r}0.0541 * \\
1.9646\end{array}$ & $\begin{array}{l}0.0450 \\
1.6157\end{array}$ & $\begin{array}{l}0.0398 \\
1.3799\end{array}$ & $\begin{array}{l}0.0509 \\
1.6007\end{array}$ \\
\hline Dividend Yield & $\begin{array}{l}-0.3012 \\
-0.6748\end{array}$ & $\begin{array}{l}-0.1432 \\
-0.2931\end{array}$ & $\begin{array}{l}0.0684 \\
0.1321\end{array}$ & $\begin{array}{l}-0.1411 \\
-0.2408\end{array}$ & $\begin{array}{l}0.0922 \\
0.1375\end{array}$ & $\begin{array}{r}-0.0301 \\
-0.0334\end{array}$ \\
\hline Tax convexity ${ }^{\circ}$ & $\begin{array}{c}0.3068^{*} \\
2.1102\end{array}$ & $\begin{array}{c}0.4751 \\
2.6081\end{array}$ & $\begin{array}{r}0.5911 * * * \\
2.9675\end{array}$ & $\begin{array}{r}0.7193 * * * \\
3.0626\end{array}$ & $\begin{array}{r}1.0373 * * * \\
3.7133\end{array}$ & $\begin{array}{r}0.6547 \\
2.4633\end{array}$ \\
\hline EBIT / Total Assets & & $\begin{array}{c}-0.0909 \% \\
-1.9313\end{array}$ & $\begin{array}{r}-0.1455^{*} \\
-2.4556\end{array}$ & & & \\
\hline Ln (H of analysts) & & & & & $\begin{array}{l}0.0033 \\
0.1910\end{array}$ & \\
\hline Managerial options ${ }^{d}$ & & & $\begin{array}{l}1.3548 \\
0.9623\end{array}$ & & & \\
\hline Foreign debi / Size & & & & $\begin{array}{r}0.1474 * * \\
1.9974\end{array}$ & $\begin{array}{r}0.2248 * * * \\
2.7895\end{array}$ & $\begin{array}{r}0.1838^{* 1} \\
1.7439\end{array}$ \\
\hline Observations & 290 & 290 & 204 & 192 & 142 & 192 \\
\hline Likelihood & 157.2689 & 120.3224 & 109.9256 & 111.5578 & 86.7286 & 88.3476 \\
\hline Adjusted $\mathbb{R}^{4}$ & $6.27 \%$ & $8.24 \%$ & $7.24 \%$ & $6.31 \%$ & $11.78 \%$ & $7.46 \%$ \\
\hline
\end{tabular}

This table presents OLS regression estimates of the relation between the extent of utilization of FCDs and proxies for incentives to hedge respectively proxies for complement or substitute hedging activities. $*$ denote significance at the 10,5 and 1 percent levels, respectively. $t-$ statistics are in italics.

iroreign sales for Belgian, Dutch and German companies are sales to non-euro zone countries (Sales to non-euro zone countries are sometimes approximated by sales to non-European countries). Foreign sales for U.K. companies are sales to non-U.K. countries.

Size is measured as the sum of market value of equity and book value of debt.

"Tax convexity is measured by the ratio of tax loss carry forwards to total assets.

'Managerial options are calculated as the ratio of CEO's option holdings nuultiplied by the yearend price of the firm share to the sum of the market value of equity and book value of debt.

" $\mathrm{CD}$ usage is approximated by the total notional value of foreign currency derivative contracts.

In model 6 the ratio foreign debt to size is replaced by the residuals of the regression of the ratio of foreign debt to size against the ratio of foreign sales to total sales and size. 
The determinants of the extent of FCD usage are obtained by estimating a regression where we use the relative importance of the total notional value of FCD contracts to firms' total assets as dependent variable. ${ }^{135}$ The sample is restricted to European non-financial firms that do use FCD contracts and provide useful information on the notional values of their foreign currency derivative holdings ( 290 firms $^{136}$ ). In line with our results of table 4.2 , the first 2 columns of table 4.3 reveal that international trade linkages - approximated by the ratio of foreign sales to total sales - and size are significantly positively related to the level of FCD usage. We note however that empirical findings reject the hypothesis that firms with more growth options in their investment opportunity set - approximated by firms with low book to market ratios - suffer more from underinvestment costs and hedge more. To test in how far a convex tax schedule determines the hedging practices of European firms, the ratio of tax loss carryforwards to total assets is also included in the regression model. The significance of the positive tax coefficient strongly confirms the convexity-based tax incentive to hedge. Consistent with the financial distress costs motives to hedge, we find furthermore that less profitable firms are more inclined to use FCDs than highly profitable ones. Results obtained through the progressive inclusion of additional explanatory variables in our model don't contradict those reported in columns 1 and $2 .^{137}$ As expected, we observe in model 4,5 and 6 that the volume of foreign debt strongly determines the extent of $\mathrm{FCD}$ hedging by European firms. ${ }^{138}$ In addition, the extent of FCD usage is shown to be negatively related to liquidity which is consistent with liquidity serving as a hedging substitute. We find however no evidence that retained dividends could similarly serve as a hedging substitute. Similarly, neither the information asymmetry nor the managerial risk aversion hypothesis aren't empirically confirmed. While the pasitive sign of the debt ratio coefficient is consistent with financial distress costs related incentives to hedge, evidence in support of this

\footnotetext{
${ }^{135}$ As stressed in Allayannis and Ofek (200》) and Craham and Rogers (2000), the fat that firms net positions in individual currencies before disclosing them in the notes of their annual reports may introduce a bias in our measurement of the total notional values of the derivative contracts. However, we believe that our observations nevertheless provide valuable insights in the hedging practices of our sample firms.

${ }^{136} 66$ firms of our sample state in their annual report that they use FCDs for hedging purposess but don"t disclose the notional values of the $\mathrm{FCD}$ contracts. These values are either aggregated with other derivative holdings (e.g. interest rate swaps, commodity derivatives) or missing.

${ }^{137}$ Due to the strong correlation between some explanatory variables the inclusion of additional explanatory variables may require the exclusion of previously incorporated explanatory variables.

${ }_{138}$ For model 6, the ratio of foreign debt to the sum of the market value of equity and book value of debt is first regressed to the ratio of foreign sales to totall salles and to the log of the sum of the market value of equity and book value of debt. The residuals of this regression are consecutively included in model 6.
} 
hypothesis is overall statistically weak. These results are in line with Graham and Rogers (2000) and Allayannis and Ofek (2001).

\subsection{Empirical evidence on the impact of corporate derivative usage on foreign exchange risk exposure}

Following the extensive literature on foreign exchange rate exposure ${ }^{139}$, we estimate the firm-specific foreign exchange risk exposure - defined as the effect of exchange rate changes on the value of a firm in excess of the global market's reaction to foreign exchange rate movements - with the following augmented market model:

$$
R_{i, i}=\alpha_{i}+B_{i} R_{m, t}+\gamma_{i} X_{i}+\varepsilon_{i, 1}
$$

where $R_{i, i}$ designates the total return of firm $i$ in period $t, R_{m, t}$ the Datastream calculated European total market index return in period $t, B_{i}$ firm $i$ 's return sensitivity to market fluctuations, $X_{t}$ the rate of return on the trade-weighted effective euro (U.K. pound) exchange rate index - measured as the foreign currencies' exchange price of one euro (respectively one U.K. pound),$- \psi_{i}$ firm $i$ 's exposure to this exchange rate index independent of the effect these variations have on the overall market, and $\varepsilon_{i, r}$ denotes the white noise error term. ${ }^{140}$ Given the definition of our exchange risk factor, a positive exchange rate movement corresponds to an appreciation of the domestic currency (euro or U.K. pound). As we expect exporters to be hurt by an appreciation of their home-currency and importers to benefit from a similar positive exchange rate change, the $\gamma_{i}$ coefficient should be negative for net-exporters and positive for net-importers. ${ }^{141}$ Equivalently, if a firm has net exposed foreign denominated assets, it should suffer from a strengthening home currency, producing a negative exposure effect (i.e., the stock return should decrease in response to a positive exchange rate movement). On the

\footnotetext{
134. See for instance the pioneer studies by Adler and Dumas (1984) and Jorion (1990).

${ }^{140}$ Including the stock market return in Eq. (4.1) dramatically reduces the residual variances of the regression. Moreover, the market retum implicitly controls for the value-relevant macroeconomic factors that are correlated with the exchange rates. It is, however, important to stress that according to Eq. (4.1), the empirical result of having zero exposure does not imply that the firm's value is independent of exchange rates, rather, a zero firm-specific exposure iniplies that the firm value is affected to the same degree as the market portfolio:

"4l The sign of the currency exposure becomes more ambiguous for a company that has importing as well as exporting activities. In this particular situation, the elasticity of the firm's demand for foreign goods relative to the elasticity of the foreign market's demand for the firm's goods have to be taken into account (Adler and Dumas, 1984; He and Ng, 1998).
} 


\section{Table 4.4: Descriptive statistics for FX exposure coefficients estimated using weekly data}

\begin{tabular}{|c|c|c|c|c|c|c|}
\hline \multirow[t]{2}{*}{ 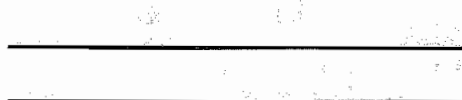 } & \multicolumn{3}{|c|}{ FCD Users } & \multicolumn{3}{|c|}{ FCD Non-Users } \\
\hline & Mean & Median & Stal. Dev. & Mean & Median & Std. Dev \\
\hline \multicolumn{7}{|c|}{ Panel A: Exposwre to the trade-weighted exchange rate index } \\
\hline Intercept & -0.0007 & 0.0004 & 0.0056 & -0.0005 & 0.0003 & 0,0063 \\
\hline European Stock Market & 0.8865 & 0.7534 & 0.6227 & 0.7597 & 0.6841 & 0.5498 \\
\hline TW Exchange Rate Index & -0.9676 & -0.7054 & 1.1674 & -1.1839 & -1.0448 & 1.0969 \\
\hline tof positive / negative FX exposures & $291 / 66$ & & & $105 / 1$ & & \\
\hline$\%$ of significant FX exposures & $38.10 \%$ & & & $38.79 \%$ & & \\
\hline \multicolumn{7}{|c|}{ Test for the difference in market risk between FCD Users ( 356 firms) and Non-Users (115 firms) } \\
\hline Equality of mean & $1.9588 *$ & 0.0507 & & & & \\
\hline Equality of median & 1.0868 & 0.2972 & & & & \\
\hline \multicolumn{7}{|c|}{ Test for the difference in FX exposure between FCD Users (356 firms) and Non-Users ( 115 firms) } \\
\hline Equality of mean & $1.7589 *$ & 0.0792 & & & & \\
\hline Equality of median & $5.4056 *$ & 0.0201 & & & & \\
\hline
\end{tabular}

Panel B: Exposwre to the bilateral US dollar exchange rate

\begin{tabular}{|c|c|c|c|c|c|c|}
\hline Intercept & 0.0000 & 0.0009 & 0.0054 & -0.0001 & 0.0006 & 0.0065 \\
\hline European Stock Market & 0.9635 & 0.8284 & 0.6795 & 0.8037 & 0.6904 & 0.5866 \\
\hline US\$ Exchange rate & -0.8208 & -0.7182 & 0.6384 & -0.6841 & -0.6484 & 0.5968 \\
\hline tof positive / negative $\mathrm{FX}$ exposures & $333 / 24$ & & & $109 / 7$ & & \\
\hline$\%$ of significant $\mathrm{FX}$ exposures & $54.19 \%$ & & & $43.97 \%$ & & \\
\hline \multicolumn{7}{|c|}{ Test for the difference in market risk between FCD Users (356 fims) and Non-Users (115 firns) } \\
\hline Equality of mean & $22722^{* *}$ & 0.0235 & & & & \\
\hline Equality of median & 1.0866 & 0.2970 & & & & \\
\hline \multicolumn{7}{|c|}{ Test for the difference in FX exposure between FCD Users ( 356 firms) and Non-Users (115 firms) } \\
\hline Equality of mean & $2.0359 * *$ & 0.0423 & & & & \\
\hline Equality of median & $3.0143 *$ & 0.0825 & & & & \\
\hline
\end{tabular}

This table reports cross-sectional summary statistics of the parameters estimated from the following regression model for the period from January 2002 to October 2004 using maximum likelihood:

$$
\begin{aligned}
& R_{i, t}=\alpha_{i}+b_{i} R_{m, i}+y_{i} \theta_{t}+\varepsilon_{i, t} \\
& \text { with } \quad \varepsilon_{i, s}=\mu_{i, t} *\left(h_{i, d}\right)^{l / 2} \quad h_{i, t}=\delta_{i}+\tau_{i} \varepsilon_{i, r-t}^{2}+v_{i} h_{i, t-1}
\end{aligned}
$$

where $R_{i, t}$ designates the total return of firm $i$ in period $t, R_{k, y}$ the Datastream calculated European totall stock market return in period $t, B_{i}$ firm i's return sensitivity to market fluctuations, $\theta_{t}$ the movement in the trade-weighted euro (U.K. pound) exchange rate index - Panel A -, respectively the movement in the bilateral euro (U.K. pound) / U.S. dollar exchange rate - Panel B $-\gamma_{i}$ firm $i s$ exposure to these exchange rate movements, $h_{i, d}$ denotes the conditional variance of the residuals; $\delta_{i,} \pi_{i}$ and $v_{i}$ unknown parameters; and $\mu_{i, 1}$ represents the white noise error term. The GARCH (1, 1) specification is added to Eq. (4.1) to take the heteroskedasticity of weekly returns into account. ***** denote significance at the 10,5 and 1 percent levels, respectively. $t$ statistics are in italics. ${ }^{\dagger}$ The equality of mean hypothesis is tested using a t-test verifying whether the variability between the sample means (between groups) is the same as the variability within any subgroup. The equality of median hypothesis is tested using chi-squared rank-based ANOVA test based on the comparison of the number of observations above and below the overall median in each subgroup. 


\section{Table 4.5: Descriptive statistics for FX exposure coefficients estimated using monthly data}

\begin{tabular}{|c|c|c|c|c|c|c|}
\hline & \multicolumn{3}{|c|}{ FCD Users } & \multicolumn{3}{|c|}{ FCD Non-Users } \\
\hline 8 & Mean & Median & Std. Dev. & Mean & Median & Std. Dev. \\
\hline \multicolumn{7}{|c|}{ Panel A Exposure to the trade-weighted exchange rate index } \\
\hline Intercept & 0.0034 & -0.0011 & 0.0219 & -0.0010 & 0.0018 & 0.0306 \\
\hline European Stock Market & $\mathbb{1 . 1 8 8 1}$ & 0.9869 & 0.8436 & 1.1232 & 1.0112 & 0.8905 \\
\hline TW Exchange Rate Index & 1.6125 & $-1,0314$ & 2.1126 & -2.2561 & -1.5550 & 2.3371 \\
\hline of positive / negative RX exposures & $295 / 63$ & & & $102 / 14$ & & \\
\hline$\%$ of significant $F X$ exposures & $42.18 \%$ & & & $39.66 \%$ & & \\
\hline \multicolumn{7}{|c|}{ Test for the difference in market risk between FCD Users (356 firms) and Non-Users (115 firms) } \\
\hline Equality of mean & 0.7072 & 0.4798 & & & & \\
\hline Equality of median & 0.0576 & 0.8104 & & & & \\
\hline \multicolumn{7}{|c|}{ Test for the difference in FX exposure between FCD Users (356 firms) and Non-Users (115 firms) } \\
\hline Equality of mean & $.7768 * * *$ & 0.0057 & & & & \\
\hline Equality of median & $2726 * * *$ & 0.0014 & & & & \\
\hline \multicolumn{7}{|c|}{ Panel B. Exposure to the bilateral US dollaw exchange rate } \\
\hline Intercept & 0.0004 & 0.0023 & 0.0211 & 0.0003 & 0.0027 & 0.0312 \\
\hline European Stock Market & 1.2332 & 1.0089 & 0.8492 & 1.1311 & 1.0307 & 0.9274 \\
\hline US\$ Exchange rate & -1.1762 & -1.0035 & 0.9654 & -1.1295 & -0.9478 & 1.1540 \\
\hline tof positive / negative $F X$ exposures & $334 / 24$ & & & $102 / 14$ & & \\
\hline$\%$ of significant $\mathrm{X}$ exposures & $61.90 \%$ & & & $52.59 \%$ & & \\
\hline \multicolumn{7}{|c|}{ Test for the difference in market risk between FCD Users (356 firns) and Non-Users ( 115 firms) } \\
\hline Equality of mean & 1.0969 & 0.2733 & & & & \\
\hline Equality of median & 0.2058 & 0.6500 & & & & \\
\hline \multicolumn{7}{|c|}{ Test for the difference in FX exposure between FCD Users ( 356 firms) and Non-Users ( 115 firms) } \\
\hline Equality of mean & 0.4303 & 0.6672 & & & & \\
\hline Equality of median & 0.1826 & $0.669 \rrbracket$ & & & & \\
\hline
\end{tabular}

This table reports cross sectional summary statistics of the parameters estimated from the following regression model for the period from January 2002 to October 2004 using ordinary least squares:

$$
R_{i, t}=\alpha_{i}+B_{i} R_{m, t}+\gamma_{i} \theta_{i}+B_{i, t}
$$

where $R_{t, s}$ designates the total return of firm $i$ in period $t, R_{m, s}$ the Datastream calculated European total stock market return in period $t_{0} \theta_{i}$ firm is return sensitivity to market fluctuations, $\theta_{i}$ the movement in the trade-weighted euro (U.K. pound) exchange rate index - Panel A-, respectively the movement in the bilateral etro (U.K. pound) / U.S. dollar exchange rate - Panel $\mathrm{B}-, \gamma_{i}$ firm $i$ 's exposure to these exchange rate movements and $\varepsilon_{i, y}$ represents the white noise error term.

*, **** denote significance at the 10,5 and 1 percent levels, respectively. t-statistics are in italics.

The equality of mean hypothesis is tested using a t-test werifying whether the variability between the sample means (between groups) is the same as the variability within any subgroup.

* The equality of median hypothesis is tested using a Chi-squared rank-based ANOVA test based on the comparison of the number of observations above and below the overall median in each subgroup. 
opposite, if a firm has net exposed foreign denominated liabilities, then an appreciation of the domestic currency should benefit it (i.e., the stock return should increase in response to a positive exchange rate movement).

In order to check the robustness of our results to the use of a different source of exchange rate risk, we also perform the analysis using the bilateral U.S. dollar exchange rate vis-â-vis the euro (respectively the U.K. pound) instead of utilizing the trade-weighted currency indices. While the trade-weighted exchange rate indices translate, in a more efficient way, alt the exchange rate uncertainties influencing European firms in their trading relationships with different countries, the bilateral U.S. dollar exchange rates have the advantage of not being affected by the potential divergent off-setting effects between multiple currencies (Miller and Reuer, 1998). Results for both exchange risk factor specifications will be simultaneously presented in the rest of this chapter. We will empirically verify that the choice of index doesn't lead to major differences in the conclusions of our analysis.

In consistence with Allayannis and Ofek (2001), we use a 3-year return period surrounding the year in which annual reports are collected to measure the contemporaneous impact of FCD use on firms' exchange rate exposures. ${ }^{1 / 2}$ The regression estimates obtained using weekly data are presented in table 4.4. First, we note that the majority of our European sample firms are facing a negative currency exposure. ${ }^{143}$ This implies that most conpanies are negatively affected by an appreciating domestic currency and behave like net-exporters. European firms are, moreover, found to be more exposed to the changes in the bilateral U.S. dollar exchange rate vis-à-vis their domestic currency than to the movements of their currency's trade-weighted exchange rate index. Regarding both exchange risk factors, it appears that among FCD users a slightly higher percentage of firms is significantly affected by currency fluctuations than anong FCD non-users. This doesn't necessarily imply that firms use FCDs to speculate but may simply translate the observation made above that FCD users have stronger international linkages

\footnotetext{
142 Following Allayannis and Ofek (2001) we check the robustness of our results to an alternative time interval -2 years - surrounding the year in which the annul reports are collected Overall the modification of the estimation period doesn't affect the findings that are presented in this paper. Results are deliwered from the authors upon request.

${ }^{143}$ At first glance these results appear to be in contrast to previous findings reported in chapter 3 of this thesis. We have to stress, however, that both estimations of European firms' currency risk exposures thawe been performed on distinctive sample periods corresponding both to different economic episodes and to distinctive currency fuctuation patterns. The results presented in this section provide, hence, further evidence in support of the time-warying behavior of exposure at the indiwidual firm level which has already been empirically highlighted in section $3.3,2$.
} 
than companies that do not use FCDs. ${ }^{144}$ The difference in market risk and foreign currency exposure between both groups of companies is specifically examined by testing the null hypothesis of equality of mean (median) exposure values between both sub-samples. Results of these tests suggest that the average market beta of FCD users is statistically higher than the average market beta observed for FCD non-users. Regarding foreign currency exposure coefficients, it is interesting to note that FCD non-users show a statistically stronger negative mean exposure to fluctuations in the trade-weighted exchange rate index, whereas FCD users seem on average to be more strongly negatively affected by U.S. dollar movements. ${ }^{145}$

The monthly results of the augmented market model regression (Eq. 4.1) are displayed in table 4.5 . In line with previous results highlighted in chapter 3 , our findings show that exchange risk exposure becomes statistically more evident when increasing the observation horizon. Approximately 42 percent ( 40 percent) of FCD hedgers (non-hedgers) appear to be significantly influenced by movements in the trade-weighted exchange rate index while roughly 62 percent (52 percent) are influenced by fluetuations in the U.S. dollar. Whereas FCD users as a group still count the higher percentage of firms with significant exposures, we observe nevertheless that non-users show consistently stronger negative mean and median exposures to movements in the trade-weighted exchange rate index. Finally, consistent with weekly results, most European sample firms appear to benefit (suffer) from an appreciation (depreciation) of their home currency.

It is a common belief that exchange risk exposure is created via foreign operations and may be reduced through the implementation of financial hedging strategies. However, foreign exchange risk effects may also be reduced through alternative channels. As a great number of distinctive exchange rates may affect firm value through many different ways, all these influences may naturally offset each other. When analyzing the impact of FCD usage on firms' foreign currency exposure, we therefore include firm size to proxy a firm's international diversification possibilities as well as its capacity to implement operational hedging strategies The ratio of foreign sales is also incorporated in subsequent models in order to take a firm's international involvement into account. As previous empirical

\footnotetext{
144 As mentioned in table 1, the average ratio of foreign sales to total sales is twice as high for FCD users compared to FCD non-users. This large difference in foreign trading activity is expected to lead to a large difference in the percentage of firms with significant foreign currency exposure. As we can't empirically verify this large difference in percentage of significantly exposed companies, we presume that this difference has been reduced through the implementation of financial hedging strategies by loD users.

14: These findings are somewhat surprising since, according to the infornation collected in annual reports, almost 90 percent of $\mathrm{FCD}$ users declare that they employ FCDs to hedge predominantly U.S. dollar currency fluctuations.
} 
evidence (Bodnar et al, 1998) suggests that among firms with foreign exchange exposure that regularly hedge, there seems to be a tendency to hedge only a small fraction of the total foreign currency exposure, we expect that the use of FCDs doesn't completely offset the currency risk exposure firms are facing but we expect that it reduces its absolute value and statistical significance. We examine, hence, subsequently the link between FCD practices and the significance of firms* exchange rate exposures as well as the relationship between these strategies and the magnitude of the exposures.

Table 4.6: FX exposure and the use of FCDs (Probit)

\begin{tabular}{|c|c|c|c|c|}
\hline & \multicolumn{2}{|c|}{ Exposture to TW index } & \multicolumn{2}{|c|}{ Exposure to USS } \\
\hline & Weekly & Monthly & Weekly & Monthly. \\
\hline Intercept & $-0.7000(-0.9864)$ & $-1.4153 *(-2.0054)$ & $-1,5994 *(-2,418)$ & $-0.5728(-0.8258)$ \\
\hline $\ln \left(\mathrm{Size}^{\dagger}\right)$ & $0.0346(0.9465)$ & $0.0736 *(2.0291)$ & $0.0786^{* 45}(2.0400)$ & $0.0423(1.2262)$ \\
\hline $\begin{array}{c}\text { Poreign Sales } \\
\text { Total Sales }\end{array}$ & $0.7341 * * *(2.8321)$ & $0.8634^{*}(3.3050)$ & $0.6699 *(2.4502)$ & $0.1136(0.4764)$ \\
\hline $\begin{array}{l}\text { FCD usage } \\
\text { dummy }\end{array}$ & $-0.1912(1.0377)$ & $-0.1112(-0.6053)$ & $-0.2113(-1.1309)$ & $-0.4591(-1.2698)$ \\
\hline Observations & 406 & 406 & 406 & 406 \\
\hline Mac Fadden $\mathrm{R}^{2}$ & 0.0166 & 0.0269 & 0.0477 & 0.0075 \\
\hline Intercept & $-0.8624(-1.2346)$ & $-1.3979^{* *}(-2.0106)$ & $-1.8327^{*} *(-2.4897)$ & $-0.2765(-0.3905)$ \\
\hline $\ln \left(\operatorname{Size}^{\dagger}\right)$ & $0.0462(0.3343)$ & $0.0759 *(2.1989)$ & $0.0958^{* * *}(2.6141)$ & $0.0150(0.411)$ \\
\hline $\begin{array}{c}\text { Foreign Sales } \\
\text { Total Salcs }\end{array}$ & $0.6291 *(2.6119)$ & $0.7763^{*} \cdot(3.2196)$ & $0.7948 * * *(3 . / 398)$ & $0.1671(0.6433)$ \\
\hline $\begin{array}{r}\mathrm{FCD}^{\text {/ Total }} \\
\text { Assets }\end{array}$ & $-1.4627(1.4198)$ & $-0.9924(-1.0373)$ & $-0.3016(-0.340 \mathrm{~J})$ & $-1.1484+(-1.2698)$ \\
\hline Observations & 406 & 406 & 406 & 406 \\
\hline Mac Fadden $\mathrm{R}^{2}$ & 0.0186 & 0.0261 & 0.0466 & 0.0166 \\
\hline
\end{tabular}

This table presents logit regression estimates of the relation between the likelihood that a firm is significantly exposed to currency exposure and firm size, the percentage of foreign sales to total sales and the use - or not - of foreign currency derivatives. **** denote significance at the 10,5 and 1 percent levels, respectively. $t$-statistics are in italics.

Size is measured as the sum of market value of equity and book value of debt.

* The FCD usage dummy variable is assigned the value 1 if the firm reports the use of foreign currency derivatives in the notes to their annual reports and 0 otherwise.

$\$$ Foreign sales for Belgian, Dutch and German conpanies are sales to non-euro zone countries (Sales to non-euro zone countries are sometimes approximated by sales to non-European countries). Foreign sales for U.K. companies are sales to non-U.K. countries. 
Empirical findings regarding the impact of FCD use on the significance of foreign exchange risk exposure of European firms are presented in table 4.6 . The dependent variable of the probit model is assigned the value 1 if the firm is statistically significantly ${ }^{146}$ affected by currency fluctuations and 0 otherwise. Consistent with the view that the percentage of foreign sales to total sales is a reasonable proxy for firms' overall international trade linkages and hence their exposure to exchange rate uncertainty, results suggest that the importance of foreign sales is the major determinant of the significance of firms' currency exposure. The more companies are selling outside of the frontiers of their country of registration (respectively outside of the euro-zone) the more they seem to be significantly affected by exchange rate fluctuations. The size of a firm is also positively linked to the significance of its foreign exchange risk exposure. On the other hand, we find that firms' decision to use FCDs has a negative effect on the significance of their sensitivity to exchange rates. This negative relationship supports the view that nonfinancial firns use FCDs primarily for hedging purposes - and not for speculation. It is however statistically insignificant. We thus may conclude that the implemented foreign currency hedging strategies are not able to efficiently reduce the exchange rate risk European companies are effectively facing.

In order to further investigate the impact of FCD use on firms' exchange risk exposure, we focus now on the relationship between the extent of FCD usage and the magnitude of the exposure. As mentioned above, the total exposure of a company should be smaller in magnitude when currency derivatives offset exchange rate effects from foreign operations. To empirically assess the relationship between $F C D$ use and the magnitude of foreign exchange risk exposure we estimate the following model:

$$
\text { Est. }\left(\gamma_{i}\right)=\alpha_{l i}+\alpha_{2 i} \ln \left(\text { Size }_{i}\right)+\alpha_{3 i}(F S / T S)_{i}+\alpha_{4 i}(F C D / T A)_{i}+\mu_{i}
$$

where Est. $\left(y_{i}\right)$ is a firm's exchange risk exposure estimated in (Eq. 4.1), $\ln \left(\right.$ Size $\left._{j}\right)$ a firm's size - measured by the natural logarithm of the sum of market value of equity and book value of debt --, (FS/TSS $)_{i}$ a firm's ratio of foreign sales to total sales and $(F C D / T A)_{i}$ a firm's ratio of foreign currency derivatives to total assets.

As the foreign operations of positively (net-importers) and negatively (netexporters) exposed firms are presumably completely different in nature, we examine these sub-samples of firms separately.

\footnotetext{
146 Reported results have been obtained with the 10 percent statistical significance level. However to test the robustness of these results, we performed the analysis as well with the 5 percent statistical significance level. Results are consistent and may be obtained from the athors upon request.
} 


\section{Table 4.7: FX exposure and the use of FCDs (Ordinary Least Squares)}

\begin{tabular}{|c|c|c|c|c|c|c|c|c|}
\hline & \multicolumn{4}{|c|}{ Negative exposures } & \multicolumn{4}{|c|}{ Positive exposures } \\
\hline & \multicolumn{2}{|c|}{ Weekly } & \multicolumn{2}{|c|}{ Monthly } & \multicolumn{2}{|c|}{ Weekly } & \multicolumn{2}{|c|}{ Monthly } \\
\hline \multicolumn{9}{|c|}{ Panel A: Dependent variable : exposure to the trade-weighted exchange rate inder } \\
\hline Iritercept & $.1 .5177^{* *}$ & -2.3943 & $-5.5918 * * *$ & 47477 & $0.9108^{*}$ & 18783 & 1.7572 & 1.3501 \\
\hline $\ln \left(\right.$ Size $\left.^{n}\right)$ & 0.0056 & 0.1784 & $0.1471^{* * *}$ & 2.5178 & -0.0269 & -1.1099 & -0.0462 & .0 .7120 \\
\hline F. Sales ${ }^{\pi}$ T. Sales & -0.3537 & $-1: 5935$ & $-0.7005^{*}$ & 1.6731 & 0.0139 & 0.0943 & 0.1046 & 0.2399 \\
\hline $\mathrm{FCD}^{\Omega} /$ Total Assets & 0.3171 & 0.3944 & 1.4466 & 0.8779 & -0.2512 & -0.4045 & -0.6397 & 0.4967 \\
\hline Observations & 235 & & 241 & & 55 & & 49 & \\
\hline Adjusted $\mathrm{R}^{2}$ & 0.0000 & & 0.0308 & & 0.0000 & & 0.0000 & \\
\hline Intercept & 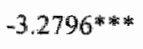 & -4.2907 & 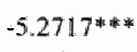 & -3.7239 & $1.3645^{* * *}$ & 2.7148 & $3.8716^{* *}$ & 2.475 \\
\hline $\ln \left(\right.$ Size $\left.^{\top}\right)$ & $0.0933^{* *}$ & 2.4255 & 0.1146 & 1.6372 & $-0.0574 * * 2$ & -2.1955 & $-0,1790^{*} *$ & -2.1447 \\
\hline F. Sales / T. Sales & -0.1736 & -0.7451 & $-0.8879 * *$ & -1.9040 & 0.1588 & 1.0258 & $-1.5444 * * *$ & -3.4534 \\
\hline $\mathrm{FCD}^{8} /$ Total Assets & 0.4783 & 0.6200 & 1.3740 & 0.8345 & -0.2485 & -0.4114 & -0.1184 & -0.1028 \\
\hline Quick Ratio & 0.0166 & 0.5781 & $-0.5779 * * *$ & -3.1436 & $0.5107 * *$ & 2.5726 & 0.0421 & 1.5683 \\
\hline LT Debt / Size ${ }^{\top}$ & -0.2939 & -0.5875 & -0.7138 & -0.7911 & 0.3708 & 1.5413 & 0.9573 & 1.1784 \\
\hline Market to Book Value & 0.1746 & 0,9052 & 0.4261 & 1.2399 & -0.0233 & -0.2658 & -0.0412 & -0.1244 \\
\hline Olxservations & 235 & & 241 & & 55 & & 49 & \\
\hline Adjusted $R^{L}$ & 0.0145 & & 0.0875 & & 0.0594 & & 0.2884 & \\
\hline \multicolumn{9}{|c|}{ Panel B: Dependern variable : exposure to the bilateral US dollar exchange rate } \\
\hline Intercept & -0.3672 & -1.0556 & $-2.4222 * * *$ & -4.2547 & 0.7793 & 0.9776 & $2.7063^{* *}$ & 2.5007 \\
\hline $\ln \left(\operatorname{Size}^{\top}\right)$ & $-0,1912$ & -1.1103 & $0.0538^{*}$ & 1.9066 & -0.0349 & -0.8747 & $-0.1125^{* * *}$ & -2.0848 \\
\hline F. Sales / T. Sales & $-0.3369^{* * * * *}$ & -2.7654 & -0.1109 & -0.5 .481 & $-0.7978^{*}$ **** & -3.2979 & $-1.6278^{\text {s0** }}$ & $-4.49 / 2$ \\
\hline FCD $/$ Total Assets & 0.1996 & 0.4523 & 1.2663 & $1.590 \mathrm{I}$ & 0.1876 & 0.1837 & -0.2018 & -0.1885 \\
\hline Observations & 265 & & 259 & & 25 & & 31 & \\
\hline Adjusted $\mathbb{R}^{2}$ & 0.0241 & & 0.0094 & & $0.193 \|$ & & 0.3008 & \\
\hline Intercept & 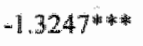 & -3.1513 & $-2.1221 *$ & -3.0793 & 1.3566 & 1.6675 & $3.8716^{4 * 2 *}$ & 24375 \\
\hline in $\left(\right.$ Size $\left.^{\mathrm{T}}\right)$ & 0.0328 & 1.5537 & 0.0317 & 0.9305 & $-0.0715^{*}$ & -1.6890 & $-0.1790^{* \text { * }}$ & -2.1447 \\
\hline F. Sales / T. Sales & $0.4813^{3}$ & -3.7551 & -0.0174 & -0.0800 & $-0.5343^{* * * *}$ & -2.1322 & $-1.5444 *$ & -3.4534 \\
\hline $\mathrm{FCD}^{\mathrm{s} / \text { Total Assets }}$ & 0.1698 & 0.4003 & 1.2773 & 1.5935 & 0.3285 & 0.3360 & -0.1184 & -0.1028 \\
\hline Quick Ratio & -0.0246 & -1.5514 & -0.1908 & -2.1325 & $0.9098 * *$ & 2.8311 & 0.0421 & 1.5683 \\
\hline LT Debt/Size & -0.2665 & -0.9688 & -0.4726 & -1.0758 & 0.3223 & 0.8277 & 0.9573 & 1.1784 \\
\hline Market to Book Value & 0.0053 & 0.0499 & 0.1144 & 0.6838 & -0.1426 & $-1,0055$ & -0.0412 & -0.1244 \\
\hline Observations & 265 & & 259 & & 25 & & 31 & \\
\hline Adjusted $\mathbb{R}^{2}$ & 0.0431 & & 0.0315 & & 0.2647 & & 0.2884 & \\
\hline
\end{tabular}

This table presents OLS regression estimates of the relation between the likelihood that a firm is significantly exposed to currency exposure and firm size, the percentage of foreign sales to total sales and the extent of FCD usage. The second OLS regression outputs reports results when liquidity, leverage and market to book wallue are included in the estimation model. *, ****** denote significance at the 10,5 and 11 percent levels, respectively, t-statistics are in italics. ${ }^{+}$Size is measured as the sum of market value of equity: and book value of debt. FCD usage is approximated by the total notional value of foreign currency derivative contracts. "Foreign sales for Belgian, Dutch and German companies are sales to non-euro zone countries ( $\$$ ales to non-euro zone countries are sometimes approximated by sales to non-European countries). Foreign sales for U.K. companies are sales to non-U.K. countries. 
Table 4.8. FX exposure and the use of FCDs (Weighted Least Squares)

\begin{tabular}{|c|c|c|c|c|c|c|c|c|}
\hline & \multicolumn{4}{|c|}{ Negative exposures } & \multicolumn{4}{|c|}{ Positive exposures } \\
\hline 8 & \multicolumn{2}{|c|}{ Weekly } & \multicolumn{2}{|c|}{ Monthly } & \multicolumn{2}{|c|}{ Weedidy } & \multicolumn{2}{|c|}{ Monthly } \\
\hline \multicolumn{9}{|c|}{ Panel A Dependent variable: exposure to the trade-ueighted exchange rate index } \\
\hline Intercept & $-23718 *$ & 42913 & $-7.0573 * *$ & -6.1702 & $0.8385^{*}$ & 1.9092 & $3.2159 *$ & 1.7421 \\
\hline In (Size) & 0.0059 & 02207 & $0.1789 * *$ & 31917 & -0.0186 & -0.8678 & -0.0877 & -0.8975 \\
\hline D. Sales $/$ T. Sales: & 0.4219 & -1.5758 & $-16212 * * *$ & -3.3673 & $0.5231 *$ & 35158 & 0.6557 & 10311 \\
\hline $\mathrm{FCD}^{3} /$ Total Assets & 1.0770 & 1.4992 & $35836^{44}$ & 1.8232 & -0.4869 & 0.6717 & $-1: 9450$ & -0.8685 \\
\hline Obserwa & 235 & & 241 & & 55 & & 49 & \\
\hline Adjusted $\mathrm{R}^{\mathrm{k}}$ & 0.7203 & & 0.6487 & & 0.8042 & & 0.5539 & \\
\hline Intercept & $-4.1883 * *$ 和 & -5.6437 & $*$ & -5.5 & $1.0481^{*}$ & 1.9168 & $2.8231^{*}$ & 1.8089 \\
\hline $\ln (\mathrm{sixe})$ & $0.0961 *$ & 2.5374 & $0.2088^{* * * * * 2 *}$ & 29107 & -0.0305 & -1.0046 & -0.1150 & -1.4203 \\
\hline F. Sales / T Sales & -0.6820 * & -2.3788 & $-1.1783^{* * *}$ & -22105 & $0.6009^{* * * * 3}$ & 3.9063 & -0.5113 & -1.0014 \\
\hline ICOD / Total Assets & 0.6614 & $1,0.333$ & $3.8114^{* *}$ & 1.9466 & -0.4677 & -0.6686 & $-2.6624 *$ & -1.7422 \\
\hline Quick Ratio & -0.1056 & -1.3111 & -0.3193 & -1.6052 & $0.3055 *$ & 23650 & $0.0425^{* * *}$ & 3.2843 \\
\hline LT Debt / Sizer & $\times 0.5405$ & -0.8915 & -0.2530 & -0.2087 & -0.1504 & $-0,57 / 2$ & $7.9375^{*}$ & 89104 \\
\hline Market to Book Vallue & 0.2927 & 1.1350 & 0.8409 & 1.8994 & $-0,0144$ & -0.8367 & -0.1821 & -0.5378 \\
\hline Obse & 235 & & 241 & & 55 & & 49 & \\
\hline Adjusted $\mathrm{R}^{4}$ & 0.7422 & & 0.6649 & & 0.8232 & & 0.8221 & \\
\hline \multicolumn{9}{|c|}{ Panel B: Dependent variable : exposure to the bilateral US dollar exchange rate } \\
\hline Inte & $6322 * * * *$ & -4.5357 & $3.1114 * *$ & -42941 & 1.1034 & 0.0761 & $83768 *$ & 5.9809 \\
\hline $\ln (\mathrm{Size})$ & 0.0071 & 0.4052 & $0.0542^{*}$ & 1.8936 & -0.0049 & -0.0762 & $-0.3479 * *$ & -4.9230 \\
\hline F. Sales" /T. Sales & 0.0613 & 0.4312 & 0.0503 & 0.2282 & $-1.5779 * * *$ & -5.1561 & $-3.3949 * * *$ & -6.3221 \\
\hline $\mathrm{FCD} /$ Total Assets & 0.6642 & 1.1314 & $2.2253^{*}$ & 1.8987 & -1.1347 & -0.5245 & -1.6748 & -0.3787 \\
\hline Obse & 265 & & $259^{\circ}$ & & 25 & & 31 & \\
\hline Adjou: & 0.7069 & & 0.6257 & & 0.7855 & & 0.6667 & \\
\hline Intercept: & $-3.0451 * * *$ & -6.5161 & $-32684 * * *$ & $-4.294 I$ & -0.5342 & -0.4034 & $9.5093 * * *$ & 5.1509 \\
\hline $\ln (\mathrm{size})$ & $0.0842 *$ & 3.5371 & 0.0458 & 1.2688 & 0.0201 & 03115 & $-0.4334 * * *$ & -4.2877 \\
\hline F. Salest / T. Sales & -0.0853 & -0.5480 & 0.2021 & 0.8467 & $-1.1665^{* * * * *}$ & -39646 & $-3.1315 * * *$ & -5.1104 \\
\hline $\mathrm{FCD}^{3} /$ Total Assets & 0.4451 & 0.9302 & $2.5070^{\text {**ik }}$ & 21251 & -2.2540 & -1.0558 & -1.2810 & -0.2910 \\
\hline Quick Ratio & -0.0246 & -0.4035 & 0.0775 & -0.7505 & $1.4178^{\text {******** }}$ & 34290 & $0.0403 *$ & 1.7941 \\
\hline LT Debt / Sizer & $-1,2737 * * *$ & -3.5608 & 0.6846 & 1.1308 & 0.5628 & 1.4732 & $2.0255^{* * *}$ & 2.5238 \\
\hline Market to Book Value & 0.1522 & 10581 & 0.2390 & 1.1 .501 & -0.1289 & -0.748 & -0.0205 & -0.0680 \\
\hline Obse & 265 & & 259 & & 25 & & 31 & \\
\hline Adjust & 0.7261 & & 0.6295 & & 0.8327 & & 0.7098 & \\
\hline
\end{tabular}

This table presents WLS regression estimates of the relation between the likelihood that a firm is significantly exposed to currency exposure and firm size, the percentage of foreign sales to total sales and the extent of FCD usage. The second OLS regression outputs reports results when liquidity, leverage and market to book value are included in the estimation model. The weighting factors are the t-statistics of the exposure eoefficients. *,**** denote significance at the 10,5 and I percent levels, respectively. t-statistics are in italios. "Size is measured as the sum of market value of equity and book value of debt. $\mathrm{FCD}$ usage is approximated by the total notional value of foreign currency derivative contracts. Foreign sales for Belgian, Dutch and German companies are sales to non-euro zone countries (Sales to non-euro zone countries are sometimes approximated by sales to non-European countries). Foreign sales for U.K. companies are sales to non-U.K. countries. 
In a first stage we estimate Eq. (4.2) using ordinary least squares The first regression outputs of panel $\mathrm{A}$ and $\mathrm{B}$ of table 4.7 show that while the link between foreign currency exposure and the level of FCD use has the expected sign, it is nonetheless again statistically insignificant. ${ }^{147}$ These findings confirm our view that the use of financial derivative instruments by European firms doesn't significantly reduce their sensitivity to exchange rate movements. As expected, we find however that for net-importing companies - that are positively affected by currency movements - foreign sales tend to naturally offset the impact of exchange rate movements. Likewise, the exposure of net-exporting firms appears to be strengthened through the existence of high foreign sales volumes. Finally, the positive (negative) relationship between firm size and negative (positive) exposure coefficients supports the argument that larger firms have greater access to international diversification benefits and operational hedging practices. Pantzalis et al. (2001) similarly conclude that firms with a greater breadth of foreign operations have lower foreign exchange rate exposure.

Following Chow and Chen (1998) and Nguyen and Faff (2003) we examine next whether our results are robust to the inclusion of additional explanatory variables that are considered in the literature as proxies for firms' incentives to hedge:

$$
\begin{aligned}
\text { Est: }\left(\gamma_{i}\right)= & \alpha_{H i}+\alpha_{2 i} \ln \left(\text { Size }_{i}\right)+\alpha_{3 i}(F S / T S)_{i}+\alpha_{4 i}(F C D / T A)_{i}+\alpha_{4 i}\left(Q_{\text {uick }}\right)_{i} \\
& +\alpha_{4 i}(\text { LT Debt } / \text { Size })_{i}+\alpha_{4 i}(B T M)_{i}+\eta_{i}
\end{aligned}
$$

where Est. $\left(\gamma_{i}\right)$ is a firm's exchange risk exposure estimated in Eq. (4.1), $\ln \left(\right.$ Size $\left._{1}\right)$ a firm's size - measured by the natural logarithm of the sum of market value of equity and book value of debt - , (FS/TSS) a firm"s ratio of foreign sales to total sales, (FCD/TA), a firm's ratio of foreign currency derivatives to total asisets, (Quick) a firm's quick ratio, $(L T$ Debr/Size) a firm's ratio of long term debt to size and $(B T M)_{i}$ a firm's book to market value.

Empirical findings of Eq. (4.3) are displayed in the second regression outputs of Panel $A$ and $B$ of table 4.7. We observe, in particular, that firms with high liquidity tend to be more exposed to currency movements. These results are in favor of Froot et al.'s (1993) argument that highly liquid firms have less incentive to hedge than firms that are facing strong liquidity constraints and are susceptible to be hurt by an increase in cash-flow volatility. Further empirical findings tend to support the view that firms with high debt ratios and strong growth opportunities

${ }^{147}$ Corroborating results are provided in De Jong et al. (2004) who find little evidence to suggest that external hedging activities decrease currency risk exposure on the Dutch market. 
tend to be affected by currency movements. These relations aren't however statistically significant.

Table 4.8 presents the coefficient estimates of Eq. (4.2) and (4.3) when weighted least squares are used. The weighting factors are the t-statistics of the exposure coefficients estimated by model (Eq. 4.1). This enables us to assign more weight to the exposure coefficients that have been estimated with higher precision and less to those estimated with lower precision. Results confirm previous findings but are generally statistically stronger compared to those obtained using ordinary least squares. Again we find that the extent of FCD use tends to reduce a firm's exposure to exchange rate risk. However this impact remains statistically weak. On the other hand, we observe once more that foreign sales significantly accentuate the exposure net exporters are facing while they tend to reduce the currency sensitivity of netimporters. The confirmation of the negative link between exchange rate exposure magnitude and firm size supports the argument that firm size is a proxy for a firm's ability to diversify international operations and implement operational hedging strategies (Bodnar et al, 1997). The inclusion of variables that approximate firms' incentives to hedge enables us to emphasize two additional features. In line with previous results, the liquidity of a firm is shown to be statistically positively linked to the magnitude of foreign currency exposure. Secondly, the weighted least squares regressions lead to strong evidence in favor of a positive relationship between leverage and exposure magnitude. The impact of the existence of growth opportunities has again the expected sign but remains statistically insignificant.

It is, ultimately, important to stress that the aforementioned probit, ordinary least squares and weighted least squares estimations almost unanimously disprove the assumption that financial hedging instruments have a stronger impact on weekly conpared to monthly currency risk exposures. We have formulated in chapter 3 two potential reasons that may explain why currency exposure effects become more evident when lengthening the observation horizon. Empirical evidence presented in tables $4.6-4.8$ reveals, however, that one of these hypotheses has to be rejected: managers have no incremental knowledge of their weekly versus monthly exposures to currency fluctuations and are hence not able to hedge these short-term risks in a more efficient way. Consequently, empirical evidence suggesting that currency exposure effects are statistically stronger when they are estimated over longer return intervals should be predominantly attributed to the fact that it is difficult for investors to differentiate between temporary versus permanent currency shocks and, hence, to predict the impact of short-term exchange rate shocks on a firm's competitive and economic environment (Bodnar and Wong, 2003; Chow et al., 1997a, 1997b; Di lorio and Faff, 2000). 


\subsection{Concluding Remarks}

This chapter examines the foreign exchange risk practices of Europeam nonfinanciall companies. In a first stage, we are concened with the motives that lead firms to use currency derivatives as well as the factors that affect their decision on how much to hedge with these instruments. In a second stage, the extent to which this usage affects their foreign exchange risk exposure is thoroughly investigated. The main contribution of this chapter is that it provides a unique insight in European firms" hedging strategies as well as an in-depth analysis of the real impacts of these hedging strategies on firms' risk exposures.

Consistent with previous studies, the main determinants of FCD use are found to be the percentage of firms' foreign trading volumes and size. While these results seem to refute the financial distress costs and informational asymmetries motives to hedge, they provide evidence in favor of the existence of economies of scale in hedging. When the firm is larger and the volume of foreign activity is sufficiently large to justify the costs, the implementation of hedging programs appears to be strongly facilitated. Further, our results lend support to the argument that the existence and extent of tax loss carryforwards play a significant role in explaining firms ${ }^{3}$ use of financial derivative instruments. The positive relationship between the percentage of foreign denominated debt and the use of FCDs reveals moreover that both types of instruments are complements in hedging foreign currency risk. Finally, in contrast to optimal hedging theories (Froot et al., 1993), our empirical findings suggest that the more growth opportunities companies have, the less they use FCDs.

The second part of this chapter investigates the role of FCD usage in influencing the significance and magnitude of firms' sensitivity to exchange rate fluctuations. The relationship between firm value and currency movements has been documented both for weekly and monthly observation horizons to examine the effect of FCDs on both the short- and medium-term currency exposures of European firms. Overall, most European companies in our sample are found to behave like net-exporters - being negatively affected by a depreciation of foreign currencies. Empirical evidence reveals as well that the impact of exchange rate changes on firm value becomes more evident when lengthening the observation horizon. Our empirical results lend strong support to the hypothesis that the degree of international involvement - approximated by the percentage of foreign sales - is a major determinant of firms' currency risk exposure. Size, on the other hand, appears to be negatively related to exchange rate exposure. The negative role of size tends to support the argument that larger firms benefit from the diversification of their foreign operations and are to a greater extent capable of implementing 


\section{Chepter 4}

operational hedging strategies. Furthermore, firms with high liquidity ratios and firms with high growth opportunities and leverage appear to be more sensitive to currency fuctuations. These findings are informative since they show that companies that use liquidity as a substitute for hedging as well as companies that are particularly vulnerable to cash-flow-volatility tend to be particularly affected by exchange rate movements. Ultimately, our evidence supports unanimously the assumption that European companies use FCDs not to speculate on the foreign exchange markets but to protect themselves against currency fluctuations. However these hedging strategies are shown to have statistically weak effects. Similarly, no conclusive evidence could be found to corroborate managers' stronger capacity to hedge the short-term versus long-term currency exposure of the company.

It is important to note that when investigating the relation between the utilization of FCDs and firms' currency exposure, our empirical findings are shown to be highly robust to the use of a wide range of alternative specifications. Results lead to the same conclusions when a different exchange risk factor or a shorter sample period is utilized for the estimation of firms" exposure to currency movements: Findings are likewise found to be robust to the use of different estimation methodologies (e.g., ordinary least squares, weighted least squares and probit regressions).

In general, this series of results may be interpreted as further evidence that managers are using FCDs to hedge only a small proportion of the currency risk they are facing and that these hedging activities are mostly unsystematic. Additionally, the fact that the relationship between currency movements and firm value is statistically and economically weaker in the short-run - as compared to the long-run - may not be attributed to managers' stronger capacity to hedge short-term versus long-tern currency exposure. It reveals, in reality, that short-term returns contain systematic mispricing errors made by investors in forecasting the long-term effects of current exchange rate fluctuations. 

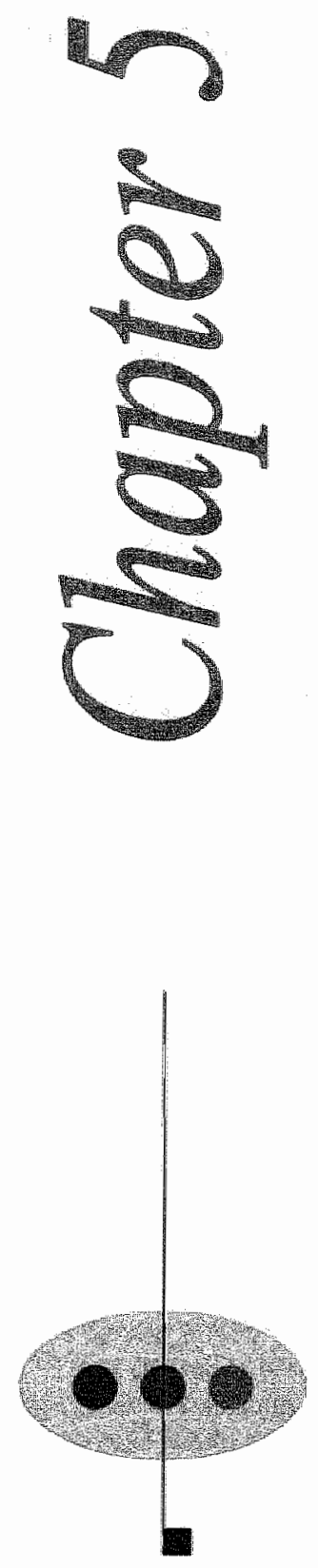

\section{The Effect of Exchange Rate Variability on U.S. Shareholder Wealth}


$\because$
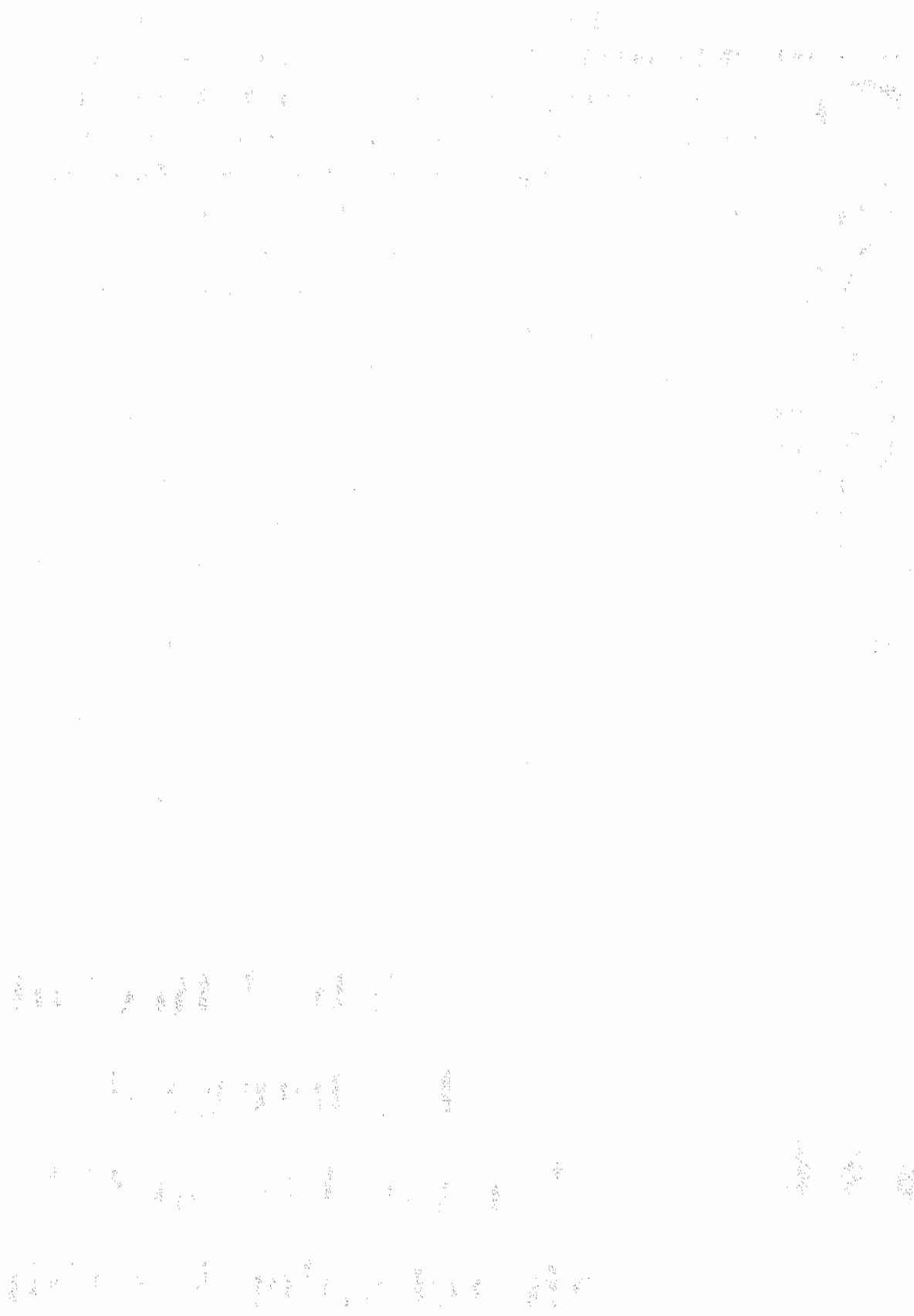


\section{The Effect of Exchange Rate Variability on U.S. Shareholder Wealth ${ }^{148}$}

\subsection{Introduction}

In the previous chapter, we concluded that firms are presumably hedging only a small proportion of the total exchange rate risk they are facing. In line with our expectations, the argument that hedging activities completely offset firms' exposure to currency fluctuations and cause the link between exchange rate movements and stock returns to be statistically insignificant seems, hence, to be empirically refuted. ${ }^{149}$ Since the debate regarding the counter-intuitiveness of previously reported resultis on currency risk exposure remains, this chapter presents an alternative approach to empirically assess the impact of exchange rate changes on firm value. Rather than analyzing the impact of exchange rate movements on firm value by regressing multinationals ${ }^{9}$ stock returns on exchange rate changes, we aim to increase our understanding of the (time-varying) relationship between exchange rates and stock prices by reconsidering the foreign exchange risk exposure puzzle from a different angle. Motivated by Bartov et al (1996) and Chen and So (2002), we concentrate hence in this chapter on the impact of increased exchange rate variability on the stock return volatility of U.S. multinationals. In this context, the turmoil periods around the major financial crises of the last decade are particularly informative. Mexico's float of the peso in December 1994, Argentina's financial crisis and its efforts not to devalue the Argentine peso in March $1995^{150}$, Brazil's decision to let the real float in January 1.999, and the Asian financial crises in Thailand, Malaysia, Indonesia and Korea in July, August and December 1997 have

\footnotetext{
14\$ This chapter is based on chapter is based on A. Muller and W.F.C. Verschoor, "The effect of exchange rate variability on U.S. shareholder wealth", LIFE Working Paper, $2004 \mathrm{~b}$.

149 Jorion*s (1990) study of U.S. firms finds that only 5 percent of his sample is significantly affected by exchange rate movements. Bartov and Bodnar (1994) also failed to find significant relationships between exchange rate changes and stock returns of 208 firms with international operations. These results are consistent with Amihud (1994), who reports no significant contemporaneous exposure for the 32 largest U.S. exporting firms.

150 The analysis of the Argentinean crisis in March 1995 enables us to explicitly verify the presence of a positive currency premium under currency boards if these currency boards are not fully credible anymore (Edwards, 2000).
} 
indeed all been characterized by a tremendous increase in exchange rate uncertainty. ${ }^{151}$ This chapter analyzes thus the change in U.S. market risk (beta) in response to the onset - or fear - of a currency regime shift in countries where these U.S. multinational firms are internationally active. Significant contribution of increased exchange rate variability to systematic risk would imply that the cost of equity capital for these firms increases relative to that of nonmultinational (domestic) firms and that the additional risk these firms are facing due to exchange rate uncertainty has a significant impact on their value.

The remainder of the chapter is organized as follows. After discussing our research design in section 5.2 , we describe the selected exchange rate crises and the nature of our sample procedure in section 5.3. Section 5.4 presents and analyzes the estimates of the extent to which U.S. multinationals are exposed to financial crises exchange rate uncertainty. Section 5.5 closes with some sensitivity analyses across industries and market capitalization classes. The last section concludes our findings.

\subsection{Research design}

The past decade witnessed a flow of financial crises in developing countries quite unlike those of the preceding decade. The decade of the 1990 s opened with many developing countries suffering from a capital inflow "problem". As suggested by many observers, one major reason explaining this problem was the quasi-U.S. dollar peg adopted by many of these economies. The maintaned exchange rate regimes were no longer viable in light of the greatly enhanced integration of these markets with international capital markets. They caused the overvaluation of the currencles (Edwards, 1999) and encouraged excessive foreign currency borrowing through provision of implicit guarantee on exchange rate stability (Eichengreen and Hausman, 1999). Whereas pegged regimes attempt to promote predictability, reduce inflationary expectations, ease trade - by eliminating exchange rate risk - and investment relations, their abandonment causes large financial shocks. When a country faces a financial crisis marked by a significant depreciation of its currency, other countries also suffer from trade spillovers. Empirical studies demonstrate that the rise in the volatility of exchange rates - and the subsequent increase in uncertainty and risk - has signiffcant consequences on trade flows. ${ }^{152}$ We expect that the large exchange rate swings in the aftermath of the financial crisis altered the trade terms between the crises countries and the U.S. and that the increased

\footnotetext{
Edwards (1999) identifies these countries as being the economies that had been most affected by the Asian currency and financial crisis in 1997.

152 Rahmatsyah et al. (2002) provide an extensive discussion of this literature.
} 
exchange rate variability contributed to the uncertainty of the economic and financial enviromment of U.S. multinationals. The rapid expansion of currency. crises to world stock markets, through an increase in the observed volatility of financial markets and capital flows around the world, has led academics and investors to re-evaluate the impact of (increased) exchange rate fuctuations on stock markets. ${ }^{153}$

In this chapter, we empirically examine how the changing exchange rate environment and the downtum faced by these emerging economies affected the U.S. economy. As much of this impact is likely to be through trade, we focus on U.S. multinationals entertaining close trading relationships with these turmoil markets. We examine whether the variability of their stock returns were affected by the financial crisis of their trading partners and whether this resulted in a significant increase in their market risk (beta). In a first step, we investigate whether the enhanced uncertainty about the future performance of U.S. multinationals active in these turmoil markets resulted into an increased stock return variability. Even if firms that didn't entertain trade relationships with the crises countries may have been indirectly influenced by the economic waves following the crisis, there is no doubt that multinational firms that had real operations in the crisis countries were the first economic actors to be affected. We, therefore, expect the increase of the stock return variability to be more important for U.S. multinationals that are engaged in foreign sales activities with these turmoll markets than for other U.S. firms. Motivated by Bartov et al (1996), we hence create a control sample of firms in the same line of business and of similar size (market capitalization) to test for a different impact of the currency crisis on "non-crises oriented" firms. This enables us further to control for the influence of other confusing forces related to industry or firm size.

The second step separates the impact of increased exchange rate variability on the stock return volatility of U.S. multinationals into systematic and diversifiable risk. Whether some proportion of this enhanced stock return variability is diversiffable or not has important implications for the firm and investors. In a well diversified portfolio, only systematic risk, which cannot be diversified away, receives compensation through higher required rates of return. Thus, an increase in a firm's systematic risk with respect to the U.S. equity market portfolio leads to an increase in the required rate of return and an increase in the cost of (equity) capital. To measure the systematic risk (beta) of U.S. companies we use the augmented market model suggested by Jorion (1990). The estimation of this multi-factor modell enables us to analyze whether increased exchange rate uncertainty influences the

${ }^{453}$ See, for instance, Bartov et al. (1996), Chen and So (2002), Chang (2002), Bin et al. (2004). 
sensitivity of U.S. multinational firms to market risk (beta) and whether the impact of exchange rate movements on the equity value of these firms rises during periods of increased exchange rate variability. Intuitively, the contribution of exchange rate uncertainty to firm"s sensitivity to market risk can be motivated by the impact of exchange rate volatility on their trade activities - and hence on their business riskas well as by the existence of other repercussions to the fundamentals of these firms that are not shared to the same degree by the market as a whole.

As underlined by Bartov et al (1996), this research design has fundamental advantages compared to the existing literature on exchange rate exposure. First, since variances are estimated over a multiperiod window, our analysis doesn"t suffer from the potential temporal instability of the sign of the exposure (Bartov and Bodinar, 1994) and reduces the necessity that the impact of the exchange rate on stock prices be contemporaneous (Bartov ef al. 1996). Second, analyzing the impact of large exchange rate swings caused by currency crises, we mitigate the effects of hedging activities because of the relative unexpectedness of these volatile currency movements. ${ }^{154}$ Third, it enables us to test the hypothesis that the impact of large magnitude currency movements on trade spillovers - hence, on firm value - is more significant than the impact of small fluctuations. ${ }^{155}$ Under these conditions and in light of the evidence discussed above, we expect that U.S. multinationals with real operations in Asia have greater exposure to exchange rate risk during the period of increased exchange rate variability. Considering that their trading activities were directly influenced by the changing currency environment, this impact should be most identifiable for these "Asia-oriented" U.S. companies. Finally, as exchange rate movements primarily affect firm value through their impact on trade flows, U.S. multinationals that produce or consume non-traded goods should be less affected by the changes in their currency environment. Similarly, due to the positive impact of a U.S. dollar appreciation on U.S. importing activities and its negative effect on U.S. exporting activities, we suppose that U.S. industry sectors that rely heavily on both exporting and importing activities are less influenced by changes in foreign exchange rates. Industries that primarily serve the consumer sectors are presumed more exposed to currency fluctuations than institution and business oriented industries. If we limit ourselves to examine aggregate results, we ignore these differential effects across industries. In this chapter, we, therefore, use an industry-level variation to identify which types of sectors are most affected by the

\footnotetext{
${ }^{154}$ The annihilating impact of hedging activities on currency risk exposure has been discussed by Adler and Dumas (1984), Bodnar and Gentry (1993) and Bartov et al. (1996).

${ }^{155}$ This assumption is supported by the huge influence of the 1997 Asian financial crisis on U.S. trade deficits as U.S. trade deficits were brought to a historical low in 1998 with 240 billion U.S. dollar.
} 
increased exchange rate variability. To strengthen our analysis further, we examine our findings across different market capitalization categories.

\subsection{Exchange rate crises and sample selection}

\subsubsection{Exchange rate crises}

This section briefly describes the events preceding and following the financial crises observed in seven countries: Mexico, Brazil, Argentina, Thailand, Malaysia, Indonesia and Korea. All these countries had been linking the value of their currencies to the U.S. dollar before the crisis. ${ }^{156}$ Mexico, Brazil and Thailand quitted very stable exchange rate regimes to let their currency float independently. Malaysia, Indonesia and Korea, who declared different types of exchange rate regimes before the crisis, didn't necessarily change their officially declared arrangements after the crisis, but allowed for a much greater flexibility of their exchange rates. The Argentinean crisis in 1995, which wasn't followed by the abandonment of the currency board, is also described.

The macroeconomic performance of the Asian economies that succumbed in 1997 to currency and banking crises (Thailand, Malaysia, Indonesia and Korea) had previously been viewed as an economic miracle. Many observers suggested that the active management of the exchange rate in pursuit of a competitiveness objective was contributing to the prosperous macroeconomic performance. The crisis forced all of these countries to abandon their de facto exchange rate pegs, and the subsequent floats of their currencies were associated with very sharp fluctuations in their values.

Thailand explicitly maintained a central parity for its currency allowing only very narrow fluctuations around a benchmark value. The parity was officially set according to an undisclosed basket of currencies but its behavior suggests that the U.S. dollar accounted for more than 90 percent of the value of the basket (Frankel and Wei, 1994). Pressures on the Thai baht had been in place since late 1996. The country's exchange rate has been appreciating in real terms and the economy suffered from high and unsustainable current account deficits. Despite some attempts to limit the worsening of the situation, the speculative pressures continued and the baht was floated on the $2^{\text {ndl }}$ of July 1997 . The value of the baht continued to depreciate in the subsequent months till it reached its all-time low value against the U.S. doliar in January 1998.

\footnotetext{
${ }^{156}$ The weight that was attached to the dollar in the observed currency baskets ranged from 0.9 to 1.0 .
} 
Table 5.1: Crisis dates and exchange rate arrangements

\begin{tabular}{|c|c|c|c|c|}
\hline \multicolumn{5}{|c|}{ Panel A: Asia } \\
\hline Country & Crisis date & $\begin{array}{l}\text { Depreciation } \\
\text { against US }\end{array}$ & $\begin{array}{l}\text { Declared exchange } \\
\text { rate regime before the } \\
\text { crisis }\end{array}$ & $\begin{array}{l}\text { Exchange rate regime into } \\
\text { which the country } \\
\text { switched after the crisis }\end{array}$ \\
\hline Thailand & July 1997 & $24.34 \%$ & Basket peg & Independently floating \\
\hline Malaysia & July 1997 & $4.19 \%$ & Managed float & Managed float* \\
\hline Indonesia & August 1997 & $16,78 \%$ & Crawling band & Independently floating \\
\hline Korea & December 1997 & $4564 \%$ & Exchange rate band & Independently floating \\
\hline \multicolumn{5}{|c|}{ Panel B: Latin America } \\
\hline Country & Crisis date & $\begin{array}{l}\text { Depreciation } \\
\text { against USS* }\end{array}$ & $\begin{array}{l}\text { Declared exchange } \\
\text { rate regime before the } \\
\text { crisis }\end{array}$ & $\begin{array}{l}\text { Exchange rate regine into } \\
\text { which the country } \\
\text { switched after the crisis }\end{array}$ \\
\hline Mexico & Decernber 1994 & $54.60 \%$ & Crawling band & Independently floating \\
\hline Argentina & March 1995 & $0.00 \%$ & Currency board & Currency board \\
\hline Brazil & January 1999 & $64.08 \%$ & $\begin{array}{l}\text { Adjustable band with } \\
\text { dual exchange rate }\end{array}$ & Independently floating \\
\hline
\end{tabular}

*Nominal depreciation against the U.S. dollar during the crisis month. * Malaysia switched to the conventional peg arrangement in September 1998, a year after the currency crisis started.

Source: IMF Annual Report on Exchange Arrangements and Exchange Restrictions; various numbers.

Prior to the Asian crisis, Malaysia had generally stronger fundamentals than other Asian economies. Although it officially didn't announce a fixed parity for the ringgit, the Bank Negara Malaysia acknowledged intervening to smooth fluctuations that it considered excessive. According to many observers (International Monetary Fund, 1999), the currency had been appreciating in real terms for about two years and was significantly overvalued in the wake of the Thai crisis. In summer 1997, the crisis was triggered by the sudden capital outflow intensifying the depreciation pressures on the ringgit. The currency depreciated by 4 percent in July 1997 and continued to depreciate as investors were further losing confidence in Malaysian economy. After the market calmed down, in September 1998, the monetary authority announced the introduction of a new fixed peg of the ringgit versus the U.S. dollar.

Since the 1980s Indonesia was linking the value of the rupiah to a basket of currencies. Key macroeconomic indicators were more favorable in Indonesia than in Thailand but the economy had a very high amount of short-term private sector external debt and faced severe liquidity problems. Intensified pressure on the 
Indonesian rupiah started in July 1997, soon after the Thai baht was floated. The exchange rate band was first widened on July 11, 1997 and the decision to let the currency float was taken on August 14, 1997. The economy fell into a circle of currency depreciation and hyperinflation. The near collapse of the banking sector during November 1997 - January 1998, the severe economic downturn, the rise of unemployment and the consecutive civil unrest were the most visible consequences of the crisis that lasted for more than a year.

In March 1990, Korea adopted the Market Average Exchange Rate System (MAR). Under this system, the daily won/dollar rate was actively managed to oscillate each day within a band centered around the previous day's weighted average spot rate. The band was regularly widened and the won depreciated steadily by a rate of 2 percent per year. In the wake of the crisis, the country had a large stock of short-term debt and suffered from weak international reserves. As the crisis unfolded, external financing conditions worsened very quickly and the won fell by over 5 percent. The authorities tried to intervene to maintain their exchange rate system but their reserves depleted very rapidly. The exchange rate was allowed to float freely on December 16, 1997. It reached its lowest value against the dollar on December 23, 1997 and started to stabilize its value by the end of 1998 .

Since November 1991 , Mexico was following a crawling band exchange policy. However, large capital inflows caused a continuous appreciation of the peso and consequently widening trade deficits. The rise in the U.S. interest rates that initialized a sudden capital outflow and domestic political tensions were at the origin of huge reserve losses. The reserves fell by 64.5 percent from October to December 1994. On the $20^{\text {th }}$ of December, the peso band's ceiling was devaluated by 15 percent and on the $22^{\text {nd }}$ the authorities abandoned the crawling band exchange rate mechanism and moved to free float. Peso depreciated by 71 percent for the whole 1994.

Since 1995, Brazil was following an adjustable crawling band exchange rate regime. But the Brazilian real had been under pressure since the collapse of the Russian ruble in August 1998. International reserves were falling since April 1998 and foreign institutional investors were more and more losing confidence in the real. The outflow of capital turned rapidly into a flood, with $\$ 1$ billion leaving the country in a single day. The devaluation became unavoldable. By widening the band of the exchange rate fluctuation on January 13,1999, the Central Bank tried to opt for a gradual depreciation of the currency. Nevertheless, the real was floated five days later on January 18, 1999. From early January to June 1999, the real lost 30 percent over its value.

Argentina is a special case in our analysis as it didn"t change its exchange rate policy while suffering from a severe financial crisis. Argentina had indeed been 
suffering a lot from the currency crisis that exploded in Mexico at the end of 1994, since most investors feared that the country was suffering from the same underlying financial imbalances as Mexico. Record trade deficits, a $\$ 1.5$ billion fiscal deficit and re-merging inflation problems in early 1995 generated an international concen that the Argentine peso had become markedly overvalued. Investors began to massively withdraw their capital, the Buenos Aires Stock exchange plunged and the Central Bank's reserves declined by more than $\$ 6$ billion. Nevertheless the administration announced that it wouldn't devalue the currency and drew up an emergency austerity plan in March 1995. The emergency plan gradually restored confidence among investors who started to bring their capital back in late 1996 while many social and unemployment problems remained.

\subsubsection{U.S. multinational firms}

In this chapter, we analyze how the financial crises experienced by seven emerging economies affected U.S. wealth. As suggested by Forbes (2004), trade linkages (either through bilateral trade or competition in third markets) are important transmission channels of exchange rate shocks. Although firms that don entertain trade relationships with the crisis countries directly, they might be indirectly affected by the economic waves following a financial crisis; there is no doubt that multinational firms that have real operations in the crisis countries are the first economic actors to be influenced by these wide exchange rate swings. We therefore only include in our test sample US. multinationals with real production and/or trade operations in the crisis countries. To identify these firms, we first select multinational firms based on the information provided in the 1995 and 1999 versions of the Directory of American Firms Operating in Foreign Countries. ${ }^{157}$ As we only include listed firms in our study, we check the selected firms for their weekly stock market return availability in the University of Chicago Center for Research in Security Prices (CRSP) database. We moreover restrict our sample to companies with at least complete six month price information both for the pre-crisis and the post-crisis windows. Finally 673 firms are identified. These multinational firms form together seven different test samples depending on the crisis country where these companies have real operations. ${ }^{15:}$

In order to prevent confounding inferences concerning the causes of the changes in the stock return variability of the sample firms, we construct for each

\footnotetext{
${ }^{157}$ The Directory of American Fiwns Operating in Fareign Countries does not provide any quantitative measure on the degree of involvement of these firms in international activities.

15\$ The seven different test samples are: Mexico (167), Brazil (45), Argentina (89), Thailand (88), Malaysia (97), Indonesia (71) and Korea (116).
} 
test sample a corresponding control sample. In order to create matching control samples consisting of firms in the same industry and of similar size as each of the sample firms, we go through the following procedure. First, within the CRSP database, we identify for each sample firm all the firms, listed on an U.S. stock market, that were active in the same 4-digit industry sector during the crisis period. Among these firms we randomly select three or four firms within the same market capitalization category as the sample firm: Finally, we sort out a total of 2398 companies. ${ }^{159}$ These control firms are either domestic or multinational companies that haven't any direct production or trading relationships with the selected crisis countries.

\subsection{Exchange rate crises and stock return volatility}

To examine empirically the link between exchange rate risk uncertainty and stock return volatility, we measure the variance of the stock returns of our sample and control firms over two two-year windows. The first window precedes the date of the decision to let the exchange rate float, whereas the second window covers the period after this decision was taken. ${ }^{160}$ To evaluate the significance of the change in stock return variability across the two periods, we use the following Chi-squared statistic (Eq. 5.1):

$$
\chi^{2}(2 N)=-2 \sum_{i=1, N} \ln p_{i}
$$

where $p_{i}$ is the $\mathrm{p}$-value for the F-test of the test of the change in variances for firm $i$ from the pre-crisis window to the post-crisis window and $N$ is the number of firms included in the sample. Under the null hypothesis of no change in stock return variance across the two sub-periods, the sample distribution of the F-statistics is random and the test statistic is asymptotically distributed $\chi^{2}$ with $2 N$ degrees of freedom. ${ }^{161,162}$

\footnotetext{
159. These firms are as well the constituents of seven different control samples: Mexico (526), Argentina (179), Brazil (333), Thailand (324), Malaysia (360), Indonesia (256) and Korea (420).

${ }^{160}$ Respectively, for Argentina, the date where the depreciation pressures were the strongest and where the Menem administration officially declared that it would nevertheless maintain the currency board.

${ }^{16}$ We define for each crisis the pre-crisis period as the 2 year window before the crisis interval. The crisis interval cowers the 4 weeks surrounding the date where the decistion to let the currency float was ttaken. The post-crisis period embraces the 2 years after the crisis interval.

${ }^{162}$ This test statistics relies on the assumption that the observations are independent of one another.
} 
Table 5.2: Stock return variability across exchange rate regimes - Crosssectional distribution of firm-level stock return variances

\begin{tabular}{|c|c|c|c|c|c|c|c|c|c|}
\hline 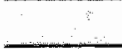 & \multicolumn{9}{|c|}{ Panel A Asia } \\
\hline \multirow{2}{*}{$\therefore$} & \multicolumn{3}{|c|}{ Test sample } & \multirow{2}{*}{\multicolumn{2}{|c|}{ : }} & 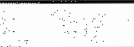 & \multicolumn{2}{|c|}{ Control sample } & \multirow{2}{*}{ Signif } \\
\hline & $\begin{array}{l}\text { Before } \\
\text { crisis }\end{array}$ & $\begin{array}{l}\text { After } \\
\text { crisis } \\
\end{array}$ & Test stat. & & & $\begin{array}{l}\text { Before } \\
\text { crisis }\end{array}$ & $\begin{array}{l}\text { After } \\
\text { crisis }\end{array}$ & Test stat. & \\
\hline \multicolumn{10}{|c|}{ Panel A. A: Thailand, Jhly 1997} \\
\hline Mean & 0.0024 & 0.0037 & 1417.97 & 0.000 & Mean & 0.0025 & 0.0040 & 5266.35 & 0.000 \\
\hline Median & 0.0015 & 0.0027 & 5.03 & 0.000 & Mediain & 0.0015 & 0.0027 & 8.77 & 0.000 \\
\hline$Q_{1}$ & 0,0005 & 0.0007 & s & & $Q_{1}$ & 0.0003 & 0.0006 & & \\
\hline$Q_{3}$ & 0.0133 & 0.0122 & & & $Q_{3}$ & 0.0203 & 0.0454 & & \\
\hline \multicolumn{10}{|c|}{ Panel A. B-Maloysia July 1997} \\
\hline Mean & 0.0029 & 0.0039 & 1910.25 & 0.000 & Mean & 0.0030 & 0.0046 & 5832.90 & 0.000 \\
\hline Median & 0.0015 & 0.0030 & 6.13 & 0.000 & Median & 0.0018 & 0.0032 & 8.32 & 0.000 \\
\hline $\mathrm{Q}_{1}$ & 0.0004 & 0.0012 & & & $Q_{i}$ & 0.0003 & 0.0003 & & \\
\hline Q & 0.0712 & 0.0126 & & & $\mathrm{Q}_{3}$ & 0.0149 & 0.0224 & & \\
\hline a: & \multicolumn{6}{|c|}{ Panel A. C. Indonesia, August 1997} & \multicolumn{3}{|c|}{ 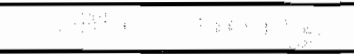 } \\
\hline Mean & 0.0022 & 0.0038 & 1253.55 & 0.000 & Mean & 0.0020 & 0.0032 & 3785.822 & 0.000 \\
\hline Median & 0.0015 & 0.0030 & 5.39 & 0.000 & Median & 0.0012 & 0.0024 & 8.40 & 0.000 \\
\hline & 0.0004 & 0.0003 & & & $Q_{1}$ & 0.0003 & 0.0005 & & \\
\hline Q & 0.0418 & 0.0564 & & & $Q_{3}$ & 0.0123 & 0.0145 & & \\
\hline \multicolumn{10}{|c|}{ Panel A. D: Korea, December 1997} \\
\hline Mean & 0.0033 & 0.0055 & 1971.80 & 0.000 & Mean & 0.0026 & 0.0045 & 8643.38 & 0.000 \\
\hline Median & 0.0018 & 0.0039 & 5.38 & 0.000 & Median & 0.0017 & 0.0033 & 11.82 & 0.000 \\
\hline & 0.0004 & 0.0009 & & & $Q_{1}$ & 0.0000 & 0.0005 & & \\
\hline $\mathrm{Q}_{3}$ & 0.0124 & 0.0234 & & & $Q_{3}$ & 0.0234 & 0.0236 & & \\
\hline \multicolumn{10}{|c|}{ Panel B: Latin America } \\
\hline \multicolumn{10}{|c|}{ Panel B. A: Mexico, December 1994} \\
\hline Mean & 0.0015 & 0.0017 & 947.14 & 0.000 & Mean & 0.0026 & 0.0024 & 2256.90 & 0.000 \\
\hline Median & 0.0011 & 0.0011 & 0.27 & 0.787 & Median & 0.0015 & 0.0015 & 1.72 & 0.085 \\
\hline Q & 0.0004 & 0.0004 & & & $\mathrm{Q}_{1}$ & 0.0001 & 0.0003 & & \\
\hline$Q_{3}$ & 0.0104 & 0.0208 & & & $\mathrm{Q}_{3}$ & 0.0247 & 0.0231 & & \\
\hline \multicolumn{10}{|c|}{ Panel B. B. Argentina, March 1995} \\
\hline Mean & 0.0023 & 0.0027 & 255.70 & 0.000 & Mean & 0.0019 & 0.0018 & 540.67 & 0.000 \\
\hline Median & 0.0010 & 0.0009 & 0.18 & 0.858 & Median & 0.0012 & 0.0011 & 0.99 & 0.322 \\
\hline $\mathrm{Q}_{1}$ & 0.0004 & 0.0003 & & & $Q_{1}$ & 0.0003 & 0.0002 & & \\
\hline$Q_{3}$ & 0.0418 & 0.0564 & & & $\mathrm{Q}_{3}$ & 0.0080 & 0.0133 & & \\
\hline \multicolumn{10}{|c|}{ Panel B. C. Brazil, Jamwary 1999} \\
\hline Mean & 0.0042 & 0.0080 & 1835.89 & 0.000 & Mean & 0.0039 & 0.0067 & 5342.99 & 0.000 \\
\hline Median & 0.0032 & 0.0063 & 5.83 & 0.000 & Median & 0.0028 & 0,0047 & 7.80 & 0.000 \\
\hline$Q_{1}$ & 0.0008 & 0.0010 & & & $Q_{1}$ & 0.0003 & 0.0005 & & \\
\hline$Q_{3}$ & 0.0221 & 0.0379 & & & $Q_{3}$ & 0.0211 & 0.0486 & & \\
\hline
\end{tabular}

The numbers are summary statistics for the variance of the firm's stock. $Q_{1}$ and $Q_{3}$ represent the first and third quartiles of the distribution, respectively. The test for the mean is a chi-squared statistic for the test that the individual firm-level changes in variance for the sample are jointly significant. 
The first four columns of table 5.2 report the summary statistics of the cross-sectional distribution of firm-level stock return variances before and after the crisis date for the test samples. The significance levels of the $\chi^{2}$ statistics reveal that the hypothesis of no change in distribution of stock return variances of U.S. multinational firms active in the crisis countries is strongly rejected. The last four columns describe the corresponding analysis for the control samples. We can observe that for the control firms we also reject the null hypothesis in favor of the alternative hypothesis that the volatility of stock returns of the control firms was higher in the post-crisis sub-period than in the pre-crisis sub-period. ${ }^{16.3}$ Our finding corroborates the results of Bartov et al. (1996) and Chen and So (2002) that firms demonstrate increased stock return volatility corresponding to periods of increased exchange rate variability.

Table 5.2 also reports the results of a nonparametric Wilcoxon signed-rank test. This test, that verifies the null hypothesis of no shift in the median variance of stock returns after the crisis, has the advantage of being less sensitive to outliers than the previously reported $\chi^{2}$ statistic. The results in panel A (the Asian financial turmoil) of table 5.2 confirm the presence of a statistically significant change in the distribution of stock return volatilities across the two sub-periods; both the sample and control firms have a distinct median variance in the two sub-periods. In contrast, the results in panel B (the Latin-American financial turmoil) indicate that Argentina and Mexico displays no significant change in the median stock return volatility across the two periods. The findings for Brazil, however, indicate a statistically significant increase in the distribution of stock return volatilities across the two sub-periods for both samples.

As we nevertheless expect that our test sample firms are more sensitive to increased exchange rate variability than the control firms, we compare the distribution of the relative change in the total stock return variability for both samples. To set the two distributions against each other we use two tests. The t-test verifies the null hypothesis that the mean distribution of the relative change in the total stock return variability of the test sample is equal to the mean distribution of the relative change in the total stock return variability of the control sample; while the nonparametric Willcoxon signed-rank test examines this hypothesis by comparing the medians of stock return variances across the two sub-periods.

Table 5.3 provides explicit results regarding the relative firm-level stock return variances for both samples. Panel A of table 5.3 suggests that for the Thai and Korean crises, there is no statistically significant difference in the change of

${ }^{163}$ As suggested by Bartov et al (1996), this may be due to the fact that large shocks in exchange rate markets are correlated with other forms of increased macroeconomic uncertainty and may therefore affect all firms independently of their foreign involvement. 
Table 5.3: Stock return variability across exchange rate regímes - Crosssectional distributions of relative firm level stock return variances

\begin{tabular}{|c|c|c|c|c|c|}
\hline \multicolumn{6}{|c|}{ Panel As Asta } \\
\hline & Test sample & Control sample & \multicolumn{3}{|c|}{ Comparison of the distributions } \\
\hline & $\begin{array}{l}\text { Post-erisis / Pre- } \\
\text { erisis variance }\end{array}$ & $\begin{array}{l}\text { Posterisis / Pre- } \\
\text { crisis variance }\end{array}$ & 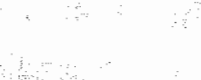 & $\begin{array}{c}\text { Test } \\
\text { statistic }\end{array}$ & Signiff \\
\hline \multicolumn{6}{|c|}{ Panel A A Thailand, July 1997} \\
\hline Mean & 1.99888 & 1.95056 & Ho: equality & 0.162 & 0.8717 \\
\hline Median & 1.84199 & 1.77375 & of means & & \\
\hline Maxinum & 4.62023 & 4.78443 & $\mathrm{H}_{0}$ equality & 0.672 & 0.5018 \\
\hline Minimum: & 0.56918 & 0.46071 & of medians & & \\
\hline \multicolumn{6}{|c|}{ Panel A B: Malaysia, July 1997} \\
\hline Mean & 2.13407 & 1.92710 & $H_{0 \prime}$ equality & 1.572 & 0.1167 \\
\hline Median & 2.01649 & 1.70584 & of means & & \\
\hline Maximunin & 6.54202 & 5.65564 & $\mathrm{H}_{0}:$ equality & 2.630 & $0.0085^{* * *}$ \\
\hline Mininum & 0.18151 & 0.47039 & of medians & & 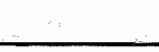 \\
\hline \multicolumn{6}{|c|}{ Panel A. C: Indonesia, August 1997} \\
\hline Mean & 2.13216 & 1.84041 & $H_{0}:$ equality & 2.728 & $0.0067 * *$ \\
\hline Median & 2.02807 & 1.75569 & of means & & \\
\hline Maximuin & 4.84700 & 5.03572 & $\mathrm{H}_{0}:$ equality & 2.135 & $0.0328 *$ \\
\hline Minimum & 0.53732 & 0.47944 & of medians & & \\
\hline \multicolumn{6}{|c|}{ Panel A. D: Korea December 1997} \\
\hline Mean & 1.98823 & 1.97008 & $\mathrm{H}_{0}$ : equality & 0.670 & 0.5034 \\
\hline Median & 1.86350 & 1.82318 & of means & & \\
\hline Maximum & 4.80327 & 5.22044 & $H_{0}:$ equality & 0.731 & 0.4647 \\
\hline Minimuin & 0.76287 & 0.23744 & of medians & & \\
\hline \multicolumn{6}{|c|}{ Panel B: Latin Anerica } \\
\hline \multicolumn{6}{|c|}{ Panel B. A: Mexico, December 1994} \\
\hline Mean: & 1.20510 & 1.13621 & $\mathrm{H}_{0 .}$ equallity & 0.351 & 0.7253 \\
\hline Median & 0.98548 & 0.89490 & of means & & \\
\hline Maximum & 9.33959 & 15.97440 & $H_{0}:$ equallity & 2.731 & $0.0063^{* *}$ \\
\hline Mininum & 0.33882 & 0.20631 & of medians & & \\
\hline \multicolumn{6}{|c|}{ Panel B. B: Argentima, March 1995} \\
\hline Mean & 1.18604 & 1.02458 & $\mathrm{H}_{10}$ : equality & 1.757 & 0.0804 \\
\hline Median & 1.03748 & 0.90673 & of means & & \\
\hline $\begin{array}{l}\text { Maximum } \\
\text { Minimum }\end{array}$ & $\begin{array}{l}5.07146 \\
0.46226\end{array}$ & $\begin{array}{l}3.74370 \\
0.17351\end{array}$ & $\begin{array}{l}\mathrm{H}_{0}: \text { equality } \\
\text { of medians }\end{array}$ & 1.511 & 0.1309 \\
\hline \multicolumn{6}{|c|}{ Panel B. C: Brazil, Jamuary 1999} \\
\hline Mean & 2.22045 & 1.94766 & $\mathrm{H}_{0}$ : equality & 1.812 & $0.0707^{*}$ \\
\hline Median & 1.85069 & 1.62552 & of means & & \\
\hline Maximum & 7.75536 & 12.98421 & $\mathrm{H}_{0}:$ equality & 2.465 & $0.0137 * *$ \\
\hline Minimum & 0.66384 & 0.44923 & of medians & & \\
\hline
\end{tabular}

The summary statistics describe the distributions of the relative change in firm-level variances from the pre-crisis to the post-crisis period. The test statistics report a t-test on the difference in means between the distributions of the test and control sample ratios and a Wilcoxon rank-sum test on the shift in median values. The significance levels are for the rejection of the null hypothesis that these distributions are equal. 
stock return wolatility between the test and control sample. The findings of the Malaysian and Indonesian crises, however, reveal that the stock return volatilities of the test sample firms increased significantly more than the volatilities of their control sample counterparts. ${ }^{164}$ Panel B of table 5,3 displays the results for the Latin-American financial crises. For each of these crises, we note that either the mean or the median of the relative variances of the test sample firms is statistically different from those of the control sample firms. For Argentina and Brazil, the variances of the test sample firms have statistically higher mean or median values than the variances of the control firms, whereas for Mexico the decrease in variability of stock retums was stronger for the control firms than for the sample firms. We, therefore, conclude that in the aftermath of a financial crisis, the stock retum variability of U.S. multinational firms with real operations in the crisis countries increased significantly more (or decreased significantly less) than the stock return variabillity of similar U.S. firms entertaining no direct foreign trading or production relationships with the crisis countries.

In order to strengthen our analysis, we furthermore examine the stock return variances at the portfolio level. ${ }^{165}$ We hence construct equally-weighted portfolios assembling test firms in one portfolio and control firms in another. Table 5.4 reports the variances of these portfolios for the pre-crisis sub-period and the post-crisis sub-period. The stated significance levels correspond to the rejection rate of the null hypothesis of no change in variance between the two periods. The table reveals two interesting observations. One, the effects of increased exchange rate variability on stock return volatility for the Asian crisis are substantially different from those obtained for the Latin-American crisis. The results for Latin America indicate that total stock return volatility for control firms increased insignificantly in the post-crisis period. In contrast, the increase in total stock return variability for control firms is particularly strong after the Asian currency crises, confirming the wide-spreading effects of these crises throughout the world. Two, all but one (Mexico) test portfolios exhibit a significant increase in total stock return variability in the post-crisis period.

Overall, our results suggest that the occurrence of exchange rate crises has a significant impact on the total stock return variability of both our test and control samples. Whereas U.S. domestic and multinational firms without real operations in

\footnotetext{
${ }^{164}$ For Indonesia, both the t-test and the Wilcoxon-test reject the null hypothesis whereas for Malaysia, only the Wilcoxon-test rejects the null hypothesis that the median of the relative variances of the test sample is equal to the median of the control sample.

$16 x$ We expect our results to be weaker for the portfolio analysis than for the firm-level analysis as the aggregation of firm-level stock retums within portfolios inevitably leads to some degree of diversification.
} 
the crisis countries seem to be affected by the financial repercussions caused by the fnancall turmoll, it appears nevertheless that U.S. multinationals with close foreign trading and production activities in the crisis countries are more sensitive to exchange rate fluctuations in the aftermath of a crisis.

Table 5.4: Stock return variability across exchange rate regimes - Equallyweighted portfolio return variances

\section{Panel A: Asia}

Test statistic for

\begin{tabular}{|c|c|c|c|c|c|}
\hline if & Before crisis & After crisis & $\begin{array}{r}\text { Test } \\
\text { change }\end{array}$ & $\begin{array}{l}\text { tic for } \\
\text { riance }\end{array}$ & Significance \\
\hline \multicolumn{6}{|c|}{ Panel A. A: Thailand, July 1997} \\
\hline Test portfolio & 0.00025 & 0.00075 & $\therefore$ & 3.063 & $0.0000 * *$ \\
\hline Contral portholio & 0.00032 & 0.00066 & & 2.102 & $0.0001 * *$ \\
\hline \multicolumn{6}{|c|}{ Panel A. B: Malaysia, July 1997} \\
\hline Test portfolio & 0.00026 & 0.00081 & & 3.188 & $0.0000^{*}$ \\
\hline Control portfollio & 0.00029 & 0.00081 & & 2.776 & $0.0000 *$ \\
\hline \multicolumn{6}{|c|}{ Panel A. C. Indonesia, August 1997} \\
\hline Test portfolio & 0.00017 & 0.00024 & & 1.395 & 0.0445 * \\
\hline Control portfolto & 0.00018 & 0.00018 & & 1.004 & 0.4923 \\
\hline \multicolumn{6}{|c|}{ Panel A. D: Korea, December 1997} \\
\hline Test portfolio & 0.00045 & 0.00100 & & 2.244 & $0,0000^{* * *}$ \\
\hline Control portfolio & 0.00032 & 0.00076 & & 2.411 & $0.0001^{*}$ \\
\hline
\end{tabular}

Panel B: Latin America

Panel B. A. Mexico December: 1994

\begin{tabular}{lllll}
\hline Test portfolio & 0.00012 & 0.00016 & 1.275 & 0.1083 \\
Control portfolio & 0.00016 & 0.00012 & 0.791 & 0.8836 \\
\hline
\end{tabular}

Panel B. B: Argentina, March 1995

\begin{tabular}{lccrr}
\hline Test portfolio & 0.00018 & 0.00024 & 1.323 & $0.0763^{*}$ \\
Control portfolio & 0.00018 & 0.00018 & 1.004 & 0.4923 \\
\hline & Panel B & C: Brazil January 1999 & & \\
\hline Test portfolio & 0.00069 & 0.00124 & 1.783 & $0.0017^{*}$ \\
Control portfolio & 0.00066 & 0.00068 & 1.026 & 0.4482 \\
\hline
\end{tabular}

The reported numbers are return variances to the equally weighted portfolios of the firms in each sample, expressed as percentage squared in decimal form. The test statistic is the ratio of the portfolio return variance in the pre-crisis window to the portfolio return variance in the post-crisis window. The reported significance is the significance of the one-tailed F-test against the alternative that the variance increases between the two periods. * indicates 10 percent significance level, * 5 percent significance level. 


\subsection{Exchange rate variability and market risk (beta) of U.S. multinationals}

For international investors and financial managers it could have important implication whether the documented increase in the total stock retum variability of U.S. multinationals resulting from the financial turmoil can be diversified away or whether it causes additional systematic risk. As in efficient markets only systematic risk receives compensation through an increase in the required rate of return ${ }_{3}$ the breakdown between systematic and diversifiable risk provides an insight into the relative cost of (equity) capital of U.S. mullinational active in the country crisis and other multinational or domestic firms.

In order to shed further light on this issue of systematic risk exposure, we use an event parameter approach. This method explicitly examines the change in the stochastic return generating process after the financial crisis. This conditioning is accomplished through the inclusion in the single-factor market model of a dummy variable set to one for the post-crisis period (Eq. 5.2):

$$
R_{i, t}=\alpha_{i}+B_{1, i} * R_{m, i}+B_{2, i} * R_{m, t} * D U M_{t}+\varepsilon_{i, t}
$$

where $R_{i, t}$ is the stock return of firm $i$ in week $t ; R_{m, t}$ the return to the CRSP equallyweighted U.S. market index in week $t ; D U M_{t}$, the dummy variable assumes values of one during the post-crisis period and zero elsewhere; and $\varepsilon_{i, r}$ is the residual. The coefficients $B_{l, i}$ and $B_{2, i}$ are the parameters of interest; $B_{l, i}$ is the index of market risk (beta) during the pre-crisis period and $B_{2, i}$ is the shift in the index of market risk during the post-crisis period form firm $i$. If the increase in exchange rate variability is associated with an increase in market risk of U.S. multinationals, $\beta_{2, i}$ will be significantly positive for our sample firms.

For each financial crisis, the augmented market model is estimated firm by firm over the total sample period surrounding the crisis date. In order to test the null hypothesis that the increase in market risk is not jointly significant for all sample firms, we use a Z-statistic based on the Newey-West corrected t-statistics of each $B_{z_{2},}$ firm-level estimated coefficients:

$$
Z=\left(1 / N^{I / 2}\right) \Sigma_{i=l, N} t_{i} /\left(k_{i} /\left(k_{i}-2\right)\right)^{1 / 2}
$$

As the Newey-West corrected $t$-statistic of $B_{2, i}$ is Student-t distributed with mean $t_{i}$ and variance $\left(k_{i} /\left(k_{i}-2\right)\right)$, the sum of these t-statistics across $N$ firms is, by application 
of the Central Limit Theorem ${ }^{166}$, normally distributed with variance $N$. Under the null hypothesis that $B_{Z_{i}}$ is jointly zero for all sample firms, the Z-statistic is consecutively a standard normal variate.

Intuitively, this approach tests the joint significance of the parameter shift in the post-crisis period among firms in the sample. The results displayed in table 5.5 enable us hence to verify whether the above documented increase of the total stock return variability of U.S. multinational firms in the aftermath of a financial crisis results or not in an increase in systematic risk for our sample firms.

The first column of table 5.5 report the cross-sectional mean ordinary least squares estimators of the coefficients $B_{l, i}$ joined with their cross-sectional standard deviation in parentheses. It appears for most samples that before the crisis the mean market risk of the sample firms was lower than that of the corresponding control firms. This observation tends to support the argument that test sample firms benefited from some sort of geographic diversification before the financial crisis exploded. This deduction, however, should be taken carefully as the control samples include not only U.S. domestic firms but also U.S. multinational firms that are indeed not active in the crisis countries but nevertheless active in other foreign countries and could, hence, profit from the geographic diversification effects of their foreign activities.

Based on our time-varying extension of the Capital Asset Pricing Model (CAPM) in Eq. (5.2) the cross-sectional mean of the $B_{2, i}$ estimates and their crosssectional standard deviation are presented in the second column of table 5.5. Panel A shows the results for the Asian financiall crises. We observe that for the test samples the cross-sectional means of the $B_{2, i}$ estimates are positive, whereas negative or close to zero for the control samples. ${ }^{167}$ As testified by the significance levels, we note that the market risk of U.S. multinationals with real operations in the Asian crisis economies grew significantly - by approximately five percent - during the period of financial turmoil. The test sample that appears to have been most affected by the financial crisis regroups U.S. multinational firms that were active in Thailand; their market beta grew from a cross-sectional mean value of 0.93756 to 1.05753. This result may be attributed to two facts; first, Thailand was the first Asian economy to decide to float its exchange rate during the crisis relative to other markets and second, Thailand experienced the most severe economic turmoil after the crisis. As such the Thai baht devaluation can be viewed as the most sudden and expected one among the four selected Asian devaluations.

\footnotetext{
Whis test statistic relies on the assumption that the estimates of $B_{2,}$ are independent one of another.

${ }^{167}$ The fact that the market risk of control firms didn't decrease as much for the Asian analysis as for the Latin American analysis suggests that the common Asian currency crises had more large-spreading economic implications than the isolated Latin American crises.
} 


\section{Table 5.5: Changes in market risk across exchange rate regimes - Cross- sectional distribution of firm-level changes in market risk}

\begin{tabular}{|c|c|c|c|c|c|}
\hline \multicolumn{6}{|c|}{ Panel A Asta } \\
\hline & & $\beta_{1}$ & $\beta_{2}$ & Z-statistic & Signif. \\
\hline \multicolumn{6}{|c|}{ Panel A. A. Thailand July 1997 } \\
\hline $\begin{array}{l}\text { Test sample } \\
\text { (std deviation) }\end{array}$ & 88 & $\begin{array}{r}0.96220 \\
0.0053\end{array}$ & $\begin{array}{r}0.05161 \\
0.0039\end{array}$ & 1.758 & 0.0394 * \\
\hline $\begin{array}{l}\text { Control sample } \\
\text { (std deviation) }\end{array}$ & 324 & $\begin{array}{r}1.09163 \\
0.0016\end{array}$ & $\begin{array}{r}-0.08594 \\
0.0014\end{array}$ & -5.613 & 1.0000 \\
\hline \multicolumn{6}{|c|}{ Panel A. B: Malaysia, July 1997} \\
\hline $\begin{array}{l}\text { Test sample } \\
\text { (std. deviation) }\end{array}$ & 97 & $\begin{array}{r}0.94443 \\
0.0050\end{array}$ & $\begin{array}{c}0.08309 \\
0.0042\end{array}$ & 1.615 & $0.0532^{*}$ \\
\hline $\begin{array}{l}\text { Control sample } \\
\text { (std deviation) }\end{array}$ & 360 & $\begin{array}{c}0.99752 \\
0.0015\end{array}$ & $\begin{array}{c}0.01740 \\
0.0016\end{array}$ & -1.271 & 0.8981 \\
\hline \multicolumn{6}{|c|}{ Panel A. C: Indonesia, August 1997} \\
\hline $\begin{array}{l}\text { Test sample } \\
\text { (std deviation) }\end{array}$ & 71 & $\begin{array}{c}0.92854 \\
0.0063\end{array}$ & $\begin{array}{c}0.06422 \\
0.0041\end{array}$ & 2.064 & $0.0195^{*}$ \\
\hline $\begin{array}{l}\text { Control sample } \\
\text { (std. deviation) }\end{array}$ & 256 & $\begin{array}{c}1.02426 \\
0.0017 \\
\end{array}$ & $\begin{array}{r}-0.07597 \\
0.0017 \\
\end{array}$ & -6.907 & 1.0000 \\
\hline \multicolumn{6}{|c|}{ Panel A. D. Konea December 1997} \\
\hline $\begin{array}{l}\text { Test sample } \\
\text { (std deviation) }\end{array}$ & 116 & $\begin{array}{r}1.06071 \\
0.0040\end{array}$ & $\begin{array}{c}0.04882 \\
0.0029\end{array}$ & 1.317 & $0.0939^{*}$ \\
\hline $\begin{array}{l}\text { Control sample } \\
\text { (std deviation) }\end{array}$ & 420 & $\begin{array}{c}0.998866 \\
0.0013\end{array}$ & $\begin{array}{r}-0.00432 \\
0.0013\end{array}$ & -2.812 & 0.9975 \\
\hline \multicolumn{6}{|c|}{ Panel B: Latin America } \\
\hline \multicolumn{6}{|c|}{ Panel B. A: Mexico, December 1994} \\
\hline $\begin{array}{l}\text { Test sample } \\
\text { (std. deviation) }\end{array}$ & 167 & $\begin{array}{c}0.83464 \\
0.0022\end{array}$ & $\begin{array}{r}0.08307 \\
0.0022\end{array}$ & 2.852 & $0.0022^{* * *}$ \\
\hline $\begin{array}{l}\text { Control sample } \\
\text { (std deviation) }\end{array}$ & 526 & $\begin{array}{c}0.95107 \\
0.0011\end{array}$ & $\begin{array}{r}-0.17495 \\
0.0011\end{array}$ & -7.270 & 1.0000 \\
\hline \multicolumn{6}{|c|}{ Panel B. B: Argentina, Manch 1995} \\
\hline $\begin{array}{l}\text { Test sample } \\
\text { (std deviation) }\end{array}$ & 48 & $\begin{array}{c}0.91626 \\
0.0071\end{array}$ & $\begin{array}{c}0.04124 \\
0.0009\end{array}$ & 1.276 & 0.1010 \\
\hline $\begin{array}{l}\text { Control sample } \\
\text { (std deviation) }\end{array}$ & 161 & $\begin{array}{l}1.05743 \\
0.0034\end{array}$ & $\begin{array}{r}-0.17600 \\
0.0034\end{array}$ & -5.885 & 1.0000 \\
\hline \multicolumn{6}{|c|}{ Panel B. C. Brazil, January 1999} \\
\hline $\begin{array}{l}\text { Test sample } \\
\text { (std. deviation) }\end{array}$ & 89 & $\begin{array}{c}0.99401 \\
0.0053\end{array}$ & $\begin{array}{c}0.05399 \\
0.0041\end{array}$ & 1.362 & $0.0866^{*}$ \\
\hline $\begin{array}{l}\text { Control sample } \\
\text { (std. deviation) }\end{array}$ & 333 & $\begin{array}{c}0.86118 \\
0.0014\end{array}$ & $\begin{array}{c}-0.04580 \\
0.0013\end{array}$ & -6.600 & 1.000 \\
\hline
\end{tabular}

The $\beta_{1}$ and $\beta_{2}$ coefficients are the mean OLS estimates of the parameter estimate for the individual firms in each sample. The reported standard errors are the cross-sectional standard errors of the means. The Z-statistics report a unit normal statistic for a test of the joint significance of the beta 2 parameter estimates. The reported significances are for the one-tailed test against the alternative that the market risk increases in the post-crisis period. * indicates 10 percent significance level, ** 5 percent significance level. 
Table 5.6: Changes in market risk across exchange rate regimes - Portfolio tests of changes in market risk

\begin{tabular}{|c|c|c|c|c|c|}
\hline \multicolumn{6}{|c|}{ Panel A : Asia } \\
\hline & $\mathrm{N}$ & $\beta_{1}$ & $B_{2}$ & t-stat for $\beta_{2}$ & Signif. \\
\hline \multicolumn{6}{|c|}{ Panel A. A. Thailand, July 1997} \\
\hline $\begin{array}{l}\text { Test portfolio } \\
\text { (sidd devianion) }\end{array}$ & 71 & $\begin{array}{l}0.93756 \\
0.04586\end{array}$ & $\begin{array}{l}0.11997 \\
0.08545\end{array}$ & 1.404 & $0.0809 \%$ \\
\hline $\begin{array}{l}\text { Control portolio } \\
\text { (sid devianon }\end{array}$ & 324 & $\begin{array}{l}1.09528 \\
0.04427\end{array}$ & $\begin{array}{r}-0.09441 \\
0.08061\end{array}$ & -1.171 & 0.8786 \\
\hline \multicolumn{6}{|c|}{ Panel A. B. Malaysia, July 1997} \\
\hline $\begin{array}{l}\text { Test portfolio } \\
\text { (std. deviation) }\end{array}$ & 97 & $\begin{array}{r}0.94329 \\
0.05030\end{array}$ & $\begin{array}{c}0.07458 \\
0.09203\end{array}$ & 0.810 & 0.2093 \\
\hline $\begin{array}{l}\text { Control portfolio } \\
\text { (std deviation) }\end{array}$ & 360 & $\begin{array}{l}1.01741 \\
0.05460\end{array}$ & $\begin{array}{r}-0.00332 \\
0.09990\end{array}$ & -0.033 & 0.5132 \\
\hline \multicolumn{6}{|c|}{ Panel A. C. Indonesia, August 1997} \\
\hline $\begin{array}{l}\text { Test portfolio } \\
\text { (std. deviations) }\end{array}$ & 71 & $\begin{array}{l}0.92867 \\
0.03334\end{array}$ & $\begin{array}{l}0.04414 \\
0.07695\end{array}$ & 0.574 & 0.2834 \\
\hline $\begin{array}{l}\text { Control portfolio } \\
\text { (std deviation) }\end{array}$ & 256 & $\begin{array}{r}1.03293 \\
0.0210 \\
\end{array}$ & $\begin{array}{r}-0.09225 \\
0.0500 \\
\end{array}$ & -1.845 & 0.9668 \\
\hline \multicolumn{6}{|c|}{ Panel A. D: Korea, December 1997} \\
\hline $\begin{array}{l}\text { Test portfolio } \\
\text { (sid. deviation) }\end{array}$ & 116 & $\begin{array}{l}1.05969 \\
0.07506\end{array}$ & $\begin{array}{l}0.03048 \\
0.10315\end{array}$ & 0.295 & 0.3840 \\
\hline $\begin{array}{l}\text { Conitrol portfolio } \\
\text { (std. dewiation) }\end{array}$ & 420 & $\begin{array}{l}1.01500 \\
0.03887\end{array}$ & $\begin{array}{r}-0.01694 \\
0.07812 \\
\end{array}$ & -0.217 & 0.5857 \\
\hline \multicolumn{6}{|c|}{ Panel B: Latin America } \\
\hline \multicolumn{6}{|c|}{ Panel B. A: Mexico, December 1994} \\
\hline $\begin{array}{l}\text { Test portfolio } \\
\text { (std. dewiation) }\end{array}$ & 167 & $\begin{array}{r}0.83467 \\
0.03665\end{array}$ & $\begin{array}{l}0.07803 \\
0.04585\end{array}$ & 1.702 & $0.0452 * *$ \\
\hline $\begin{array}{l}\text { Control portfolio } \\
\text { (sid deniation) }\end{array}$ & 526 & $\begin{array}{r}0.94728 \\
0.04426\end{array}$ & $\begin{array}{r}-0.17042 \\
0.05662\end{array}$ & -3.010 & 0.9985 \\
\hline \multicolumn{6}{|c|}{ Panel B. B: Argentina, March 1995} \\
\hline $\begin{array}{l}\text { Test portfolio } \\
\text { (std. deviation) }\end{array}$ & 48 & $\begin{array}{r}0.91746 \\
0.06987\end{array}$ & $\begin{array}{r}0.04515 \\
0.08304\end{array}$ & 0.544 & 0.2936 \\
\hline $\begin{array}{l}\text { Control portfolio } \\
\text { (std devartion) }\end{array}$ & 161 & $\begin{array}{l}1.04921 \\
0.05034\end{array}$ & $\begin{array}{r}-0.16852 \\
0.06043\end{array}$ & -2.789 & 0.9971 \\
\hline \multicolumn{6}{|c|}{ Panel B, C: Brazil, Ianuary 1999} \\
\hline $\begin{array}{l}\text { Test portfolio } \\
\text { (std. dewation) }\end{array}$ & 89 & $\begin{array}{l}0.99049 \\
0.04709\end{array}$ & $\begin{array}{l}0.06519 \\
0.06349\end{array}$ & 1.027 & 0.1529 \\
\hline $\begin{array}{l}\text { Control portfolio } \\
\text { (std deviations) }\end{array}$ & 333 & $\begin{array}{r}0.85897 \\
0.03500\end{array}$ & $\begin{array}{r}-0.03782 \\
0.05060\end{array}$ & -0.748 & 0.7722 \\
\hline
\end{tabular}

The $\beta_{1}$ and $\beta_{2}$ coefficients are the OLS estimates of the parameter estimate for the equallyweighted portfolios of firms in each sample. Newey-West corrected standard errors are reported in parentheses. The reported significances are for the one-tailed test against the alternative that the market risk increases in the post-crisis period. * indicates 1.0 percent significance level, ** 5 percent significance level. 
Furthermore, the analysis of the Latin American crises in panel $B$ reveals that the cross-sectional means of $B_{2, i}$ are systematically positive for all test samples while negative for the control samples. We note that the reported Z-statistics attest the statistically significance of the increase in market risk for the Mexican and Brazilian test samples. For Argentina we observe an average increase in market risk of 0.04124 for U.S. multinationals active in Argentina while the market beta of control firms decreases by 0.17600 . These changes in market risk are consistent with the findings of Schmukler and Servén (2002), who observe a significant increase in the exchange rate premium in Argentina in March 1995. ${ }^{168}$ However the increase in market risk for U.S. multinationals with real operations in Argentina is not statistically significant. This result suggests that the decision of the Argentinean administration to maintain the currency board in spite of the strong devaluation pressures has somewhat preserved the economic environment of some of these multinationals.

Overall, these results are consistent with our expectations. Following the sharp increase in exchange rates variability due to the currency crises, the market risk of U.S. multinationals active in these emerging economies increased significantly. While all firms experience an increase in stock return volatility, there is a significant difference in the nature of this increased volatility across the different samples of firms. The negative change in market risk experienced by many control firms during the post-crisis period moreover suggests that the relative shift in market risk between sample and control firms is even larger than reported by the $B_{2, i}$ coefficients for sample firms. Thus, U.S. multinational firms saw their beta rising as a result of the financial turmoil and, correspondingly, are faced with higher equity financing costs.

To strengthen our analysis, we examine the change in systematic risk at the portfolio level. In line with our previous findings from the firm-level analysis, we observe in table 5.6 that the reported $B_{2}$ coefficients are positive for the test portfolios while negative for most control portfolios. Our results clearly indicate that the market risk of the test portfolios relative to the market risk of the control portfolios increased strongly after the exchange rate regime shift from fixed to floating exchange rates. Nevertheless, as expected, the significance levels of the $\theta_{2}$ coefficients decrease at the portfolio level. Only the positive changes in market beta after the Mexican and Thai crises remain statistically significant for the portfolios of U.S. firms active in these countries.

\footnotetext{
16: After March 1995, the Argentimean currency premium remains high for approximately half a year and is afterwards decreasing again.
} 


\subsection{Sensitivity analysis}

\subsubsection{Across industries}

Different industries present different types of import and export patterns as well as different competitive environments. The impact of an increase in exchange rate uncertainty may therefore affect some industries differently than others. For instance, a sharp depreciation in the crisis country increases the competitiveness of its exports and has a negative impact on firms competing with those exports, whereas it has a positive influence on foreign firms using those exports as inputs in their production process. To specifically identify which types of industries are most affected by the crises that originate elsewhere, this study uses an industry-level variation both for the firm-by-firm and the portfolio analysis.

In order to perform the industry-specific analysis, both test and control samples are sub-divided in eight different industry sectors. Results shown in panel A of table 5.7 reveal that after the Asian financial crises U.S. multinationals within the Transport Communication and Transport, the Wholesale and Retail Trade and the Finance and Services sectors experienced a sharp and statistically significant increase in systematic risk (beta). It is quite comprehensive that these sectors were the hardest hit by the Asian financial turmoil. These sectors consist mainly of U.S. firms that export "finished" goods and services towards Asia. As such they suffered both from their relative loss in competitiveness compared to Asian firms and from the decrease in the Asian demand due to the income effect. As suggested in table 5.7, U.S. multinationals in the Agriculture, Mining and Construction Industries were similarly affected by the Asian crisis. ${ }^{169}$ These findings confirm the huge negative impact the Asian crisis had on the U.S. Agricultural Industry. ${ }^{170}$

The low impact of the currency crisis on other industries may be explained by the fact that U.S. manufacturing industries were affected in various different and opposite ways during periods of increased exchange rate variability. To the extent that the Asian demand fell for manufacturing goods, U.S. exports to the region were negatively affected. On the other hand, the depreciations allowed Asia to expand their position in the manufacturing industries both increasing its demand for intermediate manufacturing components from the U.S. and decreasing the relative price of intermediate manufacturing goods for U.S. importers. As a result the total impact of the financial crises on U.S. manufacturers active in the Asian region was expected to be low.

\footnotetext{
${ }^{169}$ The composition of these industry-specific test samples reveals that they contain mainly firms from the agricultural sector.

${ }^{170}$ Indeed U.S. agricultural exponts towards Asia fell by nearly one-third in 1998 (Orden, 2000).
} 
Table 5.7: Changes in market risk across exchange rate regimes - Analysis of cross-sectional distribution of firm-level changes in market nisk across industries

\begin{tabular}{|c|c|c|c|c|c|c|c|c|c|c|c|c|}
\hline \multicolumn{13}{|c|}{ Ponel A: Asia } \\
\hline & \multicolumn{3}{|c|}{ Thailand } & \multicolumn{3}{|c|}{ Malaysia } & \multicolumn{3}{|c|}{ Indonesia } & \multicolumn{3}{|c|}{ Korea } \\
\hline & $\mathrm{N}$ & $B_{2}$ & signif. & $\mathrm{N}$ & $\beta_{2}$ & sigmif & $\mathrm{N}$ & $\beta_{2}$ & stgnif & $\mathrm{N}$ & $p_{2}$ & sigmin \\
\hline Test sample & & & & & & & & & & & & \\
\hline $\begin{array}{l}\text { Agric, mining } \\
\& \text { construction }\end{array}$ & 6 & $\begin{array}{l}0.134 \\
0.039\end{array}$ & 0.213 & 7 & $\begin{array}{l}0.364 \\
0.068\end{array}$ & $0.02 .5 *$ & 9 & $\begin{array}{l}0.069 \\
0.025\end{array}$ & 0.428 & 2 & $\begin{array}{l}0.506 \\
0.101\end{array}$ & $0.030^{* 2 *}$ \\
\hline Manuf: & 1 & $\begin{array}{l}0.215 \\
0.000\end{array}$ & 0.177 & 5 & $\begin{array}{l}0.012 \\
0.067\end{array}$ & 0.448 & 5 & $\begin{array}{l}0.119 \\
0.074\end{array}$ & 0.273 & 3 & $\begin{array}{l}-0.152 \\
0.012\end{array}$ & 0.851 \\
\hline Manuf II & 12 & $\begin{array}{r}-0.122 \\
0.013\end{array}$ & 0.960 & 13 & $\begin{array}{r}-0.067 \\
0.010\end{array}$ & 0.851 & 9 & $\begin{array}{l}0.003 \\
0.021\end{array}$ & 0.654 & 15 & $\begin{array}{l}-0.012 \\
0.014\end{array}$ & 0.700 \\
\hline Manuf. III & 4 & $\begin{array}{c}-0.170 \\
0.072\end{array}$ & 0.837 & 9 & $\begin{array}{l}-0.105 \\
0.028\end{array}$ & 0.866 & 2 & $\begin{array}{l}0.077 \\
0.183\end{array}$ & 0,487 & 3 & $\begin{array}{r}0.024 \\
0.087\end{array}$ & 0.622 \\
\hline Manuf. IV & 25 & $\begin{array}{l}0.002 \\
0.013\end{array}$ & 0.477 & 31 & $\begin{array}{l}0.039 \\
0.017\end{array}$ & 0.718 & 16 & $\begin{array}{r}-0.020 \\
0.016\end{array}$ & 0.408 & 45 & $\begin{array}{l}0.048 \\
0.008\end{array}$ & 0.288 \\
\hline $\begin{array}{l}\text { Transp., Com. } \\
\text { \& Utilities }\end{array}$ & 6 & $\begin{array}{l}0.177 \\
0.089\end{array}$ & $0.023^{*}$ * & 6 & $\begin{array}{l}0.284 \\
0.073\end{array}$ & $0,005 * *$ & 8 & $\begin{array}{l}0.247 \\
0.043\end{array}$ & $0.014^{* *}$ & 7 & $\begin{array}{l}0.093 \\
0.048\end{array}$ & 0.158 \\
\hline Trade & 19 & $\begin{array}{l}0.187 \\
0.017\end{array}$ & $0.002 * *$ & 10 & $\begin{array}{l}0.083 \\
0.028\end{array}$ & $0.029 *$ & 15 & $\begin{array}{l}0.017 \\
0.022\end{array}$ & $0.076 *$ & 25 & $\begin{array}{l}0.106 \\
0.012\end{array}$ & $0.031 *$ \\
\hline $\begin{array}{l}\text { Finance } \\
\text { and Services }\end{array}$ & 15 & $\begin{array}{l}0.066 \\
0.022\end{array}$ & $0: 129$ & 16 & $\begin{array}{r}0.220 \\
0.017\end{array}$ & $0.016^{* * *}$ & 7 & $\begin{array}{l}0.177 \\
0.028\end{array}$ & $0.065^{\text {* }}$ & 16 & $\begin{array}{r}-0.016 \\
0.026\end{array}$ & 0.476 \\
\hline Control sampl & & & & & & & & & & & & \\
\hline $\begin{array}{l}\text { Agric, mining } \\
\& \text { construction }\end{array}$ & 23 & $\begin{array}{l}0.061 \\
0.025\end{array}$ & 0.920 & 28 & $\begin{array}{l}0.388 \\
0.021\end{array}$ & $0.006^{* *}$ & 32 & $\begin{array}{l}0.096 \\
0.011\end{array}$ & 0.399 & 7 & $\begin{array}{l}0.248 \\
0.048\end{array}$ & 0.109 \\
\hline Martuf I & 4 & $\begin{array}{l}0.149 \\
0.053\end{array}$ & 0.142 & 16 & $\begin{array}{l}-0.228 \\
0.025\end{array}$ & 0.999 & 19 & $\begin{array}{r}-0.341 \\
0.018\end{array}$ & 1.000 & 10 & $\begin{array}{r}-0.022 \\
0.014\end{array}$ & 0.645 \\
\hline Manuf II & 40 & $\begin{array}{r}-0.056 \\
0.008\end{array}$ & 0.924 & 49 & $\begin{array}{r}-0.088 \\
0.008\end{array}$ & 0.993 & 35 & $\begin{array}{r}-0.1136 \\
0.008\end{array}$ & 0.997 & 59 & $\begin{array}{r}-0.060 \\
0.007\end{array}$ & 0.995 \\
\hline Manulf. III & 16 & $\begin{array}{l}0.029 \\
0.025\end{array}$ & 0.549 & 31 & $\begin{array}{l}0.075 \\
0.017\end{array}$ & 0.171 & 6 & $\begin{array}{l}0.069 \\
0.080\end{array}$ & 9.619 & 11 & $\begin{array}{l}0.031 \\
0.026\end{array}$ & 0.563 \\
\hline Manuf. IV & 100 & $\begin{array}{r}-0.135 \\
0.004\end{array}$ & 1.000 & 115 & $\begin{array}{l}0.005 \\
0.004\end{array}$ & 0.556 & 49 & $\begin{array}{r}-0.027 \\
0.007\end{array}$ & $0.60 \%$ & 164 & $\begin{array}{r}-0.023 \\
0.004\end{array}$ & 1.000 \\
\hline $\begin{array}{l}\text { Transp. Com. } \\
\text { \& Utilities }\end{array}$ & 24 & $\begin{array}{c}-0.144 \\
0.013\end{array}$ & 1.000 & 22 & $\begin{array}{r}-0.021 \\
0.020\end{array}$ & 0.846 & 31 & $\begin{array}{r}-0.269 \\
0.011\end{array}$ & 1.000 & 22 & $\begin{array}{l}0.148 \\
0.027\end{array}$ & 0.336 \\
\hline Trade & 72 & $\begin{array}{r}-0.024 \\
0.005\end{array}$ & 0.911 & 40 & $\begin{array}{l}0.035 \\
0.008\end{array}$ & 0.385 & 57 & $\begin{array}{r}-0.029 \\
0.006\end{array}$ & 0.907 & 100 & $\begin{array}{r}0.006 \\
0.004\end{array}$ & 0.657 \\
\hline $\begin{array}{l}\text { Finance } \\
\text { and Services }\end{array}$ & 45 & $\begin{array}{c}-0.243 \\
0.013\end{array}$ & 0.999 & 59 & $\begin{array}{r}-0.008 \\
0.016\end{array}$ & 0.873 & 27 & $\begin{array}{r}-0.015 \\
0.030\end{array}$ & 0.789 & 57 & $\begin{array}{l}0.087 \\
0.010\end{array}$ & 0.500 \\
\hline
\end{tabular}


Table 5.7: continued

\begin{tabular}{|c|c|c|c|c|c|c|c|c|c|}
\hline \multicolumn{10}{|c|}{ Panel B: Latin America } \\
\hline & \multicolumn{3}{|c|}{ Mexico } & \multicolumn{3}{|c|}{ Argentina } & \multicolumn{3}{|c|}{ Brazil } \\
\hline$\because$ & $N$ & $P_{2}$ & Ignky & $\mathrm{N}$ & $\beta_{2}$ & sighrof & $N$ & $\beta_{2}$ & signif \\
\hline Test sample & & & & & & & & & \\
\hline $\begin{array}{l}\text { Agriculture, mining } \\
\text { \& construction }\end{array}$ & 6 & $\begin{array}{l}0.242 \\
0.041\end{array}$ & 0.126 & 5 & $\begin{array}{l}0.184 \\
0.117\end{array}$ & 0.124 & 4 & $\begin{array}{l}-0.031 \\
0.014\end{array}$ & 0.612 \\
\hline Manufacturing I & 22 & $\begin{array}{r}0.084 \\
0.020\end{array}$ & 0.143 & 5 & $\begin{array}{r}-0.155 \\
0.166\end{array}$ & 0.162 & 3 & $\begin{array}{c}-0.113 \\
0.015\end{array}$ & 0.770 \\
\hline Manufacturing in Petroleum & 37 & $\begin{array}{l}0.010 \\
0.008\end{array}$ & 0.409 & 14 & $\begin{array}{r}-0.042 \\
0.027\end{array}$ & 0.806 & 5 & $\begin{array}{r}-0.135 \\
0.020\end{array}$ & 0.886 \\
\hline Manufacturing m & 18 & $\begin{array}{l}0.094 \\
0.017\end{array}$ & 0.370 & 1 & $\begin{array}{l}-0.387 \\
0.000\end{array}$ & 0.921 & 3 & $\begin{array}{l}0.220 \\
0.193\end{array}$ & $0.100^{*}$ \\
\hline Manufacturing IV Electronics & 59 & $\begin{array}{l}0.104 \\
0.007\end{array}$ & $0.019^{* * *}$ & 17 & $\begin{array}{l}0.031 \\
0.023\end{array}$ & 0.379 & 41 & $\begin{array}{l}0.077 \\
0.009\end{array}$ & $0.068^{*}$ \\
\hline $\begin{array}{l}\text { Transport, Communications } \\
\text { \& Utilities }\end{array}$ & 4 & $\begin{array}{l}0.040 \\
0.071\end{array}$ & 0.308 & 1 & $\begin{array}{l}0.122 \\
0.000\end{array}$ & 0.357 & 6 & $\begin{array}{l}0.042 \\
0.051\end{array}$ & 0.245 \\
\hline Wholesale and Retail Trade & 14 & $\begin{array}{l}0.173 \\
0.024\end{array}$ & $0.002^{* * *}$ & 4 & $\begin{array}{l}0.507 \\
0.081\end{array}$ & $0.001 *$ & 10 & $\begin{array}{r}-0.097 \\
0.026\end{array}$ & 0.848 \\
\hline Finance and Services & 7 & $\begin{array}{r}-0.025 \\
0.045\end{array}$ & 0.627 & 1 & $\begin{array}{l}0.129 \\
0.000\end{array}$ & 0.267 & 17 & $\begin{array}{l}0.168 \\
0.026\end{array}$ & $0.040^{* * *}$ \\
\hline Control sample & & & & & & & & & \\
\hline $\begin{array}{l}\text { Agriculture, mining } \\
\& \text { construction }\end{array}$ & 22 & $\begin{array}{l}0.005 \\
0.022\end{array}$ & 0.527 & 16 & $\begin{array}{l}0.126 \\
0.044\end{array}$ & 0.538 & 14 & $\begin{array}{r}-0.161 \\
0.017\end{array}$ & 0.995 \\
\hline Manufacturing I & 68 & $\begin{array}{r}-0.157 \\
0.008\end{array}$ & 0.980 & 15 & $\begin{array}{l}-0.170 \\
0.022\end{array}$ & 0.987 & 11 & $\begin{array}{r}-0.360 \\
0.009\end{array}$ & 1.000 \\
\hline Maniufachining II Petroleum & 115 & $\begin{array}{r}0.241 \\
0.005\end{array}$ & 1.000 & so & $\begin{array}{r}-0.278 \\
0.009\end{array}$ & 1.000 & 20 & $\begin{array}{r}-0.239 \\
0.007\end{array}$ & 1.000 \\
\hline Manufacturing III & 58 & $\begin{array}{r}-0.193 \\
0.010\end{array}$ & 0.999 & 3 & $\begin{array}{r}-0.351 \\
0.148\end{array}$ & 0.937 & 9 & $\begin{array}{r}-0.293 \\
0.014\end{array}$ & 0.999 \\
\hline Manufactuting IV Electronicss & 178 & $\begin{array}{r}-0.197 \\
0.004\end{array}$ & 1.000 & 57 & $\begin{array}{r}-0.066 \\
0.008\end{array}$ & 0.965 & 154 & $\begin{array}{l}0.034 \\
0.003\end{array}$ & 0.906 \\
\hline $\begin{array}{l}\text { Transport, Communications } \\
\text { \& Utilties }\end{array}$ & 16 & $\begin{array}{l}-0.234 \\
0.047\end{array}$ & 0.982 & 4 & $\begin{array}{r}-0.431 \\
0.255\end{array}$ & 0.999 & 24 & $\begin{array}{c}-0.038 \\
0.013\end{array}$ & 0.648 \\
\hline Wholesale and Retail Trade & 46 & $\begin{array}{l}-0.006 \\
0.010\end{array}$ & 0.507 & 1.3 & $\begin{array}{r}-0.231 \\
0.040\end{array}$ & 0.982 & 37 & $\begin{array}{c}-0.188 \\
0.007\end{array}$ & $1: 000$ \\
\hline Finance and Sorvices & 22 & $\begin{array}{r}-0.144 \\
0.023\end{array}$ & 0.882 & 3 & $\begin{array}{l}-0.134 \\
0.017\end{array}$ & 0.738 & 64 & $\begin{array}{l}0.016 \\
0.009\end{array}$ & 0.989 \\
\hline
\end{tabular}

The $\beta_{2}$ coefficients are the mean OLS estimates of the change in market risk during the post-crisis period for the individual firms in each sample. The reported standard errors are the cross-sectional standiard errots of the means. The reported significances are for the one-tailed test against the alternative that the market risk increases in the post-crisis period. indicates 10 percent significance level, 5 percent significance level. 
Panel B of table 5.7 displays the umpact of the three Latin Americali financial crises across different industries at a firm-by-firm level Similarly to the observations made for the Asian crises, we observe that the U.S. multinationals that are active in the Wholesale and Retail Trade Industry experience a significant increase in market risk (beta) after the crisis. The U.S. banking firms active in Brazill have also been particularly affected. This impact might easily be explained by the fact that Brazil was the largest single foreign borrower from U.S. banks before the crisis. ${ }^{171}$

\subsubsection{Across size}

In order to perform an extensive analysis of the characteristics of U.S. multinational firms exposed to foreign exchange rate risk, we furthermore analyze the impact of increased exchange rate variability on the market risk of U.S. multinationals across different market capitalization categories. Therefore we group both test sample firms and control sample firms within five separate classes according to their market value and examine the change in market risk across these various subsamples at the firm-level as well as at the portfolio level.

Our findings displayed in panel $A$ of table 5.8 reveal two notable facts. First, the increase in market beta for U.S. multinationals active in the Asian crisis economies was particularly strong for very small firms whose market capitalization was lower than one million U.S. dollar at the event date. ${ }^{172}$ Second, we observe consistently for all Latin-American crises that among the test samples large U.S. companies experience as well an increase in their market risk in the aftermath of the financial turmoil.

Nevertheless we note in table 5.9 that this increase is not statistically significant at the portfolio-level; only the market beta change for very small U.S. multinationals remains statistically significant after both the Malaysian and Indonesian crises. Moreover, in contrast to the Asian crises, panel B of table 5.8 and 5.9 demonstrates that the market risk of large U.S. multinationals increased substantially more than that of small firms.

\footnotetext{
171 For completeness, we study the industry-specific impact of financial crises at a portfolio level. Overall, results confirm the findings described above.

${ }^{172}$ Tests confirm that these increases were highly statistically significant.
} 
Table 5.8: Changes in market risk across exchange rate regimes - Analysis of cross-sectional distribution of firm-level changes in market risk across market capitalization categories

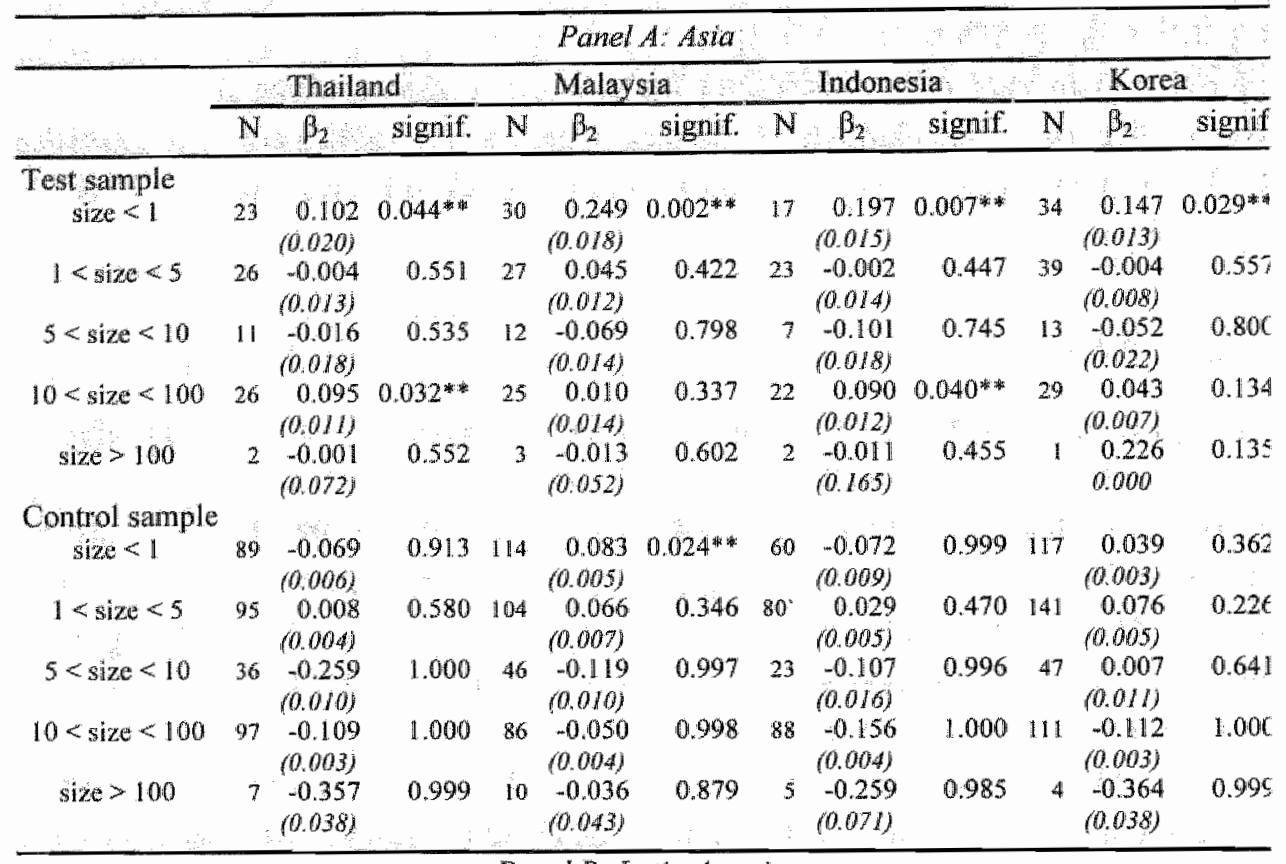

Panel B. Latin America:

\begin{tabular}{|c|c|c|c|c|c|c|c|c|c|}
\hline \multirow{2}{*}{ Test sample } & \multicolumn{3}{|c|}{ Mexico } & \multicolumn{3}{|c|}{ Argentina } & \multicolumn{3}{|c|}{ Brazil } \\
\hline & & & & & & & & & \\
\hline & 48 & $\begin{array}{r}0.102 \\
(0.010)\end{array}$ & 0.230 & 8 & $\begin{array}{l}-0.262 \\
(0.090)\end{array}$ & 0.819 & 24 & $\begin{array}{r}0.005 \\
(0.015)\end{array}$ & 0.577 \\
\hline $1<\operatorname{siz}$ & 65 & $\begin{array}{r}0.058 \\
(0.005)\end{array}$ & 0.049 & 7 & $\begin{array}{r}-0.026 \\
(0.049)\end{array}$ & 90 & 21 & $\begin{array}{r}0.0065 \\
(0.017)\end{array}$ & 0.568 \\
\hline $5<\operatorname{sizh}$ & 22 & $\begin{array}{r}0.120 \\
0.016)\end{array}$ & $0.020^{* * 1 *}$ & 10 & $\begin{array}{r}0.058 \\
(0.035)\end{array}$ & 0.467 & 8 & $\begin{array}{r}0.009 \\
(0.045)\end{array}$ & 0.732 \\
\hline $10<\mathrm{si}$ & 29 & $\begin{array}{r}0,047 \\
(0,011)\end{array}$ & 0.2 & 19 & $\begin{array}{r}0.174 \\
(0.018)\end{array}$ & $0.0 \mathrm{t}$ & 25 & $\begin{array}{r}0.115 \\
(0.015)\end{array}$ & * * * \\
\hline size $>100$ & 3 & $\begin{array}{r}0.394 \\
(0.033)\end{array}$ & $0.005^{*}$ & 1 & $\begin{array}{r}0.184 \\
(0.000)\end{array}$ & 0.236 & 11 & $\begin{array}{r}0.147 \\
(0.024)\end{array}$ & $0.046^{* * *}$ \\
\hline Contro & & & & & & & & & \\
\hline size & 149 & $\begin{array}{r}-0.198 \\
(0.005)\end{array}$ & 1.000 & 33 & $\begin{array}{r}-0.333 \\
(0.022)\end{array}$ & 1.000 & 83 & $\begin{array}{r}-0.188 \\
(0.006)\end{array}$ & 1.000 \\
\hline $1<\operatorname{size}<5$ & 206 & $\begin{array}{r}-0.113 \\
(0.003)\end{array}$ & 0.999 & 27 & $\begin{array}{r}-0,442 \\
(0,020)\end{array}$ & 1.000 & 77 & $\begin{array}{r}-0.221 \\
(0.009)\end{array}$ & 1.000 \\
\hline $5<\mathrm{si}$ & 70 & $\begin{array}{l}-0.299 \\
(0.008)\end{array}$ & 1.000 & 38 & $\begin{array}{l}-0.138 \\
(0.011)\end{array}$ & 0.991 & 32 & $\begin{array}{l}-0.188 \\
(0.015)\end{array}$ & 1.000 \\
\hline $10<s$ & 91 & $\begin{array}{l}-0.215 \\
(0.006)\end{array}$ & 1.000 & 61 & $\begin{array}{r}-0.009 \\
(0.007)\end{array}$ & 747 & 99 & $\begin{array}{l}-0.211 \\
0.005 j\end{array}$ & 1.000 \\
\hline size $>100$ & 10 & $\begin{array}{r}0.124 \\
(0.033)\end{array}$ & 0.109 & 2 & $\begin{array}{r}0.194 \\
(0.007)\end{array}$ & 0.117 & 42 & $\begin{array}{l}-0.211 \\
(0.011)\end{array}$ & 1.000 \\
\hline
\end{tabular}

The $\beta_{2}$ coeffictents are the cross-sectional mean OLS estimates of the change in market risk during the post-crisis period. Cross-sectional standard errors are in parentheses. Reported significances are for the one-tailed test against the alternative that the market risk increases in the post-crisis period. * indicates 10 percent significance level, * 5 percent significance level. Size (in US\$ millions) is measured by market capitalization. 
Table 5.9: Changes in market risk across exchange rate regimes - Analysis of portfolio tests of changes in market risk across market capitalization categaries

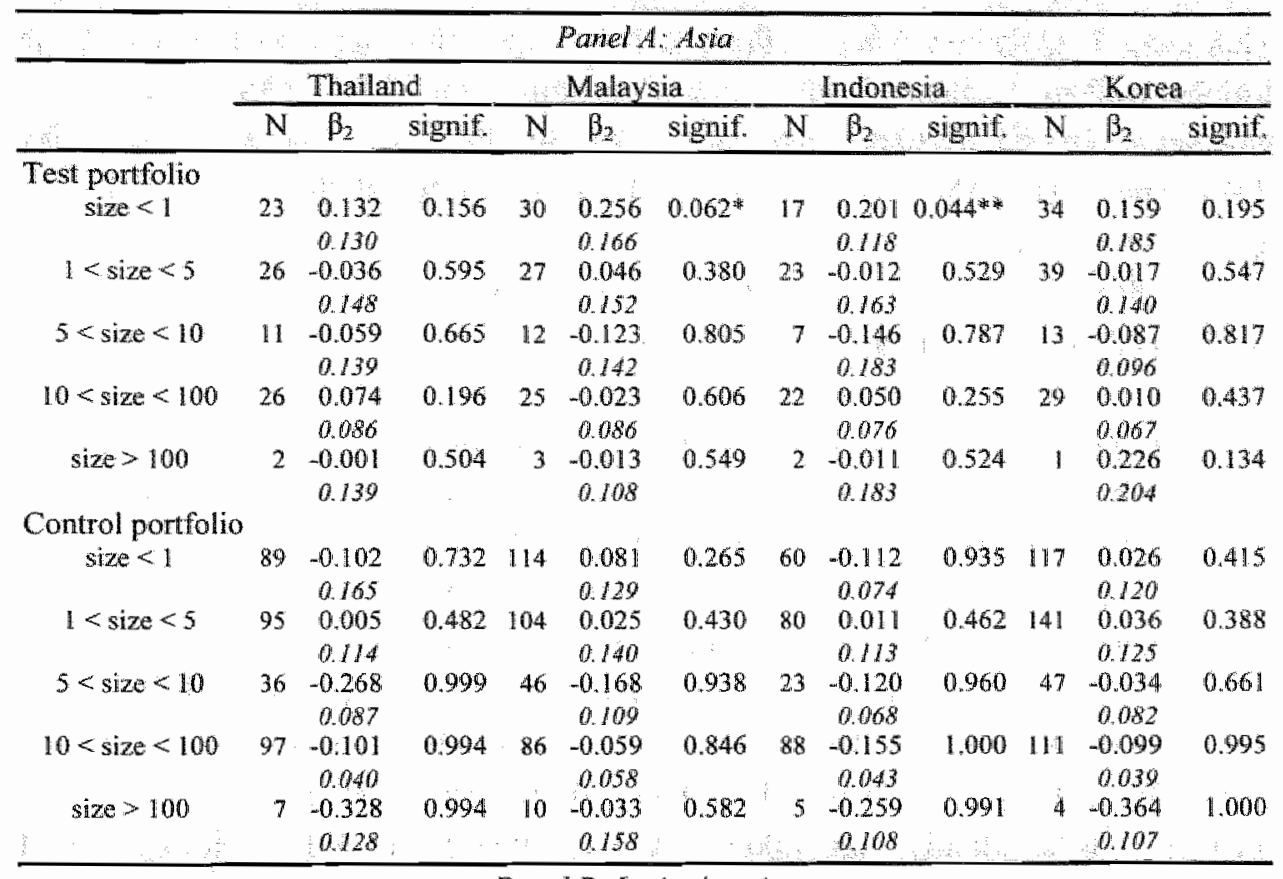

Panel B: Latin America

\begin{tabular}{|c|c|c|c|c|c|c|c|c|c|}
\hline \multirow{2}{*}{ Test portfolio } & \multicolumn{3}{|c|}{ Mexico } & \multicolumn{3}{|c|}{ Argentina } & \multicolumn{3}{|c|}{ Brazil } \\
\hline & & & & & & & & & \\
\hline \multirow[t]{2}{*}{ size $<\mathbb{1}$} & 48 & 0.085 & 0.199 & 8 & -0.183 & 0.698 & 24 & 0.017 & 0.449 \\
\hline & & 0.101 & & & 0.351 & & & 0.131 & \\
\hline \multirow[t]{2}{*}{$1<$ size $<5$} & 65 & 0.056 & 0.175 & 7 & -0.026 & 0.563 & 21 & 0.031 & 0.414 \\
\hline & & 0.060 & & & 0.167 & & & 0.141 & \\
\hline \multirow[t]{2}{*}{$5<\operatorname{size}<10$} & 22 & 0.118 & $0.093 *$ & 10 & 0.062 & 0.294 & 8 & 0.007 & 0.483 \\
\hline & & 0.090 & & & 0.114 & & & 0.163 & \\
\hline \multirow[t]{2}{*}{$10<\operatorname{size}<100$} & 29 & 0.047 & 0.266 & $\llbracket 9$ & 0.144 & 0.010 & 25 & 0.121 & $0.052^{\text {* }}$ \\
\hline & & 0.075 & & & 0.062 & & & 0.074 & \\
\hline \multirow[t]{2}{*}{ size $>100$} & 3 & 0.394 & $9.012^{*}$ & 1 & 0.184 & 0.235 & 11 & 0.147 & 0.120 \\
\hline & & 0.173 & & & 0.255 & & & 0.125 & \\
\hline \multicolumn{10}{|l|}{ Control portfolio } \\
\hline \multirow[t]{2}{*}{ size $<1$} & 149 & -0.185 & 0.963 & 33 & -0.322 & 0.995 & 89 & -0.108 & 0.935 \\
\hline & 206 & $\begin{array}{c}0.103 \\
-0.110\end{array}$ & 0.967 & 27 & $\begin{array}{r}0.125 \\
-0.373\end{array}$ & 0.999 & 82 & $\begin{array}{l}0.071 \\
0.010\end{array}$ & 0.448 \\
\hline $1<\operatorname{size}<5$ & & 0.059 & & & 0.113 & & & 0.073 & \\
\hline \multirow{2}{*}{$5<$ size $<10$} & 70 & .0 .296 & 1.000 & 38 & -0.147 & 0.958 & 32 & -0.048 & 0.756 \\
\hline & & 0.074 & & & 0.085 & & & 0.068 & \\
\hline \multirow[t]{2}{*}{$10<$ size $<100$} & 91 & -0.213 & 1.000 & 61 & -0.021 & 0.609 & 94 & -0.053 & 0.850 \\
\hline & & 0.058 & & & 0.076 & & & 0.051 & \\
\hline \multirow[t]{2}{*}{ silize $>100$} & 10 & 0.124 & 0.117 & 2 & 0.194 & 0.142 & 36 & 0.040 & 0.293 \\
\hline & & 0.104 & & & 0.180 & & & 0.074 & \\
\hline
\end{tabular}

The $\beta_{2}$ coefficients are the OLS estimates of the change in market risk during the post-crisis period for the test and control portfolios. Standard errors are in italics. Significances levels are for the one-tailed test against the altemative that the market risk increases in the post-crisis period. * indicates 10 percent significance level, * 5 percent significance level. Size (in US\$ millions) is measured by market capitalization. 


\subsection{Concluding Remarks}

This chapter examines whether there is any relationship between fluctuations in foreign exchange ate and equity return volatility for U.S. multinational firms, whether increased exchange rate variability contributes to their systematic risk (beta), and whether the impact of increased exchange rate risk display any industryspecific or size-specific pattern?

We find that the stock return variability of U.S. multinationals increases significantly in the aftermath of a crisis, even relative to the increase in stock return volatility for other U.S. firms belonging to the same industry sector and market capitalization class that are not active in the crisis countries. Our findings support the economic intuition that exchange rate fluctuations play an important role in the return generating process of U.S. multinationals. In conjunction with this increase in total volatility, there is also an increase in stock market risk for U.S. multinational firms with real foreign operations in the crisis countries. This finding suggests that the financial turmoil changed many of these firms' sensitivity to U.S. stock market movements, that is, their betas. Correspondingly, in the presence of increased exchange rate variability, these firms are faced with higher equity financing costs. Finally, our findings suggest that trade and services oriented industries are particularly sensitive to changing exchange rate conditions while manufacturing companies appear to be less affected. We find moreover that small U.S. multinationals were strongly influenced by the Asian financial crises.

The evidence presented in this chapter has several implications. From a methodological view, our results suggest that this approach effectively rules out the influence of the time variation of foreign exchange rate exposure. In addition, the observed increased stock return volatilities and the corresponding increase in market risk have important implications for the decision-making process of international investors, as well as for firms in financial operations. If the additional risk imparted to exposed firms from increased exchange rate variability is systematic in nature, it will affect the required rate of (equity) return (i.e. investors demand higher returns for holding the firm's shares). Consequently, this effect of exchange rate fluctuations increases the cost of (equity) capital for U.S. multinational firms with real foreign operations in the affected crisis countries. 

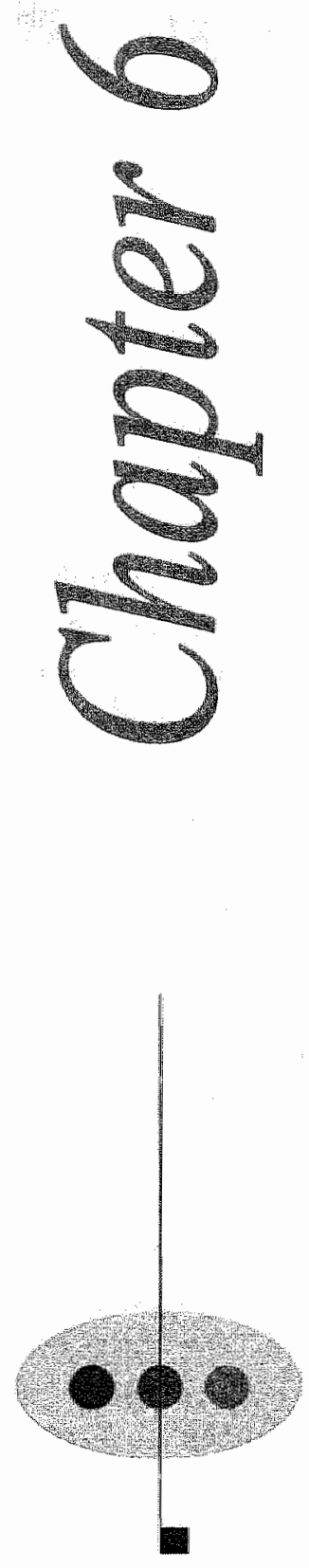

\section{Asymmetric Foreign Exchange Risk} Exposure: Evidence from U.S. Multinationals 


\section{Asymmetric Foreign Exchange Risk Exposure: Evidence from U.S. Multinationals ${ }^{173}$}

\subsection{Introduction}

As the debate regarding firms' foreign exchange risk exposure continues to be an issue in the world of business and international finance, we concentrate in this chapter on the improvement of the augmented market model used to empirically estimate the relationship between stock returns and currency fluctuations. Regarding existing estimation models, it is indeed interesting to note that most previous empirical studies rely on the assumption that the impact of exchange rate fluctuations is symmetrical, and that the sign and the size of the unexpected exchange rate shocks do not influence the resulting stock return reaction. According to Bartov and Bodnar (1994), however, this failure to account for the potentially asymmetric nature of currency risk exposure may explain the weak empirical findings reported so far.

There are numerous theoretical models focusing on trade flows, price formation, corporate behavior and investor sentiment showing that stock returns can be expected to respond asymmetrically to exchange rate shocks. Among them, (i) the asymmetric impact of hedging activities on cash-flows, (ii) firms" pricing-tomarket strategies, (iii) their hysteretic behavior, (iv) investors' overreactions and mispricing errors, and ( $v$ ) the existence of 'trigger points' at which external forces may intervene in the market are the most frequently cited arguments in favor of nonlinear currency risk exposures. While the asymmetric reaction of trade flows and prices has been empirically documented in prior literature (Baldwin and Krugman, 1989; Ohno, 1989; Knetter, 1994; Kanas, 1997; Pollar and Coughlin, 2003), the nonlinear response of stock returns to exchange rate movements hasn't

\footnotetext{
173 This chapter is based on A. Muller and W.F.C. Verschoor, "Asymmetric foreign exchange risk exposure: Evidence from U.S. multinationals", LIFE Working Paper, $2004 \mathrm{c}$.
} 
received much attention in the exchange risk exposure literature until now. ${ }^{174}$ Accordingly, the aim of present chapter is to fill this gap and provide some insight in the asymmetrical nature of foreign exchange risk exposure.

The chapter is presented in five sections. Section 6.2 reviews theoretical work on the underlying reasons why firm value can be expected to be asymmetrically affected by exchange rate movements. In section 6.3 the empirical methodology used to measure and test for asymmetric exposure is outlined. Data selection procedures and data sources are described in section 6.4. The empirical findings follow in section 6.5 , with our concluding remarks in section 6.6 .

\subsection{Asymmetries in exchange risk exposure}

While most analytical papers on currency risk exposure predict a potentially nonlinear impact of exchange rate fluctuations on firm value (Shapiro, 1975; Hodder; 1982; Hekman, 1985; Booth and Rotenberg, 1990), the implicit assumption underlying the estimation of exchange risk exposure in the extensive empirical literature is - with few exeeptions - that foreign currency exposure is linear. ${ }^{175,176}$ The possibility that stock returns react asymmetrically to currency movements, and more specifically that the sensitivity of stock returns to changes in exchange rates may depend on the sign and magnitude of these changes, has received very little attention in the empirical literature until now. Yet, there are several reasons related to the behavior of both corporations and investors that may explain asymmetries in foreign currency exposure.

\subsubsection{Asymmetries due to hedging activities}

One major argumentation in favor of the asymmetry hypothesis is that companies may take asymmetric hedging strategies to control their foreign exchange exposures. These hedging strategies may be financial or operational. Whereas forward and futures contracts eliminate both financial losses and gains if exchange

\footnotetext{
${ }^{174}$ The vast majority of empirical studies on nonlinear exchange risk exposure focus on the asymmetric nature of exchange risk exposute over appreciation-depreciation cycles (Choi and Prasad, 1995; Baba and Fukao, 2000; Koutmos and Martin, 2003a; Koutmos and Knif, 2004; Tai, 2004). On the other hand, the possibility that firm value is differently affected by large versus small exchange rate fluctuations has only been analyzed by a few authors (Di Iorio and Faff, 2000 ; Bartram, 2004).

${ }^{175}$ See Adler and Dumas (1984), Jorion (1990) and He and $\mathrm{Ng}$ (1998) for instance.

${ }^{176}$ For example if the empirical estimation of the currency risk exposure of firm $i$ is 0.5 , this means that if the currency appreciates / depreciates by 1 percent ( 10 percent), the stock return of firm $i$ falls / rises by 0.5 percent ( 5 percent). Thus neither the direction, nor the magnitude of the currency movements will affect the sensitivity of firms i's returns to exchange rate fluctuations...
} 
rates move, currency options provide the downside protection while sinultaneously allowing the upside potential. The asymmetric pay-off resulting from the use of these currency options has, thus, a non-linear impact on cash-flows and on firm value. Similarly, asymmetric responses to currency fluctuations may be observed when net exporters (net importers) decide to implement operational hedging strategies against domestic currency appreciations (depreciations) leaving depreciations (appreciations) unhedged.

The determination of the strike price(s) of currency options is another argument supporting the non-linear tesponse of stock returns to currency fluctuations. Indeed companies engaging in hedging activities choose currency options - hence corresponding strike prices and maturities - according to their needs and internal policies. 177 At the expiration date, the choice in terms of strike prices directly influences the impact of large versus small currency movements on the total pay-off of the strategy. ${ }^{178}$ Following the same line of reasoning, operational hedging activities that are, for instance, exclusively implemented for large currency changes produce a similar non-linear impact on firm value.

To conclude, it is the very asymmetrie nature of most financial and operational hedging strategies that explains why the impact of foreign exchange rate movements on stock returns may be different according to the sign and the magnitude of these movements.

\subsubsection{Asymmetries due to asymmetric pricing-to-market behavior and resulting pass-through effects}

Pricing-to-market behavior on behalf of companies has been quoted as a further potential reason for asymmetric stock price reactions to exchange rate movenents (Froot and Klemperer, 1989; Knetter, 1994). Overall, the reaction to currency fluctuations depends on whether the firm pursues a market share objective or a profit-maximizing strategy. For instance, when the domestic currency depreciates, an exporting firm pursuing market share objectives maintains its export price in its currency and allows the export price in the foreign currency to fall. "This enables the firm to gain market share when its currency depreciates. However, if the home currency appreciates, the exporter protects its market share by holding constant its

\footnotetext{
$17 \pi$ The more firms need downside protection, the more expensive the hedging strategy will be. Thus, a protection against exclusively extreme losses will be cheaper - and thus preferred by some companies. On the other hand, firms that expect currency movements to remain in a given range may choose not to hedge extreme exchange rate fluctuations.

${ }_{178}$ It has to be mentioned moreover that, generally, revenues from the sale of derivative products increase with currency volatility (Koutmos and Martin, 2003b).
} 
foreign currency export price, rather than allowing it to increase: Subsequently, an appreciation of the domestic currency causes, in this case, a weaker pass-through effect than a depreciation. On the other hand, an appreciation of the home currency may lead to stronger pricing-to-market in the presence of trade volume or capacity constraints which will similarly result in asymmetric exposure (Marston, 1990; Knetter, 1994, Goldberg, 1995, Kanas, 1997). Thus, in some cases the pass-through associated with depreciations exceeds appreciations; however, in other cases this result is reversed. The resulting impact on firms' cash-flow is, in consequence, asymmetric but there is no elear evidence on the sign of the relationship.

Firms also respond asymmetrically to the size of the change in exchange rates. Because of the costs associated with changing prices, an exporting firm may, for instance, decide to allow its markup to absorb the effect of small changes in currency movements, which leads to a low pass-through effect. In contrast, large exchange rate fluctuations may force the exporter to deviate from his policy and pass-through part of the currency change into export prices. The fact that passthrough is generally positively related to the size of the change in exchange rates (Ohno, 1989; Pollard and Coughlin, 2003) shows that the impact of currency movements on firm casli-flows depends on the magnitude of these movements and tends to confirm the asymmetric currency exposure hypothesis. ${ }^{179}$

\subsubsection{Asymmetries due to hysteretic behavior}

The asymmetric impact of hysteretic behavior on firm value has been analyzed in earlier research on international trade (Baldwin, 1988; Baldwin and Krugman, 1989; Dixit, 1989). In the context of exchange risk exposure estimation, hysteretic behawior occurs, for instance, when exporters that have been attracted to new markets due to the depreciation of their home currency and the resulting asymmetric competitive advantage, remain in this "new" market once the domestic currency appreciates again. Hysteresis is, thus, closely related to the existence of high market entry costs and more generally to the higher costs of reducing capital than increasing it - the so-called irreversibility of investment argument. ${ }^{180}$ As a consequence, the impact of a depreciation of the home currency on firm value is lowered for "new" entrants because of the high sunk-cost investments as well as for "old" exporters due to the increasingly competitive environment. On the contrary, the fact that both "old" and "new" exporters tend to remain in the market when the home currency appreciates - even if they suffer from operating losses - leads to a

\footnotetext{
${ }^{179}$ Pollard and Coughlin (2003) show even that the impaet of exchange rate movements on passthrough depends more on the size of the currency change than on the direction.

${ }^{180}$ See for example Baldwin (1986 and 1988) for a detailed discussion on hysteretic behavior.
} 
stronger negative impact on firm value. As a result, stock returns are expected to react asymmetrically to currency depreciations and appreciations.

It has nevertheless to be emphasized that referring to exchange rate exposure issues hysteretic behavior is strongly dependent on the magnitude of currency fluctuations. Baldwin and Krugman (1989) show for instance that in particular large exchange rate shocks may lead to entry or exit decisions that are not reversed when the currency returns to its previous level. On the other hand, small currency depreciations may not lead firms to extend their exporting activities to "new" markets, while sufficiently large appreciation swings in the domestic currency may induce many of the new entrants to leave the "new markets". The asymmetric impact of currency movements on firm value due to hysteresis is thus strongly dependent on the size of these exchange rate fluctuations.

\subsubsection{Asymmetries due to investors' mispricing errors}

Another argument supporting the asymmetric sensitivity of stock returns to currency movements is related to investor behavior. As highlighted in Bartov and Bodnar (1994), investors make systematic errors when characterizing the linkage between currency movements and firm value. These errors may arise because of the complex set of issues associated with (i) the identification of possible asymmetries in the impact of appreciations and depreciations, (ii) the determination of the extent to which a currency movement is temporary versus permanent, (iii) the estimation of the impact of the various changes in different foreign currencies for the overall economic performance and strategic behavior of the firm, and (iv) the evaluation of the impact of the firm's hedging activities on its sensitivity to exchange rate movements. ${ }^{181}$

Many arguments support the view that the relative importance of mispricing errors in the estimation of foreign currency exposure effects is dependent on the size and direction of exchange rate shocks. First, investors may find it difficult to assess the impact of small exchange rate movements on firm value. They, therefore, may have a tendency to assimilate these small fluctuations to random walk movements and to ignore their impact on firm value. Another argument in favor of asymmetric exchange risk exposure is related to investors" reaction to good versus bad news. There has been much research centered on the asymmetric impact of good and bad news on the mean and variance of stock returns

181 The fact that complex circumstances generally lead to systematic mispricing errors has been extensively documented in the literature. See e.g. Lakonishok and Vermaelen (1990) and Bartov (1992). 
(Bollerslev et al, 1992; Bollerslev et al,; 1995; Hentschel, 1995). The major finding concluded that investors are likely to react more to negative shocks (bad news) than towards positive shocks. Thus, we may expect that when valuing an exporting firm, for instance, investors consider a domestic currency appreciation as "bad" news which would result in a strong reaction (overreaction) in stock returns. On the other hand, domestic depreciations may not get as much consideration from investors. But, if the home depreciation gets large, the probability that investors pay attention to this favorable shock increases, leading to a positive valuation effect. It is, however, still possible that the positive news from the exchange rate market strengthens the future expected volatility - the volatility feedback effect - which in turn inereases the required rate of return on the stock and, hence, lowers the stock. price. This effect would, thus, dampen the positive impact of large favorable exchange rate shocks on firm value. In contrast, the increased expected volatility caused by large unfavorable currency movements might similarly increase the required rate of return and lower the stock price, amplifying the negative impact of "bad" exchange rate news.

\subsubsection{Asymmetries due to so-called "trigger points"}

A last line of reasoning corroborating the existence of asymmetric exchange rate exposure has been mentioned by Booth (1996). He argues that exposure changes over time with the magnitude of the currency shock and varies dramatically at "trigger points" where the nature of the market structure changes and with it the nature of the firm's exposure. It may be, for instance, that at these "trigger points" governments intervene to assist certain industries that are suffering from a huge increase in foreign imports or an erosion of their own export markets. As these interferences mostly occur in order to limit downside risks, the resulting impact on exchange rate exposure is asymmetric both regarding size and direction of currency changes.

In conclusion, it should be stressed that the extreme diversity of the numerous forces affecting the response of stock returns to exchange rate movements makes it terribly difficult to design an analytical model that fully accounts for all these different firm- and market-specific influences. The objective of this chapter is thus not to analytically predict the exact nature of foreign currency exposure but to empirically assess the asymmetrical properties of the relation between stock returns and exchange rate movements. 


\subsection{Methodology}

The firm-specific exchange rate sensitivity, called firm-specific exposure, is defined as the effect of exchange rate changes on the value of a firm in excess of the global market's reaction to foreign exchange rate movements. Following Jorion (1990) and others, it is empirically estimated by the following model:

$$
R_{i, t}=\alpha_{i}+B_{i} R_{m, i}+\gamma_{i} \theta_{t}+\varepsilon_{i, t}
$$

where $R_{i, t}$ designates the total return of firm $i$ in period $t, R_{m, t}$ the overall stock market return in period $t, B_{i}$ firm $i$ 's return sensitivity to market fluctuations, $\theta_{i}$ the movement in a trade-weighted U.S. dollar world exchange rate index ${ }^{182}, \gamma_{i}$ firm $i$ 's exposure to the exchange rate index independent of the effect these currency movements have on the overall market, and $\varepsilon_{i, r}$ denotes the white noise error term. $\gamma_{i}$ describes, hence; the sensitivity of stock returns to unanticipated changes in exchange rates. ${ }^{183}$ Since the exchange rate index is measured as the price of one U.S. dollar in units of foreign currencies, a statistically significant positive $y_{i}$ coefficient implies that an appreciation of the domestic currency has a positive impact on a firm's stock returns - suggesting that the firm reacts like a net-importer or, more generally, that it has net short foreign currency positions, on average. By way of contrast, we expect to find for a net exporting company or a company with net long foreign currency positions a negative $\gamma_{i}$ coefficient.

The implicit assumption made in the above-mentioned model (Eq. 6.1) is the hypothesis of constant variance. This assumption is often rejected for common financial weekly time series - like exchange rate and stock return series. ${ }^{184}$ As the presence of heteroskedasticity invalidates the test statistics of the ordinary least squares regression, we test whether the residuals $\ell_{i r}$ exhibit time-varying heteroskedasticity. We use the test Engle derived from the Lagrange multiplier principle to check the validity of the null hypothesis that the error terms of Eq. (6.1) $\varepsilon_{\text {it }}$ present no heteroskedasticity. If we do not reject the null hypothesis, we perform an ordinary least squares regression. Otherwise we add a GARCH $(1,1)$ process to

\footnotetext{
${ }^{182}$ The trade-weighted exchange rate index is defined as the price of one U.S. dolltar in units of foreign currencies. An appreciation (depreciation) of the U.S. dollar will, thus, produce a positive (negative) value for $X_{f}$.

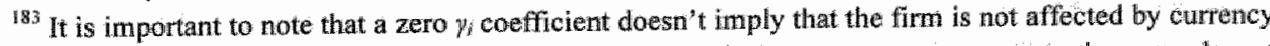
movements. It rather means that the firm value reacts to exchange rate movements to the same degree as the market portfollio.

${ }^{184}$ See, for example, Bollerslev et al (1992) and Nieuwland et al. (1994).
} 
the initial augmented market model to incorporate conditional variance into the system (Bollerslev et al., 1992). ${ }^{185}$ Thus, the regression model becomes:

$$
\begin{aligned}
& R_{i, t}=\alpha_{i}+B_{i} R_{m i, t}+y_{i} \theta_{i}+\varepsilon_{i, t} \\
& \text { with } \quad \varepsilon_{i, t}=\mu_{i, t} *\left(h_{i, i}\right)^{1 / 2} h_{i, t}=\delta_{i}+\tau_{i} \varepsilon_{i, t-1}^{2}+V_{i} h_{i, t}
\end{aligned}
$$

where $h_{i, r}$ denotes the conditional variance of the residuals; $\delta_{i}, \tau_{i}$ and $v_{i}$ unknown parameters; and $\mu_{i, f}$ represents the white noise error term. ${ }^{186}$

The trade-weighted world exchange rate index enables us to capture the sensitivity of U.S. multinationals' stock returns to the fluctuations of a basket of foreign currencies consisting of currencies from all around world. Since the index is based on trade-weights and currencies that do not always correspond to individual firms' trade patterns and since it cannot address the problem of low and negative correlations between some exchange rates, the use of a trade-weighted world exchange rate index is likely to understate currency risk exposures ${ }^{187}$ To alleviate these problems and improve the specification of the exchange risk factor, we decompose the currency risk factor in 6 different region-specific exchange rate indices. As a result; we build for each company a firm specific currency risk factor consisting of exchange rate indices of the regions in which the company has real operations. ${ }^{188}$ The model becomes thus:

$$
\begin{aligned}
& R_{i, t}=\alpha_{i}+b_{i} R_{m, t}+\Gamma_{i} \Theta_{i}+\varepsilon_{i, t} \\
& \text { respectively: } \\
& R_{i, t}=\alpha_{i}+B_{i} R_{m, t}+\Gamma_{i} \Theta_{i}+\varepsilon_{i, t} \\
& \text { with } \varepsilon_{i, r}=\mu_{i, r} *\left(h_{i,}\right)^{1 / 2} h_{i, t}=\delta_{i}+\tau_{i} \varepsilon_{i, t-1}^{3}+v_{i} h_{i, t-1}
\end{aligned}
$$

\footnotetext{
The choice of a GARCH(1,1) specification is supported by nany enpirical studies which show that the GARCH( 1,1$)$ specification is waluable for modeling the variance generating process of financial time series.

" "The unknown parameters are estimated by maximum-likelihood and generated using the Berndt ef al. (1974) algorithm..

187 Dominguez and Tesar (200la) show in their empirical study that many firms are exposed to on or more bilateral rates included in the world exchange rate index but not to the index. This in contradiction with the results in Bartran (2004) concluding that the use of a currency index versus individual, bilateral rates doesn't mitigates the significance of exposure estimates.

18: Atributing the weak evidence on currency exposure to an imprecise specification of the exchange risk factor, Ihrig (2001), builds a firm-specific exchange rate index composed of bilateral rates with the U.S. dollar of all countries in which the firm has subsidiaries and finds a higher percentage of significant currency exposure estimates than earlier studies.
} 


$$
\begin{aligned}
& \text { where } \Gamma_{i} \theta_{t}=\gamma_{E U, i} \theta_{E U, t} * D_{E U, s}+\gamma_{U K, i} \theta_{U K_{i}} * D_{U K_{i}, i} \\
& +\gamma_{A S, i} \theta_{A S, i} * D_{A S, i}+\gamma_{A U, i} \theta_{A W_{i},} * D_{A U, i} \\
& +\gamma_{L A, i} \theta_{L A, i} * D_{L, i, i}+\gamma_{S A, i} \theta_{S A, t} * D_{S A T}
\end{aligned}
$$

$\theta_{E U, t}, \theta_{U K, t}, \theta_{A S, t}, \theta_{A U_{3}, t}, \theta_{L 4, t,}, \theta_{S A, t}$ denote the fluctuations of the price of one U.S. dollar in Euros, U.K. pounds, a basket of Asian currencies, Australian dollars, a basket of Latin American currencies and South African rands. $D_{E U, i,} D_{U K, i} D_{A S,}$, $D_{A U, i,} D_{L A, i,} D_{S A, i}$ describe the presence of firm i's real activities in Europe, the U.K., Asia, Australia, Latin America and South Africa. Depending on the presence or not of firm $i$ 's real activities in region $j_{s}$, the dummy variable $D_{j_{0},}$ takes the value of 1 or 0 . Finally, $\gamma_{E U, i}, \gamma_{U, i,}, \gamma_{A S, i}, \gamma_{A U, i}, \gamma_{L A, i}, \gamma_{S A, i}$ measure the firm $i$ 's exchange risk exposure towards the Euro, the U.K. pound, Asian currencies, the Australian dollar, Latin American currencies and the South African rand.

As described in section 6.2 , there are valid reasons to expect that stock returns respond asymmetrically to currency appreciations and depreciations. To test the asymmetry hypothesis we extend the standard augmented market model following Koutmos and Martin (2003a). Under the present circumstances this means adding a dummy variable $S_{t}$ to model (Eq. 6.3) and (Eq. 6.4):

$$
R_{i, t}=\alpha_{i}+B_{i} R_{m, i}+\left(T_{i}+\Gamma_{i}^{\prime} * S_{t}\right) * \Theta_{i}+\varepsilon_{i, r}
$$

respectively:

$$
\begin{aligned}
& R_{i, r}=\alpha_{i}+B_{i} R_{m, t}+\left(\Gamma_{i}+\Gamma^{\prime}{ }_{i} * S_{i}\right) * \Theta_{t}+\varepsilon_{i, t} \\
& \text { with } \quad \varepsilon_{i, t}=\mu_{i, t} *\left(h_{i, j}\right)^{1 / 2} h_{i, t}=\delta_{i}+\tau_{i} \varepsilon_{i, t, l}^{2}+v_{i} h_{i, t-1}
\end{aligned}
$$

where $S_{t}$ equals 1 when the exchange rate movement is negative and 0 otherwise. The parameters $\Gamma^{\prime}{ }_{i}$ measure, hence, the asymmetric response of firm i's stock returns to negative exchange rate shocks.

For the estimation of the asymmetric response of stock returns towards large versus small currency fluctuations, we use logistic smooth transition regressions (Granger and Teräsvirta, 1993; Teräsvirta, 1998). The models presume that there are two regimes and that the transition from one regime to the othertriggered by the magnitude of the currency fluctuations - is a locally linear one. The two regime model is specified as:

$$
R_{i, t}=a_{i}+B_{i} R_{m, i}+\left(T_{i}+\Gamma_{i}^{\prime} * F_{i}\left(u_{i, i} k_{i}, \lambda_{i}\right)\right) * \Theta_{1}+\varepsilon_{i, t}
$$




$$
\begin{aligned}
& \text { respectively: } \\
& R_{i, f}=a_{i}+B_{i} R_{m i, f}+\left(\Gamma_{i}+\Gamma_{i}^{*} F_{i}\left(u_{i, t} ; k_{i s} \lambda_{i}\right) * \Theta_{i}+\varepsilon_{i, t}\right. \\
& \text { with } \varepsilon_{i, l}=\mu_{i, l}{ }^{i}\left(h_{i, j}\right)^{1 / 2} h_{i, l}=\delta_{i}+\tau_{i} \varepsilon_{i, k-1}^{2}+v_{i} h_{i, n-1}
\end{aligned}
$$

The transition function $F\left(u_{i, j}, k_{i s}, \lambda_{j}\right)$ is bounded between 0 and 1 and depends on the magnitude of the exchange rate movement $u_{i, t}$ defined as the squared currency movement ${ }^{189}$ in week $t$

$$
F_{i}\left(u_{i, j,} \lambda_{i,}\right)=\left(I+\exp \left(-\left(u_{i, l}-k_{i}^{*} \bar{u}_{i, j}\right)^{*} \lambda_{j}\right)\right)^{-1}
$$

where $\bar{u}_{i, t}$ denotes the mean value of the squared foreign currency movements across the entire sample period. $k_{i}$ locates, for firm $i$, where the transitions occur between the two regimes and $\lambda_{i}$ indicates, for firm $i$, how rapidly the transition from one regime to another takes place.

Estimation of the parameters of the two-regime model is performed by ordinary least-squares (Eq. 6.8) or a maximum-likelihood method (Eq. 6.9). To alleviate the problems arising from predetermining $k_{i}$ and $\lambda_{i}$, we determine the location parameter $k_{i}$ and the adjustment speed $\lambda_{i}$ using the Akaike Information Criterion (AIC). ${ }^{190}$

\subsection{Sample selection}

\subsubsection{U.S. multinationals}

It is possible that the weak evidence of a contemporaneous link between exchange rates and U.S. stock returns in the existing empirical literature is caused by the data selection procedure (Bartov and Bodnar, 1994). As real foreign trade and production activities are important transmission channels of exchange rate shocks, we thus decide to focus our empirical study on the impact of currency fluctuations

\footnotetext{
${ }^{189}$ As a first set of sensitivity tests, we redefine the magnitude of the exchange rate movement $t_{4}$ as the squared of the residual $\sigma_{i,}$ in week to the following GARCH $(1,1)$ model:

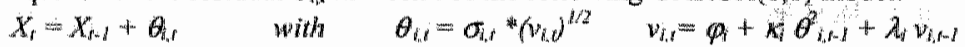
where $v_{i, j}$ denotes the conditional variance of the residuals; $\varphi_{i,} \kappa_{i}$ and $\lambda_{i}$ unknown parameters; and $\sigma_{i, i}$ represents the white noise error tern.

Results - available from the authors upon request - show that redefining this variable has no significant impact on the coefficient estimates and conclusions that are central to this chapter.

${ }^{190}$ To test for the robustness of our findings we use as well the Schwartz Criterion (SC) to detemine the location parameter $k_{i}$ and the adjustment speed $\lambda_{i}$. Results are consistent with the findings presented in this chapter.
} 


\section{Table 6.1: Summary of foreign activities of U.S. multinational sample firms by geographical region and industrial sector}

\begin{tabular}{|c|c|c|c|c|c|c|c|}
\hline 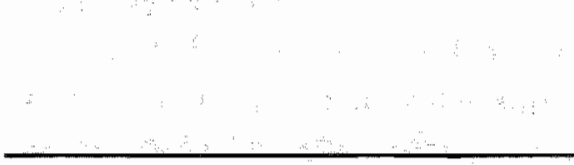 & 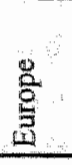 & 2 & $\frac{9}{8}$ & $\frac{10}{8}$ & - & $\stackrel{\tilde{E}}{\mathrm{E}}$ & 홍 \\
\hline $\begin{array}{l}\text { Agriculture, Mining (except oil \& gas } \\
\text { extraction) \& Construction }\end{array}$ & 11 & 9 & 9 & 10 & 12 & 3 & 17 \\
\hline $\begin{array}{l}\text { Food, Tobacco, Textlle, Wood \& Paper } \\
\text { related industries }\end{array}$ & 62 & 67 & 69 & 39 & 53 & 13 & 101 \\
\hline Chemical \& allied products & 70 & 63 & 60 & 46 & 49 & 23 & 79 \\
\hline $\begin{array}{l}\text { Oil \& gas extraction, petroleum refing \& } \\
\text { related industries }\end{array}$ & 20 & 29 & 27 & 16 & 23 & 14 & 38 \\
\hline $\begin{array}{l}\text { Rubber, Leather, Stone, Clay, Glass i } \\
\text { Concrete Products }\end{array}$ & 22 & 16 & 20 & 8 & 13 & 3 & 24 \\
\hline Primary \& fabricated metal industries* & 36 & 37 & 33 & 18 & 27 & 8 & 49 \\
\hline $\begin{array}{l}\text { Industrial \& Commercial machinery \& } \\
\text { computer equip. }\end{array}$ & 89 & 89 & 80 & 49 & 48 & 25 & $1 \mathbb{1}$ \\
\hline $\begin{array}{l}\text { Electronic \& other electrical equip. } \\
\text { (except computer equip.) }\end{array}$ & 65 & 80 & 70 & 31 & 37 & 13 & 92 \\
\hline $\begin{array}{l}\text { Transportation equip., measuring: } \\
\text { instruments \& miscellaneous }\end{array}$ & 85 & 76 & 71 & 43 & 51 & 12 & 102 \\
\hline $\begin{array}{l}\text { Transportation, communicrations, electric, } \\
\text { gas \& sanitary services }\end{array}$ & 36 & 37 & 31 & 22 & 31 & 8 & 53 \\
\hline Wholesale \& retail trade & 35 & 27 & 31 & 16 & 27 & 7 & 57 \\
\hline Finance, Insurance \& real estate & 50 & 65 & 55 & 32 & 41 & 19 & 78 \\
\hline Services & 102 & 117 & 83 & 66 & 49 & 16 & 134 \\
\hline Totall & 683 & 712 & 639 & 396 & 461 & 164 & 935 \\
\hline
\end{tabular}

Definition of industry sectors: Agriculture, Mining (except oil \& gas extraction) \& construction SIC 01241 and 1400-1999; Food, Tobaceo, Textile, Wood \& Paper related industries SIC 2000-2799; Chemicals \& allied products SIC 2800-2899; Oil \& gas extraction, petroleum refining \& related industries SIC 1300-1399 and 2900-2999; Rubber, Leather, Stone, Clay, Glass \& Concrete Products SIC 3000-3299; Primary and fabricated metal industries (*except machinery and transportation equipment) SIC 3300-3499; Industrial \& Commercial machinery \& Computer equipment SIC 35003599; Electronic \& other electrical equipment (except computer equipment) SIC 3600-3699; Transportation equipment, measuring instruments and miscellaneous manufacturing industries SIC 3700-3999; Transportation, Communications, electric, gas sanitary services SIC 4000-4999; Wholesale and Retail Trade SIC 5000-5999; Finance, Insurance and Real Estate SIC 6000-6999; Services SIC 7000-8999. 
on U.S. multinationall firms with real production and/or trade operations in foreign countries. ${ }^{191}$ To identify these firms we follow a careful selection procedure consisting of four steps. The initial sample incorporates all U.S. companies that are registered in the $15^{\text {th }}$ edition of the Directory of American Firms Operating in Foreign Countries. As we only include listed firms in our study, we check the firms for their weekly stock market return availlability in the University of Chicago Center for Research in Security Prices (CRSP) database. Subsequently, we exclude firms that hadn't at least two years of consecutive weekly returns across the entire sample period from January 1990 to December 2001 . This procedure yields a total sample size of 935 firms. ${ }^{192}$ Finally, all these firms are classified according to their fourdigit SIC codes and their foreign operations are grouped in six geographical regions: Europe, U.K., Asia, Australia, Latin America and Africa.

In table 6.1, we present the distribution of the sample firms across industry sectors and provide information about the geographical dispersion of their foreign trade or production activities. It is interesting to note that the major international trading activities of U.S. multinationals included in our sample are located in Europe, U.K. and Asia.

\subsubsection{Economic factors}

This study uses two types of economic risk factors: the market risk factor and the exchange rate risk factors. The proxy for the market portfolio used is the CRSP value-weighted U.S. market index as provided by the University of Chicago Center for Research in Security Prices (CRSP) database. The exchange rate risk factors are measured as the continuously compounded rates of change in a worldwide tradeweighted U,S. dollar exchange rate index and in region-specific trade-weighted exchange rate indices. ${ }^{193}$ The latest translate the evolution of one or more foreign currencies of the same geographical region towards the U.S. dollar. They are computed as a weighted average of bilateral exchange rates ${ }^{194}$ according to the following formula:

\footnotetext{
191 To the extent that firms within a given industry portfolio are not uniformly involved in international trading activities, do not present identical financial and operational characteristics and do not engage in simillar hedging strategies, they are not uniformly exposed to currency fluctuations. The aggregation of these different characteristics in undustry portfolios leads therefore to a strongly reduced impact of exchange rate movements on industry portlfolio returns.

192 The sample is free of survivorship bias.

193 Following Jorion (1990) exchange rate indices are parsimonious representations of the effect of multiple exchange tate changes.

194 The bilateral exchange rates are expressed in units of foreign currency per U.S. dollar and have been obtained from Datasineam Mnternational.
} 


$$
X_{i}=\sum_{l, n}\left(\left(\exp _{k}+i m p_{k}\right) /\left(\sum_{x, n}\left(\exp _{k}+i m p_{k}\right)\right) * X_{k, j}\right)
$$

where $n$ is the number of countries included in the region, exp is the export flow from the U.S. towards country $k_{s} i m p_{k}$ the import flow from country $k$ towards the U.S. and $X_{k t}$ the bilateral exchange rate between the U.S. dollar and country $k^{\prime} s$ currency. The weights of the region-specific indices, updated monthly, are based on each country's proportion of trade in the total import and export flows of the region with the U.S. $-\sum_{l, n}\left(\exp _{k}+i m p_{k}\right)$ - as reported by the Foreign Trade Division of the U.S. Census Bureau.

To provide a general understanding of the nature of each exchange rate index, summary statistics of weekly log price changes are presented in table 6.2. The statistics include index returns for mean, median, maximum, minimum, standard deviation, skewness and kurtosis. All exchange rate indices experienced positive mean weekly returns during the sample period. While all exchange rate series are positively skewed, the Latin American and South African exchange rate indices exhibit a particularly strong positive skewness indicating that large depreciations of these currencies were more common than large appreciations. On the other hand, the returns of the euro / U.S. dollar bilateral rate are approximately symmetrically distributed.

Table 6.2: Summary statistics for the European, U.K., Asian, Australian, Latin American and South African / U.S. dollar exchange rate indices

\begin{tabular}{|c|c|c|c|c|c|c|c|}
\hline & $\begin{array}{r}\text { U.S. dollar } \\
\text { trade- } \\
\text { weighted } \\
\text { world index }\end{array}$ & $\begin{array}{l}\text { U.S. } \\
\text { dollar } \\
\text { verstus } \\
\text { euro }\end{array}$ & $\begin{array}{l}\text { U.S. } \\
\text { dollar } \\
\text { versws } \\
\text { U.K. } \\
\text { pound }\end{array}$ & $\begin{array}{r}\text { U.S. } \\
\text { dollar } \\
\text { wersus } \\
\text { Asian } \\
\text { currencies }\end{array}$ & $\begin{array}{r}\text { U.S. } \\
\text { dollar } \\
\text { verstis } \\
\text { Australlian } \\
\text { dollar }\end{array}$ & $\begin{array}{l}\text { U.S. } \\
\text { dollar } \\
\text { versus } \mathrm{L} \text {. } \\
\text { American } \\
\text { currencies }\end{array}$ & $\begin{array}{r}\text { U.S. } \\
\text { dollar } \\
\text { wersus } \$ \\
\text { African } \\
\text { rand }\end{array}$ \\
\hline Mean & 0.0003 & 0.000 & 0.0000 & 0.0002 & 0.0006 & 0.0038 & 0.0025 \\
\hline Median & 0.0000 & 0.0002 & -0.0006 & 0.0007 & -0.0001 & 0.0030 & 0.001 .4 \\
\hline Maximum & 0.0280 & 0.0425 & 0.0388 & 0.0392 & 0.0664 & 0.2274 & 0.1288 \\
\hline Minimum & -0.0413 & -0.0377 & -0.0404 & -0.0235 & -0.0518 & -0.0390 & -0.0537 \\
\hline Std. Dev. & 0.0090 & 0.0114 & 0.0124 & 0.0068 & 0.0121 & 0.0147 & 0.0129 \\
\hline Skewness & -0.2275 & 0.0448 & 0.1545 & 0.2280 & 0.4180 & 7.5506 & 2.0911 \\
\hline Kurtosis & 1.3950 & 0.5970 & 3.3717 & 5.7449 & 3.1935 & 99.4495 & 18.4277 \\
\hline Obs. & 627 & 627 & 627 & 627 & 627 & 627 & 627 \\
\hline
\end{tabular}

Summary statistics are for weekly log price changes from January 5,1990 till December $31^{\mathrm{st}}$, 2001 . 
The coefficient of kurtosis for the Latin American, South African and Asian currency indices are much larger than 3, so that the return distribution of these exchange rate indices may be characterized as leptokurtic. In contrast, the euro / U.S. dollar bilateral rate as well as the trade-weighted world exchange rate index have a flat distribution relative to the normal. Finally, further tests indicate that for all reported series the assumption of normality is clearly violated.

\section{Table 6.3: Correlations between exchange rate indices}

\begin{tabular}{|c|c|c|c|c|c|c|c|}
\hline 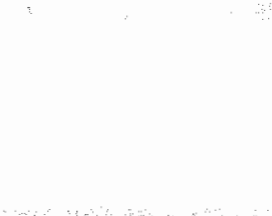 & $\begin{array}{r}\text { CRSP } \\
\text { value- } \\
\text { weighted } \\
\text { market } \\
\text { index }\end{array}$ & $\begin{array}{r}\text { US\$ } \\
\text { trade- } \\
\text { weighted } \\
\text { world } \\
\text { index }\end{array}$ & $\begin{array}{r}\text { US\$ } \\
\text { versus } \\
\text { euro }\end{array}$ & $\begin{array}{l}\text { USS } \\
\text { versws } \\
\text { UK } \\
\text { pound }\end{array}$ & $\begin{array}{c}\text { USS } \\
\text { versus } \\
\text { Assian } \\
\text { curr }\end{array}$ & $\begin{array}{r}\text { US\$ } \\
\text { versus } \\
\text { Australian } \\
\text { dollar }\end{array}$ & $\begin{array}{r}\text { USs } \\
\text { wersus } \\
\text { Latin } \\
\text { American } \\
\text { curt }\end{array}$ \\
\hline $\begin{array}{l}\text { US\$ trade-yeighted } \\
\text { world index }\end{array}$ & 0.0841 & & & & . & & \\
\hline US\& versus euro & 0.1085 & 0.8048 & & & & & $\therefore \therefore$ \\
\hline $\begin{array}{r}\text { US\$ wersus UK. } \\
\text { pound }\end{array}$ & 0.0761 & 0.6453 & 0.7095 & & & ! & \\
\hline $\begin{array}{l}\text { US\$ versus Asian } \\
\text { curr. }\end{array}$ & 0.0284 & 0.7059 & 0.3635 & 0.2427 & & & \\
\hline $\begin{array}{l}\text { US\$ versus } \\
\text { Australian dollar }\end{array}$ & -0.0831 & 0.3012 & 0.2016 & 0.2128 & 0.2236 & & \\
\hline $\begin{array}{l}\text { US versus Latin } \\
\text { American curt. }\end{array}$ & -0.1304 & -0.0197 & -0.0577 & 0.0207 & -0.0300 & 0.00001 & \\
\hline $\begin{array}{r}\text { USS versus South } \\
\text { African rand }\end{array}$ & -0.1033 & 0.3213 & 0.2733 & 0.2273 & 0.2065 & 0.1394 & 0.0860 \\
\hline
\end{tabular}

Correlation statistics are for weekly log price changes from January 5,1990 till December $31^{\text {if }}$, 2001 .

Except for the correlation of 0.709 between the U.K. pound / U.S. dollar and the euro / U.S. dollar bilateral rates ${ }^{195}$, table 6.3 reveals that correlations between region-specific exchange rate indices are relatively low. We observe that the correlations between the trade-weighted world exchange rate index and the U.K. pound / U.S. dollar, the euro/U.S. dollar as well as the Asian region-specific index rates are remarkably high, indicating that the trade-weighted world exchange rate index strongly followed the evolution of these currencies during our sample

\footnotetext{
195 Following Khoo (1994), a second set of sensitivity tests excludes the UK pound / U.S. dollar exchange rate factor as soon as the euro / U.S. dollar rate is included in any of the estimation models. This enables us to check the robustness of our results towards the impact of multicolinearity problems arising from the high correlation between these billateral exchange rates. Results show, however, that this change has a surprisingly suall effect on the estimation of the euro currency exposure of U.S. multinationals and no significant impact on the general findings of this chapter.
} 
period. ${ }^{196}$ Finally, reported statistics show that the CRSP value-weighted market index isn't strongly correlated with any of the included exchange risk factors.

\subsection{Empirical findings}

In this section, we provide evidence on the asymmetric sensitivity of firm-level stock returns to currency risk and we highlight the impact of the choice of the exchange rate factor on the estimation of foreign currency risk exposure. We therefore consider the summary statistics of the estimated exposure coefficients as well as the percentage of firms that are statistically significantly exposed to currency movements using the different methodologies outlined in section 6.3 .

\subsubsection{Linear exchange risk exposure}

Following Jorion (1990), we begin our analysis by considering whether U.S. multinationals are exposed to changes in a trade-weighted worldwide U.S. dollar exchange rate index. In table 6.4, where the results of the augmented market model described in Eq. (6.1) - respectively Eq. (6.2) - are reported, we observe several features. First, the average market beta is 0.8717 and its median values lies at $0.7924 .^{197}$ Second, table 6.4 indicates that 7.27 percent $^{198}$ of our sample firms are statistically significantly exposed to the worldwide exchange rate index, at least at the 5 percent level. ${ }^{199}$ We observe furthermore that the mean and median currency risk exposures of our sample firms are positive. These outcomes which may appear at first glance somewhat surprising - since they imply that U.S. multinational companies generally gain from U.S. dollar appreciations - are nevertheless consistent with earlier findings (Clarida, 1992; Hung, 1992; Bodnar and Wong, 2003). ${ }^{200}$ Two main arguments may, moreover, rationalize the fact that these multinationals benefit from a strengthening domestic currency. On the one hand, the

\footnotetext{
${ }^{196}$ As the world index is never simultaneously used with any of these region-specific currency indices, this doesn't lead however to any multicolinearity problem.

${ }^{19 ?}$ The fact that U.S. multinationals with foreign operations tend to be less exposed to market risk than the overall U.S. market supports the view that geographical dispersion of economic activities leads to a reduction of business risk.

198 The percentage of significantly exposed U.S. companies is slighily higher than the percentage reported by Jorion (1990) using the same estimation model.

${ }^{199}$ Throughout the chapter the 5 percent significance level is adopted.

${ }^{200}$ Section 3.3 .2 likewise suggested that European firms gain from domestic currency appreciations, It has, however, to be stressed that the analysis across sub-periods revealed in this context that the sign of firm-level currency exposures may change through time - presumably die to the different episodes undergone by both stock and exchange rate markets.
} 
positive valuation impact of an appreciation of the home currency may simply translate the fact that U.S. multinationals set up foreign operations for their local sales and their exporting activities to the world market. They may, for instance, be strongly dependent on raw materials as well as other input products for the production of goods intended both for their own domestic markets and for foreign markets. On the other hand, it is highly probable that our selection procedure which is based on the Directory of American Firms Operating in Foreign Countries - has sorted out a large number of U.S. companies with foreign production subsidiaries. For these firms, the positive valuation effects of domestic currency appreciations are, hence, not surprising given that they are facing important foreign denominated cash outflows.

Finally, it has to be mentioned that there is overwhelming evidence that the error terms of Eq. (6.1) are conditionally heteroskedastic. We incorporated, indeed, GARCH (1,1) conditional variance extensions into the system for 702 (approximately 75 percent) stock return series of our sample.

The most noticeable difference between table 6.4 and table 6.5 is that the estimation of region-specific currency exposures leads to a percentage of 29.09 percent $^{201}$ of firms that are statistically significantly exposed to currency movements. Consistent with Ihrig (2001), these results suggest that the construction of a firm-specific exchange risk factor based on the geographical dispersion of a firm's activities significantly improves the precision of individual firm-level currency risk exposure estimates. Moreover the disaggregation of the tradeweighted world exchange rate index into region-specific currency indices avoids the loss of information due to low or negative correlations between exchange rate series and, hence, improves the informative quality of our exchange risk factor. Finally, we note that U.S. multinationals are particularly sensitive to Asian exchange rate movements. Out of 639 firms that are active in this region, 110 (17.21 percent) are significantly exposed to changes in the Asian currency market.

In order to analyze the impact of these region-specific foreign exchange rate movements on different industries, the percentage of firms with significant currency exposure is calculated by industry sector (table 6.6). The industries where we find most firms with statistically significant currency risk exposures are agriculture, mining (except oil and gas extraction) and construction; wholesale and retail trade; finance, insurance and real estate; and services. ${ }^{202}$ These results are not surprising since these industries are by their very nature and the on-going internationalization of their markets highly exposed to currency fluctuations. It is

\footnotetext{
20129.09 percent of U.S. multinationals is exposed to one region-specific exchange rate index at least.

202 These findings are in line with previous empirical findings (please refer to empirical findings outlined in sections $3.3 .2,3.4 a .2,3.4 b .2$ and 5.6 .1 )
} 
also important to note that the sensitivity to Asuan exchange rate movements is also remarkably strong for the electronic and other electrical equipment (except computer equipment) sector. Given the truly intense trading relationships that exist between these U.S. and Asian industry sectors, this finding is likewise consistent with our expectations.

\section{Table 6.4: Linear foreign exchange risk exposure - world exchange rate index -}

This table reports cross-sectional summary statistics of the parameters estimated by the following regression model:

$$
R_{i, t}=\alpha_{i}+B_{i} R_{m, t}+\gamma_{i} \theta_{t}+\varepsilon_{i, i}
$$

where $R_{i, t}$ designates the total return of firm $i$ in period $t_{3} R_{m, i}$ the CRSP value-weighted stock market return in period $t, \theta_{i}$ firm $i$ 's return sensitivity to market fluctuations, $\theta_{i}$ the movenent in the trade-weighted world exchange rate index, $\gamma_{i}$ firm $i$ 's exposure to the exchange rate index and $\varepsilon_{i, s}$ the white noise error term.

If, for firm $i$, the homoscedasticity of the returns is rejected, the previous model is extended to:

$$
\begin{aligned}
& R_{i, t}=\alpha_{i}+B_{i} R_{m, i, i}+\gamma_{i} \theta_{t}+\varepsilon_{i, t} \text { with } \quad \varepsilon_{i, t}=\mu_{i, t} *\left(h_{i, j}\right)^{l / 2} \\
& \text { and } \quad h_{i, t}=\delta_{i}+\tau_{i} e_{i, l-1}^{2}+w_{i} h_{i, y-1}
\end{aligned}
$$

\begin{tabular}{|c|c|c|c|c|c|c|c|}
\hline & & mean & median & $\mathrm{Q}_{i}$ & $Q_{3}$ & $N^{*}$ & $\mathbb{N}$ \\
\hline constant & $a$ & $\begin{array}{c}-0.0007 \\
0.0001\end{array}$ & $\begin{array}{c}-0.0003 \\
0.0001\end{array}$ & -0.0019 & 0.0010 & & \\
\hline market index & $B$ & $\begin{array}{l}0.8717 \\
0.0139\end{array}$ & $\begin{array}{l}0.7924 \\
0.0174\end{array}$ & 0.5886 & 1.0919 & & \\
\hline $\begin{array}{l}\text { trade weighted U.S. dollar } \\
\text { exchange rate index }\end{array}$ & $\gamma^{\prime}$ & $\begin{array}{l}0.0408 \\
0.0136\end{array}$ & $\begin{array}{l}0.0553 \\
0.0170\end{array}$ & -0.1399 & 0.2375 & $\begin{array}{c}68 \\
7.27 \%\end{array}$ & 935 \\
\hline constant $^{3}$ & $\delta^{*}$ & $\begin{array}{l}0.0018 \\
0.0001\end{array}$ & $\begin{array}{l}0.0009 \\
0.0009\end{array}$ & 0.0004 & 0.0019 & & \\
\hline arch coefficient & $\tau^{*}$ & $\begin{array}{l}0.1539 \\
0.0072\end{array}$ & $\begin{array}{l}0.1140 \\
0.0090\end{array}$ & 0.0666 & 0.1870 & & \\
\hline garch coefficient & $V^{*}$ & $\begin{array}{l}0.4767 \\
0.0149\end{array}$ & $\begin{array}{l}0.5842 \\
0.0187\end{array}$ & 0.2907 & 0.7689 & & \\
\hline
\end{tabular}

where $h_{i, t}$ denotes the conditional variance of the residuals; $\delta_{i,} \tau_{i}$ and $v_{i}$ unknown parameters; and $\mu_{i, t}$ represents the white noise error term.

The numbers are summary statistics of the cross-sectional distribution of the ordinary least squares parameter estimates of Eq. (1), respectively the maximum likelihood (using the Berndt $a t$ al. (1974) algorithm) parameter estimates of $\mathrm{Eq} .(2-3) \cdot \mathrm{Q}_{1}$ and $\mathrm{Q}_{3}$ represent the first and third quartiles of the distribution. $\mathbb{N}^{*}$ is the number of firms with a documented significant exchange rate exposure (at the 5 percent level) at least. $N$ is size of the total sample. These iesults are reported when the homoscedasticity of the error terms $\varepsilon_{i, x}$ in Eq. (3) is rejected. ${ }^{b}$ The constant of Eq. (3). 


\section{Table 6.5: Linear foreign exchange exposure - regional exchange rate indices -}

This table reports cross-sectional summary statistics of the estimation of the following regression:

$$
\begin{aligned}
& R_{i, t}=a_{i}+B_{i} R_{i n, y}+\Gamma_{j} \theta_{i}+E_{i, i} \\
& \text { and } \Gamma_{i} \theta_{i}=\gamma_{E U, i} \theta_{E U, t} * D_{E U, i}+\gamma_{U K, i} \theta_{U K_{t}} * D_{U K_{i},}+\gamma_{A S_{i}} \theta_{A S, i} * D_{A S, i}
\end{aligned}
$$

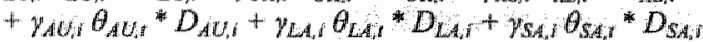

where $R_{i, y}$ designates the total return of firm $i$ in period $t, R_{m: t}$ the CRSP value-weighted stock market return in period $\theta_{i}$ firm $i$ 's return sensitivity to market fluctuations; $\theta_{j, i}$ the movement in the region $y$ specific trade-weighted U.S. dollar exchange rate index, $D_{j,}$ a dummy variable that takes the value 1 if firm $i$ has real activities in region $j$, $y_{f, 3}$ firm $i$ 's exposure to the region $j$ specific trade-weighted U.S. dollar exchange rate index and $\varepsilon_{i, t}$ the white noise error term.

If, for firm $i$, the homoscedasticity of the error terms $\varepsilon_{i, f}$ is rejected, the model is extended to:

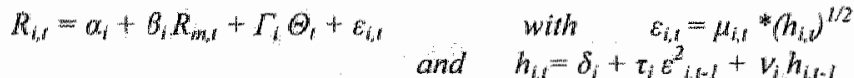

\begin{tabular}{|c|c|c|c|c|c|c|c|}
\hline & & mean & median & $\mathrm{Q}_{\|}$ & $Q_{3}$ & $\mathrm{~N}^{*}$ & $N$ \\
\hline constant & $a$ & $\begin{array}{l}-0.0007 \\
0.0001\end{array}$ & $\begin{array}{c}-0.0002 \\
0.0001\end{array}$ & -0.0327 & $0.0 \rrbracket 31$ & & \\
\hline $\begin{array}{l}\text { CRSP value-weighted } \\
\text { market index }\end{array}$ & $B$ & $\begin{array}{l}0.8725 \\
0.0138\end{array}$ & $\begin{array}{l}0.7806 \\
0.0173\end{array}$ & $0.588 \mathbb{1}$ & 1.0998 & & \\
\hline USS versus euro & $\gamma_{E U}$. & $\begin{array}{l}0.0169 \\
0.0155\end{array}$ & $\begin{array}{l}0.0162 \\
0.0194\end{array}$ & -0.1557 & 0.2140 & $\begin{array}{c}61 \\
8.93 \%\end{array}$ & 683 \\
\hline $\begin{array}{l}\text { US\$ versus U.K. } \\
\text { pound }\end{array}$ & $\gamma_{U K}$ & $\begin{array}{l}0.0662 \\
0.0136\end{array}$ & $\begin{array}{l}0.0550 \\
0.0171\end{array}$ & -0.1000 & 0.2173 & $\begin{array}{c}66 \\
9.27 \%\end{array}$ & 712 \\
\hline $\begin{array}{l}\text { USS wersus Asian } \\
\text { currencies }\end{array}$ & $\gamma_{A S S}$ & $\begin{array}{l}0.0274 \\
0.0182\end{array}$ & $\begin{array}{l}0.0494 \\
0.0229\end{array}$ & -0.2182 & 0.2862 & $\begin{array}{l}110 \\
17.21 \%\end{array}$ & 639 \\
\hline $\begin{array}{l}\text { US\$ versus Australian } \\
\text { dollar }\end{array}$ & $\gamma_{A U}$ & $\begin{array}{c}-0.0971 \\
0.0168\end{array}$ & $\begin{array}{l}-0.0741 \\
0.0211\end{array}$ & -0.2871 & 0.0935 & $\begin{array}{l}36 \\
9.09 \%\end{array}$ & 396 \\
\hline $\begin{array}{l}\text { USS versus Latin } \\
\text { American currencies }\end{array}$ & $\gamma_{L A}$ & $\begin{array}{l}0.0064 \\
0.0107\end{array}$ & $\begin{array}{l}0.0016 \\
0.0135\end{array}$ & -0.0745 & 0.0899 & $9.54 \%$ & 461 \\
\hline $\begin{array}{l}\text { USS versus South } \\
\text { Aftican rand }\end{array}$ & $\gamma_{S A}$ & $\begin{array}{l}0.0094 \\
0.0192\end{array}$ & $\begin{array}{c}-0.0180 \\
0.0240\end{array}$ & -0.1188 & 0.1324 & $\begin{array}{l}15 \\
9.15 \%\end{array}$ & 164 \\
\hline constant ${ }^{5}$ & $\delta *$ & $\begin{array}{l}0.0017 \\
0.0001\end{array}$ & $\begin{array}{l}0.0008 \\
0.0001\end{array}$ & 0.0004 & 0.0018 & & \\
\hline arch coefficient & $\tau^{*}$ & $\begin{array}{l}0.1626 \\
0.0080\end{array}$ & $\begin{array}{l}0.11 .78 \\
0.0100\end{array}$ & 0.0673 & 0.1901 & & \\
\hline garch coefficient & $v_{\text {o }}^{\text {ok }}$ & $\begin{array}{l}0.4812 \\
0.0148\end{array}$ & $\begin{array}{l}0.5944 \\
0.0185\end{array}$ & 0.2623 & 0.7657 & & \\
\hline \multicolumn{6}{|c|}{$\begin{array}{l}\text { Iotal munber of companies that are significantly exposed to one currency } \\
\text { index at least: }\end{array}$} & $\begin{array}{l}272 \\
29.09 \%\end{array}$ & 935 \\
\hline
\end{tabular}

where $h_{i, t}$ denotes the conditional variance of the residuals; $\delta_{i} \tau_{i}$ and $v_{i}$ unknown parameters; and $\mu_{i, d}$ represients the white noise error term.

Reported numbers are summary statistics of the cross-sectional distribution of the ols parameter estimates of Eq. (4), respectively the maximum likelihood (Berndt et al, 1974) parameter estimates of Eq. $(6-7), Q_{1}$ and $Q_{3}$ denote the first and third quartiles of the distribution. $N *$ designates the number of firms with a documented significant (at the 5 percent level) exchange rate exposure to one of the regional currency indices at least. $\mathbb{N}$ is the number of firms that have activities in the corresponding geographical region. * These results are reported when the homoscedasticity of the error terms $\varepsilon_{i, t}$ in Eq. (4) is rejected. ${ }^{8}$ The constant of Eq. (7). 
Table 6.6: Linear foreign exchange risk exposure

\begin{tabular}{|c|c|c|c|c|c|c|c|}
\hline : & $\begin{array}{l}\frac{8}{8} \\
\frac{5}{4}\end{array}$ & $\stackrel{3}{5}$ & 要 & 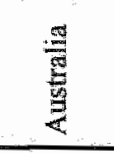 & 5 & $\sum^{\frac{T}{2}}$ & ? \\
\hline $\begin{array}{l}\text { Agriculture, Mining (except oil } \\
\& \text { gas) \& Construction }\end{array}$ & $0.00 \%$ & $11.11 \%$ & $55.56 \%$ & $70.00 \%$ & $33.33 \%$ & $3333 \%$ & $35.29 \%$ \\
\hline $\begin{array}{l}\text { Food, Tobacco, Textile, Wood } \\
\& \text { Paper related industries }\end{array}$ & $12.90 \%$ & $10.45 \%$ & $18.84 \%$ & $128 \%$ & $16.98 \%$ & $15.38 \%$ & $17.82 \%$ \\
\hline Chemical \& allied products & $12.86 \%$ & $17.46 \%$ & $18.33 \%$ & $19.57 \%$ & $22,45 \%$ & $34.78 \%$ & $27.85 \%$ \\
\hline $\begin{array}{l}\text { Oil \& gas extraction, petroleum } \\
\text { refing \& related ind. }\end{array}$ & $0.00 \%$ & $0.00 \%$ & $7.41 \%$ & $0.00 \%$ & $4.35 \%$ & $7.14 \%$ & $21.05 \%$ \\
\hline $\begin{array}{l}\text { Rubber, Leather, Stone, Clay, } \\
\text { Glass \& Concrete Products }\end{array}$ & $9.09 \%$ & $12.50 \%$ & $10.00 \%$ & $12.50 \%$ & $7.69 \%$ & $33.33 \%$ & $12.50 \%$ \\
\hline $\begin{array}{l}\text { Primary \& fabricated metal } \\
\text { Industries* }\end{array}$ & $16.67 \%$ & $16.22 \%$ & $15.15 \%$ & $16.67 \%$ & $11.11 \%$ & $12.50 \%$ & $28.57 \%$ \\
\hline $\begin{array}{l}\text { Industrial \& Commercial } \\
\text { machinery \& computer equip. }\end{array}$ & $12.36 \%$ & $15.73 \%$ & $1625 \%$ & $26.53 \%$ & $22.92 \%$ & $24.00 \%$ & $31.53 \%$ \\
\hline $\begin{array}{l}\text { Electronic \& other electrical } \\
\text { equip. (exc. computer equip.) }\end{array}$ & $12.31 \%$ & $15.00 \%$ & $28.57 \%$ & $29.03 \%$ & $13.51 \%$ & $0.00 \%$ & $29.35 \%$ \\
\hline $\begin{array}{l}\text { Transportation equip., } \\
\text { measuring inst. \& misc. }\end{array}$ & $17.65 \%$ & $14.47 \%$ & $7.04 \%$ & $20.93 \%$ & $15.69 \%$ & $8.33 \%$ & $18.63 \%$ \\
\hline $\begin{array}{l}\text { Transp. communication, } \\
\text { electric, gas \& sanitary serv. }\end{array}$ & $16.67 \%$ & $29.73 \%$ & $12.90 \%$ & $18.8 \%$ & $6.45 \%$ & $0.00 \%$ & $18.87 \%$ \\
\hline Wholesale \& retail trade & $28.57 \%$ & $18.52 \%$ & $58.06 \%$ & $18.75 \%$ & $2593 \%$ & $28.57 \%$ & $38.60 \%$ \\
\hline Finance, Insurance \& real estate & $28.00 \%$ & $20.00 \%$ & $43.64 \%$ & $18.75 \%$ & $29.27 \%$ & $15.79 \%$ & $50.00 \%$ \\
\hline Services & $13.73 \%$ & $12.82 \%$ & $39.76 \%$ & $9.09 \%$ & $20.41 \%$ & $18.75 \%$ & $36.57 \%$ \\
\hline Total & $893 \%$ & $9.27 \%$ & $17.21 \%$ & $9.09 \%$ & $9.54 \%$ & $9.15 \%$ & $29.09 \%$ \\
\hline
\end{tabular}

Reported percentages represent - per industry sector - the ratio between the number of firms that are significantly exposed to the European, U.K., Asian, Australian, Latin American, respectively South African exchange rate index and the number of firms that are active in the corresponding region.

Definition of industry sectors: see table 6.1. 


\subsubsection{Sign-asymmetries in exchange risk exposure}

Table 6.7 reports the findings of the augmented market model Eq. (6.6) respectively Eq. (6.7) that takes sign asymmetries in the estimation of currency exposure coefficients into account. Results show that for 15.72 percent of all selected U.S. multinationals the null hypothesis of symmetric currency exposure against the altemative allowing for sign asymmetries is strongly rejected. More specifically, for more than 40 percent ( 100 of 240 ) of firms with documented significant exchange rate exposure, the exposure is shown to be asymmetric during appreciations and depreciations. Furthermore, we observe that $\gamma$ and $\gamma^{\prime}$ coefficients are generally of opposite sign. It is interesting to note that these results are consistent with the findings of Koutmos and Martin (2003a) who analyzed industry portfolios. ${ }^{203}$ The nonlinear specification of the model enables us moreover to detect 353 U.S. multinationals ( 37.75 percent) that are - linearly or asymmetrically - exposed to currency movements. This increases the number of documented exchange risk exposures by approximately 30 percent as compared to the linear model. It has to be noticed that the nonlinear model highlights particularly the impact of Asian as well as Latin American currency movements on U.S. firm value.

Ultimately, it should be pointed out that U.S. multinationals appear to be predominantly affected by U.S. dollar appreciations. One potential explanation for this finding could be that U.S. firms are probably able to hedge the adverse effects resulting from their short foreign currency positions in a more efficient way than they are hedging the economic exposure effects resulting from a loss of competitiveness due to an appreciation of their domestic currency. However, many other justifications may be advanced ${ }^{204}$ and further empirical evidence is needed to truly validate these different theories.

\subsubsection{Magnitude-asymmetries in exchange risk exposure}

In table 6.8, we report the estimates of the model outlined in Eq. (6.8) and Eq. (6.9). Several important points can be drawn from the results. As we anticipated, the inclusion of size-asymmetries in the estimation of currency exposures enables us to detect the nonlinear nature of exchange risk exposures. Allowing for asymmetry in decreasing and increasing exchange rate movements, it appears that approximately 56 percent of U.S. multinationals is significantly affected by currency

\footnotetext{
203 Their results show indeed that 42.9 percent of the industry portfolios with significant exchange rate exposure are found to be asymmetric during appreciations and depreciations and that $y$ and $\gamma^{*}$ coefficients are similarly of opposite sign.

204 Please refer to section 6.2 of this chapter.
} 


\section{Table 6.7: Non-Linear foreign exchange exposure - sign asymmetries -}

This table reports cross-sectional summary statistics of the parameters estimated by the following regression model:

$$
\begin{aligned}
& R_{i, t}=\alpha_{i}+B_{i} R_{i, i}+\left(\Gamma_{j}+\Gamma_{i} S_{j}\right) * \Theta_{i}+\varepsilon_{i, r}
\end{aligned}
$$

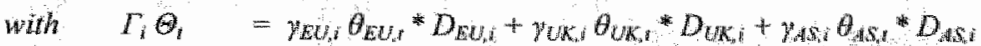

$$
\begin{aligned}
& +\gamma_{A U, i} \theta_{A U, i} * D_{A U, i}+\gamma_{L A, i} \theta_{L A, i} * D_{L A, i}+\gamma_{S A, i} \theta_{S A, i} * D_{S A_{i} i}
\end{aligned}
$$

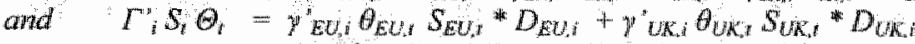

$$
\begin{aligned}
& +\gamma_{A S, i} \theta_{A S, i} S_{A S, t} D_{A S, i}+\gamma^{\prime}{ }_{B U i} \theta_{A U, i} S_{A U, t} * D_{A U, i}
\end{aligned}
$$

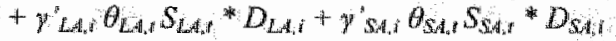

where $R_{i, t}$ designates the total return of firm $i$ in period $t, R_{m, i}$ the CRSP value-weighted stock market return in period $t, \theta$ firm is return sensitivity to market fluctuations, $\theta_{j, t}$ the movement in region $j$ 's specific trade-weighted U.S. dollar exchange rate index in period $t, D_{j, i}$ a dummy variable that takes the value 1 if firm $i$ has real activities in region $j, S_{j, r}$ dummy variable that takes the value 1 if $\theta_{j, i}$ is negative, $\gamma_{j, i}$ firm $i$ 's symmetric exposure to region $j / \mathrm{s}$ specilic tradeweighted U.S. dollar exchange rate index, $\gamma_{j,}^{b}$ firm $i$ 's asymmetric exposure to region $j^{3} \mathrm{~s}$ speeific trade-weighted U.S. dollar exchange rate index and $\varepsilon_{i, t}$ the white noise error term.

If, for firm $i$, the homoscedasticity of the error terms $\varepsilon_{h,}$ of Eq. (8) is rejected, the nodel becomes:

$$
\begin{aligned}
& R_{i, t}=\alpha_{i}+\theta_{i} R_{m, t}+\left(\Gamma_{i}+\Gamma_{i}^{i} S_{i}\right)^{*} \Theta_{i}+\varepsilon_{i, t} \quad \text { with } \quad \varepsilon_{i, t}=\mu_{i, i} *\left(h_{i, t}\right)^{1 / 2}
\end{aligned}
$$

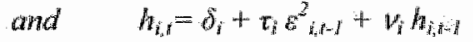

where $h_{i, i}$ denotes the conditional variance of the residuals; $\delta_{j}, x_{i j}$ and $v_{i}$ unknown parameters; and

\begin{tabular}{|c|c|c|c|c|c|c|c|}
\hline & & mean & median & $Q_{1}$ & $\mathrm{Q}_{3}$ & $N^{*}$ & $\mathrm{~N}$ \\
\hline constant & $\alpha$ & $\begin{array}{c}-0.0002 \\
0.0002\end{array}$ & $\begin{array}{l}0.0000 \\
0.0002\end{array}$ & -0.0027 & 0.0024 & & \\
\hline $\begin{array}{l}\text { CRSP value-weighted } \\
\text { market index }\end{array}$ & $B$ & $\begin{array}{l}0.8730 \\
0.0139\end{array}$ & $\begin{array}{l}0.7847 \\
0.0174\end{array}$ & 0.5862 & 1.0985 & & \\
\hline \multirow{2}{*}{ US\$ versus euro } & $\gamma_{E U}$ & $\begin{array}{l}0.0693 \\
0.0255\end{array}$ & $\begin{array}{l}0.0670 \\
0.0320\end{array}$ & -0.2651 & 0.3742 & $\begin{array}{c}55 \\
8.05 \%\end{array}$ & 683 \\
\hline & $\gamma_{E U^{\prime}}$ & $\begin{array}{c}-0.0952 \\
0.0409\end{array}$ & $\begin{array}{c}-0.0801 \\
0.0512\end{array}$ & -0.5714 & 0.3782 & $\begin{array}{c}47 \\
6.88 \%\end{array}$ & \\
\hline \multirow{2}{*}{ USS versus U.K. pound } & $y_{u K}$ & $\begin{array}{l}0.0747 \\
0.0221\end{array}$ & $\begin{array}{l}0.0360 \\
0.0277\end{array}$ & -0.1642 & 0.2909 & $\begin{array}{c}55 \\
7.72 \%\end{array}$ & 712 \\
\hline & $\gamma u K^{*}$ & $\begin{array}{c}-0.0342 \\
0.0359\end{array}$ & $\begin{array}{l}0.0303 \\
0.0450\end{array}$ & -0.3419 & 0.3573 & $\begin{array}{c}49 \\
688 \%\end{array}$ & \\
\hline \multirow{2}{*}{$\begin{array}{l}\text { USS versus Asian } \\
\text { currencies }\end{array}$} & $\gamma_{A S}$ & $\begin{array}{c}-0.1051 \\
0.0314\end{array}$ & $\begin{array}{l}-0.0152 \\
0.0394\end{array}$ & -0.44115 & 0.3307 & $\begin{array}{c}79 \\
12.36 \%\end{array}$ & 639 \\
\hline & $\gamma_{A S}$ & $\begin{array}{l}0.2264 \\
0.0490\end{array}$ & $\begin{array}{l}0.1321 \\
0.0614\end{array}$ & -0.4328 & 0.8328 & $\begin{array}{c}64 \\
10.02 \%\end{array}$ & \\
\hline \multirow{2}{*}{$\begin{array}{l}\text { US\$ versus Australian } \\
\text { dolllar }\end{array}$} & $\gamma_{A U}$ & $\begin{array}{c}-0.1532 \\
0.0249\end{array}$ & $\begin{array}{l}-0.1523 \\
0.0311\end{array}$ & -0.3835 & 0.1027 & $\begin{array}{c}29 \\
7.32 \%\end{array}$ & 396 \\
\hline & $\gamma_{A B^{\prime}}$ & $\begin{array}{l}0.1261 \\
0.0405\end{array}$ & $\begin{array}{l}0.0870 \\
0.0507\end{array}$ & -0.3203 & 0.4693 & $\begin{array}{c}32 \\
8.08 \%\end{array}$ & \\
\hline \multirow{2}{*}{$\begin{array}{l}\text { USS versw Latin } \\
\text { American currencies }\end{array}$} & $\gamma_{L A}$ & $\begin{array}{c}-0.0129 \\
0.0121\end{array}$ & $\begin{array}{c}-0.0220 \\
0.0152\end{array}$ & -0.1024 & 0.0671 & $\begin{array}{c}51 \\
11.06 \%\end{array}$ & 461 \\
\hline & $\gamma_{L A^{\prime}}$ & $\begin{array}{l}0.1312 \\
0.0376\end{array}$ & $\begin{array}{l}0.1282 \\
0.0477\end{array}$ & -0.1898 & 0.4908 & $\begin{array}{c}41 \\
8.89 \%\end{array}$ & \\
\hline
\end{tabular}
$\mu_{i, t}$ represents the white noise error tern. 
Table 6.7: continued

\begin{tabular}{|c|c|c|c|c|c|c|c|}
\hline & & mean & median & $Q_{1}$ & $\mathrm{Q}_{3}$ & $N^{*}$ & $N$ \\
\hline \multirow{2}{*}{$\begin{array}{l}\text { USs versus South African } \\
\text { rand }\end{array}$} & $\gamma_{S A}$ & $\begin{array}{l}-0.0262 \\
0.0251\end{array}$ & $\begin{array}{r}-0,0497 \\
0,0314\end{array}$ & -0.1584 & 0.0877 & $\begin{array}{c}16 \\
9.76 \%\end{array}$ & \multirow[t]{5}{*}{164} \\
\hline & $y s A^{*}$ & $\begin{array}{l}0.1077 \\
0.0570\end{array}$ & $\begin{array}{l}0.0533 \\
0.0714\end{array}$ & -0.2989 & 0.4956 & 13 & \\
\hline constant & $8 *$ & $\begin{array}{l}0.0016 \\
0.0001\end{array}$ & $\begin{array}{l}0.0008 \\
0.0001\end{array}$ & 0.0004 & 0.0018 & & \\
\hline arch coefficient & $\tau$ & $\begin{array}{l}0.1705 \\
0.0083\end{array}$ & $\begin{array}{l}0.1196 \\
0.104\end{array}$ & 0.0678 & 0.1992 & & \\
\hline garch coefficient & Wits & $\begin{array}{l}0.4732 \\
0.0150\end{array}$ & $\begin{array}{l}0.5803 \\
0.0188\end{array}$ & 0.2581 & 0.7647 & & \\
\hline \multicolumn{6}{|c|}{$\begin{array}{l}\text { Total mumber of companies that ane - linearly or asymmetrically- } \\
\text { significanily exposed to at least one currency index: }\end{array}$} & $\begin{array}{c}353 \\
37.75 \%\end{array}$ & 935 \\
\hline \multicolumn{6}{|c|}{$\begin{array}{l}\text { Total mumber of companies that are - linearly and asymmetrically - } \\
\text { significanly exposed to at least one currency index: }\end{array}$} & $\begin{array}{l}100 \\
1070 \%\end{array}$ & 935 \\
\hline \multicolumn{6}{|c|}{$\begin{array}{l}\text { Number of companies jor which the likelinood ratio test rejects the null } \\
\text { hypothesis of linear currency exposure? }\end{array}$} & $\begin{array}{c}147 \\
15.72 \%\end{array}$ & 935 \\
\hline
\end{tabular}

The numbers are summary statistics of the cross-sectional distribution of the ordinary least squares parameter estimates of Eq. (8), respectively the maximum likelihood (using the Berndt ef al. (1974) algorithm) parameter estimates of $\mathrm{Eq}:(9-10) . \mathrm{Q}_{1}$ and $\mathrm{Q}_{3}$ represent the first and third quartiles of the distribution, respectively. N* designate the numbers of firms with a documented significant exchange rate exposure to the regional currency index (at the 5 percent level) at least. $N$ are the numbers of firms that have activities in the corresponding geographical regions. * These results are reported when the homoscedasticity of the error terms $\varepsilon_{i, t}$ in $\mathrm{Eq} .(8)$ is rejected. "The constant of Eq. (10). The likelihood ratio test is performed against the alternative hypothesis that stock returns react asymmetrically to positive versus negative exchange rate movements. 


\section{Table 6.8: Non-Linear foreign exchange risk exposure - size asymmetries -}

This table reports cross-sectional summary statistics of the estimation of the following regression model:

$$
\begin{aligned}
& R_{i, t}=\alpha_{i}+B_{i} R_{m, t}+\left(T_{i}+\Gamma_{i}^{*} * F_{i}\left(u_{i, t}, k_{\mathrm{i}} \lambda_{i}\right)\right) * \theta_{i}+E_{i, t}
\end{aligned}
$$

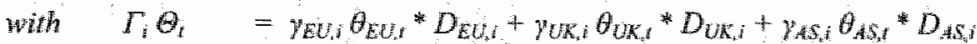

$$
\begin{aligned}
& +\gamma_{A, i, i} \theta_{A U, t} * D_{A U, i}+\gamma_{L A, i} \theta_{L, i} * D_{L A, i}+\gamma_{S A, i} \theta_{S A, i} * D_{S A, i} \\
& \text { and } \quad F_{i}\left(u_{i, k} \lambda_{i, j}\right)=\left(I+\exp \left(-\left(u_{i, i}-k_{i}^{*} \bar{u}_{i, j}\right)^{*} \lambda_{j}\right)\right)^{-1}
\end{aligned}
$$

where $R_{i, t}$ designates the total return of firm $i$ in period $i, R_{m, t}$ the CRSP value-weighted stook market return in period $t_{3} B_{i}$ firm $i$ 's return sensitivity to market fluctuations, $\theta_{j}$, the movement in region $j s$ specific trade-weighted U.S. dollar exchange rate index in period $t_{n}, D_{j, i}$ a dummy variable that takes the value 1 if firm $i$ has real activities in region $j, F\left(u_{i, j}, k_{i j} \mu_{i}\right)$ a transition function that is bounded between 0 and 1 and depends on the magnitude of region $j$ 's specific exchange rate index. movement " $u_{j i}$ " defined as the squared of region $j$ "s specific exchange rate index movement in week $t, \gamma_{j, \text { firm }} i$ 's symmetric exposure to region $j$ 's specific trade-weighted U.S. dollar exchange rate index, $\gamma_{j, i}^{\prime}$ firm $i$ 's asymmetric exposure to region $j$ 's specific tradeweighted U.S. dollar exchange rate index and $\varepsilon_{i,}$ the white noise ertor term.

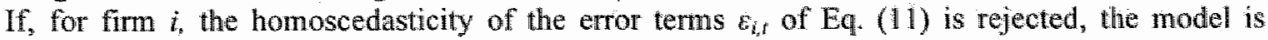
extended to:

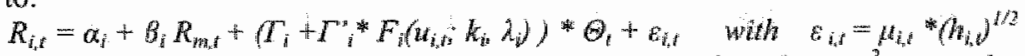

$$
\begin{aligned}
& h_{i, r}=\delta_{i}+x_{i} \varepsilon_{i, r+1}^{2}+v_{i} h_{i, r}
\end{aligned}
$$

\begin{tabular}{|c|c|c|c|c|c|c|c|}
\hline & & mean & median & $Q_{1}$ & $Q_{3}$ & $N^{*}$ & N \\
\hline constant & $\alpha$ & $\begin{array}{c}-0.0009 \\
0.0001\end{array}$ & $\begin{array}{l}-0.0006 \\
0.0001\end{array}$ & -0.0022 & 0.0010 & & \\
\hline $\begin{array}{l}\text { CRSP value-weighted } \\
\text { market index }\end{array}$ & $B$ & $\begin{array}{l}0.8745 \\
0.0137\end{array}$ & $\begin{array}{l}0.7855 \\
0.0172\end{array}$ & 0.5911 & 1.1082 & & \\
\hline HISS vercus pura & $\gamma_{E U}$ & $\begin{array}{l}0.1193 \\
0.0350\end{array}$ & $\begin{array}{l}0.1122 \\
0.0438\end{array}$ & -0.3277 & 0.5959 & $\begin{array}{c}78 \\
11.42 \%\end{array}$ & 683 \\
\hline US\$ Dersus etro & $\gamma_{E U^{r}}$ & $\begin{array}{c}-0.1244 \\
0.0426\end{array}$ & $\begin{array}{l}-0.0310 \\
0.0534\end{array}$ & -0.7330 & 0.3421 & $\begin{array}{c}141 \\
20.64 \%\end{array}$ & \\
\hline USS versus U.K. & $\gamma_{U K}$ & $\begin{array}{c}-0.0290 \\
0.0345\end{array}$ & $\begin{array}{c}-0.0193 \\
0.0432\end{array}$ & -0.4349 & 0.3603 & $\begin{array}{c}78 \\
10.96 \%\end{array}$ & 712 \\
\hline$\quad:$ & $\gamma_{U K}$ & $\begin{array}{l}0.1110 \\
0.0378\end{array}$ & $\begin{array}{l}0.0275 \\
0.0474\end{array}$ & -0.3030 & 0.5360 & $\frac{134}{18.820 \%}$ & \\
\hline US\$ versus Asian & $\gamma_{A S}$ & $\begin{array}{c}-0.1391 \\
0.0688\end{array}$ & $\begin{array}{c}-0.0130 \\
0.0862\end{array}$ & -0.8123 & 0.7065 & $\begin{array}{c}79 \\
12.36 \%\end{array}$ & 639 \\
\hline currencies & $\gamma_{A S}$ & $\begin{array}{l}0.1986 \\
0.0815\end{array}$ & $\begin{array}{l}0.0318 \\
0.1022\end{array}$ & -0.7737 & 0.9658 & $\begin{array}{c}133 \\
20.81 \%\end{array}$ & \\
\hline USS versus Australian & $\gamma_{A U}$ & $\begin{array}{c}-0.1401 \\
0.0368\end{array}$ & $\begin{array}{c}-0.1205 \\
0.0461\end{array}$ & -0.4517 & 0.2424 & $\begin{array}{l}33 \\
8.33 \%\end{array}$ & 396 \\
\hline dollar & $\gamma_{A W^{*}}$ & $\begin{array}{l}0.0446 \\
0.0446\end{array}$ & $\begin{array}{l}0.0213 \\
0.0559\end{array}$ & -0.3841 & 0.4058 & $\frac{54}{13.64 \%}$ & \\
\hline \multirow{2}{*}{$\begin{array}{l}\text { US\$ versus Latin } \\
\text { American currencies }\end{array}$} & $\gamma_{L A}$ & $\begin{array}{l}0.1630 \\
0.0294\end{array}$ & $\begin{array}{l}0.1635 \\
0.0368\end{array}$ & -0.0903 & 0.4641 & $\begin{array}{c}68 \\
14.75 \%\end{array}$ & 461 \\
\hline & $\gamma_{L A}$ & $\begin{array}{c}-0.1684 \\
0.0309\end{array}$ & $\begin{array}{c}-0.1727 \\
0.0388\end{array}$ & -0.5277 & 0.0753 & $\begin{array}{c}98 \\
2126 \%\end{array}$ & \\
\hline
\end{tabular}

where $h_{i, t}$ denotes the conditional variance of the residuals; $d_{i} \tau_{i}$ and $v_{i}$ unknown parameters; and $\mu_{i, i}$ represents the white noise error term. 
Table 6.8: continued

\begin{tabular}{|c|c|c|c|c|c|c|c|}
\hline & & mean: & median & $\mathrm{Q}$ & $Q_{3}$ & N* & $N$ \\
\hline \multirow{2}{*}{$\begin{array}{l}\text { US\$ versws South } \\
\text { African rand }\end{array}$} & $y_{S A}$ & $\begin{array}{l}0.0767 \\
0.0422\end{array}$ & $\begin{array}{l}0.0912 \\
0.0529\end{array}$ & -0.2231 & 0.3711 & $\begin{array}{c}16 \\
9.76 \%\end{array}$ & \multirow[t]{5}{*}{164} \\
\hline & $y_{M^{\prime}}$ & $\begin{array}{l}-0.0679 \\
0.0481\end{array}$ & $\begin{array}{c}0.0104 \\
0.0609\end{array}$ & -0.4414 & 0.2102 & $\begin{array}{c}23 \\
14.02 \%\end{array}$ & \\
\hline constant ${ }^{8}$ & $\delta^{*}$ & $\begin{array}{l}0.0016 \\
0.0001\end{array}$ & $\begin{array}{l}0.0008 \\
0.0001\end{array}$ & 0.0004 & 0.0017 & & \\
\hline arch coefficient & $\tau^{*}$ & $\begin{array}{l}0.1727 \\
0.0087\end{array}$ & $\begin{array}{l}0.1204 \\
0.0109\end{array}$ & 0.0644 & 0.2008 & & \\
\hline garch coefficient & $v *$ & $\begin{array}{l}0.4826 \\
0.0149\end{array}$ & $\begin{array}{l}0.5957 \\
0.0187\end{array}$ & 0.2745 & 0.7626 & & \\
\hline \multicolumn{6}{|c|}{$\begin{array}{l}\text { Total number of companies that are - linearly ar asymmetrically - } \\
\text { significantly exposed to at least one currency index: }\end{array}$} & $\begin{array}{c}524 \\
5604 \%\end{array}$ & 935 \\
\hline \multicolumn{6}{|c|}{$\begin{array}{l}\text { Total number of companies that are - linearly and asymmetrically - } \\
\text { significantly exposed to at least one currency index: }\end{array}$} & $\begin{array}{c}216 \\
23.10 \%\end{array}$ & 935 \\
\hline \multicolumn{6}{|c|}{$\begin{array}{l}\text { Number of companies for which the likelihood ratio test rejects the mull } \\
\text { hypothesis of tinear curency exposure". }\end{array}$} & $\begin{array}{c}247 \\
26.42 \%\end{array}$ & 935 \\
\hline
\end{tabular}

The numbers are summary statistics of the cross-sectional distribution of the ordinary least squares parameter estimates of Eq. (11), respectively the maximum likelihood (using the Berndt et al. (1974) algorithm) parameter estimates of Eq. (13-14). $Q_{1}$ and $Q_{3}$ represent the first and

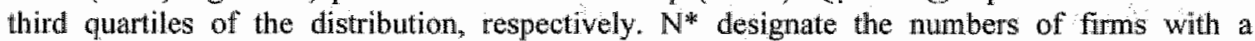
documented significant exchange rate exposise to the regional currency index at the 5 percent level at least. $N$ are the numbers of firms that have activities in the corresponding geographical regions. * These results are reported when the homoscedasticity of the error terms $\varepsilon_{i, t}$ in $\mathrm{Eq}$. (11) is rejected. "The constant of Eq. (14). ${ }^{\dagger}$ The likelihood ratio test is performed against the alternative hypothesis that stock returns react asymmetrically to large versus small exchange rate movements.

movements. The number of firms with documented significant exchange risk exposures is, thus, approximately two times higher compared to the linear model and 50 percent higher compared to the model including size- asymmetries.

Moreover, it appears that among empirically significant exchange rate exposures, the currency sensitivity turns out to be asymmetric over large and small movements in almost 75 percent $\left(216\right.$ of 289 ) of the cases. ${ }^{205}$ Taking into account the entire sample of U.S. multinationals, we observe, further, that the null hypothesis of a linear relationship between exchange rate movements and stock returns - against the alternative allowing for size asymmetries - is rejected for

\footnotetext{
${ }^{205}$ Not surprisingly, regarding the Asian and Latin American currencies, we note that the percentage of significant currency exposures that turns out to be asymmetric is even stronger. This can easily be explained by the higher volatility of these currency markets
} 
more than 26 percent of our sample companies. These results, in comparison with the previous reported models, are peculiarly striking. They suggest that models assuming symmetric exposure over small and large exchange rate movements are very frequently misspecified. They are, thus, not able to detect the link between exchange rate movements and stock returns and tend to underestimate the impact of currency movements on firm value. When considering the impact of large versus small exchange rate movements; our findings unanimously reveal that the valuation effects of large currency shocks are statistically and economically more relevant in terms of firm value. This series of results sheds new light on various issues that have already been thoroughly discussed in this thesis: firstly, it may lend support to the hypothesis that investors find it particularly difficult to forecast the valuation effects of small currency fluctuations; secondly, it pleads for the view that increased exchange rate variability constitutes a particularly influential source of risk for companies; thirdly, it may indicate that companies are facing difficulties in implementing efficient hedging activities when exchange rate markets undergo turbulent market conditions; finally, it may as well reveal that pass-through effects are positively linked to the magnitude of exchange rate movements (Ohno, 1989; Pollard and Coughlin, 2003) and / or that large currency fluctuations lead to market entry or exit decisions that are not overruled when the foreign currency returns progressively to its initial value.

\subsection{Concluding Remarks}

Previous empirical literature on foreign exchange risk exposure suggests that there is weak evidence on the sensitivity of U.S. stock returns to exchange rate movements. This chapter examines the impact of the linearity assumption on the estimation of foreign exchange risk exposure of U.S. nultinationals. It uses a new extensive data set of 935 U.S. companies with real operations in foreign countries and tests the hypothesis that stock returns react differentially both to positive versus negative news from exchange rate markets and to large versus small currency shocks.

First, empirical findings show that the disaggregation of the worldwide trade-weighted U.S. dollar exchange rate index into six region-specific tradeweighted indices increases the precision and significance of exposure estimates. Results show furthermore that the inclusion of both sign and size asymmetries significantly increases the number of U.S. companies that document a significant sensitivity to currency movements. For more than 40 percent ( 100 of 240 ) of firms with documented significant exchange rate exposure, the exposure is shown to be 
asymmetric during appreciations and depreciations. On the other hand, it appears that among empirically significant exchange rate exposures, the currency sensitivity turns out to be asymmetric over large and small movements in almost 75 percent (216 of 289) of the cases. This could be interpreted as evidence that size asymmetries are of greater importance than sign asymmetries when estimating the link between stock returns and currency movements.

Finally, results are highly robust to a number of changes in the model specification. The impact of redefining the market index return and excluding the U.K. pound/U.S. dollar exchange rate movements are consecutively examined. Although the significance of exposure coefficients is found to depend on the definition of the market index, the conclusions regarding the impact of asymmetries remain unaffected.

This chapter provides hence strong and robust evidence that U.S. multinationals are significantly affected by exchange rate movements. We show that previous weak evidence may be attributed to the failure to account for the asymmetric nature of currency risk exposure and the use of too aggregated exchange rate indices. Empirical findings reveal furthermore that, compared to the direction, the magnitude of currency movements has a particularly strong influence on firms' sensitivity to exchange rate fluctuations. These unique results inevitably shed extra light on the underlying mechanism of foreign exchange risk exposure and provide stimulating routes for future research. The empirical investigation of the role played by corporate hedging activities, pass-through effects and hysteretic behavior as well as the influence of investors' msipricing errors and external interventionism will not only help us to assess the importance of all these forces in the determination of the exact asymmetric nature of foreign currency exposure. It will also enable us to identify other sources of time-variation that are embedded in the relationship between exchange rate movements and stock returns. These very challenging areas of research belong definitely to the most promising ways to develop precise and exhaustive techniques to appraise, understand and manage foreign exchange rate risk. 

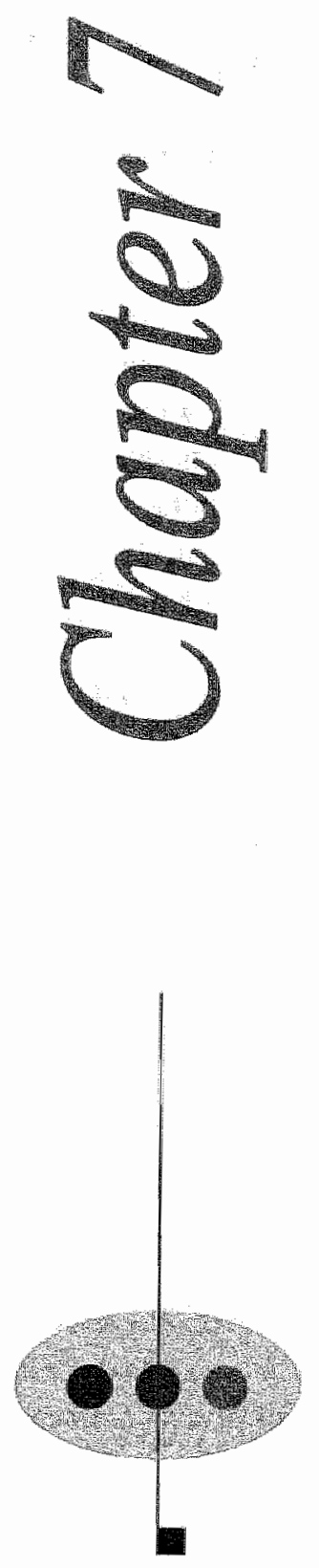

\section{Concluding}

\section{Comments and}

Suggestions for

Future Research 


\section{Concluding Comments and Suggestions for Future Research}

After more than thirty years of experience under floating exchange rates since the breakdown of the Bretton Woods fixed-parity system, the rationales behind the dramatic increase in exchange rate volatility as well as the assessment of its associated risks still belong to the most stimulating topics in economics, business and international finance. Since neither the large cyclical movements nor the extreme short-term instability undergone by floating exchange rates have slowed down the intemationalization of trade around the world, the simultaneous increase in exchange rate uncertainty and international trade have generated extremely challenging issues for managers, investors and regulators: managers have to adopt new approaches to cope with the impact of exchange rate movements on both firms" operational cash flows and the discount rate employed to value these cast flows; foreign investment strategies are forcing investors to manage the risk of currency losses on their portfolios as well as to deal with the exchange rate sensitivity of the domestic and foreign shares they are holding; finally, regulators have to implement optimal monetary strategies in order to ensure that currency volatility doesn't hamper the benefits of international trade and finance for the overall economy. With such relevant and far-reaching issues at hand, it is evident that foreign exchange risk exposure - defined as the sensitivity of asset values to exchange rate movements - doesn't only find its roots but has also crucial implications at the macroeconomic, corporate and international finance level of our society.

Given the relevance of the topic, it is no surprise that, in spite of its youth, the foreign exchange risk exposure literature has centralized one of the most active debates of recent decades. From a theoretical perspective, it is a generally held view that exchange rate fluctuations are an important source of macroeconomic uncertainty affecting firm value regardless of whether the firm is domestically or internationally oriented (Shapiro, 1995; Hodder, 1982; Levi, 1994; Marston, 2001). However, the empirical stream of research hasn't been able so far to give a clear answer on the real impact of foreign exchange rate risk. While in earlier years a consensus seemed to have emerged suggesting that exchange rate movements have no perceptible influence on stock returns (Jorion, 1990; Bodnar and Gentry, 1993; 
Amihud, 1994), today, after more than fourteen years of research, evidence in support of a significant impact of exchange rate movements on firm value still confronts with inconclusive and puzzling results showing that this impact is weak and trivial (Griffin and Stulz, 2001).

Within this controversy, the present thesis provides a methodologically rich and diversified perspective on foreign exchange risk exposure issues An important set of empirical questions regarding the sensitivity of stock returns to currency fluctuations are addressed and altemative approaches to measure the impact of currency changes on firm value presented. The intention is definitely not to bring down the curtain on foreign exchange risk exposure but, on the opposite, to shed new light on this challenging topic in order to distinguish the most promising routes to follow in the future. This concluding chapter will therefore summarize the major empirical results that have emanated from our studies, formulate the central messages of the preceding chapters and, most importantly, outline key questions and research areas which will help us to design the most accurate and efficient techniques to manage foreign exchange rate risk.

The empirical analysis of this thesis starts in chapter 3 which re-examines the foreign exchange rate exposure of individual firms with respect to data aggregation and increasing return horizons. To offer a diversified and exhaustive perspective on foreign exchange risk exposure, the analysis is performed on two distinctive investigation fields: in a first round, we concentrate on the valuations effects of changes in the most actively traded currencies and, in a second round, we analyze the impact of the highly volatile fluctuations in the values of emerging countries" currencies. For completeness we examine the implications of these movements not only on local firms established in these developing countries but also on companies that are listed on mature stock markets but have active trading relationships with these emerging markets. Empirical results reveal that for the period from January 1988 to December 2002 about 13 percent of our 817 European sample firms experienced economically significant exposure effects to the Japanese yen, 14 percent to the U.S. dollar and 22 percent to the U.K. pound. Asian firms are shown to be more sensitive to exchange rate changes: for the period January 1993 to January 2003, approximately 25 (22.5) percent of these firms were significantly affected by U.S. dollar (Japanese yen) fluctuations. Thus, in line with popular belief, emerging markets are more perceptive to external shocks than more mature markets. In our third analysis, we examine the sensitivity of U.S. multinationals with real operations in Mexico, Brazil, Chile or Argentina to Latin-American currency fluctuations. This trade-specific approach, that focuses on highly volatile currency movements, intends to re-evaluate the counter-intuitiveness of previously reported results on U.S. companies. As a matter of fact, it enables us to reveal that 
roughly 17 percent of our sample U.S. firms experienced economically significant currency exposure effects for the period of January 1970 to December 2001. Globally, our findings are robust across different sub-periods. However, we observe that part of the adverse valuation effect of euro depreciations is driven by the financial turmoil experienced throughout the 1988-1992 period, respectively the 1998-2002 period. The overall extent of sigmificant foreign currency exposure of Asian and U.S. multinationals is, however, not sample dependent: a depreciating (appreciating) Asian currency against foreign currencies has a net negative (positive) impact on Asian stock returns, while a depreciating (appreciating) U.S. dollar against Latin American currencies has a net positive (negative) impact on U.S. multinationals. We observe consistently, across all three studies, that individual firms belonging to the same industry group show high positive as well as negative exposure, suggesting that exposure is not necessarily economically significant in the aggregate. Similarly, all our results indicate that firms with insignificant exposure effects are concentrated only in a small number of industries. It is, finally, important to note that our findings confirm collectively one of the well established empirical regularities in the exchange risk exposure literature. The extent to which firms are exposed to exchange rate fluctuations varies with return horizon: while foreign exchange risk exposure appears to be difficult to identify in the short-term, it becomes increasingly evident when lengthening the observation horizon.

The statistical evidence presented in chapter 3 shows, overall, that the impact of exchange rate movements on firm value is statistically and economically sufficiently relevant to motivate further research. Foreign exchange risk exposure could be investigated in different market conditions, when currency movements are, for instance, exceptionally volatile. If the variability of exchange rate fluctuations turns out to influence the sensitivity of stock returns to these shocks, the question emerges whether the relationship between currency fluctuations and firm value is linear - or not. More generally, the identification of all sources of time-variation in foreign exchange risk exposure is itself an extremely challenging research area. However, before handling these issues, we have to keep in mind that foreign currency risk may be hedged, for instance, by recourse to foreign currency derivative instruments. The empirically estimated foreign exchange risk exposure is, hence, a so-called 'residual' foreign exchange risk exposure that has possibly been reduced through the implementation of hedging strategies. The question in how far corporate hedging activities do influence firms' sensitivity to currency movements is essential for the rest of the thesis and is analyzed in clapter 4.

Chapter 4 intends to empirically identify the determinants of foreign currency derivatives usage and its impact on firms" currency risk exposure. A major 
adwantage of this work is that it relies on a unique dataset of financial statistics; foreign currency derivative positions and stock return data for 471 European companies. The separate investigation of a firm's decision to use FCDs from its decision of how much to use FCDs enables us to conclude that both European firms. decision and degree of utilization of FCDs are primarily driven by the relative importance of their foreign trading activities as well as by their size. These results corroborate the existence of economies of scale in hedging: when the size and the foreign trading activities of a firm are sufficiently important to justify the costs, the implementation of hedging strategies is facilitated. It is likewise important to note, that the presence of tax loss carryforwards is also found to be a strong incentive to use external hedging techniques. In contradiction with underinvestment costs related motives to hedge, firms with strong growth opportunities tend, however, to hedge less. Interestingly, foreign debt is empirically shown to act as a complement to FCDs in hedging foreign exchange rate risk. In a second stage of our analysis, the empirical evidence on European firms" weekly and monthly exchange risk exposures is sufficiently strong to suggest that a prevailing part of European firms may be considered as net-exporting firms - or, more generally, that most of them behave like companies with net foreign denominated assets. Empirical findings regarding the effect of FCD use on the sensitivity of European firm value to currency fluctuations lend support to the hypothesis that the weight of firms" international trading linkages is a major determinant of their exposure to exchange rate risk. However, larger firms appear to be to greater extent capable of diversifying their forelgn operations and implementing operational hedging strategies as the relation between firm size and the magnitude of currency exposure is shown to be significantly negative. Further results indicate that companies with high liquidity - that may use liquidity as a hedging substitute - and firms with high growth opportunities and strong leverage - that are vulnerable to cash-flow volatility - are more sensitive to currency movements. Finally, the relationship between the use of FCDs and exchange risk exposure is found to be consistently negative but statistically week. This chapter provides, hence, further evidence in support of the hypothesis that firms use FCDs for hedging - and not speculating purposes. It reveals, however, that the implementation of these external hedging techniques has only a weak effect on their overall exposure to currency risk.

In chapter 5, we follow a new direction to increase our understanding of the impact of exchange rate uncertainty on stock returns. In order to explore foreign exchange risk exposure in different market conditions, we describe the effects of an increase in exchange rate variability in the aftermath of a financial crisis. The analysis is performed on a sample of 673 U.S. multinational firms with real operations in the crisis-contaminated countries. As pointed out by Bartov et al. 
(1996), this approach has the advantage to prevent results to be influenced by the time variation of foreign exchange rate exposure and the desynchronized relationship between stock returns and currency movements. Our results indicate that enhanced currency uncertainty has a significant impact on stock returns variability of U.S. multinationals that are engaged in foreign sales activities with these turmoil markets in comparison with the control firms belonging to the same industry and market capitalization class. The breakdown between systematic and diversifiable risk indicates, moreover, that the market risk (beta) of these U.S. multinationals increases significantly during periods of increased exchange rate uncertainty. Finally, we demonstrate that the wholesale and retail trade, the transportation, communications and utilities as well as the finance and services sectors are particularly sensitive to exchange rate crises uncertainty. Small capitalization firms are likewise exposed to changes in the international trade environment. The broad conclusion emerging from this chapter is that the additional risk firms are incurring from increased exchange rate variability appears to be systematic in nature. This has strong economic and financial implications since their required rate of (equity) return is altered - i.e. investors demand, for instance, higher returns for holding these firms' shares - affecting both internal financial decision-making and investors' portfolio choices.

Chapter 6 proposes an alternative model to estimate the contemporaneous relationship between exchange rate movements and stock returns. Until recently, most empirical work on foreign exchange risk exposure was devoted to linear estimation models. We clearly document in chapter 6 that the sensitivity of U.S. stock returns to exchange rate movements is asymmetrical in nature as these asset returns respond differentially both to positive versus negative news from exchange rate markets and to large versus small currency shocks. In order to perform our individual firm-level analysis, we construct a new data set consisting of 935 U.S. companies with real operations in foreign countries. The analysis is furthermore enhanced through the disaggregation of the worldwide trade-weighted U.S. dollar exchange rate index into six region-specific trade-weighted indices. The comparison of our result with previous U.S. evidence suggest that models assuming symmetric exposure are frequently misspecified and, thus, not able to detect the impact of currency movements on firm value. Furthermore we find strong evidence that size asymmetries are of greater importance than sign asymmetries when estimating the link between stock returns and currency movements. While for 41.67 percent ( 100 of 240) of firms with documented significant exchange rate exposure, the exposure is shown to be asymmetric during appreciations and depreciations, it appears that 75 percent ( 216 of 289 ) of exposed companies are asymmetrically affected by large versus small exchange rate shocks. 
Through the extension of previously examined investigation fields, the improvement of existing methodologicall designs and the exploration of new research questions, we have demonstrated in this work the power and economic relevance of foreign exchange risk exposure. As new empirical facts always lead to new questions, this thesis suggests the need for not only a further careful reassessment of the relationship between exchange rate movements and firm value but also further empirical work on the economic, corporate and financial implications of this link. Before outlining some new directions for future research, we will conclude this thesis by discussing and interpreting key points that have emerged consistently from our empirical studies:

1) "...(exchange rate) movements constitute a source of risk for intemational firms which can affect actions taken by decision-makers within such firms" This excerpt from Hodder's (1982) analytical paper on foreign exchange rate exposure has found its empirical interpretation and justification in this thesis. We have not only seen along preceding chapters that firm value may be significantly affected by foreign currency movements but we have verified as well that the surge of a currency crisis - with the subsequent increase in exchange rate uncertainty - exposes companies to an additional risk that is systematic in nature. Due to the outbreak of the Asian currency crises, for instance, many U.S. multinationals entertaining active trading relationships with the crises countries were facing this additional uncertainty and saw their market beta inerease. Given that their required rate of (equity) return was altered, managers had to adapt their internal financial decision-making process and investors their portfolio choices. This recent economic and financial episode provides a precise illustration of the potential consequences of foreign exchange rate risk. From a larger perspective, the observed stock market reactions lend credence to a long-held concern on the economic effects of monetary institutions and policies - revealing once again that foreign exchange exposire issues are intimately linked with the ongoing debate regarding the optimal exchange rate regime to adopt.

2) Empirical evidence of foreign exchange risk exposure tends to disappear under data aggregation. Firms within the same industry sector show high positive as well as negative foreign exchange risk exposures which suggests per se that exposure is not necessarily economically significant in the aggregate. The heterogeneity of these exposures proceeds, in reality from the extreme diversity of circumstances in which companies may evolve. Foreign exchange risk exposure effects depend, indeed, on a large number parameters as, for instance, the nature of firms" activities, their export and import structures, the competitiveness of their 
input and output markets, the geographical dispersion of their operations and the effectiveness of their hedging activities. It is hence logical that firms are not homogeneously affected by currency movements and that the aggregation of this large disparity will lead to off-setting effects, resulting, in turn, to the disappearing of exposure effects. This loss of information due to data aggregation - if the data is heterogeneous - may, however, as well be illustrated from another point of view: Many previous empirical studies on foreign exchange risk exposure have, indeed, suffered from the use of too aggregated exchange risk factors. We have shown in this thesis that the disaggregation of the worldwide trade-weighted U.S. dollar exchange rate index into six region-specific trade-weighted indices, for instance, avoids the loss of information due to low or negative correlations between the exchange rate series brought together in the exchange risk factor - which leads, in the end, to more accurate foreign exposure estimates. Like in other research areas, the informative quality of the variables included in the estimation plays, hence, a central role in the empirical investigation of foreign exchange risk exposure.

3) The longer the return horizon, the more foreign exchange risk exposure effects become visible. Chapter 3 and 4 have consistently highlighted the fact that, while foreign exchange risk exposure is difficult to identify in the shortrun, it becomes increasingly evident when lengthening the return horizon. Two alternative lines of reasoning emerge to justify these results. According to the first explanation, short-horizon returns contain errors made by investors in forecasting the long-term effects of current exchange rate changes and hence doesn't fully translate the impact of currency movements. The second argument suggests that short-term exposure may be offset by hedging activities while long-term 'economic' exposure is more difficult to hedge since it isn't related to known transactions. This second justification couldn"t, however, be supported by the empirical evidence provided in chapter 4 since the empirical impact of corporate derivative usage is not stronger on short-term (versus long-term) currency exposures. The well-established fact (Chow and Chen, 1998; Di lorio and Faff, 2001; Bodnar and Wong, 2003) that an increase in the return horizon increases the statistical significance of currency exposure estimates seems, thus, to rely predominantly on the existence of systematic mispricing errors. It has, however, to be emphasized that the fact that these errors are systematic leads inevitably to the question whether observed stock returns contain a persistent predictable component.

4) Companies are hedging only a small proportion of the foreign exchange rate risks they are facing. The literature, so far, suggests unanimously that firms are not hedging their total foreign currency risk exposure. While this 
empirical fact may be easily explained by the fact that it is extremely difficult for a company to identify all the foreign exchange risks incurred, the argument has to be elaborated to take the efficiency of existing hedging strategies into account. We have verified in chapter 4 that the impact of corporate usage of foreign currency derivatives is statistically trivial. Such a result probably deserves more attention than it has received in the literature so far. While the ineffectiveness of corporate hedging activities reanimates the debate on optimal hedging theories, it reveals as well managers" lack of knowledge regarding foreign currency exposure issues.

5) Foreign exchange risk expasure is asymmetric. The asymmetric reaction of trade flows and prices has been extensively discussed in the literature. However, the nonlinear response of stock returns to exchange rate movements hasn't received much attention so far. Among the hypotheses suggesting that this response could be asymmetrical we find (i) the asymmetric impact of hedging activities on cash-flows, (ii) firms' pricing-to-market strategies, (iii) their hysteretic behavior, (iv) investors' mispricing errors, and (v) the existence of trigger points at which external forces may intervene on the market. While previous empirical studies have almost exclusively focused on sign asymmetries, empirical evidence in this thesis does not only show that firms do react asymmetrically to currency shocks, it highlights as well the fact that the magnitude of the shock affects, to a greater extent, firms' sensitivity to currency fluctuations than the sign of the shock.

Many routes exist to interpret and justify these stylized facts that have emerged from our empirical studies. We will summarize the most pertinent questions that arise depending on the viewpoint one decides to adopt. Most of them constitute challenging and promising areas for future research:

a) Does a decrease in exchange rate uncertainty influence firm value? The ongoing internationalization of trade and finance, the frequency of recent currency crises and the reemergence of new monetary unions have shed new light on the continuing debate between fixed and floating exchange rates. We have seen in this thesis that if a company is confronted with an unexpected increase in exchange rate uncertainty - due to a currency crisis for instance - in one of its input or output markets, its market risk increases and all its financial decision-making process is affected. Given the crucial implications in terms of economics, business and international finance, further research in this area is needed to accurately appraise not only the consequences of monetary choices but also, for instance, the opportunities and dangers of foreign investment strategies in emerging markets. One way to reevaluate the effects of exchange rate uncertainty is to extend the 
analysis presented in chapter 4 to the exploration of different types of currency regime shifts. The introduction of the euro - corresponding to a decrease in exchange rate uncertainty - offers here a promising investigation field. While the effects of a common currency on trade have been thoroughly discussed in the literature, the question in how far the beneficial trade effects and the reduction of foreign exchange risk affect both local and foreign stock markets remains unsolved. The empirical puzzle is yet fundamental since it could provide evidence to open a far larger debate: if exchange rate uncertainty is costly for companies, are monetary unions desirable?

b) What are the consequences of foreign exchange risk exposure heterogeneity? Since, due to heterogeneity, foreign exchange risk exposure tends to empirically disappear under data aggregation, it is important to discuss the consequences of this heterogeneity in terms of portfolio management. Investors who own foreign assets are directly exposed to falls in the currencies where they own the assets - if they want to repatriate those assets the exchange rate will have a negative effect on the home currency value. Investors are as well indirectly confronted to foreign exchange risk as a result of the exchange rate exposure incurred by individual firms comprising the portfolio. One important issue in the evaluation of international portfolios is, hence, to determine the extent to which the portfolio is exposed to changes in exchange rates but also the extent to which the portfolio could gain from the heterogeneity of the foreign exchange risk exposure of its assets. In other words, further empirical research should not only focus on the policies that are implemented in managing the foreign exchange rate risk of an existing portfolio but, given the observed heterogeneity of exposures, it should also include foreign exchange risk exposure issues in the determination of optimal portfolio allocations.

c) What is the impact of corporate hedging on foreign exchange risk exposure? The empirical result suggesting that the use of foreign currency derivatives does not significantly reduce the foreign exchange risk exposure companies are facing does not close the discussion on the impact of these corporate hedging activities. The question in how far the properties of foreign exchange risk exposure are altered through the implementation of these hedging activities remains, in reality, unanswered. While, first empirical evidence tends to suggest that the horizon-dependency of foreign exchange risk exposure can't be attributed to managers' stronger capacity to thedge short-term versus long-term currency exposure, no research so far has been exploring the impact of foreign currency derivatives usage on the asymmetrical properties of the relationship between 
exchange rate movements and stock returns. A better understanding of the concrete effects of corporate hedging strategies should shed new light on the strengths and weaknesses of existing risk management practices and enable us to develop potentially more powerful tools to deal with foreign exchange rate risk.

d) How do investors' mispricing errors influence the foreign exchange risk exposure mechanism? Bartov and Bodnar (1994) report that investors are making systematic errors when characterizing the relationship between currency fluctuations and stock returns. The complexity of the issues involved - e.g., the identification of the possible asymimetries in the impact of exchange rate changes, the differentiation between temporary versus permanent currency shocks and the determination of the impact of exchange rate shocks on a firm's competitive and economic envifonment - is even enhanced by an information bias, as investors are not always fully aware of the firm's hedging activities nor of the strategy the firm plans to adopt if the competitive environment changes due to currency movements. That's why it is presumable that investors learn to evaluate the relationship between exchange rate changes and firms" future cash flows in a more efficient way over time and that foreign exchange risk exposure becomes increasingly evident when lengthening the return horizon. Since, mispricing errors are apparently closely related to investors" lack of informational knowledge, one way to assess the precise role played by mispricing errors would be to investigate whether an increase in information conveyed to investors decreases the horizon-dependency of foreign exchange risk exposure. Another way to solve the apparent puzzle and to put the debate in a broader perspective would be to explore in how far investors' reactions to an increase in exchange rate uncertainty during a currency crisis, for instance, is determined by the fact that investors are abruptly forced to recognize the generally negative - impact of foreign currency movements. This issue leads inevitably to investors' stronger reaction to large currency shocks that are perceived as 'bad' news than to small 'good' news - hence, to asymmetries in the relationship between exchange rate movements and stock returns. A straight-forward way to close the circle would thus be to combine the occurrence of msipricing errors with the asymmetrical properties of foreign exchange risk exposure effects.

e) Why is foreign exchange risk exposure asymmetric? The model proposed in chapter 6 to capture the asymmetrical effects of currency movements on stock returns has produced indispensable insight in the mechanism of foreign exchange risk exposure. The small amount of research projects that has been conducted so far in non-linear foreign exchange exposure models brings the opportunity that many things can still be done. The analysis performed may be 
extended to simultaneously incorporate sign and size asymmetries and to discriminate between the relative strengths of both effects. One could as well think of investigating the asymmetrical properties of foreign exchange risk exposure across different exchange rate markets conditions in order to assess the importance and strength of existing asymmetrical forces. An open mind would, however, also, attempt to explore empirically the rationales behind the asymmetrical properties of currency exposure. While it appears unrealistic to analytically predict the exact functional form of foreign exchange risk exposure, the empirical investigation of the role played by hedging activities, pricing-to-market strategies, hysteretic behavior, investors" mispricing errors and external interventionism in the determination of the asymmetrical relationship between exchange rate movements and stock returns is clearly one of the most challenging and stimulating research areas of the future. Ulimately, the rationalization of the characteristios of firms" foreign exchange risk exposure, in general, should be empirically investigated. In this context, the multiplicity of the parameters involved in determining the foreign exchange risk exposure of companies has to be highlighted. The complexity is moreover enhanced through the fact that these parameters are note stable over time, which naturally leads to a time-variation in the empirically estimated exposure. While this thesis has explored the asymmetrical properties of foreign exchange risk exposure, it appears evident that there are still many other sources of time-variation to be explored in the future.

Numerous promising and stimulating areas of research have still to be investigated in the foreign exchange risk literature. Focusing on the continuing debate whether stock returns are - or not - significantly exposed to currency fluctuations may not be the most productive approach. Instead, research should concentrate on a better understanding of the mechanism and practical implications of foreign exchange risk exposure. Several new directions and ideas have been suggested. We hope that their exploration will provide managers, investors as well as regulators with the most efficient tools to manage the risks they will be facing in our increasingly internationalized economies. 
$\therefore \therefore \quad \therefore \quad \therefore \quad \therefore \quad \therefore \quad \therefore$

H. $\quad \cdots \quad \cdots$

:

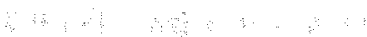

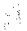

$\therefore$ 

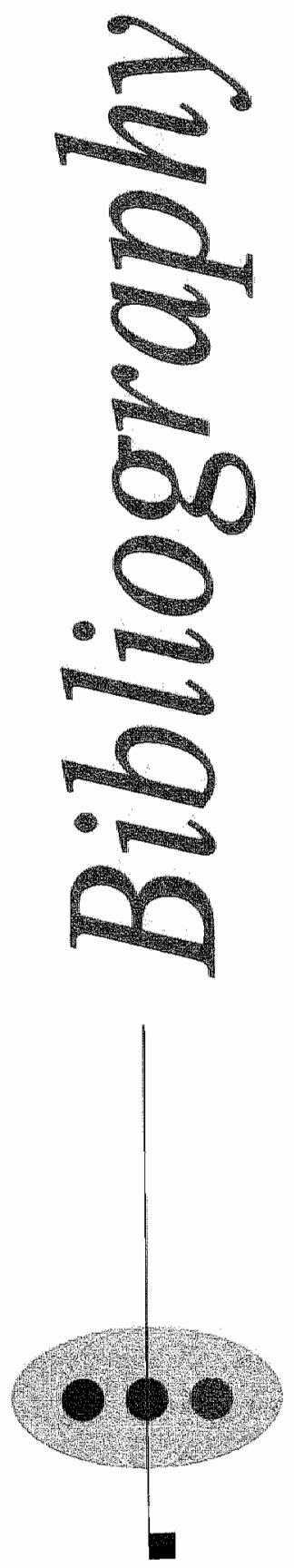


\section{Bibliography}

Abuaf, N. and P. Jorion, 1990, Purchasing power parity in the long run, Journal of Finance, 45: 157-174.

Adler, M., and B. Dumas, 1984, Exposure to currency risk: Definition and measurement, Financial Management, Summer: 41-50.

Adler, M., B. Dumas and D. Simon, 1986, Exchange risk surprises in international portfolios, Journal of Portfolio Management, Winter: 44-53.

Aggarwal, R.A.J. and B.J. Simkins, 2004, Evidence on voluntary disclosures of derivatives usage by large U.S. companies, Joumal of Derivatives Accounting, 1: 61-81

Aliber, R.Z. and C.T. Stickney, 1975, Accounting measures of foreign exchange exposure: the long and short of it, The Accounting Review, 51: 44-57.

Allayannis, G., 1995, Time-variation of the exchange rate exposure: An industry analysis, Working paper, New York University.

Allayannis, G., 1996, Exchange rate exposure revisited, Working Paper, New York University.

Allayannis, G. and J. Ihrig, 2001, Exposure and markups, Review of Financial Studies, 14: 805-835.

Allayannis, G., J. Ihrig and J.P. Weston, 2001, Exchange rate hedging: financial versus operating strategies, American Economic Review Papers and Proceedings, 91 : 391-395.

Allayannis, G. and A. Mozumdar, 2000, Cash-flow, investment and hedging, Working paper, Virginia Tech University.

Allayannis, G. and E. Ofek, 2001, Exchange rate exposure, hedging and the use of foreign currency derivatives, Journal of International Money and Finance, 20: $273-296$. 
Allayannis, G. and J.P. Weston, 1999, The use of foreign currency derivatives and industry structure, published in Brown, G. and D. Chen [eds.], Corporate Risk: Sirategies and Management, Risk Books.

Allayannis, G. and J.P. Weston, 2001, The use of foreign currency derivatives and firm market value, Review of Financial Studies, 14: 243-276.

Amilbud, Y., 1994, Exchange rates and the valuation of equity shares, published in Y. Amihud and R. M. Levich [eds.], Exchange rates and corporate performance, Irwin, New York, pp. 49-59.

Amihud, Y. and H. Mendelson, 1989, Index and index-futures returns, Journal of Accounting, Auditing and Finance, 10: 415-431.

Andersen, T.G., T. Bollerslev, F.X. Diebold and H. Ebens, 2001, The distribution of stock return volatility, Journal of Financial Economics, 61: 43-76.

Ang, S., J. Chua and J. McConnell, 1982, The administrative costs of corporate bankruptcy: A note, Journal of Finance, 37: 219-225.

Arshanapalli, B., D. Coggin and J. Doukas, 1998, Multifactor asset pricing analysis of international value investment strategies, Journal of Portfolio Management, 24: 10-33.

Baba, N. and K. Fukao, 2000, Currency risk exposure of Japanese firms with overseas production bases: Theory and evidence, IMES Discussion Paper Series, No. 2000-E-1.

Bailey, W. and Y.P. Chung, 1995, Exchange rate fluctuations, political risk, and stock returns: Some evidence from an emerging market, Journal of Financial and Quantitative Analysis, 30: 541-561.

Baldwin, R., 1986, Hysteresis in trade, MIT mimeo prepared for 1986 NBER Summer Institute.

Baldwin, R., 1988, Some empirical evidence on the hysteresis hypothesis, NBER Working Paper No. 2483.

Baldwin R. and P. Krugman, 1989, Persistent trade effects of large exchange rate shocks, The Quarterly Journal of Economics, 104(4): 635-654.

Bartov, E., 1992, Patterns in unexpected earnings as an explanation for postannouncement drift, The Accounting Review, 67: 610-622.

Bartov, E., and G.M. Bodnar, 1994, Firm valuation, earnings expectations, and the exchange rate exposure effect, Journal of Finance, 49: 1755-85. 
Bartov, E., G.M. Bodnar and A. Kaul, 1996, Exchange rate variability and the riskiness of U.S. multinational firms: Evidence from the breakdown, Journal of Financial Economics, 42: 105-132.

Bartram, S., 2002, Enhancing shareholder value with corporate risk management, Corporate Finance Review, 7: 7-12.

Bartram, S., 2004, Linear and nonlinear foreign exchange rate exposure of German nonfinancial corporations, Joumal of International Money and Finance, 23(4): 673-699.

Bartram, S., G.W. Brown and F.R. Fehle, 2004, International evidence on financial derivative usage, Working Paper, Lancaster University.

Belaire-Franch, J. and K.K. Opong, 2005, Some evidence of random walk behavior of euro exchange rates using ranks and signs, Journal of Banking and Finance, 29: 1631-1643.

Berben, J.-P. and D.J. van Dijk, 1998, Does the absence of cointegration explain the typical findings in long horizon regressions?, Erasmus University Rotterdam Report, No. 9814.

Berkman H. and M.E. Bradbury, 1996, Empirical evidence on the corporate use of derivatives, Financial Management, 25: 5-13.

Berkman, H., M.E. Bradbury and S. Magan, 1997, An international comparison of derivatives use, Financial Management, 26: 69-73.

Berkowitz, J. and L. Giorgianni, 2001, Long-horizon exchange rate predictability, The Review of Economics and Statistics, 83: 81-91.

Bernard, V. and J. Thomas, 1990 , Evidence that stock prices do not fully reflect the implications of current earnings for future earnings, Joumal of Accounting and Economics, 13:305-340.

Berndt, E.K., H.B. Hall, R.E. Hall and J.A. Hausman, 1974, Estimation and inference in nonlinear structural models, Annals of Economic and Social Measurement, 4: 653-666.

Bessembinder, H., 1991, Forward contracts and firm value: investment incentive and contracting effects, Journal of Financial and Quantitative Analysis, 26: 519-532.

Bin, F.S., L.P. Blenman and D.H. Chen, 2004, Valuation impact of currency crises: Evidence from the ADR market, International Review of Financial Analysis, forthcoming. 
Bodnar, G.M., De Jong, A. and V. Macrae, 2004, The impact of institutional differences on derivatives usage: a comparative study of US and Dutch firms, Ewopean Financial Management, 9: 271-297.

Bodnar, G.M., B. Dumas and R.C. Marston, 2002, Pass-through and exposure, Journal of Finance, $57: 199-231$.

Bodnar, G.M and G. Gebhardt, 1999, Derivatives usage in risk management by US and German non-financial fims, Journal of International Financial Management and Accounting, 10: 159-187.

Bodnar, G.M. and W.M. Gentry, 1993, Exchange rate exposure and industry characteristics: evidence from Canada, Japan and the USA, Journal of International Money and Finance, 12:29-45.

Bodnar, G.M., G.S. Hayt and R.C. Marston, 1998, 1998 Wharton Survey of Financial Risk Management by US Non-Financial Firms, Financial Management, $27: 70-91$.

Bodnar, G.M., C. Tang and J. Weintrop, 1997, Both sides of corporate diversification: The value impacts of geographic and industrial diversification, NBER Working $\# 6224$.

Bodnar, G.M. and M.H.F. Wong, 2003, Estimating exchange rate exposures: Issues in model structure, Financial Management, 32(1): 35-67.

Bollerslev, T., R.Y. Chou and K.F. Kroner, 1992, ARCH modeling in finance, Joumal of Econometrics, $52 ; 5-59$.

Bollerslev, T., R. Engle and D.B. Nelson, 1995, ARCH models, in Z. Griliches and M. D. Tntriligator [eds.], Hondbook of econometrics, vol. IW, Amsterdam: North Holland, 361-363.

Bollerslev, T. and J.M. Wooldridge, Quasi-maximum likelihood estimation and inference in dynamic models with time varying covariances, Economemic Reviews, $11: 143-172$.

Bonfiglioli, A. and C.A. Favero, 2000, Measuring co-movements between US and European stock markets, CEPR Discussion Paper \#2517.

Booth, L. 1996, On the nature of foreign exchange exposure, Jownal of Multinational Financial Management, 6:1-24.

Booth, L. and W. Rotenberg, 1990, Assessing foreign exchange exposure: theory and application using Canadian firms, Joumal of International Financial Management and Accounting, 2: 1-22. 
Branson, W., H. Halttunen and P. Masson, 1977, Exchange rates in the short run: The dollar / deutschmark rate, European Economic Review, 10: 303-324.

Breeden, D. and S. Viswanathan, 1998, Why do firms hedge? An asymmetric information model, Working Paper, Fuqua School of Business, Duke University.

Campbell, J.Y., 2001, Why long horizons? A study of power against persistent alternatives, Joumal of Empirical Finance, 8: 459-491.

Caramazza F., L.A. Ricci and R. Salgado, 2004, International financial contagion in currency crises, Journal of International Money and Finance, 23(1):51-70.

Carter, D., C. Pantzalis and B.J. Simkins, 2001, Integration of operational and financial hedges in currency risk management", FSR Forum 3:6-14.

Chamberlain, S., J.S. Howe and H. Popper, 1997, The exchange rate exposure of US and Japanese banking institutions, Journal of Banking and Finance, 21: 871-889.

Chang, Y., 2002, The pricing of foreign exchange risk around the Asian financial crisis: evidence from Taiwan's stock market; Journal of Multinational Financial Management, 12: 223-238.

Chen, N.F., R. Roll and S.A. Ross, 1986, Economie forces and the stock market, Journal of Business, 59: 383-403.

Chen, C.C., and R.W. So, 2002, Exchange rate variability and the riskiness of US multinational firms: Evidence from the Asian financial turmoil, Journal of Multinational Financial Management, 12: 411-428.

Choi, I., 1999, Testing the random walk hypothesis for real exchange rates, Journal of Applied Econometrics, 14: 293-307.

Choi, J.J. and Y. Kim, 2003, The Asian exposure of U.S. firms: Operational and risk management strategies, Pacific-Basin Finance Journal, 11: 121-138.

Choi, J.J. and A.M. Prasad, 1995, Exchange risk sensitivity and its determinants: A firm and industry analysis of U.S. multinationals, Financial Management, 24: 77-88.

Chow, E.H. and H.-L. Chen, 1998, The determinants of foreign exchange rate exposure: Evidence on Japanese firms, Pacific-Basin Finance Journal, 6: 153-174. 
Chow, E, W. Lee, and M. Solt, 1997a, The economic exposure of U.S. multinational firms, The Jourrial of Financial Research, 20: 191-210.

Chow, E.H., W.Y. Lee and M.E. Solt, 1997b, The exchange-rate risk exposure of asset returns, Journal of Business, 70: 105-123.

Christoffersen, P.F. and F.X. Diebold, 2000, How relevant is volatility forecasting for financial risk management?, Review of Economics and Statistics, 82: $12-22$.

Clarida, R., 1992, The real exchange rate and U.S. manufacturing profits: a theoretical framework with some empirical support", International Joumal of Finance and Economics, 2: 177-187.

Connolly, R.A., A. Ozoguz and D.J. Ravenscraft, 2000, Foreign market cash flow exposure: A multi-country, firm-level study, Working Paper, University of North Carolina.

Cornell, B. and A. Shapiro, 1983, Managing foreign exchange risks, Midland Corporate Finance Journal, Fall: 16-31.

Crabb, P.R., 2002, Multinational corporations and thedging exchange rate exposure, International Review of Economics and Finance, 11:299-314.

Cragg, J., 1971, Some statistical models for limited dependent variable with application to the demand of durable goods, Econometrica, 39: 829-844.

Dahlquist, M. and G. Robertsson, 2001, Exchange rate exposure, risk premia, and firm characteristics, Working Paper, Duke University.

De Ceuster, M.J.K., E. Durinck, E. Laveren and J. Lodewyckx, 2000, A survey into the use of derivatives by large non-financial firms operating in Belgium, European Financial Management, 6: 301-318.

De Grauwe, P., 1996, The economics of monetary integration, Oxford University Press, Oxford.

De Jong, A., J.Ligterink, V. Macrae, 2004, A firm-specific analysis of the exchange-rate exposure of Dutch firms; Journal of International Financial Management and Accounting, forthcoming.

De Santis, G. and B. Gerard, 1998, How big is the premium for currency risk ?, Joumal of Financial Economics, 49: 375-412.

DeMarzo, P. and D. Duffie, 1995, Corporate incentives for hedging and hedge accounting, The Review of Financial Studies, 95: 743-771. 
Dewenter, K.L., R.C. Higgins and T.T. Simin, 2004, Can event study methods solve the currency exposure puzzle, Pacific-Basin Finance Journal, forthcoming.

Di Iorio A. and R. Faff, 2000, An analysis of asymmetry in foreign currency exposure of the Australian equities market, Joumal of Multinational Financial Management, 10: 133-159.

Di Iorio, A. and R. Faff; 2001, The effect of intervaling on the foreign exchange exposure of Australian stock returns', in Multinational Finance Journal, 5 : $1-33$.

Dixit, A.K., 1989, Trade and insurance with adverse selection, Review of Economic Studies, 56: 235-248.

Doidge, C., J. Griffin and R.G. Williamson, 2002, Does exchange rate exposure matter, Working Paper, Georgetown University.

Dolde, W. 1993, Use of foreign exchange and interest rate risk management in large firms, Working Paper, University of Connecticut.

Dolde, W., 1995, Hedging, leverage and primitive risk, The Journal of Financial Engineering, 4: 187-216.

Dominguez, K.M.E., and L.L. Tesar, 2001a, A re-examination of exchange rate exposure, American Economic Review, 91: 396-399.

Dominguez, K.M.E and L.L. Tesar, 2001b, Trade and exposure, American Economic Review Papers and Proceedings, 91: 367-370.

Donnelly, R and E. Sheehy, 1996, The share price reaction of UK exporters to exchange rate movements: An empirical study, Journal of International Business Studies, 27: 157-165.

Doukas, J., P.H. Hall and L.H.P. Lang, 1999, The pricing of currency risk in Japan, Journal of Banking and Finance, 23: 1-20.

Doukas, J., P.H. Hall and L.H.P. Lang, 2003, Exchange rate exposure at the firm and industry level, Financial Markets, Institutions and Instruments, 12: 291-346.

Dumas, B., 1978, The theory of the trading firm revisited, Journal of Finance, 33: 1019-1029.

Dumas, B. and B. Solnik, 1995, The world price of foreign exchange risk, Journal of Finance, $50: 445-479$. 


\section{4 if Bibliography}

Edison, H.J., 1985, The rise and fall of sterling: Testing alternative models of exchange rate determination, Applied Economics, 17: 1003-1021.

Edwards, S., 1999, On crisis prevention: lessons from Mexico and East Asia, NBER Working Paper 7233 .

Edwards, S., 2000, Exchange rate regimes, capital flows and crisis prevention, Paper presented at the NBER Conference on Crisis prevention.

Eichengreen, B, and R. Hausman, 1999, Exchange rate and financial fragility, NBER Working Paper \# 7418 .

Elliott, W.B., S.P. Huffman and S.D. Makar, 2003, Foreign denominated debt and foreign currency derivatives: complements or substitutes in hedging foreign currency risk?, Journal of Multinational Financial Management, 13: $123-139$.

El-Masry, A., 2004, The exchange rate exposure of UK non-financial companies: industry level analysis, WUSTL International Finance Discussion Paper \#0401001.

Elton, E.J. and M. Gruber, 1991, Modern portfolio theory and investment anallysis, $4^{\text {th }}$ edition, John Wiley, New York.

Engel, C. and J. Hamilton, 1990, Long swings in the dollar: are they in the data and do markets know it?, American Economic Review, 80: 689-713.

Entorf, H. and G. Jamin, 2000, German stock returns: The Dance with the Dollar, W.E.P.-Discussion Paper \#19.

Entorf, H. and G. Jamin, 2004, German exchange rate exposure at DAX and aggregate level, international trade, and the role of exchange rate adjustment costs, Working Paper, Darmstadt University of Technology.

Ethier, W., 1973, International trade and the forward exchange market, American Economic Review, 6: 494-503.

Fabozzi, F.J. and J.C. Francis, 1977, Stability tests for alpha and betas over bull and bear market conditions, Journal of Finance, 32: 1093-1099.

Fama, E.F. and K.R. French, 1988, Dividend yields and expected stock returns, Joumal of Financial Economics, 22: 3-25.

Fama, E.F. and K.R. French, 1996, Multifactor explanations of asset pricing anomalies, Journal of Finance, 51: 55-84. 
Faust, J., J.H. Rogers and J.H. Wright, 2003, Exchange rate forecasting: the errors we've really made, Journal of Intemational Economics, 60:35-59.

Flood, E.Jr. and D.R. Lessard, 1986, On the measurement of operating exposure to exchange rates: A conceptual approach, Financial Management, Spring: 25-37.

Fok, R., C. Carroll and M.C. Chiou, 1997, Determinants of corporate derivatives: a revisit, Journal of Economics and Business, 49: 569-585.

Forbes, K., 2004, The Asian flu and Russian virus: The international transmission of crises in firm-level data, Journal of International Economies, 63: 59-92.

Frankel J.A., and S.-J. Wei, 1994, Trade blocs and currency blocs, NBER Working Paper $\$ 4335$.

Fraser, S. and C. Pantzalis, 2004, Foreign exchange rate exposure of US multinational corporations: a firm-specific approach, Journal of Multinational Financial Management, 14: 261-281.

Frenkel, J.A., 1976, A monetary approach to the exchange rate: Doctrinal aspects and empirical evidence, Scandinavian Journal of Economics, 78: 200-224.

Friberg, R. and S. Nydahl, 1997, Openness and the exchange rate exposure of national stock markets - a note, Working Paper, Stockholm School of Economics.

Froot K.A. and P.D. Klemperer, 1989, Exchange rate pass-through when market share matters, The American Economic Review, 79(4): 637-654.

Froot, K.A., D. Scharfstein and J. Stein, 1993, Risk management: Coordinating investment and financing policies, Joumal of Finance, 48: 1629-1658.

Gao, T., 2000, Exchange rate movements and the profitability of U.S. multinationals, Journal of International Money and Finance, 19: 117-134.

Geczy, C., B.A. Minton and C. Schrand, 1997, Why firms use currency derivatives, Journal of Finance, 52: 1323-1354.

Gendreau, B.C., 1994, Comments on exchange rates, the macroeconomic environment and the firm, in Y. Amihud and R. M. Levich [eds.], Exchange rates and corporate performance, Irwin, New York, pp. 49-59.

Giliberto, M., 1985, Interest rate sensitivity in the common stocks of financial intermediaries: a methodological note, Journal of Financial and Quantitative Analysis, 20: 123-126. 
Glaum, M, 2000, Foreign exchange risk management in German non-financial corporations: An empirical analysis, in $M$. Frenkel, U. Hommel and $M$. Rudolf [eds.], Risk Management: Challenge and Opportunity, Springer, Berlin, 373-393.

Glaum, M., 2002, The determinants of selective exchange risk management: Evidence from Germany, Journal of Applied Corporate Finance, 14: 108121 .

Glaum, M., M. Brunner and H. Holger, 2000, The DAX and the Dollar: The economic exchange rate exposure of German corporations, Journal of International Business Studies, 31: 715-724.

Goldberg, P.K., 1995, Product differentiation and oligopoly in international markets: the case of the U.S. automobile industry, Econometrica, 63: 891951.

Goldberg, S.R., C.A. Tritschler and J.H. Godwin, 1995, Financial reporting for foreign exchange derivatives, Accounting Horizons, 9(2): 1-16.

Graham J.R. and D.A. Rogers, 2000, Is corporate hedging consistent with value maximization? An empirical analysis, Working Paper, Fuqua School of Business, Duke University.

Graham J.R. and D.A. Rogers, 2002, Do firms hedge in response to tax incentives?, Journal of Finance, 57: 815-839.

Graham J.R. and C.W. Smith, Jr., 1999, Tax incentives to hedge, Journal of Finance, 54: 2241-2262.

Granger, C.W.J. and T. Terăsvirta, 1993, Modelling nonlinear economic relationships, Oxford University press, Oxford.

Griffin, J.M., and R.M. Stulz, 2001, International competition and exchange rate shocks: A cross-country industry analysis of stock returns, Review of Financial Studies, 14: 215-241.

Guay, W.R., 1999, The impact of derivatives on firm risk: An empirical examination of new derivative users, Journal of Accounting and Economics, 26: 319-351.

Guay, W.R. and S.P. Kothari, 2003, How much do firms hedge with derivatives, Jounal of Financial Economics, 70: 423-461.

Hansen, L., Large sample properties of generalized method of moments estimators, Econometrica, 50: 1029-1054. 
Haushalter, G.D., 2000, Financing policy, basis risk, and corporate hedging: evidence from oil and gas producers, Joumal of Finance, 55: 107-152.

$\mathrm{He}_{*} J$., and $\mathbb{L} . \mathrm{Ng}, 1998$, The foreign exchange exposure of Japanese multinational corporations, Journal of Finance, 53: 733-753.

He, J., L. Ng and X. Wu, 1996, Foreign exchange rate exposure, risk and the Japanese stock market, Working Paper, University of Wisconsin.

Heckermann, D., 1972, The exchange risks of foreign operations, Joumal of Business, 45: 42-48.

Hekman, C.R., 1985, A financial model of foreign exchange exposure, Journal of International Business Studies, 41(2): 83-99.

Hentschel, L., 1995, All in family nesting symmetric and asymmetric GARCH models, Journal of Financial Economies, 39: 71-104.

Hentschel L. and S.P. Kothari, 2001, Are corporations reducing or taking risks with derivatives, Journal of Financial and Quantitative Analysis, 36: 93-118.

Hodder, J.E., 1982, Exposure to exchange rate movements, Journal of International Economics, 13: 375-386.

Howton, S.D. and S.B. Perfect, 1998, Currency and interest derivatives use in US firms, Financial Management, 27: 111-121.

Hung, J., 1992, Assessing the exchange rate's impact on U.S. manufacturing profits, Federal Reserve Bank of New York Quarterly Review, 4: 44-63.

Ihrig, J. 2001, Exchange rate exposure of multinationals: Focusing on exchange rate issues, International Finance Discussion Papers \$709.

Interinational Monetary Fund, 1999, Malaysia: Selected issues, Country Report No. 99/86, August.

Jensen, M.C. and W.H. Meckling, 1976, Theory of the firm: managerial behavior, agency costs and capital structure, Journal of Financial Economics, 3: 305360.

Jorion, P., 1990, The exchange rate exposure of U.S. multinationals, Journal of Business, 63: 331-345.

Jorion, P., 1991, The pricing of exchange rate risk in the stock market, Journal of Financial and Quantitative Analysis, 26: 363-376. 
Joseph, NL., 2000, The choice of hedging techniques and the characteristics of UK industrial firms, Journal of Mulinational Financial Management, 10: 161184.

Judge, A., 2004, The determinants of foreign currency hedging by UK non-financial firms, Working Paper, Middlesex University.

Kanas, $A_{.}, 1997$, Is economic exposure asymmetric between long-run depreciations and appreciations? Testing using cointegration analysis, Journal of Multinational Financial Management, 7: 27-42.

Karemera, D., K. Ojah and J.A. Cole, 1999, Random walks and market efficiency tests: evidence from emerging equity markets, Review of Quantitative Finance and Accounting, 13: 171-188.

Karolyi, G.A. and R.M. Stulz, 1996, Why do markets move together? An investigation of US - Japan stock return comovements, Journal of Finance, 51: $951-986$.

Khoo, A., 1994, Estimation of foreign exchange exposure: an application to mining companies in Australia, Joumal of International Money and Finance, 13: 342-363.

Kiymaz, H., 2003, Estimation of foreign exchange exposure: an emerging market application, Journal of Multinational Financial Management, 13: 71-84.

Knetter, M.M., 1994, Is export price adjustment asymmetric?: Evaluating the market share and marketing bottlenecks hypotheses, Journal of International Money and Finance, 13:55-70.

Koutmos, G. and A.D. Martin, 2003a, Asymmetric exchange rate exposure: theory and evidence, Joumal of International Money and Finance, 22:365-383.

Kottmos, G. and A.D. Martin, 2003b, First and second moment exchange rate exposure: evidence from U.S. stock returns, Financial Review, 38: 455471 .

Koutmos, G. and J. Knif, 2004, Exchange rate exposure: Evidence from Finnish stock returns, Working Paper, Fairfield University.

Krishnamoorthy, A., 2001, Industrial structure and the exchange rate exposure of industry portfolio returns, Global Finance Journal, 12: 285-297.

Lakonishok, J. and T. Vermaelen, 1990, Anomalous price behavior around repurchase tender offers, Journal of Finance, 45: 455-478. 
Lee, C.I., Y.A. Liu and M.-S. Pan, 2001, On market efficiency of Asian foreign exchange rates: evidence from a joint variance ratio test and technical trading rules, Joumal of International Finarial Markets, Institutions and Money, 11: 199-214.

Leland, H.E., 1998, Agency costs, risk management and capital structure, Joumal of Finance, vol. 53: 1213-1243.

Lessard, D.R., 1979, International financial management: Theory and application, Warren Gorham and Lamont, Boston, MA.

Lessard, D., 1990, Global competition and corporate finance in the 1990s, Jownal of Applied Corporate Finance, 3: 59-72.

Levi, M.D., 1994, Exchange rates and the valuation of firms, Chapter 3 in $Y$. Amihud and R. M. Levich [eds.], Exchange rates and corporate performance, Irwin, New York, pp. 37-48.

Lioui, A. and P. Poncet, 2002, Optimal currency risk hedging, Journal of International Money and Finance, 21: 241-264.

Loderer, C. and K. Pichler, 2000, Firms, do you know your currency risk exposure? Survey results, Journal of Empirical Finance, 7: 317-344.

Longin, F. and B. Solnik, 2001, Extreme correlation of international equity markets, Journal of Finance, 56: 617-648.

Luehrman, T.A., 1990, The exchange rate exposure of a global competitor, Journal of International Business Studies, 21: 225-242.

Luehrman, T.A., 1991, Exchange rate changes and the distribution of industry vallue, Joumal of International Business Studies, 22: 619-649.

Mark, N.C., 1990, Real and nominal exchange rates in the long run: An empirical investigation, Journal of International Economics, 28: 115-136.

Mark, N.C., 1995, Exchange rates and fundamentals: evidence on long-horizon predictability, American Economic Review, 85: 201-218.

Marshall, A.P., 2000, Foreign exchange risk management in UK, USA and Asia Pacific multinational companies, Journal of Multinational Financial Management, 10: 185-211.

Marston, R.C., 1990, Pricing to market in Japanese manufacturing, Journal of International Economics, 29: 217-236. 
Marston, R.C., 2001, The effects of industry structure on economic exposure, Journal of International Money and Finance 20(2): 149-164.

Martin, A.D. and L.J. Mauer, 2004, Scale economies in hedging foreign exchange cash flow exposures, Global Finance Journal, 15: 17-27.

Meese, R.A and K. Rogoff, 1983a, Empirical exchange rate models of the seventies: Do they fit out of sample?, Journal of International Economics, 14: $3-24$.

Meese, R.A. and K. Rogoff, 1983b, The out-of-sample failure of empirical exchange rate models: Sampling errors or misspecification?, in J. Frenkel, [eds.], Exchange Rates and International Macroeconomics, University of Chicago Press for the National Bureau of Economic Research.

Mello, A.S and J.E. Parsons, 2000, Hedging and liquidity, The Review of Financial Studies, 13: 127-153.

Mian, S.L., 1996, Evidence on corporate hedging policy, Journal of Financial and Quantitative Analysis, 31: 419-439.

Miller, K.D. and J.J. Reuer, 1998, Firm strategy and economic exposure to foreign exchange rate movements, Journal of International Business Studies, 29 : 493-514.

Minton, B.A. and C. Schrand, 1999, The impact of cash flow volatility on discretionary investment and the costs of debt and equity financing, Journal of Financial Economics, 54: 432-460.

Modigliani, F. and M.H. Miller, 1958, The cost of capital, corporate finance and the theory of investment, American Economic Review, 48: 261-297.

Muller, A. and W.F.C. Verschoor, 2003a, The Latin American exchange risk .exposure of U.S. multinationals, LIFE Working Paper, Maastricht University.

Muller, A. and W.F.C. Verschoor, 2003b, Asian foreign exchange risk exposure, LIFE Working Paper, Maastricht University.

Muller, A. and W.F.C. Verschoor, 2004a, European foreign exchange risk exposure, European Financial Management, forthcoming.

Muller, A. and W.F.C. Verschoor, 2004b, The effect of exchange rate variability on U.S. shareholder wealth, LIFE Working Paper, Maastricht University. 
Muller, A., and W.F.C. Verschoor, 2004c, Asymmetric foreign exchange risk exposure: Evidence from U.S. multinationals, LIFE Working Paper, Maastricht University.

Muller, A., and W.F.C. Verschoor, 2005a, The impact of corporate derivative usage on foreign exchange risk exposure, LIFE Working Paper, Maastricht University.

Muller, A., and W.F.C. Verschoor, 2005b, Foreign exchange risk exposure: Survey and suggestions, LIFE Working Paper, Maastricht University.

Myers, S.C., 1977, Determinants of corporate borrowing, Journal of Financial Economics, Vol. 5: 147-175.

Nance, D.R., C.W. Smith Jr. and C.W. Smithson, 1993, On the determinants of corporate hedging, Journal of Finance, 48: 267-284.

Newbold, P., T. Rayner, N. Kellard and C. Ennew, 1998, Is the dollar/ecu exchange rate a random walk?, Applied Financial Economics, 8: 553-559.

Newey, W. and K. West, 1987, A simple, positive semi-definite heteroskedasticity and autocorrelation consistent covariance matrix, Econometrica, 55: 703708.

Nguyen, H, and R. Faff, 2003, Can the use of foreign currency derivatives explain variations in foreign exchange exposure? Evidence from Australian companies, Journal of Multinational Financial Management, 13: 193-215.

Nieuwland, F.G.M.C., W.F.C. Verschoor and C.C.P. Wolff, 1994, Stochastic trends and jumps in EMS exchange rates, Journal of International Money and Finance, 13: 699-727.

Nydahl, S., 1999, Exchange rate exposure, foreign involvement and currency hedging of firms: some Swedish evidence, European Financial Management, 5: 241-257.

Ohno, K., 1989, Export pricing behavior of manufacturing firms: A U.S. - Japan Comparison, IMF Staff Papers, 36(3): 550-579.

Orden, D., 2000, Exchange rate effects on agricultural trade and trade relations, in R.M.A. Lyons, R.D. Knutson, K. Meilke and A. Yanez-Naude [eds.]: Policy harmonization and adjustment in the North American agricultural and food industry, Texas A\&M University Press.

Oxelheim, L. and C. Wihlborg, 1995, Measuring macroeconomic exposure: The case of Volvo cars, European Financial Management, 3: 241-264. 
Oxellheim, L. and C. Wihlborg, 1998, Managing in the turbulent world economy Corporate performance and risk exposure, John Wiley and Sons, New York.

Pantzalis, C., B. Simkins and P.A. Laux, 2001, Operational hedges and the foreign exchange exposure of U.S. multinational corporations, Journal of International Business Studies, 32: 793-812.

Parsley, D. and H. Popper, 2002, Exchange rate pegs and Foreign Exchange Exposure in East Asia, WUSTL Economics Working Paper \#0211001.

Pentaings, J.M.E. and P. Garcia, 2004, Hedging behavior in small and medium-sized enterprises: The role of unobserved heterogeneity, Journal of Banking \& Finance 28: 951-978.

Petersen, M.A. and S.R. Thiagarajan, 2000, Risk measurement and hedging: With and without derivatives, Financial Management, 29: 5-30.

Pollard, P.S. and C.C. Coughlin, 2003, Size matters: Asymmetric exchange rate pass-through at the industry level, Working Paper, The federal Reserve Bank of St. Louis.

Poterba, J.M. and L.H. Summers, 1988, Mean reversion in stock returns: evidence and implications, Journal of Financial Economics, 22: 27-60.

Pramborg, B., 2004, Derivatives hedging, geographical diversification and firm market value, Joumal of Multinational Financial Management, 14: 117133.

Prevost, A.K., L.C. Rose and G. Miller, 2000, Derivatives usage and financial risk management in large and small economies: A comparative analysis, Journal of Business, Finance and Accounting, 27: 733-759.

Priestley, R. and B.A. Ødegaard, 2004a, Long swings in the dollar and the exchange rate exposure of stock returns, Working Paper, Norwegian School of Management.

Priestley, R. and B.A. Ødegaard, 2004b, Linear and nonlinear exchange rate exposure and price of exchange rate risk, Working Paper, Norwegian School of Management.

Rahmatsyah, T., G. Rajaguru and R.Y. Siregar, 2002, Exchange rate volatility, trade and "fixing for life" in Thailand, Japan and the World Economy, 14: 445470 . 
Raposo, C.C., 1997, Corporate risk management and optimal hedging disclosure, Working Paper, ISCTE Business School.

Rogoff, 1996, The purchasing power parity puzzle, Joumal of Economic Literature, 34: $647-668$.

Ross, M.P., 1997, Corporate hedging: What, why and how?, Working Paper, University of California, Berkeley.

Roulstone, D.T., 1999, Effect of SEC financial reporting release No. 48 on derivative and market risk disclosures, Accounting Horizons, 13(4): 343m 363.

Schmukler, S.L., and L. Servén, 2002, Pricing currency risk under currency boards, Journal of Development Economics, 69: 367-391.

Schrand, C. and H. Unal, 1998, Hedging and coordinated risk management: Evidence from thrift conversions, Journal of Finance, 53: 979-1013.

Shapiro, A.C., 1975, Exchange rate changes, inflation and the value of multinational corporations, Joumal of Finance, May: 485-502.

Shapiro, A. and S. Titman, 1985, An integrated approach to corporate risk management, Midland Corporote Finance Journal, Summer: 41-56.

Simkins; B. and P. Laux, 1997, Derivatives use and the exchange rate risk of large U.S. corporations, Proceeding of the Chicago Risk Management Conference, 1998.

Smith, C.W. Jr and R.M. Stulz, 1985, The determinants of firms' hedging policies, Journal of Financial and Quantitative Analysis, 20: 3914405.

Smoluk, H.J., G.M. Vasconcellos and J.K. Kramer, 1998, Random walks in the U.K. pound/U.S. dollar exchange rates, International Review of Financial Analysis, 7: 65-82.

Starks, L.T. and K.D. Wei, 2003, Foreign exchange exposure and short-term cash flow sensitivity. Working Paper, Red McCombs School of Business.

Stulz, R., 1984, Optimal hedging policies, Journal of Financial and Quantitative Analysis, 19: 127-140.

Stulz, R., 1990, Managerial discretion and optimal financing policies, Journal of Financial Economics, 26: 3-28.

Stulz, R., 1996, Rethinking risk management, Journal of Applied Corporate Finance, Fall: 8-24. 
Stulz, R. and R. Williamson, 2000, Identifying and quantifying exposures; in Brown, G. W. and D. H. Chew [eds.], Corporate Risk Strategies and Management, Risk publications, London.

Teräsvirta, T., 1998, Modeling economic relationships with smooth transition regressions, in A. Ullah and D. Giles [eds.], Handbook of Applied Stratistics, New York: 507-552.

Tufano, P., 1996, Who manages risk? An empirical examination of risk management practices in the gold mining industry, Joumal of Finance, 51 : $1097-1137$.

Urrutia, J.L., 1992, Variance ratio tests of random walk for foreign exchange rates, Economics Letters, 38: 457-465.

Venkatachalam, M., 1996, Value-relevance of banks' derivatives disclosures, Journal of Accounting and Economics, 22: 327-355.

Viswanathan, G., 1998, Who uses interest rate swaps? A cross-sectional analysis, Journal of Accounting, Auditing and Finance, 13: 173-200.

Von Ungern-Sternberg T. and C.C. von Weizsäcker, 1990, Strategic foreign exchange management, Journal of Industrial Economics, 37: 381-395.

Ware, R. and R. Winter, 1988, Forward markets, currency options and the hedging of foreign exchange risk, Journal of International Economics, 25: 291-302.

Warner, J., 1977, Bankruptcy costs: Some evidence, Journal of Finance, 32: 337347.

Weiss, A.A., 1984, ARMA models with ARCH errors, Joumal of Time Series Analysis, 5: 129-143.

Weiss, A.A., 1986, Asymptotic theory for ARCH models: Estimation and testing, Econometric Theory, 2: 107-131.

White, H., 1982, Maximum likelihood estimation of misspecified models, Econometrica, 50: 1-25.

Williamson, R.G., 2001, Exchange rate exposure and competition: Evidence from the automotive industry, Journal of Financial Economics, 59: 441-475.

Wong, M.H.F., 2000, The association between SFAS derivatives disclosures and the foreign exchange risk exposure of manufacturing firms, Journal of Accounting Research, 38: 40-80. 


\section{Nederlandse Samenvatting (Summary in Dutch)}

$\mathrm{Na}$ het loslaten van het Bretton Woods' stelsel van vaste wisselkoeren (1973) is de aandacht voor de werking van valutamarkten sterk toegenomen. De overgang naar een systeem van zwevende wisselkoersen in april 1973 heeft het karakter van wisselkoersfluctuaties aanzienlijk veranderd en de volatiliteit van wisselkoersschommelingen substantieel doen toenemen. Was men begin jaren zeventig de mening toegedaan dat de overgang naar een systeem van zwevende wisselkoersen een evenwichtiger kader voor monetair en fiscaal beleid zou opleveren, de turbulente valutaire ontwikkelingen van de afgelopen drie decennia geven alle aanleiding om deze opvatting te herzien.

Binnen de moderne financieringsliteratuur wordt een vooraanstaande plaats ingenomen door empirisch onderzoek waarbij wereldwijd veel energie wordt gestoken in het verzamelen en interpreteren van gegevens, die inzicht geven in het gedrag van marktparticipanten op de internationale valutamarkten. Mede als gevolg van de sterke toename van wisselkoersschommelingen (zie bijvoorbeeld de financiële crises in Zuid-Oost Azië, Latijns-Amerika en Rusland) heeft het internationaal onderzoek naar het begrijpen en verklaren van de prijsvorming op de valutamarkt een vlucht genomen. Meer recent, echter, wordt het onderzoek gedreven door de vraag of, en in welke mate, de waarde van een onderneming onderhevig is aan wisselkoersinvloeden. Deze invloeden kunnen zowel een positief als negatief effect op de ondernemingswaarde hebben. Binnen de financieringstheorie wordt de sensitiviteit van de ondernemingswaarde voor wisselkoersschommelingen valuta-exposure genoemd. Wanneer de waarde van een onderneming wordt berekend als de contante waarde van de verwachte toekomstige kasstromen, dan kan het valuta-exposure worden opgevat als de gevoeligheid van de ondernemingswaarde voor ongeanticipeerde wisselkoersveranderingen.

Internationaal opererende ondernemingen zijn op verschillende manieren blootgesteld aan wisselkoersschommelingen. Het meest voor de hand liggend zijn de exporteur en importeur, die beiden valutarisico lopen. Ook ondernemingen met buitenlandse vestigingen hebben valuta-exposure. Als gevolg van het open karakter van de internationale economie kan een puur lokaal bedrijf zonder buitenlandse 


\section{Nederlandse Samenvatting}

geldstromen toch worden geconfronteerd met een zekere gevoeligheid voor de (grillen van de) valutamarkt. Gesteld kan worden dat bijna alle ondernemingen worden blootgesteld aan de toegenomen volatiliteit van wisselkoersen - met alle gevolgen van dien. In dit kader bezien is het belangrijk te onderzoeken welke factoren het valuta-exposure van een onderneming bepalen en in hoeverre ondernemingen er in slagen hun valuta-exposure actief te managen door het gebruik van financiële en operationele hedging-technieken. Zo kan een onderneming gebruik maken van derivaten, zoals termijncontracten of opties, of leningen in vreemde valuta (financièle hedging) of haar inkomende en uitgaande kasstromen matehen middels de verplaatsing van productiefaciliteit naar het buitenland (operationele hedging) waar het haar producten afzet. Anderzijds kunnen bedrijfskentmerken, zoals bedrijfsresultaat, buitenlandse omzet, investeringen en schuldenpositie de gevoeligheid van de marktwaarde van de onderneming voor de wisselkoers beïnvloeden. Het bovenstaande illustreert dat valuta-exposure een complex geheel is en sterk afhankelijk is van bijvoorbeeld de openheid van de economie, de operationele en financiële status van een onderneming, en de gehanteerde onderzoeksmethodiek.

De omvangrijke empirische studies op het gebied van valuta-exposure zijn weinig bemoedigend te noemen; de meeste studies betreffen de VS en zij worden gekenmerkt doordat zij allen slechts een laag percentage ondernemingen met significant exposure effect vinden. Belangrijke studies zijn Jorion (1990), Amihud (1994) en Bartov en Bodnar (1994); allen illustreren zij de moeilijkheid om de aanwezigheid van (gelijktijdig) valuta-exposure te bewijzen. Als belangrijkste oorzaak voor het zwakke bewijs voor valluta-exposure geldt het feit dat de Amerikaanse economie relatief gesloten is. Internationale studies bevestigen het beeld dat bedrijven in meer open economieèn gevoeliger zijn voor wisselkoersschommelingen. De vaak wisselende resultaten van internationale studies tonen aan dat de exposures een grote mate van variatie vertonen en illustreren tevens dat het voot managers en internationale beleggers zinvol is om een beter inzicht te krijgen in de wisselkoersgevoeligheid van hun bedrijven en beleggingen.

Dit proefschrift omvat een empirische analyse van de relevantie van valutaexposure voor internationaal opererende ondernemingen. De relatie tussen (veranderingen in) de koers van de belangrijkste valuta's en de waarde van beursgenoteerde ondernemingen in Europa, de VS en Zuid-Oost Aziê wordt nader onderzocht. Allereerst wordt in hoofdstuk twee de bestaande literatuur over het meten van wisselkoers-exposure van de afgelopen drie decennia samengevat en nader geanalyseerd, waarbij zowel de theorie achter de hypothesen als de belangrijkste internationale empirische bevindingen worden gepresenteerd. 
Vervolgens wordt er in het overzichtshoofdstuk een aantal pogingen gedaan om de schijnbare tegenstelling tussen theorie en empirie te verklaren, en waar mogelijk te weerleggen. Een aantal van de mogelijke werklaringen van het doorgaans zwakke empirische bewijs voor valuta-exposue dient als bron voor onderzoek in het vervolg van het proefschrift; de empirische relevantie van een aantal puzzels en de daaruit voortvloeiende kansen staan daarbij centraal.

Op basis van de in hoofdstuk twee genoemde verklaringen analyseren we in hoofdstuk drie de wisselkoersgevoeligheid voor beursgenoteerde bedrijven in Europa, de VS en Zuid-Oost Azië over de periode januari 1970 tot januari 2003. Aangezien de exposures een grote variatie vertonen, formuleren we in dit hoofdstuk hypothesen met betrekking tot de determinanten van wisselkoersgevoeligheid. In tegenstelling tot eerder onderzoek maken we hierbij gebruik van individuele waarnemingen voor de aandelenrendementen op landen en sector niveau ten einde het aggregatie probleem van de wisselkoers-exposure te reduceren. Daarnaast hebben we als gevoeligheidsanalyse onderzocht of (een toename van) de tijdshorizon van de rendementen een rol spelen bij de gemeten valuta-exposure. $O p$ basis van de door ons gekozen methodiek geven de resultaten aanleiding voor het bestaan van wisselkoers-exposure. In vergelijking met eerdere studies, met name voor de VS, is de gevoeligheid voor international opererende bedrijven voor valutaschommelingen veel sterker; ruim 13 procent van de Europese bedrijven is significant gevoelig voor de Japanse yen, 14 procent voor de Amerikaanse dollar en 22 procent voor het Engelse pond. Daarnaast heeft meer dan 25 procent van de Aziatische ondernemingen een significant exposure-effect ten opzichte van de Amerikaanse dollar en 22 procent ten opzichte van de Japanse yen. De resultaten voor Amerikaanse bedrijven die actief zijn in Latijns-Amerika zijn eveneens bemoedigend te noemen; ruim 17 procent beschikt over significant exposure. Daarnaast neemt het aantal ondernemingen met een significant exposure fors toe wanneer we de tijdshorizon van de aandelenrendementen vergroten. Uit de analyse blijkt verder dat het percentage ondernemingen met significant valuta-exposure in subperiodes stijgt en daalt ten opzichte van de volledige periode, waardoor het exposure over de tijd fluctueert en (schijnbaar) afhankelijk is van de volatiliteit op de valutamarkt. Wisselkoersen hebben met name in periodes van hoge volatiliteit invloed op aandelenkoersen.

In hoofdstuk vier staan de risicomanagementpraktijken van Europese multinationals centraal. We richten ons daarbij op de vraag in welke mate Europese niet-financiële beursgenoteerde ondernemingen gebruik maken van financiele derivaten alsmede de invloed van thet derivatengebruik op de wisselkoersgevoeligheid van de aandeelhouderswaarde. In enkele additionele analyses onderzoeken we de gevoeligheid van onze resultaten en richten ons daarbij 
op het korte en lange termiju verband tussen het gebruik van derivaten en valutaexposure. Het managen wan valutarisico's beoogt de risico's te identificeren en de negatieve invloed hiervan op de aandeelhouderswaarde te verminderen. In de financieel-economische literatuur wordt beschreven hoe een onderneming door middel van hedging op indirecte wijze waarde kan creëren. Veelal zijn deze theorieên gebaseerd op de veronderstelling dat hedging de volatiliteit van de kasstromen reduceert, waardoor bijvoorbeeld in het geval van convexe belastingtarieven, agencykosten, en faillissementskosten, ondernemingswaarde kan worden gecreëerd. De resultaten tonen aan dat buitenlandse omzet, buitenlandse schuldenpositie en ondernemingsomvang (totale activa) de belangrijkste determinanten zijn van derivatengebruik. Tevens vinden we empirisch bewijs dat zowel het aandeel van de buitenlandse omzet ten opzichte van de totale omzet als een goede liquiditeitspositie en sterke groeimogelijkheden een positief effect heeft op het exposure. Daarentegen hebben grotere ondernemingen doorgaans minder exposure; kleine ondernemingen zijn gevoeliger voor wisselkoersveranderingen dan grote ondernemingen. De uitkomsten suggereren verder dat de Europese managers het gebruik van financiële derivaten benut voor het afdekken van de wisselkoersrisicoposities en derhalve niet (of nauwelijks) speculatief van aard is.

Mede op basis van de bevindingen in hoofdstuk drie, beschouwen we in hoofdstuk vijf het verband tussen de volatiliteit van de wisselkoersen en de volatiliteit van de aandelenrendementen. Meer specifiek wordt onderzocht of wisselkoersen in perioden van hoge volatiliteit van invloed zijn op het systematische risico ("beta") van Amerikaanse ondernemingen. De resultaten illustreren de aanwezigheid van tijdsvariërende valuta-exposures; wisselkoersen hebben doorgaans in perioden van hoge volatiliteit een positieve invloed op de "beta' van een ondememing. Dit betekent dat de gevoeligheid van ondernemingen voor (veranderingen in) het marktrendement significant zal toenemen als gevolg van de toegenomen wisselkoersvolatiliteit tijdens een financiële crisis. Kortom, de financieringskosten voor het aantrekken van eigen vermogen zullen stijgen - met alle negatieve gevolgen voor de waarde van de onderneming.

In hoofdstuk zes introduceren we een aantal theoretische uitgangspunten die de relatie tussen wisselkoersen en aandelenkoersen nader beschrijven. Verondersteld wordt dat de sensitiviteit van de ondernemingswaarde voor wisselkoersschommelingen asymmetrisch van aard is; een depreciatie van de valuta tegenover de valuta van de handelspartners genereert een verschillend effect op de ondernemingswaarde dan een appreciatie van dezelfde valuta. Hetzelfde geldt voor grote dan wel kleine veranderingen in de wisselkoers; ook hier veronderstellen we dat er sprake is van een bepaalde asymmetrie in valuta-exposure. Onze empirische resultaten illustreren het bestaan van een dergelijke asymmetrie in exposure. 
Daanaast constateren we dat het doorgaans zwakke empirische bewijs deels kan worden toegeschreven aan het negeren van het asymmetrische exposure-effect.

Tenslotte geven wij in hoofdstuk zeven de belangrijkste empirische bevindingen weer en formuleren wij een aantal algemene conclusies betreffende onze resultaten. Tevens wordt aandacht besteed aan mogelijk toekomstig onderzoek naar aanleiding van de discussie in dit hoofdstuk. 
$\therefore \quad \therefore$

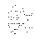




\section{Curriculum Vitae}

Aline Muller was born on August 19 $9^{\text {th }}, 1973$ in Luxembourg. In 1998, she obtained her Master's Degree in Business Economics (specialized in Financial Markets) at the University of Liège, Belgium. After that she was appointed as a research assistant at the Business Economics Department of the University of Liège. Two years later she joined the Finance Department at the University of Maastricht, the Netherlands. She completed her work on this Ph.D. dissertation during the period September 2000 - September 2004. Aline Muller is currently Assistant Professor at the Economics Department of the Radboud University Nijmegen. Her work on Foreign Exchange Risk Exposure has been presented at numerous leading international conferences, including the Annual Meetings of the European Finance Association and the Financial Management Association, and has been published or is forthcoming - in various academic journals like European Financial Management, Joumal of Multinational Financial Management and Managerial Finance. Her current research projects focus on international finance and its interactions with corporate finance and development economics. Aline Muller is frequently lecturing at several universities in Europe, the Middle East and Africa. 